
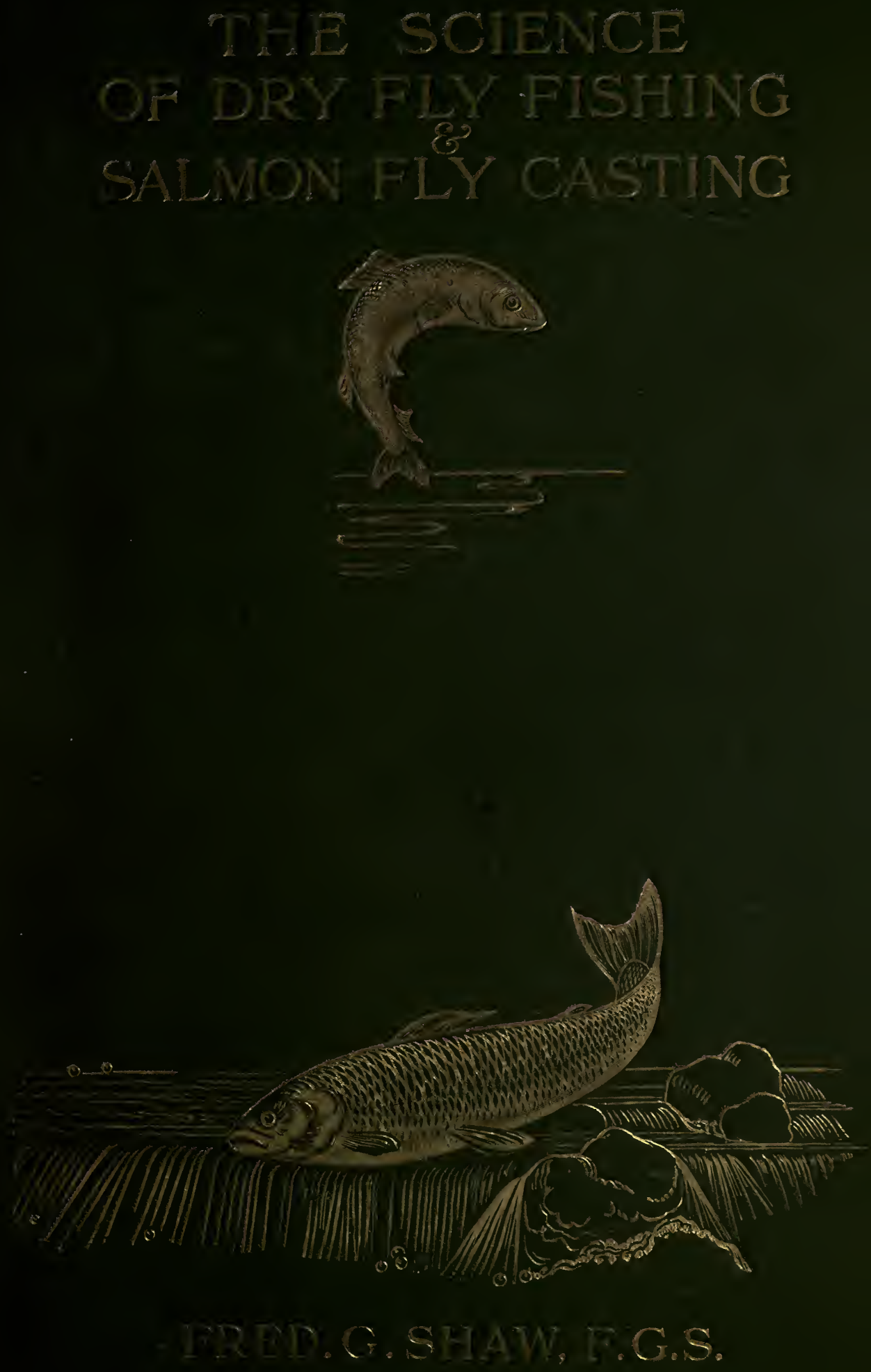


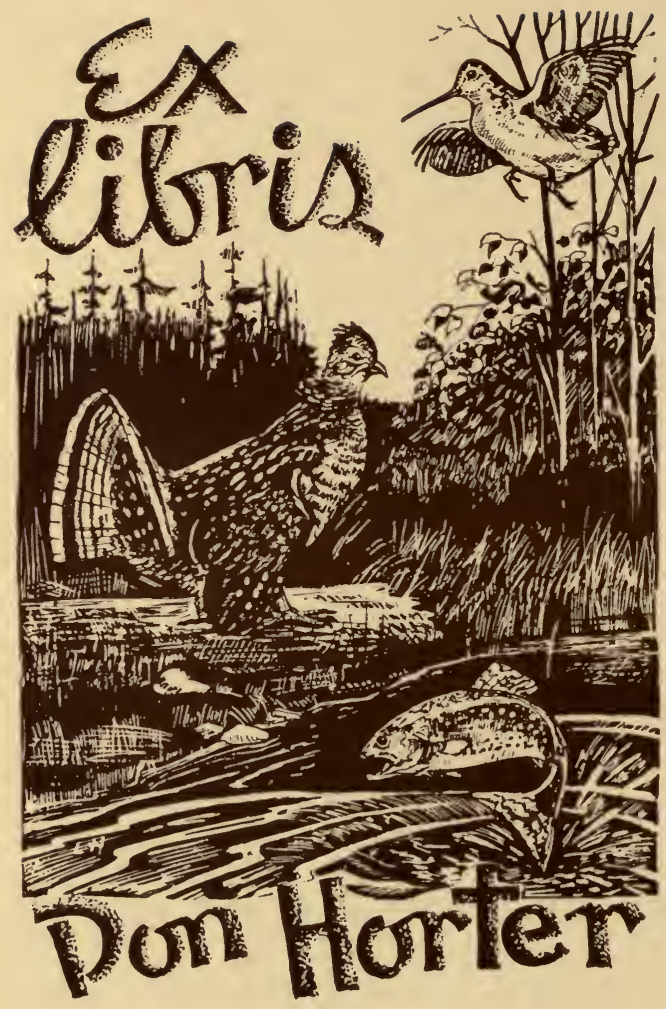


Digitized by the Internet Archive in 2007 with funding from Microsoft Corporation 
kex 


THE SCIENCE OF DRY FLY FISHING AND SALMON FLY FISHING 
Works by the Same Author

COMETS AND THEIR TAILS

THE GEGENSCHEIN LIGHT

OUR COUNTRY PROGRAMME

A NATIONAL POLICY

THE PSEUDO-MORPHIC THEORY

OF THE WITWATERSRAND

CONGLOMERATES

FISCAL FACTS AND FICTIONS

Erc. 


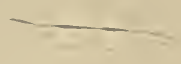

1 


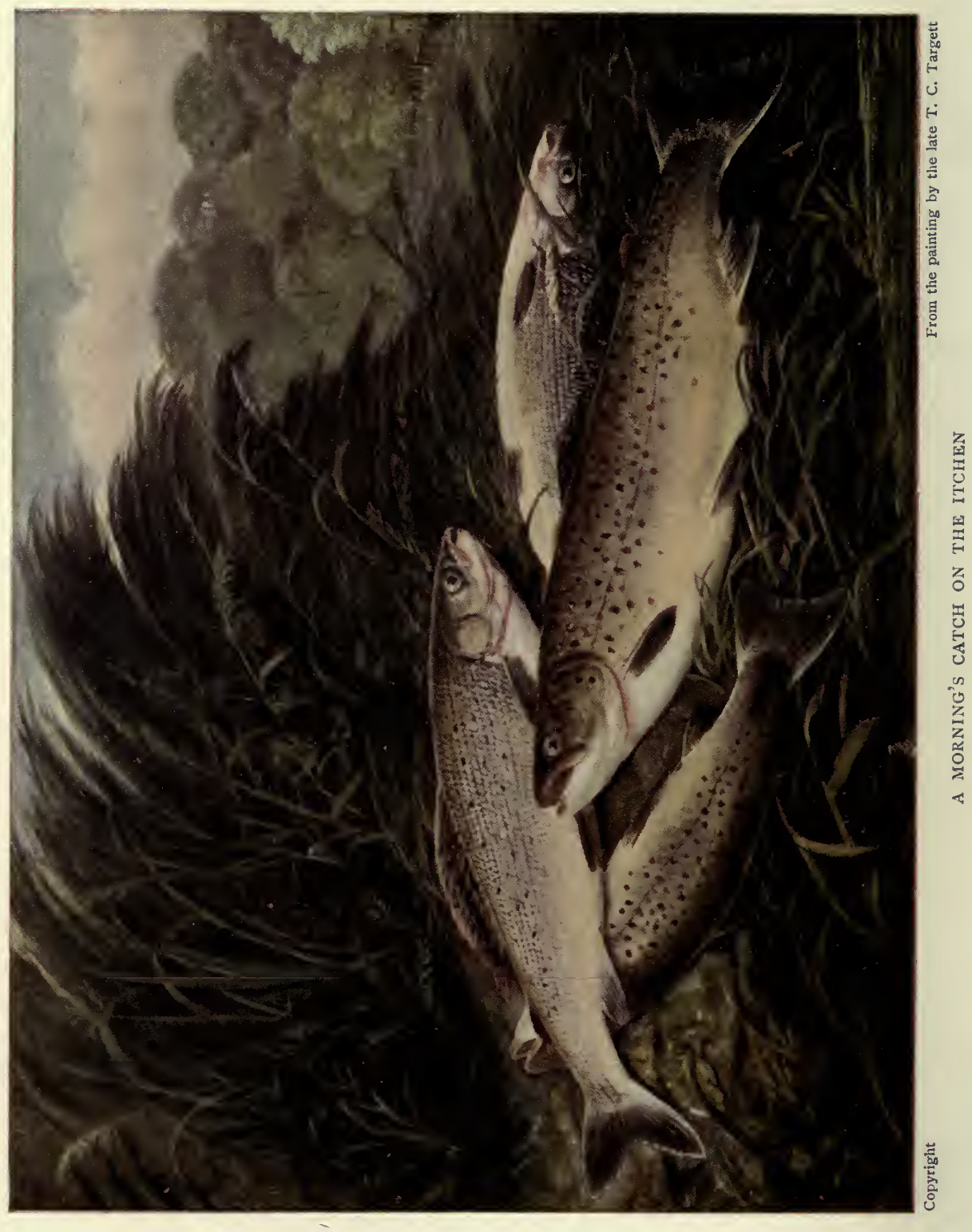




\title{
THE SCIENCE OF
}

\section{DRY FLY FISHING AND SALMON FLY FISHING}

\author{
BY FRED. G. SHAW, F.G.S. \\ Assoc. M.Inst.C.E., M.M.S.
}

AMATEUR CHAMPION TROUT FLY CASTING AT THE INTERNATIONAL TOURNAMENT, I9O4

WITH ILLUSTRATIONS

LONDON

JOHN MURRAY, ALBEMARLE STREET, W. 



\title{
SH4 45 55 1907
}

\author{
DEDICATED \\ TO THE MEMORY OF \\ MY FATHER AND MOTHER
}





\section{PREFACE 'TO 'THE SECOND EDI'TION}

2

IT had been my intention to issue the second edition of this book in its original form, and to write a new work entitled "The Science of Salmon Fishing"; but finding that the "Science of Dry Fly Fishing" could with great advantage be revised, and that this revision would make it practically a new work, I determined, on the advice of a literary friend, to rewrite the whole of the trout fishing section, and to add to it the subject-matter which I had proposed to form into a new book.

This consists, in the first place, in the life-history of the salmon, from the time it is deposited as ova by the parent fish in the redd until it attains its fullgrown state. I have ventured, when dealing with this interesting matter, to introduce some original theories as regards those questions which are still a subject of controversy.

In the second place, I have dealt with the different methods of casting, and by plates and diagrams have endeavoured to show the various casts for presenting the lure to the salmon, and explained the methods to be adopted when actually fishing.

In the third place, I have dealt with the preservation and conservation of the fish in British waters, treating 


\section{viii PREFACE TO THE SECOND EDITION}

the subject of fishing generally, including the laws as to the Boards of Conservators, and the question of netting as affecting the future of the salmon industry, and have added an Appendix on the question of Salmon $v$. Trout in our Fishing Rivers, dealing principally with the question as it refers to the Hampshire streams.

The dry fly fisherman has, as a rule, only one opportunity at each fish, and it is with him that the making or marring of that chance rests. Each initial cast for a trout possesses a greater or less difficulty, and it will be due to the immediate and skilful manner in which he takes advantage of the opportunity that his success will depend. The most essential portion of the dry fly fisherman's art and the most difficult to acquire is the power to place at once and with certainty the right fly, delicately and accurately, over his fish.

The beginner, he who has been badly taught, or the self-taught man who may have acquired bad habits, fails to understand why his friend catches readily and easily fish after fish during a long day, while he secures but a few, if any.

The skilful fly fisherman who takes every possible fish within his reach seldom, if ever, attributes his success or his friend's failure to the real cause, which is, the eertain and immediate skilfulness or unskilfulness of each, and I am of the opinion that "The greatest success in fishing will attend the most skilful rod."

Since launching the first edition, just one year ago, practical experience acquired in teaching others has taught me that I could improve in several ways the written instruction in which $I$ had therein 


\section{PREFACE TO THE SECOND EDITION ix}

endeavoured to teach the novice the art of fly casting, and I have added considerably to the general information contained in it. It is, therefore, in reality a new book which I have now the pleasure of prefacing as the second edition of my former work. I have endeavoured to take advantage of the friendly criticism of the press, and have to acknowledge the great assistance and friendly influence which my publishers have given me in editorial matters.

In some of the half-tone reproductions the fishingline, which is of course barely visible on the original photograph, has been slightly strengthened, as it is necessary that it should be clearly seen, for the purpose of explaining the casts.

F. G. S.

August, 1907. 



\section{PREFACE TO THE FIRST EDITION}

WHILE the sporting instincts will be aroused by the difficulties and thrilled by the triumphs of fly fishing, the artistic and poetic side of the fisherman's temperament will be as strongly appealed to and affected by the surroundings of the salmon rivers and trout streams on which his fly may be cast.

The salmon river will inspire the soul with the strength and force of its beauty, and invigorate the body with the health-giving scent of its pine forests and heather; the trout stream will charm the mind, and lull the senses into delicious content, as the rippling note of its liquid harmony soothes the listener, and the delicate perfume of its thousand surrounding flowers is inhaled.

The pride of place as regards the very pink of Nature's charms must be given to our trout streams. The lavish profusion of their summer beauty and the ambrosial essence of their woodland delights will efface the cares and stress of modern life, and refresh our jaded senses with the delights of their neverending variety of delicate beauties. These haunts of the trout will soothe our wearied eyes with the delicate shades of their leafy surroundings and with the exquisite pictures reflected in their limpid depths, 
while our city-tainted nostrils will be cleansed by the delicious fragrance of the country-side.

Hence it is that even the novice in fly fishing, vexed as he may be by his want of success, is consoled and comforted by the beauty surrounding him, and by the lessons which he absorbs with every breath drawn from the scented bosom of Mother Nature.

There is no experience he will find more enjoyable or pastime more delightful than those associated with that perfection of natural life which is to be found by an English trout stream.

Hardly any water-side exists which fails to interest and attract the fisherman, and the pleasure of wandering by the scented side of any brook or sylvan stream and watching the varying beauties and the wonder of its natural life is always enhanced by the infinite probabilities of trout which it suggests to the ardent angler, and the recollections which it arouses of sunlit days and happy associations of the past.

When one recalls the pleasure and assistance which have been derived from the literature devoted to fly fishing, the works of Izaak Walton, Buxton, Cholmondeley-Pennell, Maxwell, Francis, Marston, Sheringham, Sir Edward Grey, Hart-Davis, Val Consons, William J. Long, Thomas, Senior, Hodson, Halford, Dewar, Hutchinson, Gathorne-Hardy, and others, the delightful reminiscences which have been revived, and the extensive fields of sport which have thus been thrown open, it would indeed be ungrateful to deny the efficacy of written instructions in this delightful science.

If it be desirable and necessary to obtain help in order to become a proficient fly fisherman, the author 
admits the greater advantages of personal tuition when it is obtainable. But, on the other hand, he is confident that, by explaining in simple language the science of casting and fishing with the trout fly, in similar terms to those which he uses when teaching the student personally, the reader will, by careful attention, find himself competent to take the field, rod in hand, and rapidly acquire a success which will well repay him for his trouble. It is to those who are anxious to learn, but who, at the same time, may regard this delightful accomplishment as not only difficult to acquire, but necessitating a greater expenditure of time and money than may possibly be at their disposal, that the author has written these pages.

If he should be successful in imparting to others a skill which has afforded him so many delightful and happy hours, he will, in some measure, repay debts which he owes, not only to a kindly Providence for affording so many opportunities of fishing, but to those who have, by their writings or by personal assistance, enabled him to profit by it.

He would ask his brother angler to deal gently with this book, for which he can only claim one meritnamely, that it is written in all sincerity to assist others who, through lack of opportunity, are neither very experienced nor skilful; and if any excuse is needed for such an attempt, it is that he is impelled to do so by as great a love for this noble sport as that felt by that dear old past master Izaak Walton. 



\section{CON'TEN'TS}

\section{CHAPTER I}

Opening remarks - The back cast-The forward cast-The steeple cast-The side cast-Avoiding the drag-Lightness in picking the line from water-The wind cast-Practising over waterAccuracy-Long-distance casting-Varying the direction of cast-The loop cast-Overcoming the force of wind - 1-36

\section{CHAPTER II}

Wet and dry fly fishing discussed-A morning on a trout stream -Hints-The Blue Quill-The rise-The use of the butterflynet-The food of trout-Fishing the stream-Fishing the rise-The spear-Use of paraffin-Stream lore-Varying the fly-The Red Quill-Catching fish-Killing the fish-The fishing knife-The rise and its advantages-The rise discussed -A comparison-Undivided attention to floating fly-The dangers of jumping fish, and how to conquer them-Consideration for others-The file and disgorger-The broken cast-Useful knots-The blunted hook-A chat at luncheon -Further hints on fishing-Casting the fly on a rock, etc. 37-73

\section{CHAPTER III}

Hints to the student-Hasty judgments-The natural fly-The Ephemeridæ-The Trichoptera-The Perlidæ-The Sialidæ 
- The Diptera-The rise-The best time to fish-The evening rise-Keeping the line clear-Changing the fly after darkFishing by moonlight-Bulging trout-The senses of a trout - The vision of a trout .

\section{CHAPTER IV}

Pisciculture-Temperature-Trout and the close season-Times of spawning-Close season too short-The Board of Conservators -The appearance of trout-What sort of flies to use-The cap as a fly-holder-Moths-Dry fly fishing with three flies -The dry fly fisherman's flies-Knots used when fishingWet fly fishing up-stream-Striking-Wet fly fishing-Weeds - Long-distance casting - Fungus on grown fish-Ambidexterity-Spinning for trout-Where to fish -

- $102-150$

\section{CHAPTER V}

The instincts of the salmon-The life of the salmon-ReddsThe deposition of the ova-The dangers to the ova-The appearance and life of the ova-The alevin and its birthThe parr-Its appearance and life-The smolt-Its descent to the sea

- $151-160$

\section{CHAPTER VI}

The physiological change of the parr into the smolt-The natural arguments in favour of the earlier change of the male parrThe smolt's life-Appetite and growth in salt water-The grilse and his return-The run up to the spawning-groundThe dangers of the ascent-When injured-Arrival at the spawning-bed-Selection of a mate-Spawning-Making the redds-Appearance of the grilse-The kelt and the well$\begin{array}{lllllllll}\text { mended kelt } & - & - & & - & - & & - & 161-169\end{array}$ 


\section{CHAPTER VII}

Feeding in fresh water-Rejection of food when caught-Aggressiveness of salmon-The sustenance of salmon in fresh water -A new theory-Analogies drawn from other fish-The gastric juices of salmon-Facts advanced on other theoriesImportant evidence as to food in salmon's stomach in fresh water-Other views of this evidence-The gastric glands discussed-A general view-Another theory-Stoning a pool -Salmon entering fresh pools-Actual fishing and non-rising fish-The record take of salmon

- $170-192$

\section{CHAPTER VIII}

Boards of Conservators and their influence-The double-handed rod-Salmon and trout netting-Salmon fishing-A sagging line-Method of fishing the river-Hauling for salmonUsing a spinning line-Your first salmon-The rise of the salmon-Gaffing-Necessity of learning how to cast-The position of the salmon reel-Casting -

- 193-213

\section{CHAPTER IX}

The right-hand overhead cast-The left-hand overhead castShooting the line-Casting a salmon fly when wading from the bank-Changing the direction of the cast-The left-hand cast to the right-The right-hand cast to the left-The Galway cast-The right-hand side-cast-The left-hand sidecast-Curved casts-The loop cast-The Spey throw-The author's variation of the Wye cast-The use of a variation of the Wye cast-Diagrammatic illustration of this castA 50-pound salmon - A few additional maxims for fishermen

- 214-246 


\section{CONTENTS}

\section{CHAPTER X}

The necessities of the fisherman-The rod-Length-PliabilityWeight and action of the rod-Makers and makers of rods -The fly fisherman's knife-Wading and waders-Basket creels and fishing bags-Salmon and trout lines-The oilbottle-The salmon and trout reel makers-SpinningThe fly hook-The cast-Trout and salmon flies-Fly books -Muscatol-Binoculars-Gear-case-Gaff-The landing-net -Waterproofs-Fisherman's spectacles-The fly-net and fisherman's lamp

- 247-280 APPENDIX -

- 281-290

INDEX

- 291-296 


\section{LIS'T OF ILLUS'TRA'TIONS}

\section{PLATES}

A Morning Catch on the Itchen. (From the painting by the late T. G. Targett) - Frontispiece

I. Correct Position for making Back Cast - To face page 6

II. READY TO STRIKE OR TO MAKE A BACK CAST " 8

IIA. A 4-lb. Test Trout, caught by the Author,

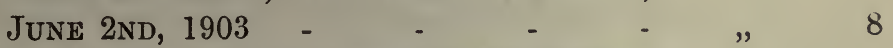

III. END OF BACK CAST: THE LINE IS SEEN

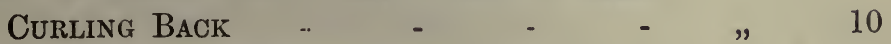

IV. LINE GOING STILL FURTHER BACK - - " " 10

V. Commencing Forward Cast - - - " " 12

VI. End of Forward Cast : Line beginning to CURL Forward - $\quad$ - $\quad$ - $\quad$ - $\quad$ " 16

VII. Line alighting on Water : the Left HaNd SHOWN FEEDING LINE -

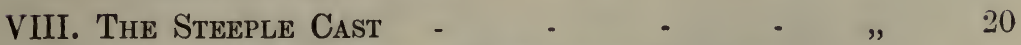

IX. The Author's Method of Casting a Line AGAINST THE WIND - - - $\quad$ " $\quad 24$

X. Preparing to Land a 4-Lb. Trout on a

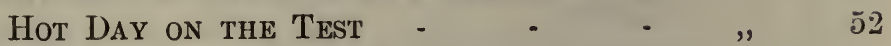

XI. Don't LOWER the PoINT OF ROD, bUt USE Very Delicate Wrist Action - - $\quad$ - $\quad 64$

XII. LOWER POINT OF ROD - $\quad$ - $\quad$ - $\quad$ " $\quad 64$

XIII. The River Irfon, Breconshire - - " " 71

XIV. The Ephenerid A ANd Perlid

XV. The Tricoptera or Caddis Fly in its
Larval and Pupal Conditions - $\quad-\quad, \quad 30$ xix 


\section{PLATES (continued)}

XVI. The Itchen Trout Breeding Establish-

$$
\text { MENT, HANTS - - - - - To face page } 106
$$

XVII. The Pound for Two-year-old Fish - " " 108

XVIII. The Home Pound for Eight-Inch Fish.

NetTing Trout For Stocking other

WATERS - $\quad$ - $\quad$ - $\quad$ - $\quad$ ” 110

XIX. River IVEL, WoOton Fisheries, BALDOCK " 110

XX. "HeXcuse Me, Sir, But your 'At is H'ALL H'OVER H'INSECKS"!! - - " 122

XXI. A Natural Dam of Weeds - - " 134

XXII. Mr. Shaw Fishing on the AXe in May , " 144

XXIII. Plunges DOWN Stream with Your

JoCK SCOTT IN HIS MoUth - - " $\quad 151$

XXIV. The Overhead Cast - - - " " 215

XXV. The Forward Cast - $\quad$ - $\quad$ - $\quad$ " 216

XXVI. The Forward CAST - $\quad$ - $\quad$ - $\quad$ " 218

XXVII. The Galway Cast - $\quad$ - $\quad$ - " " 223

XXVIII. The Galway Cast - $\quad$ - $\quad$ - $\quad$ " 223

XXIX. The Galway Cast - - - " " 223

XXX. The Galway Cast - - - " "

XXXI. FORWARD CAST - - - - - " ” 224

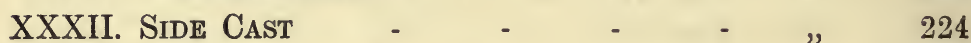

XXXIII. The Vertical LoOP CAST - - " " 227

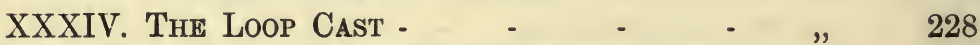

XXXV. The Loop Cast to the Right-hand

Side. The Loop Travelling For-

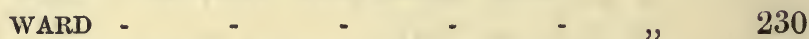

XXXVI. The Backward Swing of the Spey

THROW - $\quad-\quad$ - $\quad$ - $\quad 232$

XXXVII. The End of the Forward Cast is the

UNDERHAND VARIATION OF THE WYE

CAST, WITH NO IMMEDIATE DANGER BEHIND ; USEFUL WHEN WADING

XXXVIII. The Forward Action in the Under-

haNd Variation of the Wye Cast.

The DANGer MORE IMMEDIATELY BE- 


\section{PLATES (continued)}

XXXIX. The Forward Action of the Side Loop Cast is immediately Behind. The Lower Portion of the LiNe haS beEN TOUCHED UP

XL. Model of a 50-Lb. Namsen Salmon Killed bY the Author in AUgust, 1897, on the Namsen River, Norway -

\section{DIAGRAMS}

1. Showing Positions of Rod in Back Cast

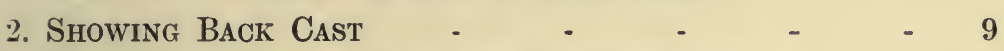

3. Showing Positions of Rod in Forward Cast - 18

4. Showing Forward CaSt - $\quad$ - $\quad$ - $\quad$ - 19

5. Showing Rod Action in Casting from Left to Right 31

6. Showing Rod Action in Casting from Right to Left 33

7. Horizontal Plane of Trout's Vision - - $\quad 95$

8. Radius of the Upward Vision of the Trout - - 96

9. Vertical Section of Upward Vision of the Trout - 97

10. Various Knots for Fishermen - - - - $\quad$ - 125

11. Various KNots for Fishermen - - - - 126

12. Showing a Perfectly Safe Knot for the Larger-

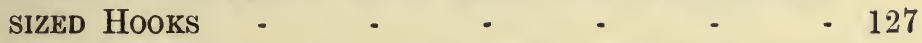

13. The best Method of Joining Two Ends of Gut TOGETHER $\quad$ - $\quad$ -

14. Action of the Hands in the Backward and Forward Cast with the Double-handed Rod - • $\quad 216$

15. Variation of the Wye Cast - • - • 234

16. SeCtion of the Wye CAST -

17. Section of the Wye Cast - . - - - 235

18. Section of the Wye Cast -

19. Section of the Wye Cast - $\quad$ - $\quad$ - $\quad 235$

20. Showing the Wye CAST - - - - - 240

21. The Fiy Fisherman's Knife - - - - $\quad 257$ 

THE

\section{SCIENCE OF DRY FLY FISHING}

\section{HOW TO CAST A TROUT FLY}

\section{CHAPTER I}

Opening remarks-The back cast-The forward cast-The steeple cast-The side cast_-Avoiding the drag-Lightness in picking the line from water-The wind cast-Practising over waterAccuracy-Long-distance casting-Varying the direction of cast-The loop cast-Overcoming the force of wind.

IT may be most seriously argued and maintained that dry fly fishing takes a place second to no other pastime in the world. No game is more alert or more wary than the trout, and certainly there is no pursuit more engrossing, nor any sport more fascinating, than trout fishing. It cannot be claimed that there are any odds, as between a man and his quarry, more evenly balanced, or of so sporting a character, as the chances between the trout and the angler.

There is no sport in which skill, knowledge and enthusiasm meet with so certain a reward throughout a season as in Dry Fly Fishing, and herein lies its deserved popularity. 
The most delightful of all successes is that which can be directly traced or even attributed to our own mental or physical efforts, and the ability to cast an accurate and delicate trout fly is a pleasure which is in itself a sufficient reward on a day which may be barren as regards the take of fish.

As regards the construction of the sporting weapons and appliances used in the various fields of sport, but very few can approach in science and delicacy the modern split-cane fly rod, the tapered lines and casts, the patent reels, and the artificial flies, etc., which are now used.

What sporting knowledge can possibly exceed that required by a disciple of Izaak Walton, if he would obtain even an average skill in dry fly fishing ? while few pleasures are greater than that felt by a fly fisherman who, after an all too short day spent by some lovely trout stream, can produce a dish of speckled beauties as the result of his knowledge and the skilful use of his most treasured rod and delicate tackle.

This book, however, is not written to extol "the gentle art," but with the serious object of assisting those who may be anxious, to learn the science of fly fishing, or to become expert fishermen.

A well-known and most charming writer on piscatorial matters, says: "For my part, indeed, I am inclined to believe that the best way to become an accomplished dry fly fisherman is, in these particular matters, to steer clear of teachers and preachers, either in the book or in the flesh, get down to the water, 
look out for a rising trout, and hammer away till one is at length hooked and landed, after very many have been scared."

One can hardly take this advice as being seriously meant, and although other writers and many fishermen may argue on similar lines, they all admit the difficulty and length of time required before a novice is able to throw a fly in anything like a satisfactory manner. Such Mentors might just as well advise an absolute novice at cricket to don some pads, borrow a bat, face the bowling and fielding of an Australian eleven, and slog away until he has made a century or acquired the science and skill of Dr. W. G. Grace, or Mr. L. C. H. Palairet.

How many fishermen can say that they owe nothing to the advice or assistance of others in their earliest attempts at handling the rod? I myself caught a trout when only four years of age, but my dear old father was there all the time; and although I afterwards fished for over thirty-six years in most parts of the world, I never realized the real science of casting a salmon fly until 1896, when Mr. John Enright, of Castle Connell fame, took me in hand.

With every respect, then, for the writer I have quoted, I am fully persuaded that the one thing a novice can and should do before he goes down to "scare the trout" is to learn the art of casting a fly. With the best personal tuition the average novice can obtain a perfect style in trout fly casting if he will devote a little time between each lesson to practice ; but 
if that is not possible, then he should at least be able to cast a good fly by carefully studying the instruction and diagrams in this book.

When a beginner is able to cast his fly lightly and gently in any required direction, he can then seek his trout stream, and be in a position to fish with everincreasing delight and confidence. With the advice and help of an experienced lover of the art, his progress should be rapid; he would have nothing to unlearn, and may, indeed, as far as science in actual fly casting is concerned, step down to the water-side a better man than the one from whom he himself has in other respects very much to learn.

Besides these advantages, the beginner should consider the saving in time and material which he will effect by first acquiring the ability to cast a fly, also the satisfaction he will feel in knowing that when he arrives at the water-side, he will not appear as a novice to his brother angler. I am convinced that the greatest success will attend the man who, both in favourable and unfavourable circumstances, can with certainty cast the lightest and most accurate fly, and that to learn this takes but a short time when properly coached; that, without the assistance of an expert in casting and fishing, many, if not all, the years of the average man's fishing life will be stultified by mistaken conception and faulty efforts to teach himself an art which has taken centuries to perfect.

The student need not, however, seek the water-side in order to learn how to cast : his, or any other lawn, 
will for the preliminary lessons be preferable; neither need he purchase an expensive outfit. He must, however, possess a rod, reel, and line, and it will be well for him to get these three articles from a good maker. I shall content myself by advising the student to go to any good English firm and select a split-cane rod between 9 feet 6 inches and 10 feet in length, and from 5 to 9 ounces in weight. It must be well balanced and not too whippy, and is all the better for being fitted with a "spear." A good rod of this description, if carefully selected, should last a lifetime. It will retain a larger share of the affection, fill more of his life, and, in short, be more to the keen fisherman than a good and favourite gun to the shooting man, a time-honoured bat to the cricketer, a cue to the billiard-player, or a racket to the tennis-player, etc., and hence the importance of getting the identical rod which will best suit the touch and power of the angler.*

The same may be said, though in a lesser degree, of the reel.

The reel should be light and strong, with a fairly large winding barrel, a regulating check, and capable of holding plenty of line; it should be as sweet in tone and as pleasant to manage as a good wife. Thirty to forty yards of medium fine silk tapered line, dressed under a vacuum pump, will complete his first outfit.

I am going to assume that the reader knows how to * For further hints on the selection of a rod see Chapter V. 
put a rod together, to place the reel on the rod, and thread the line ; but just here a word as to the reeland $I$ am now speaking to the right-handed fisherman. Always use your left hand for manipulating the reelthat is, have the reel fixed on the rod so that its handle is pointing towards the left hand when the rod is being used. It is quite a simple matter to learn to use the reel with the left hand, and it is of infinite advantage to the fisherman.* The rod can thus be always retained in the right hand after striking a fish, avoiding the risky and, in my opinion, unnecessary changing of the rod from right to left hand when a fish is hooked, and leaving the left hand free at all times for the landing-net, for manipulating the line and reel, for one's pipe, glasses, etc.

The rod and line being now ready, take your stand in the middle of your grass plot. The rod should be in your right hand, pointing forward, the reel being on the lower side of the rod, and your hand firmly grasping the butt, with the thumb extending along the rod on the upper side (see Plate I.).

Get a friend to take the end of your line in his hand and walk out about 12 yards. Lower your rod to a nearly horizontal position as the line runs off the reel, keeping the check on. Your friend must now lay his end of the line on the grass. The position of your body should be as follows:

The right foot slightly advanced and pointing in the direction of the line, the left foot slightly behind and

* See Ambidexterity, p. 137. 
PLATE I.

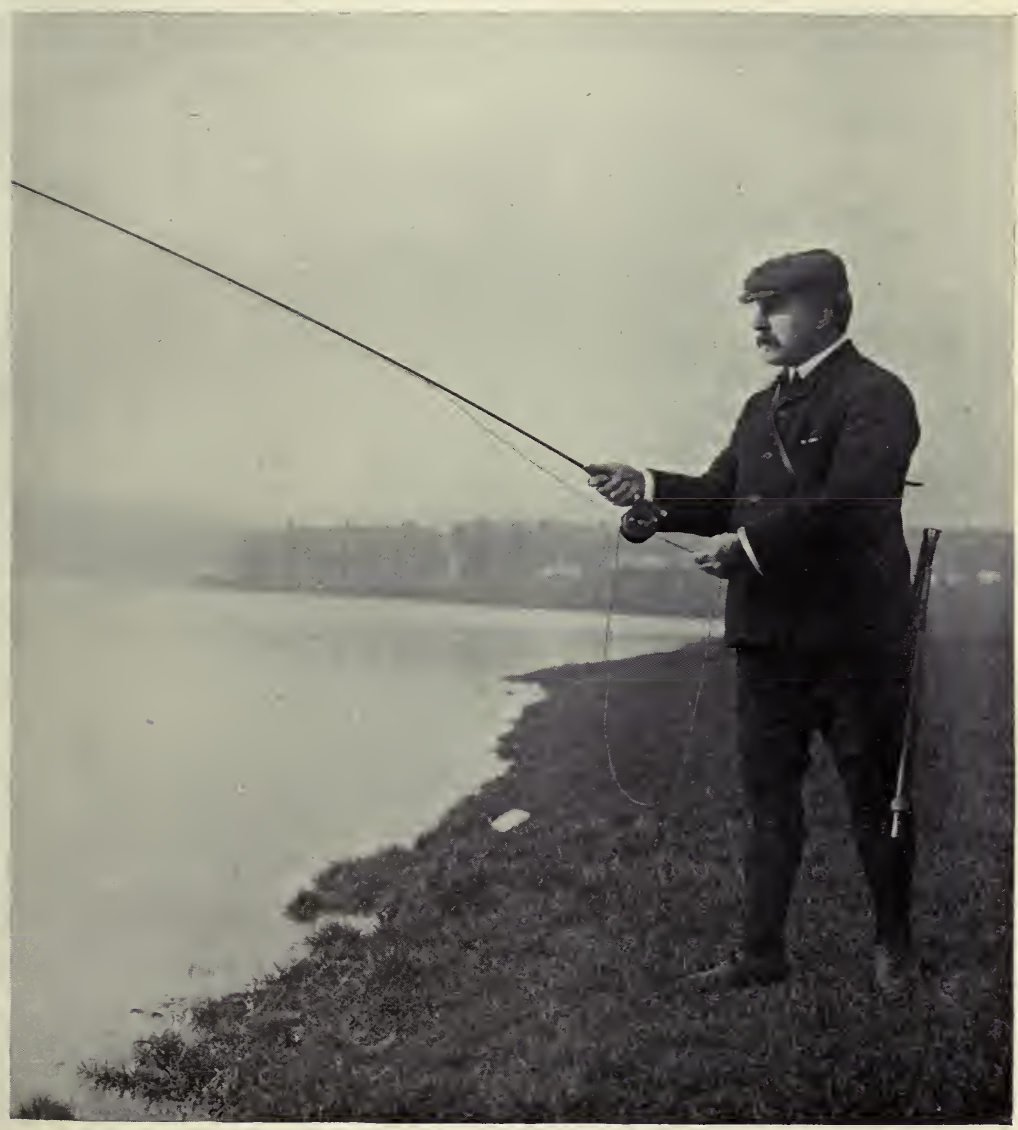

CORRECT POSITION FOR MAKING BACK CAST. 

pointing to the left, the weight of the body resting on both feet, the right shoulder very slightly advanced, and the body erect. The upper part of the right arm should point downwards, with the elbow well in advance of the body, and the forearm extended in the same nearly horizontal direction with the rod, which latter must be held firmly (see Plates I. and II.).

Now, the object you should have in view is to learn how to cast your line (and fly) straight in front of you, and it will be evident that before casting forward, you must get the line more or less extended behind you ; thus the back cast, which effects this, is the first, and probably the most important, to learn; therefore I want you to practise this back cast before attempting to make the forward one. There is one important point to remember : the right elbow should be used as the pivot of the cast, and be raised as little as possible during the preliminary practice. If there is a tendency to raise the elbow too high, a good plan is for you to have-just at first - a string or cord fastened right round the body and the arm just above the elbow, not too tight, but sufficiently so to keep the elbow well down. This will prevent the shoulder acting as the pivot in either the back or forward cast. The hand at the finish of the back cast should be tightly clenched, the forearm brought back with a jerk against the biceps, and the wrist made rigid by clenching the hand: a perfect back cast should result. If this is done, and the rod tightly grasped, the extended thumb will do its 


\section{THE WRIST, THE ELBOW, AND THE THUMB}

duty and prevent a most fatal error-that is, the rod going too far back over your shoulder (see Plates III. and IV.). Now steadily raise your forearm and rod to an angle of about 40 degrees (see Diagram 1), and when the rod has reached this angle, without stopping this upward movement of the arm and rod, convert it into a smart backward switch, the rod passing in a vertical plane over the shoulder, and stopping suddenly

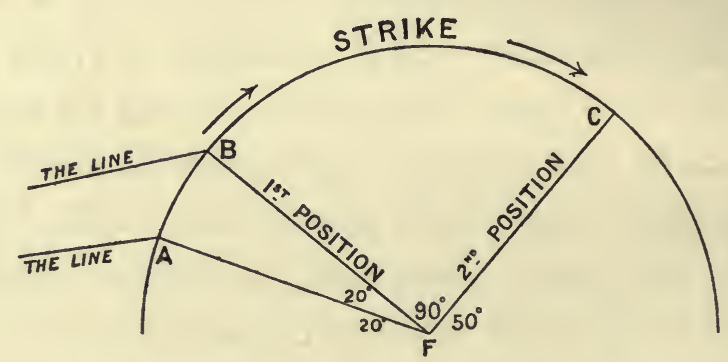

Diagram 1.-Showing Positions of Rod in Back Cast.

F A, position of rod (Plate II.).

F B, position of rod (Plate I.).

B F C, angle of back cast.

F C, position of rod as in Plates III. and IV.

F, the point of the elbow, the pivot of the stroke.

at an angle of 40 degrees over the right shoulder (see Diagram 1). If the elbow is kept down, with the hand tightly clasped and the thumb pressed firmly against the rod, the wrist cannot be bent, and the rod cannot go back beyond this angle; but when the wrist, the elbow, and the thumb have learnt to do their duty, the elbow can be raised at pleasure. Plates III., IV., and V. show clearly the correct position of the rod and arm at the end of the back overhead cast. 
PLATE II.

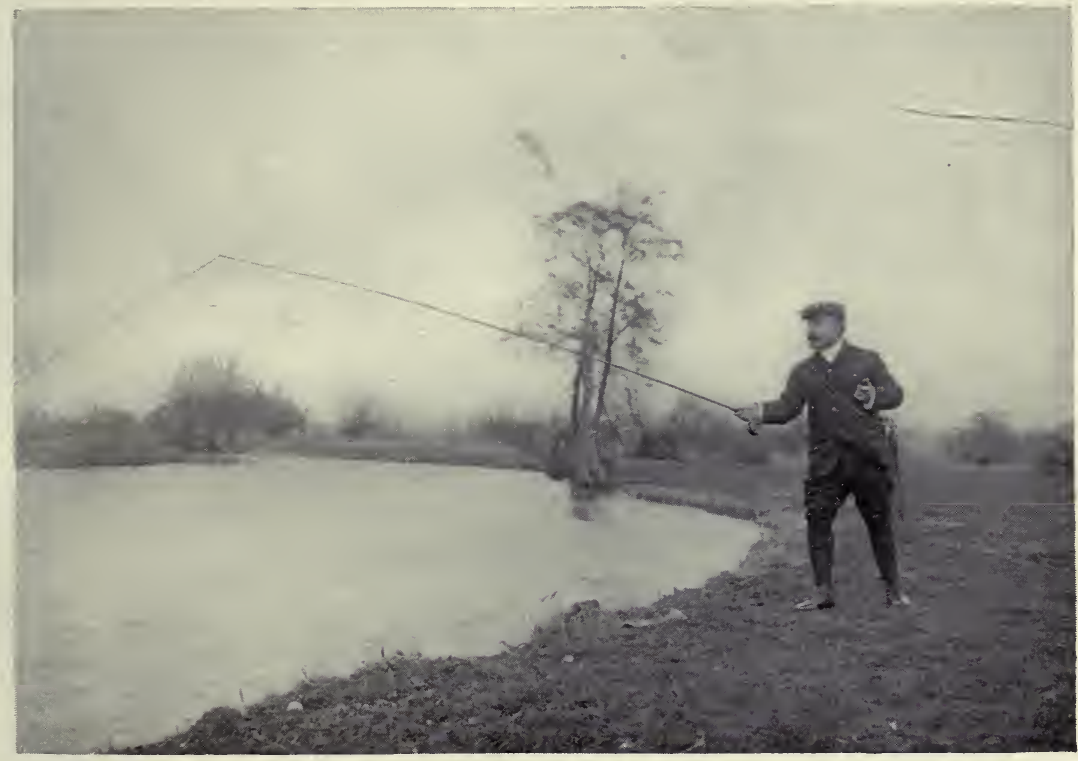

READY TO STRIKe OR TO MAKE A BACK CAST.

Copyright.]

PLATE $\|_{A}$.

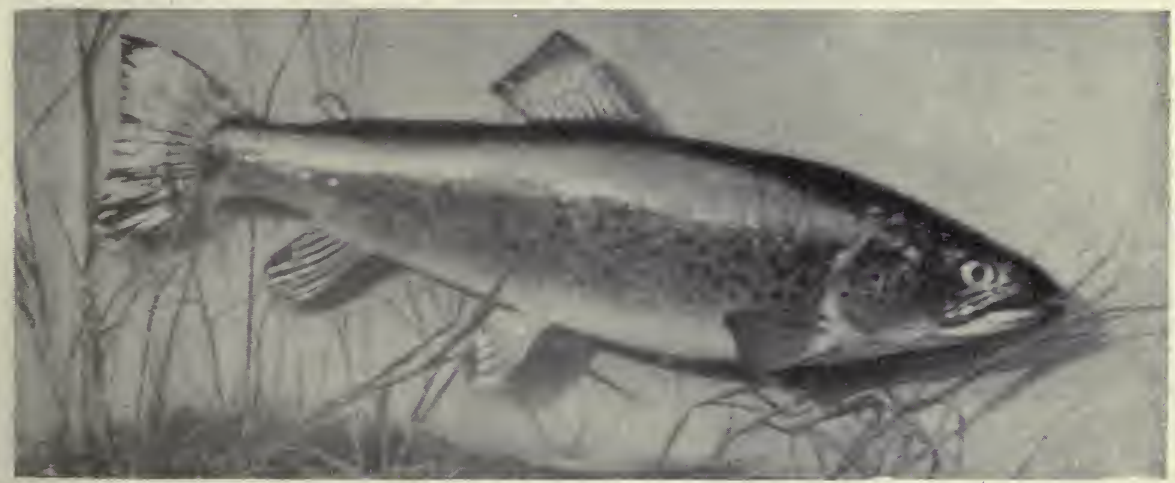

[Set up by Rowland Ward.

A 4-Lb. Test Trout, CaUght by the Author, June 2ND, 1903. 

If the line is switched as described, it will begin to travel back above the top of the rod (see Plates III. and IV.). The wrist must be kept rigid. If there is a tendency of the rod to overcome this rigidity of the wrist, a handkerchief may be at first loosely fastened round the forearm and the butt of the rod to keep the

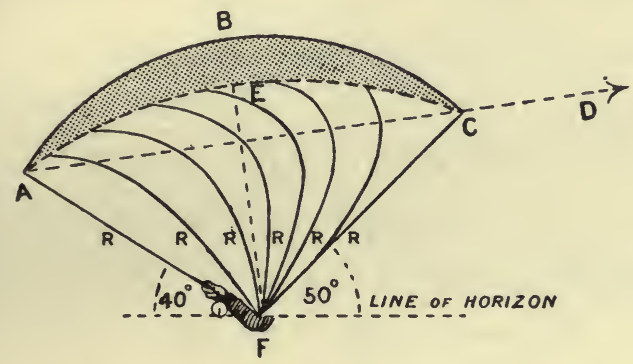

Diagram 2.-Showing Back Cast.

F A, position of rod before casting back.

F C, position of rod at end of back cast.

$\mathrm{R} R \mathrm{R}$, etc., position of rod during back cast.

$\mathrm{F}$, the elbow, which is the pivot of the back cast.

A B C, theoretical curve made by top rod when moved from A to $\mathrm{C}$.

A E C, real curve made by rod between $\mathrm{A}$ and $\mathrm{C}$ when pulling line.

F E B, a dotted line showing mean position of rod at the moment of greatest force.

A C D, the mean direction of force as applied to line.

A B C E, shaded crescent showing increase and decrease of force applied.

latter close to the arm, or, as an alternative, the hand can be brought back straight towards the face and checked in front of the right eye.

In order that you may grasp clearly the kind of stroke, or pull, required for this back cast, you should imagine that there is a small piece of wet clay stuck 
rather insecurely on the top of your rod, and that from the first position, as shown in Plate I., you have, by a steady but increasing force, to switch this piece of clay backward over your shoulder in a horizontal direction. The force should therefore gradually accumulate from the commencement of the stroke, and culminate at the end (see Plate IV.). This would of necessity jerk the clay off the rod backward at the sudden conclusion of the stroke.

Diagram 1 shows the angles made by the rod in the back cast. Diagram 2 shows the increase of force and the direction taken by the line, etc., which will be in the same plane as that described by the rod.

The force employed in the back stroke should be sufficient to extend the line behind after the backward action of the rod has been arrested, and, having thus extended itself, it will fall to the ground in a more or less straight line behind you. Later on, when fishing, you may find your line during a long back cast coming into collision with your rod, and you will learn to make a slight curve with the rod to one side or the other during the back stroke, thus keeping the rod clear of the line in its backward course. This collision may be due either to a side wind, a faulty back stroke, or from using too long a line. If a correct motion of the back cast is made when using a medium length of line, it is sufficient to lift the line above the level of the top of the rod as the line travels backward. The longer the line used, however, the less power will this upward 
PLATE III.

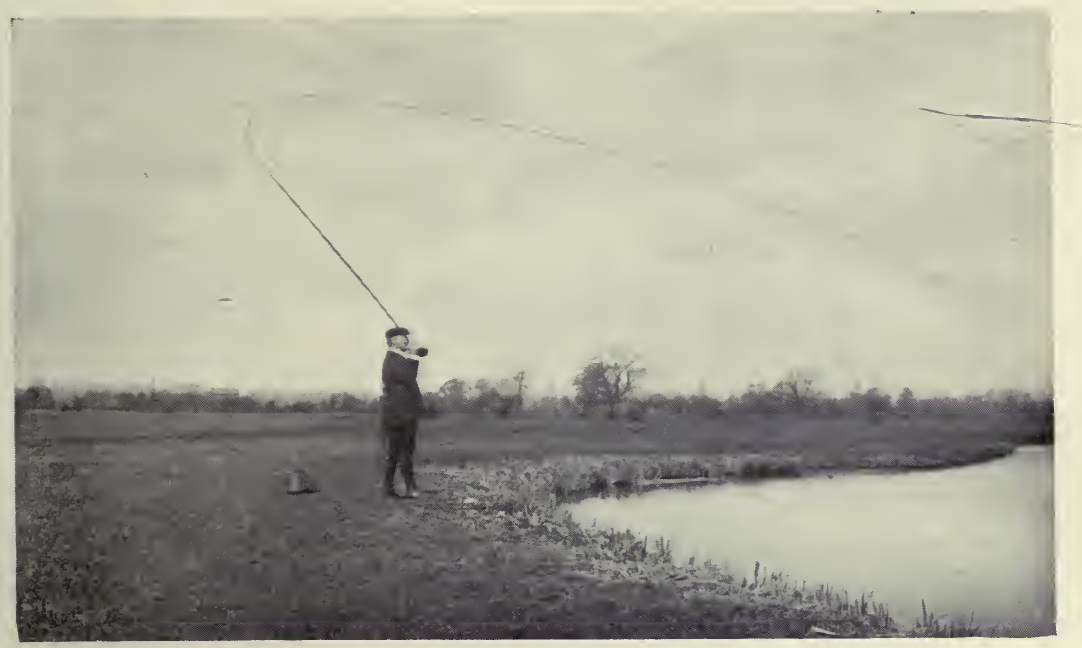

End of Back Cast. The Line is seen curling Back.

Copyright.]

PLATE IV.

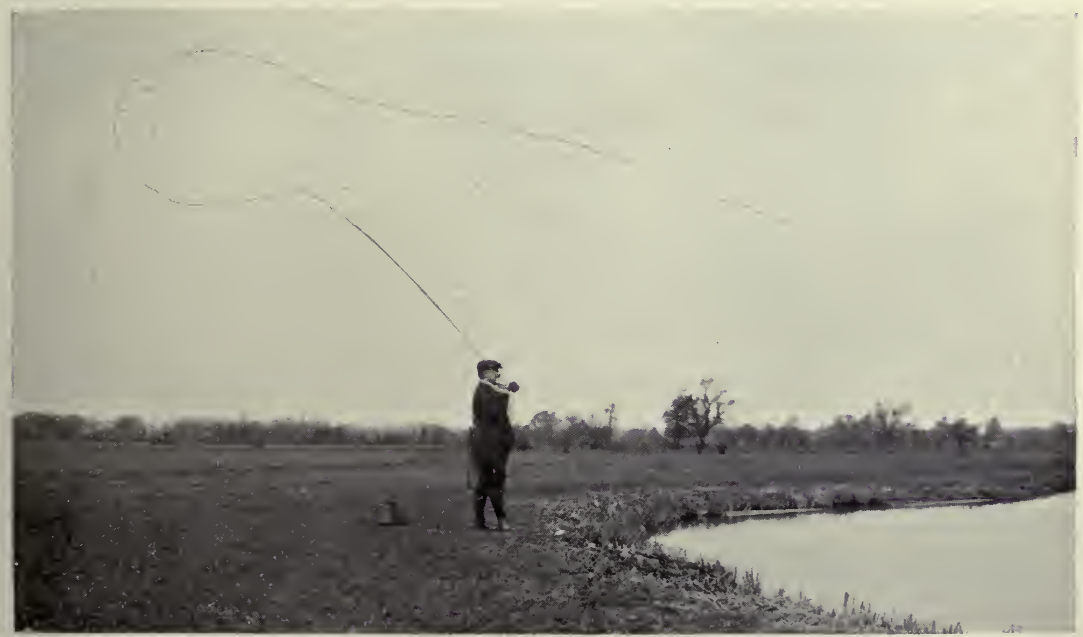

LiNE GOING STILL FURTHER BACK.

Copyright.]

TO FACE PAGE IO. 

motion have to lift it above the top of the rod, and the greater, therefore, is the tendency of the line to collide with the rod as it travels backward.

Now repeat the back cast until you are satisfied that your line travels back clear of the rod, and falls in a straight line behind you. It is a good plan to follow it back with your eye, and by doing this you will soon be able to regulate the strength of your backward cast. It is not force but knack which results in a correct cast.

You must now learn to make your back cast without your friend's assistance.

Shorten the line, leaving only about 20 feet beyond the top ring of your rod.

Get into the first position again, holding the line in your hand, and the rod at an angle of about 20 degrees (see F A, Diagram 1). Now straighten out your arm, and at the same time lift it and the point of the rod together, letting go the line, and as it flies away from you in a circular outward sweep the back stroke must be made as before, from the elbow. Repeat this until you can make the back cast in this way easily and without fouling. You are now ready to make the forward cast.

The two essential points to remember are-first, that the best forward cast can be made from a position in which the line is extended immediately opposite the point to which the fly has to alight, and that it is therefore towards this position that the line should be thrown in the backward cast; and second, that in all 
strokes the line follows the movement made by the point of the rod, whether that movement be made in a plane or in any more or less extended curve.

\section{The Forward Cast}

In following the line in its backward journey it will be noticed that it takes some little time to extend itself before falling to the ground, and a pause is therefore necessary between the back stroke and the forward cast in order to allow this extension of the line. It is precisely the timing of the correct length of this pause which is one of the secrets of a successful forward cast. This pause will vary in duration : the wind, the quality of rod, the length of line, and the force and speed of the back cast, will all influence the velocity of the backward moving line, and, consequently, no fixed length of time for this pause could possibly be given. It must not be of such duration as to permit the line falling to the ground.

Under average conditions I have found that, with 15 yards of line out, a pause equal in length to the time taken in making the back cast is sufficient; but by following back your line with the eye in practice, you will soon be able to seize the psychological moment for your forward cast.

The forward action of the rod, when commenced, must be made more rapidly than the backward motion. In the latter, the line being on the ground or water cannot suffer by falling any lower, however slowly the 
PLATE V

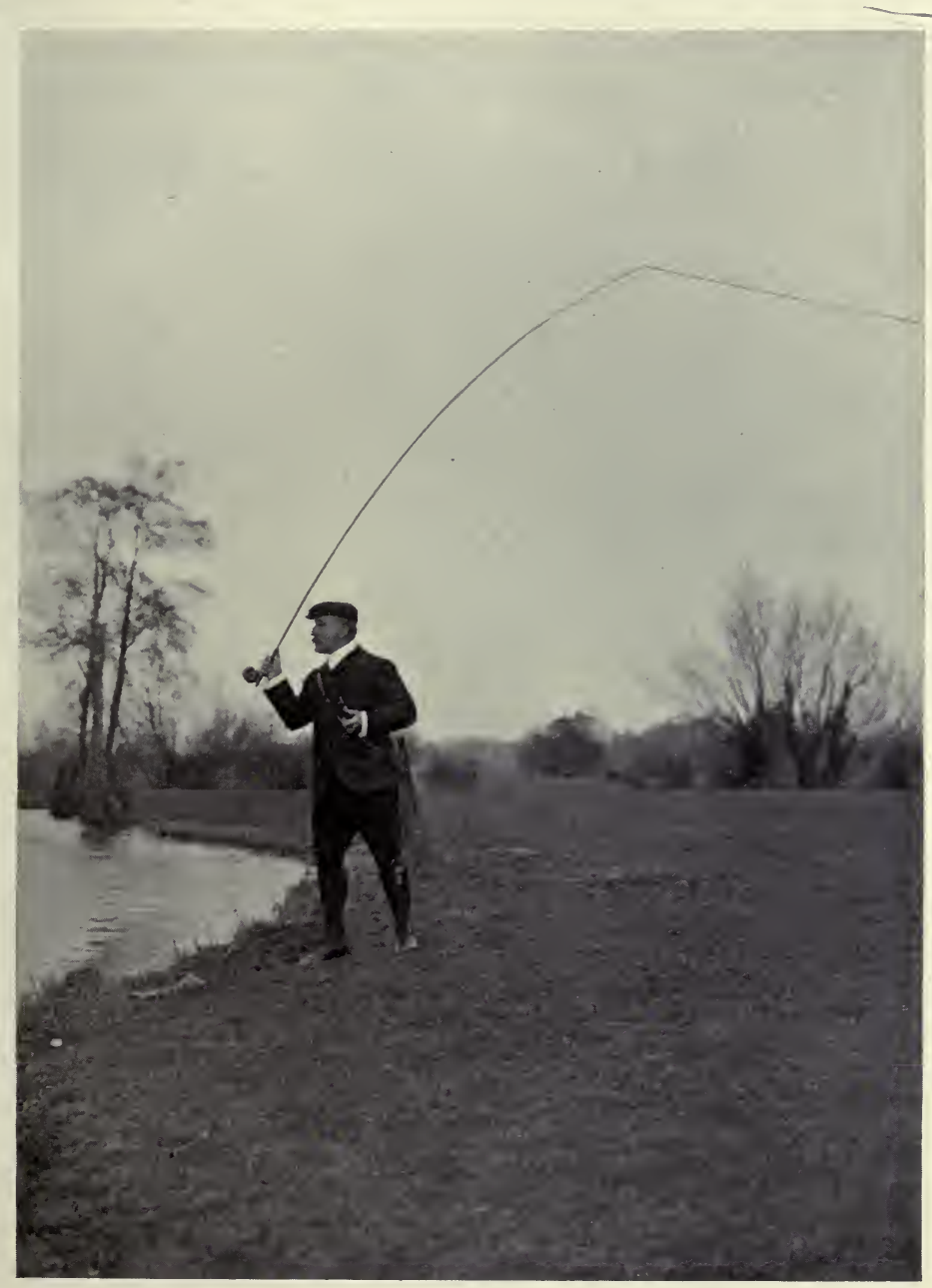

Commencing Forward CAST. 

rod may be raised, whereas, unless the forward action of the rod follows fairly quickly on the back stroke, the line will fall to the ground, and the forward cast will suffer in consequence. Exactly the same proportionate increase of force must, however, be applied to each inch of the forward or backward switch when the line is once in the air.

The old theory of permitting the line to extend itself backwards before the return stroke is made is absolutely correct, and in my opinion it is the most easily acquired method of making an accurate and delicate overhead or side cast. In practice, though the absolute extension of the line at the moment of the forward cast is rarely achieved, yet the result is one which enables the fisherman to extend and shoot his line further than in any other style of overhead or side casting. It is one, too, which offers less difficulty to the beginner. Besides these advantages which I claim for it, this method is most efficient when adopting the side and wind casts. Anyone who has carefully watched Enright will have noticed that in all his most successful casts his best forward casts have been made from a position in which his line is almost fully extended behind him, and directly away from the point at which his fly has to alight. One might describe the position of his line as follows : the line at the end of the straight back cast is extended upward toward the highest point of an inclined circular plane, the tip of his rod at its moment of greatest tension is the centre, and the place at which the fly has to alight the lowest 
point of the plane. Some of the best of our English fishermen, however, do not extend their lines behind them, and their overhead casts are in reality made when their line is in a vertical upward curve or loop -in other words, they make their forward casts when their lines are in a position such as is shown in Plate IV. Practice and skill have made Mr. Valentine Corrie's casting not only delightful to watch, but accurate and delicate in its results, and Mr. Halford, after taking a series of photographs of Mr. Corrie when casting, asserts that "the old theory of waiting until the line is fully extended behind before commencing to make the cast was utterly exploded." Mr. Halford declares this because the results of these photographs showed that Mr. Corrie does not wait for any extension of his line backward to occur before making his forward cast. The problem is, not to question the merits of such a style of casting, but rather to consider whether a result equally as good in so far as delicacy and accuracy are concerned, with better results as to distance, would not be more easily acquired by permitting the line to extend itself as much as possible to its full length before making the forward cast.

In the first place, if the reader will turn to Plate IV., and imagine that the fisherman is proceeding to make his forward stroke, he will at once notice that this forward impulse will be transmitted to only the shortest portion of the line; but a good deal of the impulse will apparently be lost in dragging the longer part of the line in the opposite direction to that in 
which it has to go. If, however, the line be extended behind to its full length, as in Plate V., every atom of impulse will be applied to the line in the right direction, and consequently a better result should theoretically occur, and a greater accuracy be acquired, in that the pull on the line will be made in one straight line, and not applied to a curve. It is also better for a beginner in that he will be able to judge the moment for the forward throw more accurately when his line is, as nearly as possible, extended behind him than when it is curved in the air. And again, if the back cast has been properly made, the line will extend itself with a slight pull on the rod; and if this moment be seized for the forward cast, every particle of strength applied to the rod will be given to the line. In not permitting the line to extend itself backward, the danger of cracking off the fly becomes greater, as the continuous pull on the line should not be relaxed. Mr. Corrie drops his arm at the conclusion of his back stroke, thus going on with a continuous motion, and then without pause brings the rod forward, converting this downward motion into the forward cast. It is by this continuity that he saves himself from the danger of a crack. Mr. Corrie, however, is an expert, and can do his casting in a variety of ways. He is one who uses his head in all that he does; but I should like to hear from him his own experience, as I think it would probably deter the student from attempting a style which, in less experienced hands, might not lead to such excellent results. 
By the terms "strike" and "cast" I mean the switching impulse given to the rod by the arm, either backward or forward respectively, and not any lowering, side, or other movements of the arm or rod, unless made at the same time as the strike or cast.

The forward cast should be made at the expiration of the necessary pause. The force required is slightly less than that used in the back stroke, and should gradually increase in strength until the rod is stopped with a jerk at an angle of from 40 to 20 degrees above the object aimed at (see Plate VI.). This angle will, however, depend on the resistance or otherwise of the wind. In order to get this action correctly, it is necessary to imagine that you are again throwing forward a small portion of clay from the top of your rod, and that it will be this jerk which causes it to leave the rod and fly forward.

The line, actuated by the forward switch, will be seen to travel forward as the rod is checked at this angle, and the downward droop of the under side of the belly of the advancing line should be followed by a quiet lowering of the rod, until the line touches the grass or water (see Plate VII.).

Some hours' practice should now be made, remembering the above instructions and endeavouring to direct the end of the line to some definite mark on the grass, on which the eye must be fixed. The friend should be asked to watch the rod, and to see that it does not incline backward beyond the angle shown in Plate III. The force applied to each cast must be 
PLATE VI.

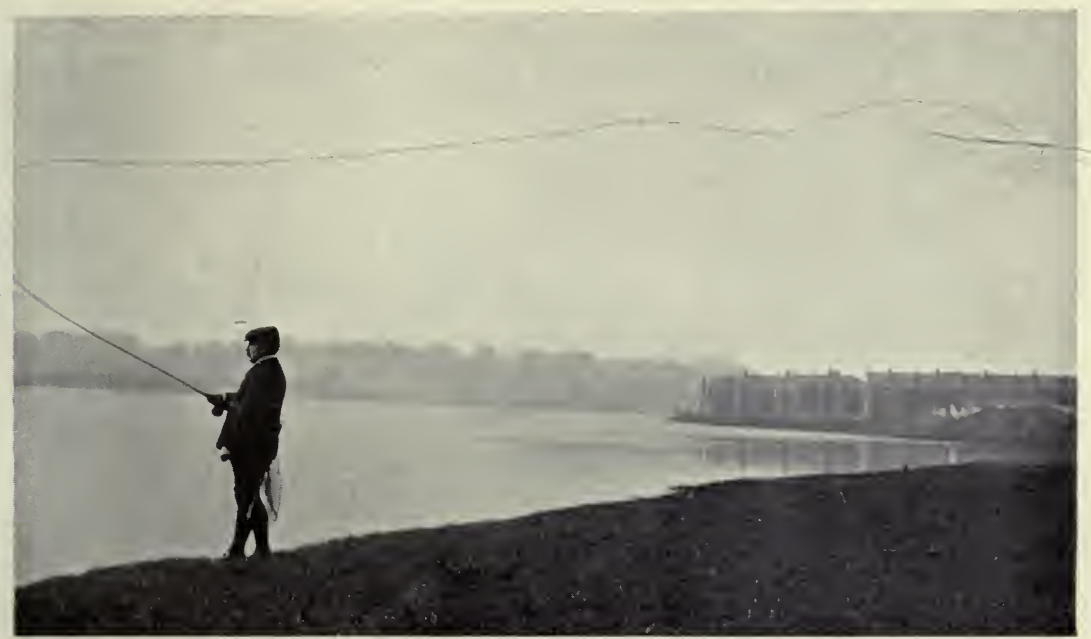

ENd of Forward Cast. Line beginning to CURL Forward.

Copyright.]

PLATE VII.

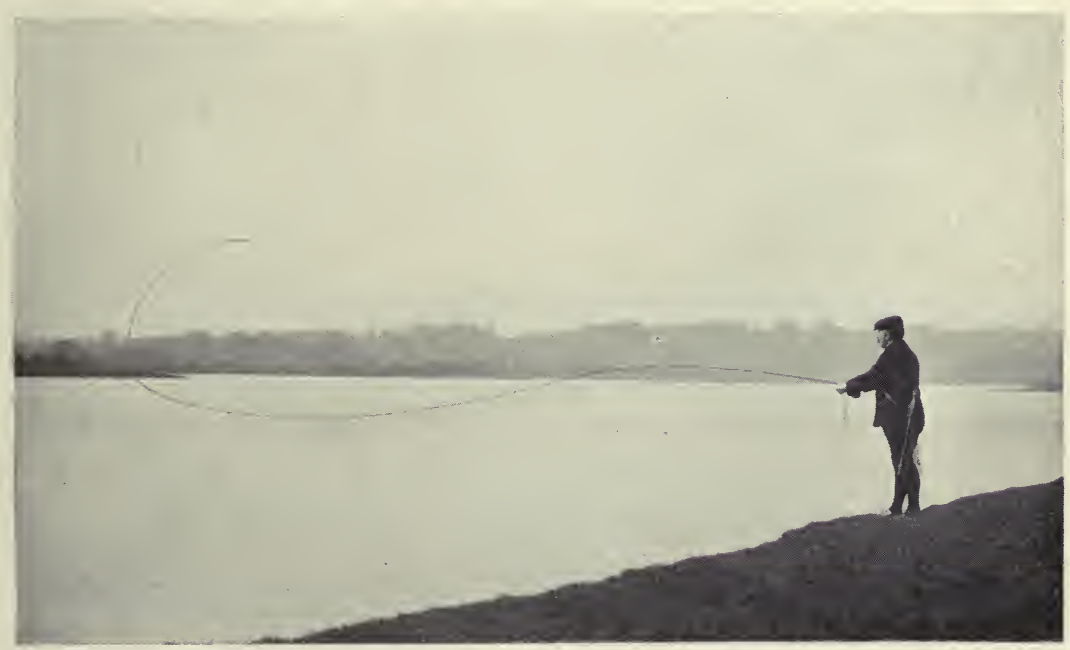

Line alighting on Water. The Left Hand shown feeding Line.

Copyright.]

TO FACE PAGE I6. 

derived from the muscles of the arm; neither the shoulder nor body should be used to assist the cast.

It will be found that as the line (see Plate VI.) comes forward at the conclusion of the forward cast, the pull of the forward belly of the line will be sufficient, if the rod is kept pointing towards the travelling line, to drag through the rings of the fishing-rod the slack line between the first or lowest ring and the reel. The slack line should be held in the left hand, and released at the moment when the forward action of the rod is checked. This is called "shooting" the line, and is of great assistance in getting the line out when fly casting; it counteracts the backward drag of the fly as the line extends itself forward, and enables the fisherman to get out a longer, lighter, and more accurate cast (see Plate VII.). In this photograph the fly is about to alight on the water; the left hand is shown as having fed the slack line up to the lower ring as the travelling line shot forward.

Diagram 3 shows the angles made by the rod in the fore cast. A G shows the line as it should be when commencing the forward cast. B D shows the line shooting forward at the end of the forward cast and at the moment when the rod should be lowered and the line fed.

It is of the first importance that when the line is in the air it should always be under the influence of the force applied to it by the rod. It should, in other 
words, be alive, and not dead. The end $G$ of line A G in Diagram 3 should therefore still possess backward energy when the forward cast is made. The wind, when against the back cast, will frequently destroy the backward energy of the line before it has fully extended itself, the end of the line thus becoming dead. This is a fruitful source of danger, as the forward switch of the rod communicates itself to the dead portion of the line with a jerk, which cracks

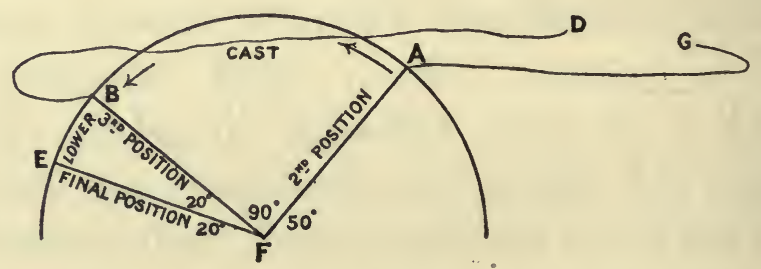

Diagram 3.-Showing Positions of Rod in Forward Cast.

A G, position of line when commencing cast (see Plate V.).

A F B, angle of forward cast.

B C D, line coming forward as fore cast is finished-the moment for lowering the rod.

F E, final position of rod (Plate II.).

off the fly. The same result may happen if insufficient energy is not applied to extend the line fully backward.

Diagram 4 shows the increase of force used and the direction taken by the line in the forward cast.

The beginner should, at the commencement of the backward strike, hold the line between the finger and thumb of the left hand, having a few feet of slack 
line hanging down between the hand and the reel, as in Plate I.

As the strike backward is made the left hand can, if required, assist the rod by a downward pull of the line, and when the forward impulse is terminated, the line should be released, and, as the belly of the line

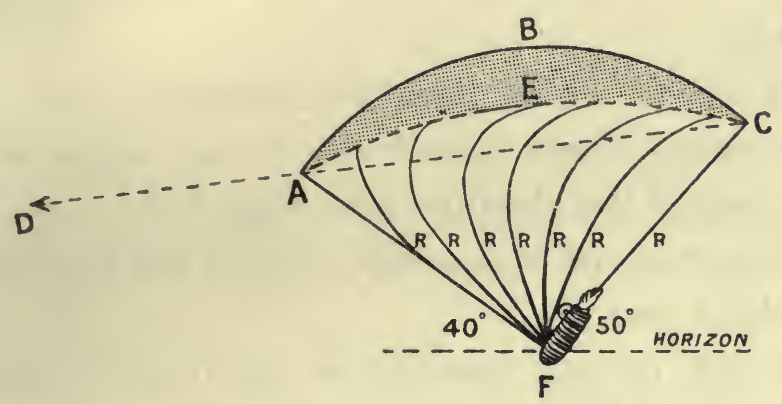

Diagram 4.-Showing Forward Cast.

F C, position of rod before casting forward (Plate V.).

$\mathrm{R} R \mathrm{R}$, etc., position of rod during cast.

F A, position of rod at end of cast before lowering (Plate VI.).

C B A, theoretical curve made by top of rod when moved from $\mathrm{C}$ to $\mathrm{A}$.

C E A, real curve made by rod from $\mathrm{C}$ to $\mathrm{A}$ when propelllng line.

C A D, a dotted line showing direction of force.

A B C E, a shaded crescent showing increase and decrease of force applied.

shoots forward, the left hand should feed the line towards the lower ring. The more directly the rod is pointed at the forward travelling line, the more easily the line will run or shoot through the rings. As the student practises and acquires the correct action of casting, "shooting" the line will come quite 
naturally, and therefore I should not advise him to let this part of the matter engage his attention just at first.

I can now condense this lesson into the following sentences :

(1) Raise the rod to an angle of about 40 degrees in front of you (see Plate I. and Diagram 1); don't pause, but

(2) Switch or strike, using the elbow as pivot, with ever-increasing force backward to an angle of 40 degrees behind the shoulder (see Plate III.).

(3) Keep the rod stationary, and let the line extend itself behind you.

(4) Switch or cast forward to the former angle of 40 degrees in front, and as the line comes forward (see Plate VI., Diagram 3),

(5) Lower the point of the rod as far as may be advisable until the fly alights (see Plate VII.).

Condensed into words as follows :

Raise.

Strike,

or

Switch backward.
Pause.

Cast, or

Switch forward.

Later on, when delicacy of action has been obtained, the student will notice that as the line extends itself backward, it gives a small and just perceptible back pull to his rod. This pull may be perceptible when the back stroke is perfect, and it will be a guide as to the duration of the pause before casting. It must be evident that the more nearly a horizontal 
PLATE VIII.

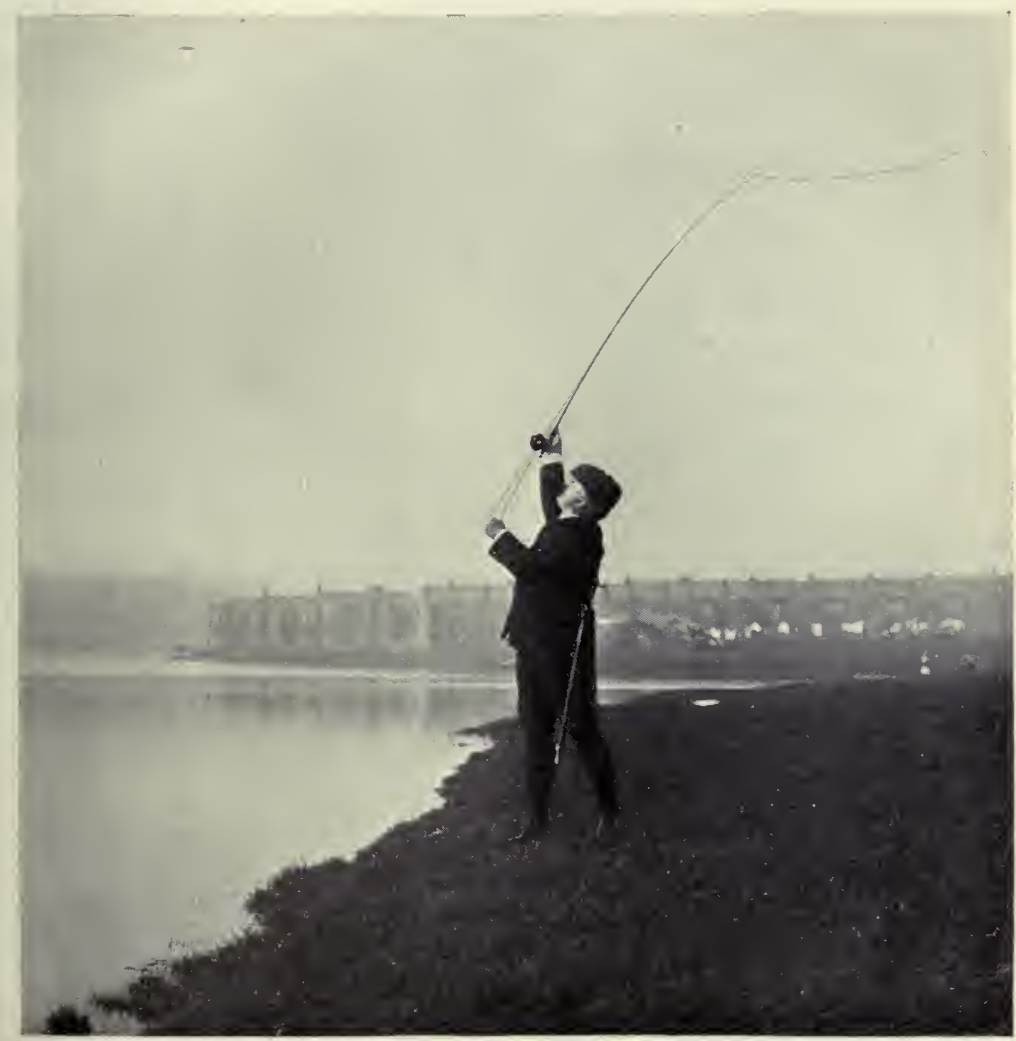

The Steeple Cast. 

position is obtained by the line when extended, the more lightly will it fall on the water, which is the object of all fly casting.

\section{The Steeple Cast}

The steeple cast, which may be used at times to avoid dangers behind the fisherman, or to get out an extra long line, is somewhat similar to the overhead cast. In the back cast, however, the muscles of the shoulder are used. The whole arm is swung back to the right, and extended to its full length above and behind the shoulder; thus the rod is not, as before, brought vertically over the shoulder. The right shoulder, the side, and the hip of the body swing round with the arm as the stroke is made, the weight of the body being supported on the flat of the right foot and the fore part of the left foot (see Plate VIII.). Before casting forward when using the steeple cast, I recommend that during the pause the elbow should be dropped, the point of the rod brought forward a little, and the shoulders squared, the line being returned vertically from over the shoulders, as in the overhead cast. I, personally, can get a longer line forward this way than when making the forward cast with the extended arm and forward swing of the right side of the body, and, I think, with a more delicate result. 


\section{The Side Cast}

The right-hand side cast is made with a precisely similar rod action to the overhead cast, but the rod is brought back more or less horizontally to the right side of the body, and returned in the same plane, the object being to prevent the line rising to any height in the air. This cast is useful against the wind, and also when casting under branches and bushes, while the fly should fall more lightly on the water than in the overhead cast. The right foot should be pointed to the right, at a right angle to the direction of the cast, and the left foot straight forward. The rod action should be from the elbow, with a rigid wrist: the body should turn completely round to the right, and the rod should then be brought back to an angle of about 45 degrees above the horizon and about 30 degrees behind, the weight of the body being principally on the right foot; the eye can thus easily command the line in the back stroke, and the action is most instructive. At the conclusion of the back stroke the position of the arm should be as follows : elbow down, palm up and held easily extended from the shoulder in the same line as the rod.

Directly the rod is checked, at an angle of about 30 degrees behind the direction of the right foot, the body should again turn forward, facing the spot to which the fly has to be cast, the principal weight coming on the left foot; the eyes should be directed towards the mark aimed at, and the forward stroke 
should then be made. The body action should in each case slightly precede the rod action. As the body swings round toward the mark, the forearm and rod must remain pointing backward, and if necessary, and to ease this position, the elbow can be drawn in toward the side, and the forward cast can then be made from the elbow, and not with any body or shoulder action. To get a clearer idea of the angles made by this rod in backward and forward motions of the side cast, the reader should take Diagrams 1 and 3 as being the horizontal instead of the vertical angles made by the rod, the right foot being situated at $\mathrm{F}$ and pointing midway between $\mathrm{B} \mathrm{C}$ and $\mathrm{B} \mathrm{A}$ respectively in these two diagrams.

\section{Avoiding the Drag}

A trout will often be noticed rising in comparatively still water on the further side of a stream, while between the fish and the angler the current may be rapid. To cast a dry fly which will remain on the water sufficiently long to give the fish an opportunity of rising is, under such circumstances, perhaps one of the most difficult casts which have to be made, as the current will, if the line is thrown straight, cause an almost instantaneous drag on the fly which has fallen in the still water beyond it, a fault which will most certainly deter the fish from taking it. A side cast of the line up-stream is in this case the only method by which the immediate drag can be avoided, and 
should be made as follows : At the end of the forward side stroke, which should be made up-stream, a slight forward wrist action will cause a belly of the line to fall in an up-stream curve, and thus give a momentary respite from the fatal drag, which respite should be sufficiently long if the fly has fallen in the right spot to ensure a rise.

The left-hand side cast is made in a precisely similar manner, but to the left hand.

\section{The Wind Cast}

If the wind is blowing against the back cast, use the side cast backward, keeping the fly well down, and instead of pausing at the end of the back stroke, bring the rod with an upward sweep vertically over the shoulder, and deliver the fly as in the overhead forward cast.

Having mastered the principles of overhead and side casting, the student will have little difficulty in adapting them in order to baffle the wind and get his fly out in spite of any moderate breeze in his teeth; also in casting under trees, bushes, etc. In making the overhead cast, if the wind is slightly against the fisherman, the forward switch would be made more in front and downward; the line of direction C A D, Diagram 4, will thus be inclined more toward the water. The backward switch in this case need not be carried so far over the shoulder, and in consequence the line A C D, Diagram 2 (the line of direction), will 
PLATE IX.

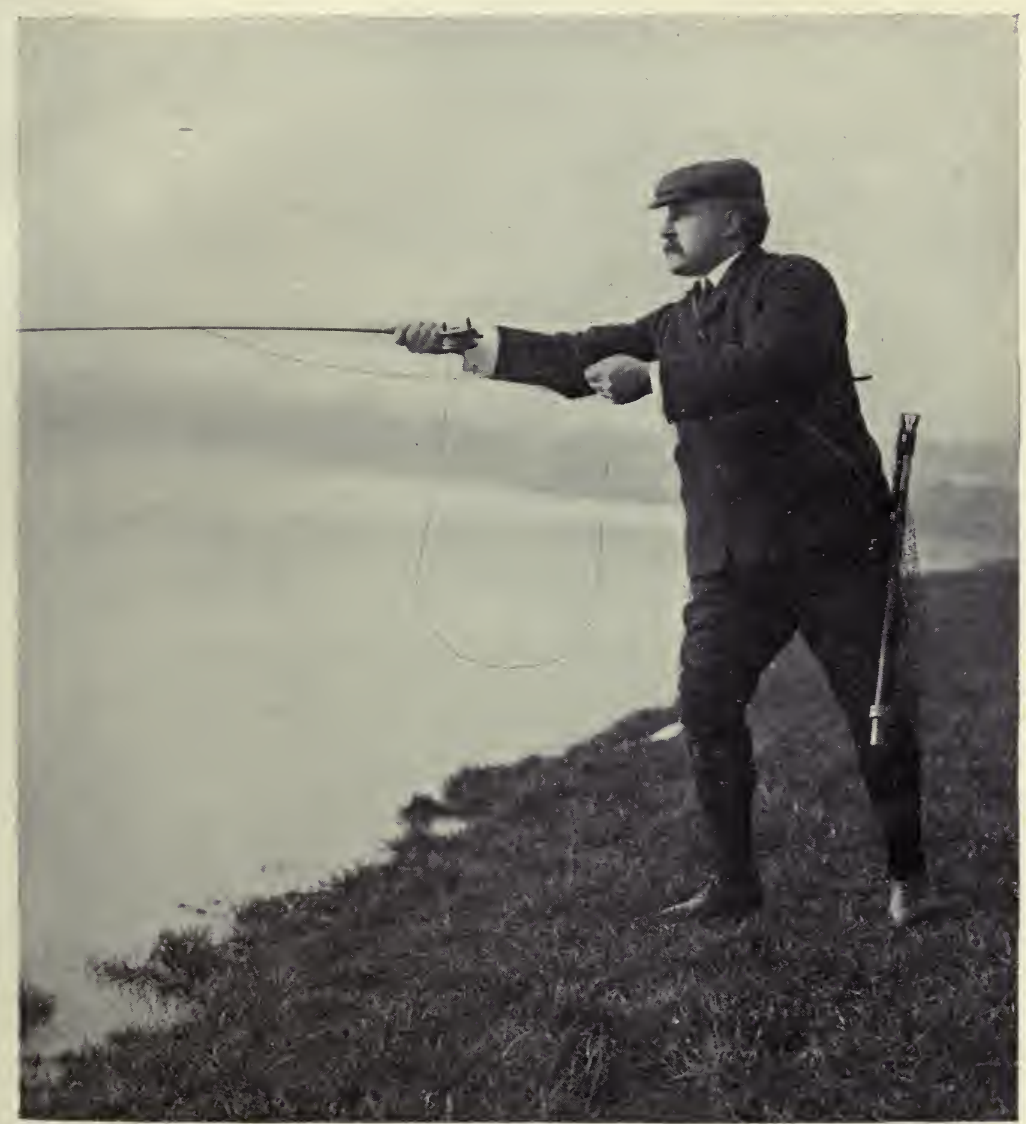

The Author's Method of Casting a Line against the Wind. 

be inclined more upward. The wind will flatten the line down to the horizontal quickly enough. When, however, the wind is a serious factor the wind cast should be adopted.

In making this cast it must be remembered that the force of the wind against which the fisherman has to contend will, in most cases, be greater the higher his line is above the ground. In casting against the wind, therefore, he should complete his back stroke as in the overhead cast, thus taking advantage of the wind, and at the finish of this stroke, instead of pausing, he should bring the rod down sideways until it is some 45 degrees above the right-hand horizon, and still pointing slightly behind, which is the position of the rod at the end of the back stroke in the side cast, as described above (see F C in Diagram 1), when used horizontally. By the time this is done the line will have extended itself behind in the same plane as the rod, and he should then make the forward cast sideways, extending his arm as he does so to its full length, and giving his wrist a sharp outward and downward twist at the end of the forward movement, finishing his stroke with the top of the rod pointing towards the spot at which he wishes his fly to alight. This twist of the rod will bring his thumb to the right and his reel to the left side of his rod, reel and thumb, with the palm up, being in the same horizontal plane (see Plate IX.). This twist is somewhat similar to the screw used by a right-hand bowler when breaking a ball from the off; it forces the fly against the wind, and at the same time 
keeps the line well down, and as far out of the wind as possible. I think I may claim this method as original. I have found it most useful when casting against the wind.

The wind cast can be very easily made after the backward movement of the rod in the side cast has been effected. In this case, as the body turns forward, the right foot makes a step toward the mark aimed at, and the body at the same time comes forward, this forward impulse materially assisting that which is given to the rod and line. In this wind cast the check to the forward movement of the rod must not be made until the wrist action is applied.

When using the overhead cast against the wind, the forward switch, instead of finishing at an angle of 40 degrees, is continued down towards the water, the arm being extended. The same screw or twist of the wrist as described above must be used at the end of the stroke, at which moment the full force of the forward cast must be delivered, and the elbow, pointing down, brought slightly back towards the body. The top of the rod must be pointing to the spot at which the fly has to alight. The back switch in this case should be started sooner, and not carried so far back over the shoulder.

\section{Practising over Water}

The student will soon acquire the ability to extend his line easily and lightly in any direction, remembering 
always to point his right foot towards the object at which he aims, and always to keep his eye directed towards the spot at which he wishes his fly to alight.

A plate should now be placed on the lawn, and after fixing an old May-fly on his line, and snapping off the point of the hook, he should endeavour from different distances to place this fly on or near the plate.

When he has acquired accuracy in this important matter, he can commence his casting on any available and adjacent water. A fairly stout and well-soaked cast of gut, about 4 feet in length, and an artificial fly of fairly large pattern should be attached to the end of his tapered line, the point of the hook being again broken off. For his own convenience that part of the line he is likely to use, as also the fly, should be greased either with deer or mutton fat.

He should anchor a wooden hoop about 15 yards away, and continue his practice, trying to cast the fly within the circle of the hoop, and endeavouring to do it in a light and delicate manner. When casting on water the necessity of raising the rod before making the back cast will be appreciated. The rod should be raised or the line drawn in until that part of it in the water is well on the surface, and can be easily picked up. The backward switch should then be given. The more suited to one another are the rod and line, the better the result; the weight of the rod and line should always be relative to each other-a light rod and a light line, a heavier rod and a heavier line, and so on. A tapered line is perhaps the best to use; it not only 
increases the distance to which a fisherman can cast his fly, but in my opinion makes a more accurate and delicate cast.

\section{Long-Distance Casting}

When endeavouring to "get out" a particularly long line, you must always remember that you can cast a greater length of line than you can lift off the water. The final cast but one should be of such a length that you are absolutely certain of not only lifting it off the water, but of extending it behind you in a live statei.e., so that every portion of the line is still under the influence of its initial backward impetus when you make your final forward cast.

The secret of long-distance casting, therefore, consists in the actual knowledge of the greatest length of line which you can lift and cast backward, and the ability to shoot (see p. 17) the greatest amount of line when returning this length in your forward cast. To be able to cast a long, and at the same time an accurate and delicate, line is of inestimable use at times when dry fly fishing; the greater the distance at which you can reach your fish, the less necessity there is to crouch, crawl, etc. It may be taken as an axiom that he who can from his skill and experience cast a long and delicate line can with equal ease, and even greater accuracy, cast his fly over any intermediate distance. 


\section{Lightness in Picking the Line off the Water}

After each cast is made and the position of the fly noticed, the rod should be raised steadily until the line is straight and begins to be drawn along the surface of the water; the back stroke should then be made. Lightness in picking the line off the water is a most important art, which can be acquired by following out these and my former suggestions. When fishing down-stream with the single- or double-handed rod, with a long line and rapid current, a very slight upward switch can be given to the top of the rod just as the back cast is about to be made; this will cause a small upward wave motion to run down the line and will materially assist in lifting the line off the water. Lightness in casting, as before mentioned, is achieved by extending the line horizontally as far as possible before the fly drops on the water.

When the rod is moved in any direction, the line, subject to the influence of the wind, will travel in the plane of this movement, and so long as the line is in motion, it will always be influenced by any altered movement of the rod.

The following axioms must be kept constantly in the mind of the student :

1. That the line follows every movement of the point of the rod.

2. That the easiest and most accurate forward cast in any direction can be made from a position in which 
the line is extended towards the opposite quarter to that at which the fly has to alight.

We must now consider the best method of placing the fly in any spot other than that to which it has been previously cast. In order to effect this, the line must first be extended directly away from the spot at which the fly has to alight (see axioms above). To do this, a curved backward side motion of the point of the rod must be made in the opposite direction, and while this is being made, the body must have turned so as to face toward the spot at which the fly has to alight; and on the time and the manner of this combined movement will depend the success of the cast in the new direction.

\section{Altering the Direction of the Cast}

We will assume that your line is extended toward A (see Diagram 5), and that you desire to lift your fly from that point, and to cast it in one movement towards B. In order to be able to do this correctly, you must first extend your line as much as possible in the opposite direction. This position of the line can best be gained by a right-hand circular side sweep backward of the rod $\mathrm{H} \mathrm{C}$ from A upward in a spiral curve behind the shoulder to D (see Diagram 5), the body turning toward B as this backward side sweep is being made. The rod at the commencement of this stroke should be held at an angle of about 20 degrees above the horizon, pointing towards the fly 
as it rests on the water. It should then, by the continnous circular movement of the wrist, be swung round to the right in a backward and upward sweep, until the rod attains a position, as at $\mathrm{H} \mathrm{D}$, about 30 degrees behind the shoulder, the arm being brought back and round over the right shoulder, with the thumb down
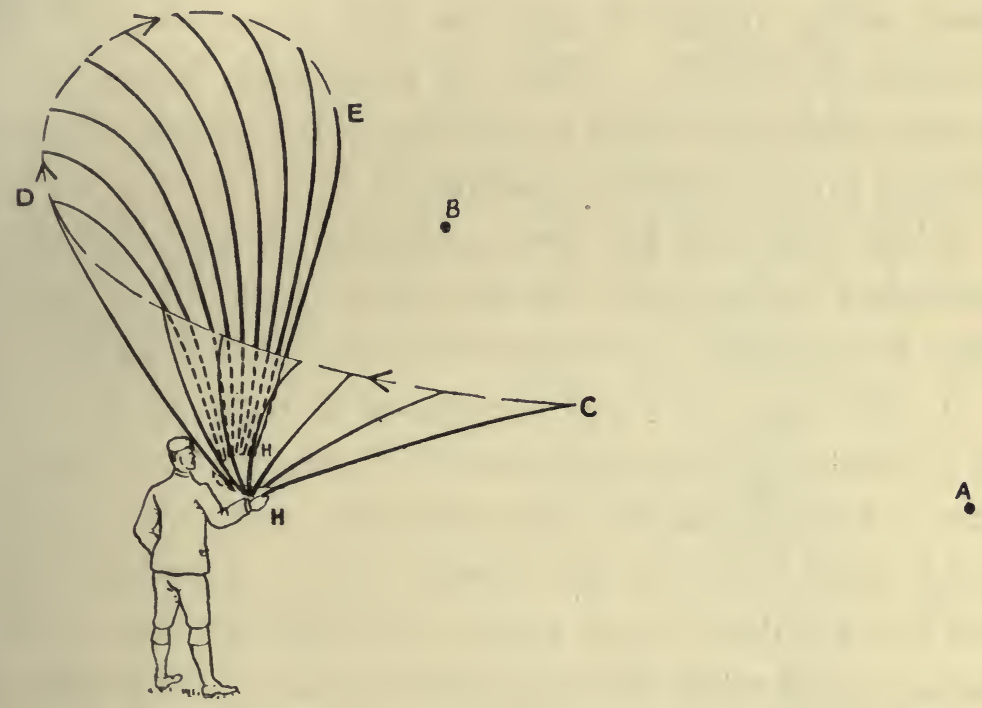

Diagram 5.-Rod Aotion in casting from A on the RIGHT TOWARDS B.

The line is not shown. The path of the hand is shown from $\mathrm{H}$ to $\mathrm{H}$.

and the palm towards the head, this upward movement then being merged into the forward cast D E towards B. The line, which has been extended towards A, will first fly outward away from B, following the point of the rod backward as this sweep is made, and then, as the rod is raised upward behind the body, it will more or 
less extend itself directly away from $\mathrm{B}$, and from thence it will be most easily cast forward towards B.

A point to be remembered in this cast is that the continuity of the movement of the rod must in no case be checked until the end of the final forward effort from $\mathrm{D}$ to $\mathrm{E}$. Another point is, that directly the outward backward sweep of the rod is commenced, the body must swing round at once to face the next desired position for the fly. The rod movement, being continued while the body is moving, will naturally bring the rod into its correct position, $\mathrm{H} \mathrm{D}$.

When this cast has been perfected, it will then be necessary to get the reverse cast-that is, to pick your fly up from A (Diagram 6) and cast it toward B.

In this cast the rod should be brought backward in a similar circular side sweep to the left; the right arm is brought to the left across the body; the right hand, held knuckles up, should rise as it approaches the left shoulder to an angle of 30 degrees above the horizon; and while the arm and wrist have been making this backward and upward movement, the body should be swung round to face towards B; the arm meanwhile, continuing the back stroke, should be raised until the hand has been brought, by the continued movement of the body and arm, well above the head, with the thumb held down, and the elbow of the rod arm pointing towards $\mathrm{B}$, in the same plane as the rod; the latter having reached the point $\mathrm{H} \mathrm{D}$, will point backward over the head at an angle of about 30 degrees; and this spiral side sweep of the rod from $\mathrm{C}$ to $\mathrm{D}$, should now be 
converted without the slightest pause into the forward cast D E toward B, the elbow being lowered as the cast is made. It will be seen, therefore, that the movement of the point of the rod is really a spiral from $A$ to $D$, and is then continued as in the forward overhead cast. The success of this cast will depend on the con-

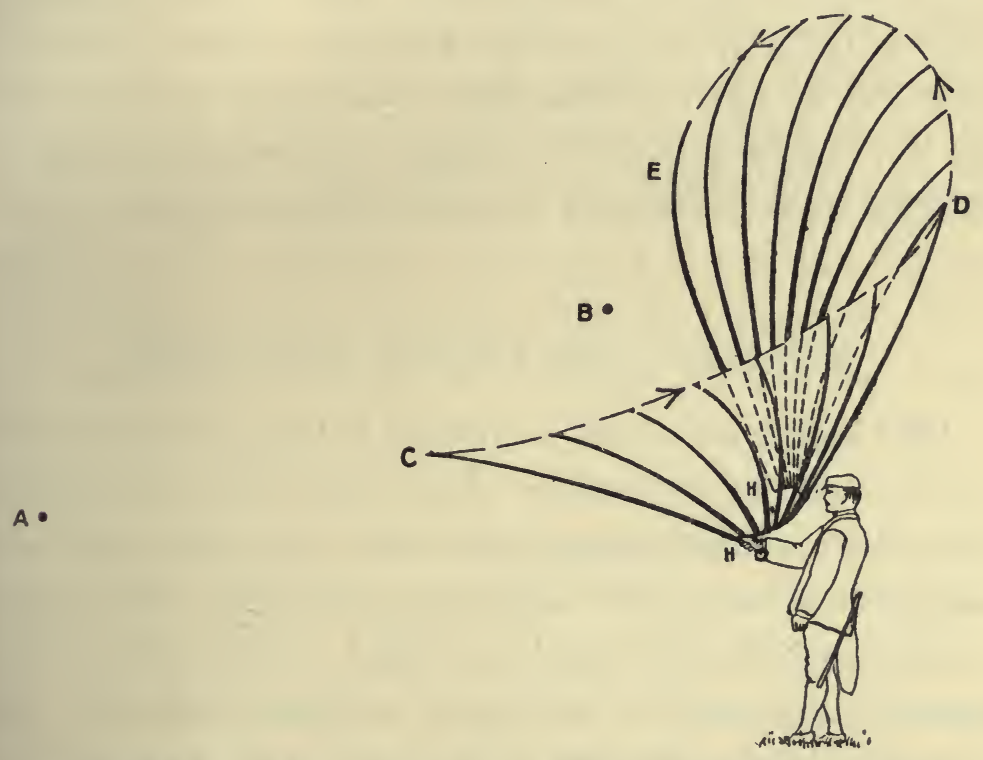

Diagram 6.-Rod Action in Casting from A on the LEFT TOWARDS B.

The line is not shown. $\mathrm{H} \mathrm{H}$, path of hand.

tinuity of the rod action, the correct timing of the body movement, the use of the wrist, and the easy upward lift of the arm. As the body faces B, the rod should be just arriving at $\mathrm{H} \mathrm{D}$, the position for the forward cast (see Plate V.), and as it attains this position, it is then brought forward along $\mathrm{D} \mathrm{E}$ towards $\mathrm{B}$. The 
movement of the rod from $\mathrm{C}$ to $\mathrm{D}$ is made by the arm and wrist action, pivoting from the elbow.

The student will find that his fly will eventually alight and remain poised on the water in the most natural manner near the mark at which he aims. The more carefully he carries out these hints the greater will become his accuracy and lightness of casting. After every three or four casts he should dry his line and fly by switching them backwards and forwards in the air, always when doing so allowing the line to extend itself before the reverse stroke is made.

\section{The Loop Cast for the Trout Rod}

The loop cast of the trout rod is made when danger exists both behind and to either side of the fisherman, and, as a consequence, when the line cannot be sent either backward or to either side, and only the vertical position of the rod can be effected. The rod is raised steadily upward to a nearly vertical position, but inclining slightly to the right or left side of the fisherman. The line will be drawn back along the water by this movement, and a slight loop, as in Plate XXXIII., will be made to the right or left side, but well clear of the shoulder. As the rod arrives at this nearly vertical position, its movement is altered by raising the elbow, and then making the forward and downward switch from the elbow, which is dropped and brought slightly back at the moment this forward switch of the rod is checked; a forward and downward curl will thus be 
given to the line, which, checked at the point of the rod, will curl over and run forward in a similar manner to the loop made by the salmon rod, as shown in Plate XXXIII. The movement of the elbow assists this curved motion of the line. Like most of the curved casts, it is extremely simple, and any difficulty there may be lies in the fact that the beginner will be nearly certain to make two distinct actions, as in his straight casts, forgetting that the whole cast has to be a continuous one, and that the first position of the stroke is neither a jerk nor a switch, but merely a very steady backward movement continued up and over into an ever-increasing forward impulse, which is checked at an angle of about 30 degrees above the horizon, as the hand is brought down and the elbow is drawn backward.

The side loop may be described as an underhand backward movement continued into a forward overhand side switch. It is made when the rod can neither be brought back, up, vertically, nor moved sideways behind the fisherman. It consists in a steady underhand side and backward movement of the point of the rod, which is brought as far back as is safe, and is then continued upward in a circular movement, but with the same steady pull. In the upper portion of this circular movement, however, it is altered into a forward overhand impetus toward the spot at which the fly has to fall. The first portion of this cast is obviously very simple: the line and fly are not lifted from the water, but follow back after the rod. The 
latter portion of the cast, however, requires some practice before the correct forward loop of the line is created by the vertical circular and forward movement of the point of the rod, and before it can be made to travel forward over the water in a similar manner to the overhead loop cast explained above. Neither the line nor the fly is permitted to come behind the fisherman in this cast.

The student, having mastered these preliminaries, should be competent to begin fly fishing for trout, and as he may have no friend at hand to answer his questions, to show him where to throw his fly, what sort of fly to use, or to tell him the nature and habits of the speckled beauties he is so anxious to secure, I must lead him still further afield in the study of this delightful and engrossing pursuit, and show him not only where to cast his fly, but how to determine what fly he should use, where the fish are to be most readily found, and how to catch them. 


\section{CHAPTER II}

Wet and dry fly fishing discussed-A morning on a trout streamHints-The Blue Quill-The rise-The use of the butterfly-net -The food of trout-Fishing the stream-Fishing the riseThe spear-Use of paraffin-Stream lore-Varying the flyThe Red Quill-Catching fish-Killing the fish-The fishing knife-The rise and its advantages-The rise discussed-A comparison-Undivided attention to floating fly-The dangers of jumping fish, and how to conquer them-Consideration for others - The file and disgorger-The broken cast-Useful knots -The blunted hook-A chat at luncheon-Further hints on fishing-Casting the fly on a rock, etc.

THE student must first grasp this most essential factthat there are two distinct and widely different methods of fishing with a trout fly, and that these are known as the dry and the wet fly methods.

In the former one fly only is used. This fly is cast up-stream just above the rise, or above the spot at which the trout is supposed to be lying, and should then float down toward the fish on the surface of the water.

In the latter from two to four flies should be attached to the cast. These flies are cast either across and up stream or across and down stream, and in both cases are allowed to sink below the surface of the water. Wet fly fishing is in itself thus divided into two distinct variations. 
In the one the flies at the end of a long line and cast are allowed to sink well below the surface, and to be carried down-stream towards every spot where trout may be lying. The stream is thus thoroughly searched by the flies, both fish and lure being invisible to the angler, and, in consequence, no dependence can be placed on the rise of the fish being seen, the angler having, in most cases, to depend on his sense of touch for a knowledge as to when the fish takes his fly; and, therefore, when a fish is caught, it is generally because the fish hooks himself.

In the other a short line is used, and each cast is made with the definite object of fishing either for a rising or for a feeding fish, whose position is therefore either known or assumed. The flies are allowed to sink only a few inches at the most below the surface, and the rise of the fish should, in consequence, be apparent to the angler, the fish in this style being mostly hooked by the angler's initiative in striking. This style of fishing, which is undoubtedly more interesting than fishing with wet fly down-stream, is, comparatively speaking, but little known, and it is often condemned by those who have not given it a fair trial.

When a trout is seen to rise, then the strike most frequently determines its capture. In wet fly fishing up-stream the angler, in four cases out of five, is dependent on his skill and alertness in striking for his fish. In wet fly fishing down-stream the angler is dependent in four cases out of five on the chance of the fish hooking itself, and in this respect alone it 
will be admitted that the greater interest must centre in fishing up-stream.

However, whether the angler elects to fish by dry or by wet method, or whether he may be spinning a minnow or throwing a salmon fly, the essential object he has to achieve is to throw his line in the lightest manner, and thus avoid splashing and the consequent scaring of the fish; and if he wishes to accomplish this, he should remember that the more nearly he approaches a horizontal direction for the forward cast of his line and fly, the more lightly will his fly or line fall on the surface of the water. Lightness and delicacy of casting are especially necessary for dry fly fishing, as the line has to be cast more or less over the trout, and success will depend, therefore, to a great extent on skill in casting.

To be successful in either of these methods of trout fly fishing requires patience, experience, observation, quickness, and skill.

Many excellent fishermen confine their fishing to either the wet or dry fly method, but the most successful fisherman generally will be he who is in reality the master of both.

Even on such classical waters of dry fly fame as the Itchen or the Test there are days, especially in the early part of the season and before the dry fly purist gets to work, when the trout who cannot or who will not see the floating fly will yet be caught on the sunken one. Again, there are times on the northern waters of wet fly streams when the wet fly expert 
may use his sunken lures in vain, but when the fish will eagerly take the floating fly; especially is this so on a late summer's evening. Both wet and dry fly can be used with success on the same day. The Rev. Hamilton Young, of Alne Vicarage, Yorkshire, and the inventor of the Ham-Young salmon hook, caught in one day, on the Deveron, 44 pounds of trout, using both wet and dry fly methods. Here is the entry from his diary :

"The Deveron, May 10, 1899.-Fished from 9.30 to 1.30 with wet fly, using the Hareslug and Yellow Cotterel. Wind south, rainy and squally; then sun came out; wind dropped. Fished with Olive Quill, dry, and got most heavy trout. Total weight, 44 pounds."

It will be readily admitted, however, by those who are skilled in both methods that not only is the dry fly more successful in southern waters during May, June, July, and August, but that, as a means to sport, it is infinitely more fascinating and delightful than the wet fly. The tendency of every wet fly fisherman is toward dry fly fishing, and the often repeated statements, "Oh, it is too scientific for me," "I should like to learn," etc., are my apology for dealing mainly with the dry fly method. The dry fly enthusiast may find in this work some points with which he disagrees, yet I trust that the attempt to explain my views of the science of dry fly fishing may at least be of use to the wet fly fisherman and the student. It will be, therefore, the art of dry fly fishing to which I shall first turn the student's attention, dealing with the wet fly later on. 
I will, therefore, take my reader with me for a few hours' dry fly fishing. You can leave the rod and line with which you have been practising at home, but first remember to unwind that portion of the line which has been previously wetted. Make it up in your hand (if you have no winder) into large loops; put your rod on the horizontal rests and hang up your winder, or put the loops on the butt. A fishing-rod should always be supported in three places at least-each end and the middle. We will take my own rod, which is all ready for use, with gut cast and fly attached. The first thing to be considered is whether we have everything we shall want, and if we are quite prepared for our fishing. Let me see. Are you well shod with good serviceable watertight boots with plenty of nails ? All right. Then, as you have your tobacco, pipe, and matches, and some sandwiches, never mind anything else to-day. I have all that is required-my fishingbag, my net, etc. Your tweeds are a good colour, but you had better put on a soft cap, as that straw hat of yours is too conspicuous. And now, while we are walking down to the lower end of our water, we can discuss the nature of the day's sport. We shall fish-that is, cast the fly-up-stream, which, except when fishing on still water, is essential for dry fly fishing. The dry fly must not be influenced by any motion of the line or rod after it has alighted, and by casting up-stream the fly floats down towards the fisherman, who steadily takes up the slack line as it approaches him, first by the reel and then by raising the point of his rod, but 


\section{2}

ADVANTAGES OF DRY FLY FISHING

without interfering with that portion of the line and cast floating on the water near the fly. He thus allows the fly to float easily and naturally down-stream. Any drag or movement imparted to a dry fly while on smooth water is fatal, and will most certainly scare the ordinary trout.

The dry fly fisherman, all circumstances being alike, is far less likely to be seen by the trout than is the wet fly fisherman, and consequently can take his sport more at his ease. For he of the wet fly who fishes upstream has to use a shorter line, and is consequently nearer the fish, while he who fishes down-stream is faced by the trout, and has to exercise the greatest caution in order to escape observation. Trout lie invariably with their heads pointed up-stream or against the current, and are in consequence looking up-stream and away from the dry fly artist, but towards the wet fly man. Trout can easily see from a point right ahead to an angle of 150 degrees on either side in the plane in which they are lying, leaving an angle of about 60 degrees in which the fisherman may escape observation, provided he is not perched too much over them, so that in fishing outside this zone of safety he must endeavour to be as near the surface of the water as possible (see "The Vision of Trout," p. 98). This position of the trout facing up-stream is also an important advantage to the angler when fishing dry fly, as his hook will be pulled back into the mouth of the trout, instead of being pulled out and from the mouth of the trout, as in the case of down-stream fishing. 
As we are now approaching the stream, we will look at the water and see if anything is moving. By standing here and looking up-stream we shall not scare the fish, and in order to see if the trout are feeding we must look out for any unusual movement on the surface of the water, such as the ring or dimple made by a rising fish. No, there is nothing moving yet; it is perhaps a little too early or not quite warm enough to tempt the pupæ to come to the surface in order to enter their aerial life, and therefore until they begin to move upward to the surface the trout are not likely to rise. In my creel is a self-contained butterfly-net; it is ready for use in a few seconds, and by its aid I catch that gnat-like fly floating on the water. It is the sub-imago or dun called the Blue Quill, the very fly the trout were taking yesterday. Look! There is another one on the water floating down, probably one of a previous so-called hatch of the same fly. I will catch him to make certain. Watch how I do it. I slip the net into the water just in front of the fly, which floats into it. Here he is, clinging to the muslin. Now look at these two flies carefully. You can see at once that both are just like the Blue Quill fly on my line, which is one of the best-known flies on English waters. If you fit this watchmaker's magnifying-glass into your eye, you will notice more distinctly the colour and appearance of its delicate wings, its body, and its legs.*

* If a fly is caught the name of which is unknown to the student, it should be placed in a small specimen bottle and either shown to a friendly authority or forwarded to the retailer with whom the student 
Now we will see if there is any rise. No, there are no signs of a move yet, as the pupæ which will form to-day's hatch are possibly waiting among the weeds until the water becomes a little warmer, or perhaps altered by some meteorological change, before rising to the surface, and therefore the trout have not been as yet excited by their appearance.

We had better, therefore, continue our walk down to our starting-point at the lowest end of our water. What! You saw a rise? Where ? Oh, I see. That is not a trout, but a water-rat. See him working his way up-stream among the rushes and under the long grass of the bank. Notice how he makes a long, slanting, rippling line from the bank out into the stream, instead of the detached ripple or ring peculiar to the rise of a fish. The rise of a trout varies in size, from the most delicate circular dimple on the surface to the splash and wave made as he jumps clean out of the water. We will now go on down-stream, keeping well away from the water, as we don't want to frighten the fish. Trout, as I said before, lie with their heads upstream, and their attention is thus directed to any food which may come floating down toward them either on or below the surface of the water ; it is necessary, therefore, for the fisherman to find out what the trout are feeding on, and then present this food to them in the most natural manner possible. The wet fly fisher-

may deal. By this means a general entomological knowledge will be obtained. A single watchmaker's glass is always a most useful adjunct to carry in your fishing-bag, also a small butterfly-net. 
man does this by sinking his flies below the surface, and dropping them down-stream toward the fish, and the dry fly fisherman throws his fly on the surface of the water and lets it float down to the fish.

The food which the wet or dry fly fisherman has to imitate, in order to attract and secure the trout, are the various forms of water insects, either in their pupa, sub-imago, or imago state. During the larval stages of the Ephemeridæ they pass into the pupal condition of their life, which is the metamorphism, while still under water, preceding their adult life. This latter is known first as the sub-imago, and after as the imago or perfected flying state. The transition from the pupa to the sub-imago is quite naturally, though erroneously, alluded to by most fishermen as "hatching." The water insect is hatched when it enters the larval stage of life, not when it undergoes the metamorphosis into the pupa, the sub-imago, or imago state.

There is but little difference in the appearance of an Ephemera when it is bursting its mask and entering into its sub-imago existence and that of the sub-imago in a drowned condition, and it is therefore in these two conditions that the wet fly fisherman imitates its appearance and presents it to the trout. But it is only when this water insect is in its living and flying subimago or imago condition that the dry fly fisherman copies its appearance. Hence you will readily understand that the latter has not only to use the more perfect and lifelike form of fly, but to present it poised naturally and in lifelike condition on the surface of the 
water. The wet fly fisherman can, on the other hand, present flies to the trout either on or under the surface of the water, and in a far less perfect condition.

Now, as the water is clear and the weather is warm, water flies and gnats will be numerous, and consequently the fish will most likely be taken by the dry fly; therefore we will first of all try our friend the Blue Quill fished as a dry fly; for two things are certain : that the fish were taking this fly yesterday, and also that there are some of these flies already on the water, and probably there will be an early hatch of the same kind before long. We have seen no rise, it is true, but we may be able to tempt a fish before the rise proper commences, and this I call "fishing the stream." When the rise commences we shall try for rising fish, and this I call "fishing the rise." There is more scientific knowledge required when fishing the stream with a dry fly than in fishing the rise, and the former is perhaps the most successful method throughout the day; for while the rise may be uncertain and very brief, fish can be taken at all times during the day if a knowledge of the locality and habits of the trout be possessed, by casting the fly in the most likely spots, even though the trout are not rising in the strict sense of the term.

The dry fly fisherman should fish the rise when it is apparent, and fish the stream at all other times. It is impossible for anyone to see more than a limited extent of the water, even in his immediate vicinity, and innumerable rises may, therefore, escape 
his notice. Fish are not always feeding, and even when feeding are by no means always rising to the surface. It follows, therefore, that if a fly is cast in all likely places-while not omitting at the same time to keep a sharp look-out for rising fish-trout will be taken whose rise has not been seen, or who may not have felt inclined to rise before seeing the angler's fly.

We have now reached our starting-point, and before commencing we will carefully examine our tackle. First let me caution you against laying the rod on the ground. It is always dangerous to lay your rod on the ground; even if you should never tread on it, someone else might possibly do so. Press the spear, which should be always fitted into the butt end of the rod, firmly but delicately into a soft tuft of grass, and you have thus both hands at liberty. If you drive the rod into the ground with a jerk you will put a strain on to your winch, especially if it be a Nottingham one, which may injure it, and in any case a jerk can do no good to the rod. When you have no spear, place the butt of the rod on the ground, and let the upper part rest against the body between the arms. You have, as before, your hands at liberty. Now the rod is standing up out of any danger, and we must look carefully at the gut cast and at the fly, and see that they are in good order. Everything being all right, we must render the line and fly as buoyant as possible, and this we do by applying some odourless paraffin-oil, which is contained in the small bottle you see hanging from the second button of my Norfolk 
jacket. By taking out the cork, in which is held a camel-hair brush with the hair immersed in the oil, we find we have enough oil on it to touch lightly the wings and heckle - the legs - of the fly. Only a very little oil is required on the fly, and the rest can be lightly applied to the line. After this is done squeeze the fly in a handkerchief between the finger and thumb - being careful not to injure the wings-and thus take away any superfluous oil.

I certainly advise the student to grease his cast, by no means forgetting the prevalent idea that a floating cast will put the trout down, or that the life of a cast is injured by the use of fat. I do not think that a good and carefully prepared gut cast will suffer from the application of any pure fatty substance, and I have noticed the very great advantage which a floating cast possesses, and to secure this advantage I take care that my cast is sufficiently greased to float on the surface.*

Certain makes of casts which I have tried, and which are more generally used for wet fly fishing, have certainly not turned out well; but whether this has been due to the fat I placed on them I cannot say, as I have not again purchased casts of that particular make. It may be, of course, that the method employed in the preparation of certain casts renders them incapable of standing fatty dressings.

In any case, I should advise the reader to use

* By a floating cast I mean one which will lie straight and evenly, and only partially submerged, on the surface of the water. 
pure animal fats, and to avoid chemical mixtures, however much they may be advertised; for although greasy to the touch, they have frequently a pernicious effect on the delicate lines and casts used in dry fly fishing. Now we are ready.

You see, there are one or two more Blue Quill coming down, but no signs of a trout, and as we have plenty of water ahead, we will try and tempt the fish to rise to our fly. Now, this is where experience and stream lore are so necessary. Trout, though fairly home birds, to use an Irishism, alter their position constantly from one point of the stream to another, and though they seldom go far from their retreat, yet the wind, the time of day, the heat or cold, the clear or thick state of the water, considerably affect their relative positions. Loch Leven trout are rarely stationary when feeding, moving from one position of a pool to another.

The most successful fisherman is, therefore, he who has, from former experience, an intuitive knowledge of just where a trout is likely to be lying, and also what the trout is likely to be thinking about when there. So now, with no fish in sight-i.e., risingI yet feel confident that there ought to be a decent fish just at the lower side of the opening between those weeds, also that he is thinking about food, and that on this occasion it is floating food. I shall try, therefore, to place my fly about 2 feet above the opening, so that it will float down to where I think he is waiting. It is a nice easy cast of about 15 yards right up-stream ; the breeze is also up-stream, and therefore in our favour. 
You will notice that I get my correct length of line, not by trial casting in the air over the fish, which would scare him, but by casting in the air to one side or the other. Now watch! There! The fly has fallen just in the right place. See, the wings are beautifully cocked, and the fly is sailing down through the opening of the weeds, and as it does so the point of my rod is being gently raised so as to keep the line fairly straight. There! Tut! tut! I have missed him ! Of course, I don't blame myself-fishermen rarely do so. I think, or say I think, he came rather short; but one thing is certain-he came at my fly. I flick my line backward and forward twice, and it is quite dry again, so I will try once more. There! just as before: the fly floated down beautifully, but I missed him again. I will try him just once more. No luck !

So we will give him a rest, and, as the fish are not on the shallows yet, try the opposite side just by the bank. The water is deep and dark, and if one is there he will be a big one. You see that I now stoop well down, as much out of sight as possible, when I cast, because from here I am more noticeable to the fish opposite than to the one we have just missed (see "Vision of Fish," p. 95). I have no luck ; three tries, but if one is there he is not to be tempted. We will try our first friend again. I can stand upright again, being almost directly behind him. Observe I dry my line and fly by three preliminary casts. Once more the fly alights just above the opening and floats down, but this time I get no notice at all from 
the trout. Once more-failure again! Well, as I don't like to leave a rising fish, we will try another fly, and this time one of a warmer tint. Often it is a good plan, when the fish have not started really feeding on the fly of yesterday, to try a fly with red heckles. So you see this fly in my cap that I am going to use; it is called the Red Quill. It has double starling wings, red heckle, and quill body. I now press the spear of the rod into the turf again, and my hands are free. You see these small but sharp scissors in my knife, which I have secured by a chain and keep in my right-hand coat pocket; I snip off the gut with them close to the eye of the hook, cutting the knot if possible, and, after clearing out the gut from the eye of the hook with the pricker in the knife, stick the fly into my cap, just where you see two or three more flies of the same colour. I place the end of the gut in my mouth to soften while I detach the Red Quill by taking it firmly between the finger and thumb, and by working it gently, it readily comes free from the rough material of my cap. I now slip the end of the softened gut through the eye of the fly, passing it round the cast above the eye in an overhand knot. I then draw this knot taut, and by pulling on the cast bring this overhand knot close to the eye of the fly. I have used as small an end as possible, which I now cut off.* The Red Quill fly must now be oiled, and the re-

* For further particulars of this and other knots see Chapter IV., page 125 . 
mainder of the oil on the brush can be used on the cast and line, as before. We are now ready again. The scissors are closed, the knife I have placed in my pocket, the cork is in the oil-bottle; and I take the rod, lift the spear out of the ground, get my length, and cast again. Now watch! There! He has risen, you see, and this time, by a slight turn of my wrist, I have hooked the trout, and before he has time to realize what is the matter I have drawn him below and away from the dangerous vicinity of the weeds. See! how he fights to get back to his retreat, but it is no good. Now he is trying to bore down into that dark hole ; there may be danger there, so I keep him well up. I have plenty of water, and firmly, and by wrist work alone, I check every rush he makes, and finally bring my prize well below the unfished water. My left hand is on the reel, which is bringing him nearer and nearer. Watch the end of the rod; it is well up, and the bend is nearly always the same. The line must never be slack after a fish is hooked, and this important point is achieved by delicacy of wrist play alone. By firmness and tact I have at last beaten him, and the line is short enough to make the landing-net available, so my left hand leaves the reel and steals to the net; it is lifted out of its ring and flicked out to its full length, and then, gently stooping, I bring the fish slowly towards the net, which you see I hold diagonally, well under the water, keeping it quite stationary until the trout is above it. Then, by a steady lift, I have the 
$x$
$\frac{w}{5}$
$\frac{5}{a}$

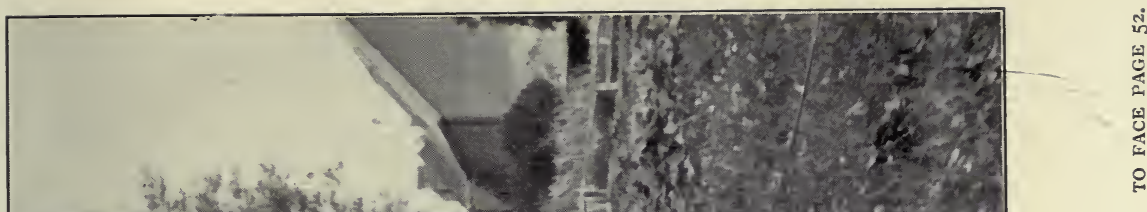

군

that the

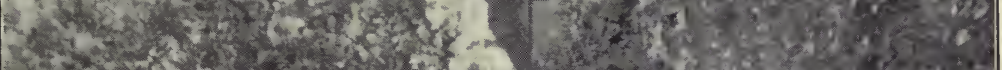

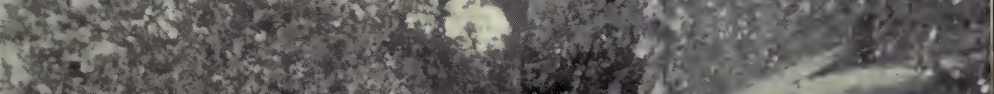

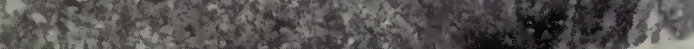

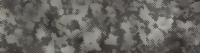

$-x^{2}$

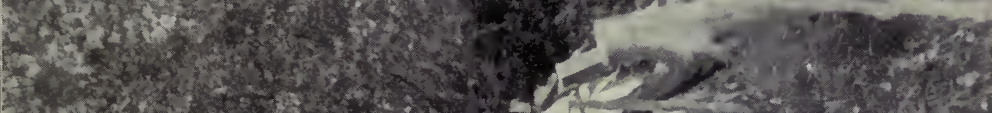

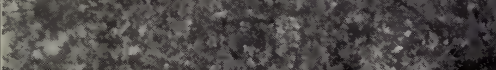

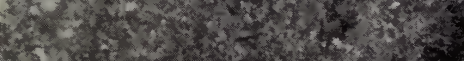

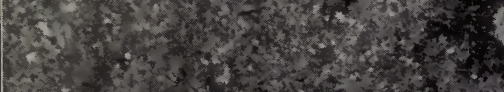

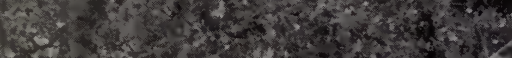

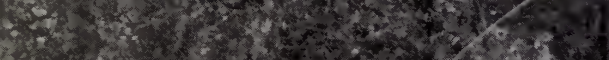

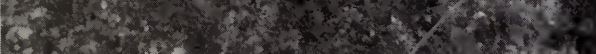

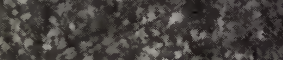
10.007 .

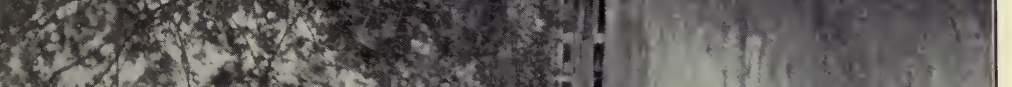

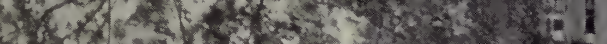

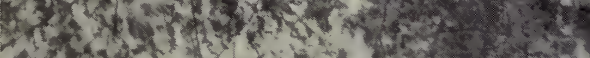

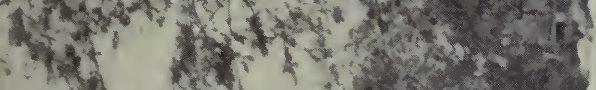

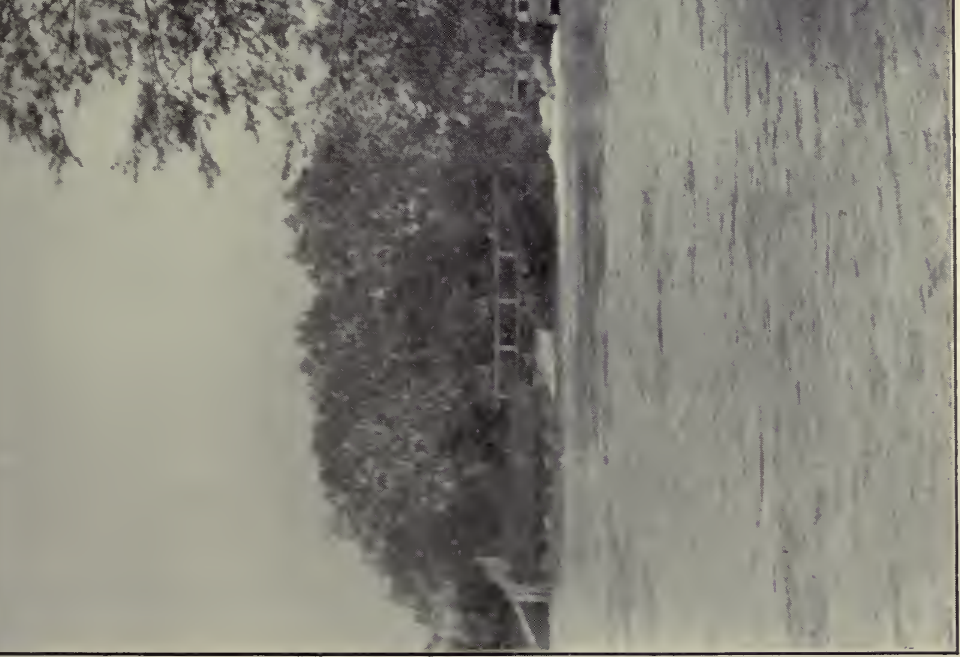

㨐 

beauty secure, and carry him up the bank (see Plate X.).

Once more my spear is used, and my disengaged right hand grasps the fish below the gills, the thumb and forefinger seeking the gill opening, leaving my left to kill and unhook my fish. Notice how well hooked he is-fairly back in the mouth, in the lower part of the tongue! Here again let me remind you of the advantage in the dry fly method. As you now know, the fish takes the fly in most cases when he sees it coming towards him from up-stream ; when, therefore, you are fishing below him, the hook, as a natural consequence, is jerked further into his mouth, as in this case, instead of being jerked out of his mouth, as when fishing above him, and hence the chance of hooking a rising fish by the dry fly method is infinitely greater than when wet fly fishing downstream.

It is a good fish, and so it will go into the creel; but how are we to kill it? Knock its head? No ; there is a better, quicker, cleaner, and more merciful way in dealing with fish of this size. I still have hold of it in my right hand; I turn the belly towards me, and insert the thumb of my left hand into its mouth, nail down, and bend back its upper jaw and head towards the dorsal fin, and in a second its neck is broken. It is dead and inert, and is not disfigured, and even if it now slipped into the water the landing-net would easily recover it.

With any trout whose weight is under a pound this, 
in my opinion, is the best manner of administering the coup de grâce. Bigger fish may, as the angler chooses, be knocked on the back part of the head, on the brain-pan, and for this purpose a "priest" is carried. Now we have to get the fly out of the tongue, ready for further work.

I open the file (for sharpening the points of flies, etc.) contained in my knife, the end of the file being a disgorger having a lancet face on the lower side; with this I lance the tongue, and by a gentle pressure of this disgorger on the belly of the hook, the gut being held tight by the forefinger on the file, I instantly free the hook without injuring the fly by any rough pressure on the wings, etc.

It is, however, more or less soiled by the slime from the trout's mouth, so I cast it down-stream and pull it through the water once or twice, and thus wash it. A few flicks overhead, and it is once more dry and fit for work.

We will now try the bank again on the further side. There is still no rise, but a fish, and a good one, should be there. Take the rod in your hand, keep as low as you can, and try a cast.

Don't be nervous. Imagine that you are casting your fly into a plate which is close by that root on the other side, and take plenty of time. It is not a matter of life and death, and if you do make a bad cast and frighten the fish, there are plenty more just above. Steady! You are forgetting your lessons in the excitement of the moment; you made your forward cast 
too soon, and the fly has fallen but half-way to the spot you wished to reach. Try again. Dry the fly well and let your pause be longer after you have switched the fly back-so-pause. Now cast. Well done! A good straight line, and the fly has fallen lightly. Let your left hand fall at once on the reel, and as the line comes back with the stream, reel up for a bit. Don't let your hand leave the reel; raise your rod a little as the line comes still further back. Look out! Strike! Steady! You have him; bring him out from the bank and down-stream. Dear! dear! By dropping the point of your rod you have allowed him to get into the weeds. Keep a steady strain on the rod; luckily he is only in the lower end of the weeds, and we shall perhaps get him as he is beginning to struggle! Steady and firm. There he comes! He is free again, and exhausted. Reel in with your left hand-easy; let him go a little if he makes a rush, and then reel in again. Keep at him. Keep the point of your rod higher. That's better. The net is all ready; bring him in slowly and quietly toward the net. There, I have him for you. Quite a beauty. Well done! Your first fish, and eleven ounces if he is a pennyweight. See, I repeat the former process : the Red Quill does not want a disgorger ; it is in his lip. It is soon out of his mouth; the trout is out of pain, and we will now weigh him. Thirteen ounces. Quite a good fish.

Never take your eye off the fly when it is on the water. If there appears no probability of a fish taking 
as your fly passes the spot at which the rise occurred, your left hand can leave the reel and find the line just above the reel, and then, as you gradually raise the rod, draw some of the line off the reel again, ready for shooting at the next cast. It is very inadvisable to have any slack line in the hand when striking. Never take your eye away from the fish when it is hooked. In this case you committed this fault in order to guide your hand to the reel, and as a consequence the fish got into the weeds. Stand in front of your glass, and practise reeling up with the left hand; use the glass only to guide your hand to the reel.

In order to keep these trout we have caught and your creel or fishing-bag sweet, it is a very good plan to gather a few leaves of the wild thyme or mint which you see growing by the water-side and put them with the trout; it also abates the fly nuisance. And, remember, the creel or fish-bag should invariably be well washed and hung up to dry every night when the trout are taken_out.

\section{The Rise and its Advantages}

While you have been killing your fish you did not see that rise just above. Look! Ah! You saw it that time, and now you know what you have to look out for when I tell you to watch for a rise.

Now a few words as to the rise. It does not follow that the commotion caused by a rise bears any relative proportion to the fish making it, and "the 
bigger the fish the more gentle the rise" is almost an axiom. The reasons for this are simple. The dignified assurance with which a big trout rises at a floating fly is due, not only to his greater experience, but to the fact that he is more often in the deeper and more slowly running portions of the stream ; and the floating fly therefore comes into his ken and towards his station slowly, and permits of a well-regulated and leisurely approach.

His smaller brother, on the other hand, is more often found in the shallow and rapidly running portions of the stream; hence, not only from the greater rapidity with which a floating fly will travel, but from the uncertainty of a lesser experience, and possibly from having a keener appetite, he will be galvanized into a more impulsive action when taking the fly. This rush will of necessity disturb the surface more, and make it appear a more important rise, than will the selfcontrolled action of the older or bigger fish.

See there again, under the bank in the deep water, about 30 yards higher up. Just a dimple, no more. As there are no Red Quill on the water, we will now try the Blue Quill, going back if necessary to the former fly. We can dispense with the butterfly-net, which is closed in three seconds, and placed in the fishing-creel ready for use when required.

Our sport is now made simple, for we know where certain feeding fish are by these rises, and also which fly they are apparently taking. There is no necessity to bring experience and knowledge to bear in order to 
determine the probable position of the trout; we have only to notice the rise, and try for rising fish.

There goes a fish again by our bank, just ahead. You can locate the exact place of the rise by that sedge on the bank; therise is just opposite it, and three feet from the bank. If you do not take some landmark, your eye will follow the ripple as it comes down with the stream, and you will probably cast your fly below the fish.

When a trout has risen, the sooner the fly is placed above him the better. His appetite has just been whetted by a tasty morsel-he has probably just returned to his stand, and therefore the swirl of the water, his own motion, and the alteration of his position will probably have prevented a too analytical scrutiny of the fall and the appearance of the fly you have just presented to him.

Take the rod, and when you have found the distance cast the fly lightly, just two feet above the position we have marked. No! no! What a mess you have made of it ! You are again forgetting your lessons in your eagerness, and have smashed your line on the water, and probably put the fish down. In making your cast, instead of finishing the switch when the rod was at an angle of about 40 degrees, and then lowering your rod as the line travelled forward, you brought your rod right down almost to the water, and consequently the direction of your line was downward instead of horizontal. It's no good trying for that fish again! This time try for the one in the 
middle that has just risen. Throw your fly two feet above him, and high this time instead of low. Don't lift your line too soon; let it get well below the place where the fish rose, for sometimes a trout will let a fly pass, and then turn and follow it down-stream ; and even if the fish does not then take the fly, he would be scared by your lifting your line too soon. That's better. Now look out! Strike! You were too late, and too forcible. It only requires a turn of the wrist to hook the fish so long as your line is straight. Just wait a minute, and give him a rest while you listen to me. The strike depends a great deal on a person's temperament. Some men are always slow, and others very quick. It is exactly the same in raising a gun when shooting; both actions become intuitive after a time, though there is always the personal equation which dominates the rapidity of the individual action. Striking will become second nature after much experience, but the health and condition of the mind and body will always affect even the most experienced fisherman. Careful attention and a straight line are the best conditions to warrant success, and a healthy, alert, nervous temperament the best factor to ensure it ; but you must not expect to be proficient in striking until you have had more practice.

If a strike is made when the hand is off the reel and the line is not held in either hand, but runs untouched from the reel to the fly, then the angler is said to have struck from the reel.

In dry fly fishing the art of striking firmly and 
gently is of the greatest importance. Very little weight can be lifted by an ordinary trout rod, and but little direct pull can be given when the rod, line, and object are not in the same straight line. Little as may be the pull, however, which the rod gives, it sometimes happens that the hold of the hook in the mouth of the trout is considerably less. Consequently, for the man whose hand is heavy, striking from the reel is advisable, so long, of course, as the check is on. With even a slightly resisting check, the pull will be sufficient to drive the hook home into the softer parts of the mouth of the trout. The disadvantage, however, of striking from the reel is that the line is nearly always lengthened, and at a moment when it should, if possible, be shortened. The trout rises at the fly; the strike is made from the reel, and the impetus and pull thus given to the reel are sufficient to unwind from 1 to 3 feet, if not more, of the line. As the trout very frequently comes down-stream towards the angler the moment he feels the hook, the amount of line thus drawn off the reel is an additional tax on the capability of the fisherman to reel up the slack line sufficiently fast to keep a strain on his fish.

You must give your absolute and undivided attention to your floating fly. Every angler knows how many chances of striking a good fish have been lost by a momentary lapse from this vigil. The one rise of a heavy fish at your fly may be missed and the fly rejected during the momentary glance aside at the opalescent gleam of a kingfisher, the metallic brilliance 
of a dragon-fly, a cluster of wild roses, or at any of the thousand delights of the trout stream. It is, however, only when your fly is on the water that this vigilance is imperative, and the fisherman has practically every other moment of the long and delicious summer day in which to enjoy the loveliness of his surroundings. No patience is required in observing this pleasing vigilance. The fascinating expectation of an answering rise to your scientific and delicate cast will be as strong and inspiring during the final cast of your day's fishing as it was during the first cast. It is this absorbing pleasure of looking for and anticipating immediate action during the whole length of an innings lasting practically from morning till night which constitutes one of the principal charms of dry fly fishing, and places it so far above wet fly fishing down-stream, or, in my opinion, any other sport.

The difference between the two methods, fishing up and fishing down, may be compared to the intellectual pleasure and anticipation of the sportsman during every moment of a long and arduous day in September when shooting over well-trained pointers or setters, and the jaded indifference of the gunner who strides along, with his principal sense, sight-after the first few hours - used solely to keep him in line and out of ditches, etc., and who is suddenly aroused and jerked back to the realities of life by the nerve-jarring rush of the birds he has chanced to kick up.

Now watch me carefully once more. The fish you put down are again rising, and I am going to try for 
the big fellow right under the bank. He has shifted in quite close, so I shall hit that grass above him with my fly, and let it fall into the water and float down quite close to the edge. See, I have done so, and there it comes, now sailing outward with a little sweep, and now siding quite close in to the bank and almost stationary. There! what did I tell you? I have him, and this time I am into a good fish. You noticed how I dropped the point of my rod when he jumped? There he goes again. What a fighter! Now he is going for those weeds down-stream. Observe the tug as I check him. He has the stream to help him, but I must hold him up, for if he gets into the weeds we shall lose him for a certainty. I have beaten him, I think. No, not I. Look how he clears the water and goes again to the bank. He's all right there, for you can see that the bottom is gravel and there are no weeds or snags. Now to get in a little line. Steady does it. No, he is off again down to the weeds. How the reel screams ! and the rod-look at it - bent nearly double. I have still all my work to do to keep him from those weeds. $\mathrm{Ah}$ ! he is beaten at last, and now I can get some of the line in on the reel as I go down-stream to get close to him. A little more - that's it ; now take this landingnet, crouch down, as much out of sight as you can, and hold the net slanting well in the water, between the trout and myself. I shall draw him over and into it, and when I say "Lift," do so with both hands. "Lift!" Well done! Now bring him up the bank, and let's have a look at him. What a beauty! Are not 
these crimson spots lovely ? He is rather big, so I will not attempt to kill him as I did the smaller ones, but smite him well back on the head with the priest on the end of my fly-net. Notice how well this Blue Quill had him. We will weigh him; and see, he is just over $1 \frac{1}{2}$ pounds, and in good condition. We will put him with the others, but first add a few more leaves of thyme as a fitting tribute to his prowess, and while we fill our pipes I will give you a hint as to your best action when dealing with a jumping fish. Before doing so I will just drift the Blue Quill in the water to wash off the slime, and then press it with my handkerchief and let it dry.

The reason I twice lowered the point of my rod when the fish jumped was in order to slacken the line.

You will often see a good fighting trout throw himself out of the water in his efforts to escape. Frequently this is a deliberate attempt to break the line by a blow of his tail. The general practice is to drop the point of the rod instantly, but I consider that this is not always the soundest policy. The action of the rod must be influenced by the direction in which a fish is moving when he breaks water. If the fish springs straight up in the air, or in any direction away from you, then lower your rod immediately. If, however, as sometimes happens (it has to me on several occasions), the fish is heading more or less toward you at the time he leaves the water, you should continue to keep the line fairly taut, as this slight strain 
will keep the head of the fish towards you and prevent his tail coming forward and striking against your line ; it will also prevent the fly loosening in his mouth. If ever a delicate wrist action be required, it is at this moment.

In Plate XI. a taut line will keep his head toward you, the line out of danger, and the hook fast.

In Plate XII., by slackening the line at once, the fish will get no purchase if his tail does strike the line, while the weight of the line will keep the hook embedded as the fish moves away from you.

In both cases just now, as you could see, the trout was heading away from me and up-stream, so I promptly lowered my rod and kept my line clear of his tail. The lowering of the point of the rod when the fish is heading as in Plate XI. may be just as dangerous as not lowering the point when the fish is in such a position as Plate XII., and for the following reason: Lowering the rod slackens the line and releases the strain on the hook - a most risky proceeding, for if the fish happens to be lightly hooked on some bony portion of the mouth, the toothed tongue of the trout, which is constantly endeavouring to shift the fly when in its mouth, will at once get the opportunity it requires, and the fly will be rubbed or torn away from its hold. This latter position, however, is the more common one, and always lowering the rod is better than always keeping it up. The best advice I can give is always to lower the point when there is a probability of the fish striking the line with his 
PLATE XI.

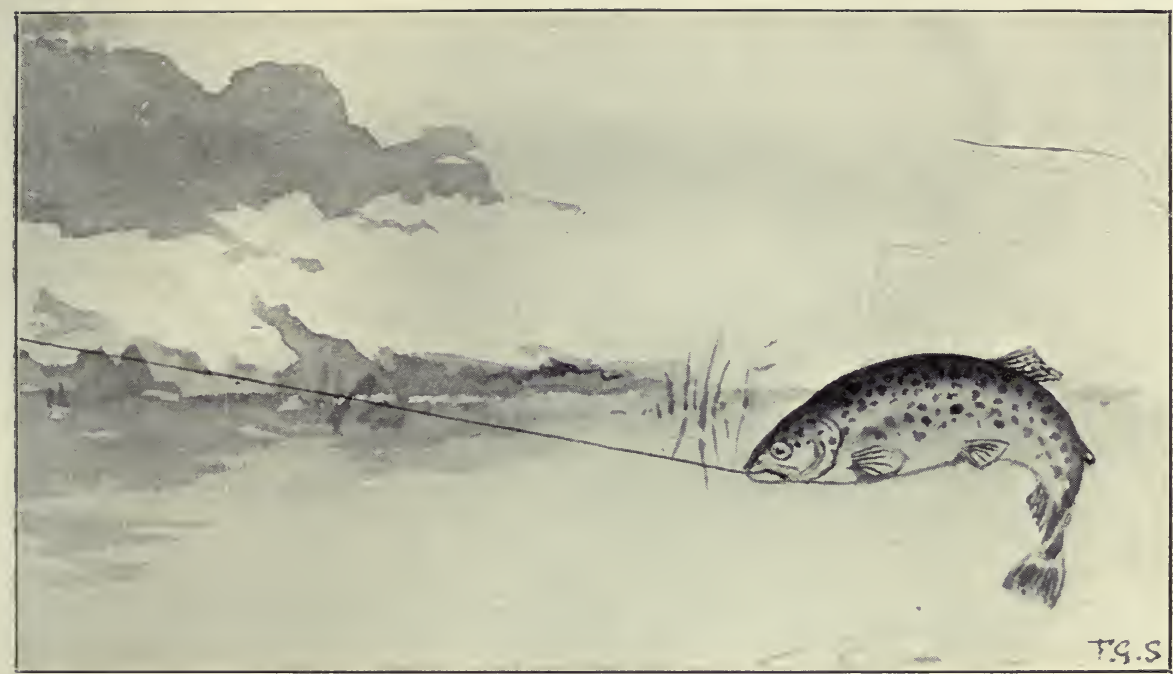

DON'T LOWER the POINT OF ROD, BUt USE very Delicate Wrist Action.

Copyright.]

PLATE XII.

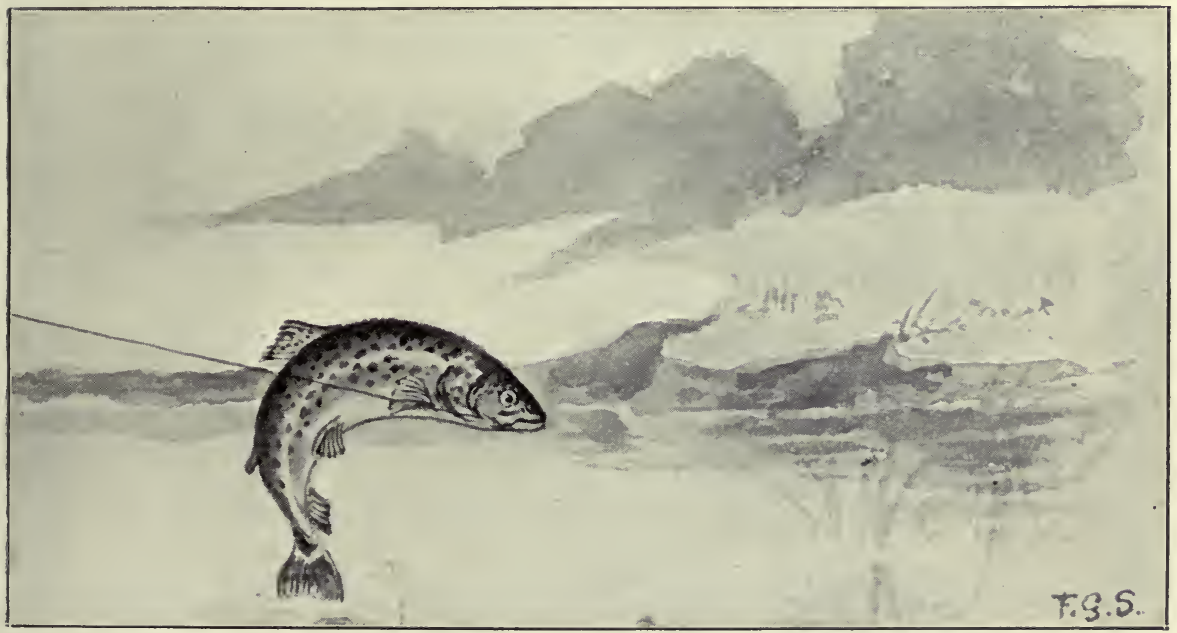



tail; but it must be evident that if the trout, as in Plate XI., is likely to throw a somersault so as to bring its tail down between its head and the fisherman, this somersault will be all the more easily executed if the line is slackened.

By this time the fly is dry, and we will just touch it with a little oil. We must go up-stream a bit, as our big fight has put down the fish here for a time. There, you saw the rise. A feeding fish just ahead and close in to our bank! Get well down to the water and use a shorter line, and you should get him. That's low enough. Remember the grass and bushes behind you; make certain to throw well above the fish, and don't lift your fly too soon in your next cast; let it float well down behind the fish before you make your back cast. Yes, that's right: you threw your fly well. Drop your left hand on the reel; don't take your eye off the fly, but reel up, and raise your rod gently as the fly comes back towards you. Now the fly has passed the spot where the trout rose, and as your rod is nearly vertical, stop winding and take hold of the line above the reel and gather in a little; straighten your line, make the back cast, and try again. Never take your eye off the fly. Strike! You have him! Reel up and bring him down, and keep him well away from the bank at your feet; don't let him come in under you if you can help it. He's a small fish, but plucky. Well done! Here's the landing-net; you must net him yourself. No, your line is too long to do so yet; reel up a little more 
line first-not too much, or you will be unable to bring your rod backward over your shoulder. Now bring your rod and arm vertically backward over your shoulder and draw the fish toward the net; lift your net and you have him. Well done again! but, you see, as he is only just over the limit, and as it is always better to err on the right than on the wrong side, I think we will put him back, and he will have a chance to grow into a bigger fish.

Just here let me impress upon you that you should have due consideration for the rights of the owners, your fellow-fishermen, the trout, and the stream. Give them all a chance. Never take undersized trout; never make a boast about big takes of trout. Never be discouraged. If the fish are small, put on the finest tackle. Every day on which you fish you will most certainly add to your knowledge and skill. Although the fish may be untakable and your luck villainous, your fortune will turn. The apparently worst day may before it closes produce the biggest fish. You will find as your skill increases that the pleasure of netting a fish you have beaten is much greater than killing it and carrying it home.

Now try that rise on the other side. Keep well down and see that your fly is clean and dry before casting. Why, you have risen two fish and touched them both! Allow me to look at that fly. Ah! I thought so. Now feel the point of your hook, and you will find that it has become blunted, perhaps from having been carelessly broken out of the last fish, 
or maybe from catching it in that bough a minute ago.

The fine splitting file on the disgorger in my knife now becomes useful. Two or three applications of the file to the point of the hook, and it has as fine a needle point as ever. It does not take more than five seconds to sharpen the point of a hook. It renews the usefulness of the fly and saves time; therefore, always carry a file. It may be that your last specimen of the taking fly has become blunted, and if you have no file you will most likely lose your fish and spoil the rest of your day's sport.*

Now fish up that run, beginning where you saw the rise in the pool below it. Cast your fly just where the rush of the stream begins to lessen, and let it float well down. Strike! Well done! Bring the fish down into the pool, so as not to frighten the others in the stream above. Keep him out of that dark deep bend, where the blackberry-bushes hang over the stream. That's right: don't touch your net until you have beaten him. Shorten your line a bit more, and now use your net; stoop down as much as you can, so as to keep out of sight, not only of the fish on your line, but of others which may have followed him down. Well done! Give me the fish and dry your fly again, and try the run right up from where you caught your

* In my original design for this knife I omitted the screwdriver, and I owe the idea of this useful tool to Mr. Marston, senior, and Mr. R. B. Marston, who separately, when looking at the knife, suggested that it only wanted a screwdriver to make it perfect. I was only too happy to avail myself of their dual experience. For further particulars of this knife, see p. 257. 
last. Never mind looking for a rise: there are sure to be fish there. Well done again! and a good one, but you struck with your arm and shoulder, and have broken your cast. Now quickly! we must not lose time while the fish are taking so freely. Let me see your cast. Yes, you have broken off the lower point, so I place about 2 inches of the end of the cast in my mouth to soften. You see this round and flat cast-box; it has some slightly moist white flannel in it, a spare cast, and some fine points. I take out a point, look at it with my watchmaker's glass in my eye. Yes, it is all right - smooth and free from glints. So I pass it through my lips, close the box again, and, taking the point I have selected, make an overhand knot in the extreme end. I take the broken end out of my mouth, run it through the overhand knot, and make another knot of the same kind in the end of it, only enclosing the gut point in this knot.* I draw both overhand knots firmly but completely taut. Each knot now encloses the gut which has formed the other knot. I draw the two knots firmly together by pulling the cast and the point, and, taking out my knife, I open the scissors and snip off each end fairly close. Place this quite new Blue Quill, which I have taken out of my fly-box, on the end of the fresh point, oil it carefully, take off the superfluous oil, and replace oilbrush. Now continue to fish the run right up beyond the ripple at its head. Stop! You have thrown your fly amid those alder branches on the far side. Do not

* See Diagram 13, p. 128. 
attempt to jerk or forcibly pull it clear. Drag it very gently and steadily toward you. There, that's right; it is clear again. In most cases a fly will come clear by a gentle pull, but if it catches while thus pulling it, try first a gentle jerk, for it may be only in a leaf, and then a harder one. If it still refuses to budge, and you can reach the twig with the point of the rod, reel right up until the point of the rod touches the fly, and then gently twist the rod round to the right or left. This very frequently liberates the fly. If you cannot reach the fly or break the bough, point your rod at the spot and pull gently. You may probably lose your fly, but you have no alternative. It is inadvisable to climb a tree in waders. They suffer at times, and a particularly cold and unpleasant reminder of this fact will follow your re-entering the water.

Start again at the bottom of the run. Ah, I thought so! You are into a big one this time. Reel up! reel up! Walk back, man! Keep your point up and line taut, or you will lose him. Keep him out of the dark corner "an you love me." Steady ! drop your point if he leaves the water as he goes up-stream again. There! you have him at last, after a splendid fight. Why, you have beaten my fish. Let us see! One pound nine ounces, and in every respect a beauty. If you take my advice you will send him up to London by this night's train to your taxidermist. Your first big fish is always remembered with the greatest pleasure, and, if set up, is a trophy of which you will always be proud. 


\section{The Midday Rest}

As the rise has now stopped and the sun is very hot, we may as well take our luncheon in the grateful shade of this willow, and resume our chat as regards dry fly fishing.

After fishing experiences embracing nearly every portion of both hemispheres, I am confident that at certain times and seasons the dry fly can be used with success on any water which harbours a fish whose food partly consists of any of the forms of the water insect which attains, as one stage of its existence, a flying state, and hence the importance of learning how to use a dry fly. Even amid the brawling cascades of a Norwegian foss there will be found places where the dry fly is deadly. I remember on one such stream, which tumbles some 1,500 feet down the side of the precipices enclosing Vadheim, taking over twenty good trout with a single dry fly, as I clambered up from pool to pool to reach the lake from which the stream issues. I have used the dry fly for perch in Australia; for the "yellow fish" (the Mahseer) of South Africa; for trout in the Scottish lakes and their brawling tributaries; on the Swedish lakes and rivers ; in Germany on the lovely Wutach; in the Black Forest and in Austrian Tyrol; in the chalk streams of Normandy, etc. In fact, my experience tells me that in all trout streams wherever water insects assume a flying condition the dry fly can, at certain times and in certain places, be used with the greatest success. I don't 



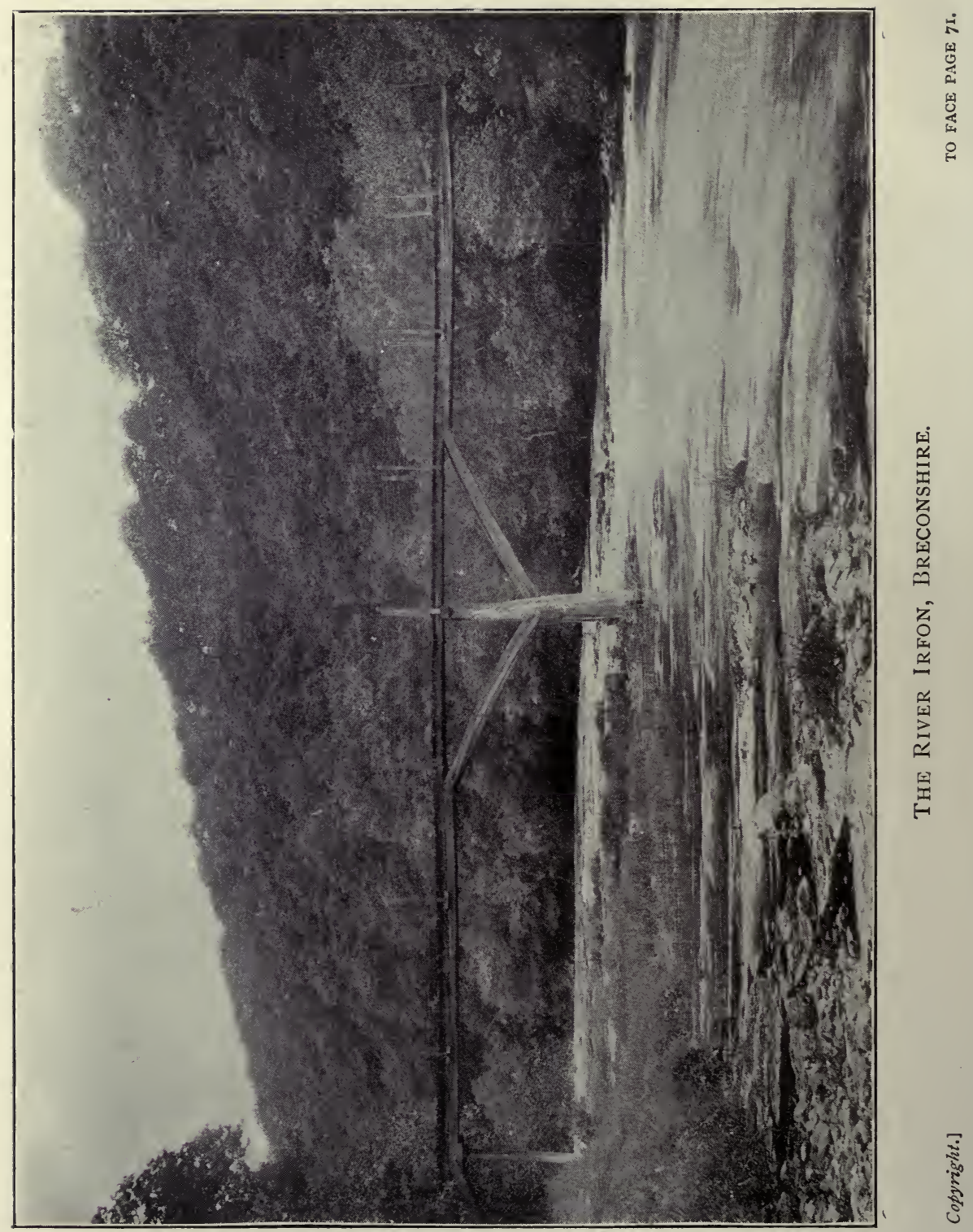


believe that any trout stream can be claimed solely as a wet fly stream.

As an instance of this, during the summer of 1905 several well-known wet fly fishermen staying at Llangammarch Wells Hotel, on the Irfon, a beautiful Welsh river, had for some weeks given up all attempts to catch trout, and, being invited over by the host of that excellent hotel, I converted every fisherman there to the usefulness of the dry fly method by killing fourteen fine fish on my first afternoon, and seventeen as good fish the following day, fishing with my dry fly pattern of the Stone Fly (see Plate XIII.).

On the lovely little Sid, in Devonshire, just as on the waters of the Irfon, on the Otter as on the waters of the Welsh Wye, on the Lambourne as on the waters of the Coquet, or the Eden, or the Derbyshire Wye, the dry fly will, in June, July, and August, be as effective as is the wet fly in March and April. It is on the correct choice of either method that the greatest success depends. When the trout are being taken freely by the dry fly method, the wet fly fisherman would be well advised to adopt that method, and vice versa. For dead or perfectly smooth water, especially later in the year, the dry fly method of fishing is without doubt the better.

Take the Wye about Bakewell, the Dove in the neighbourhood of the Dove Holes, the Itchen above Bishopstoke, the Otter on the Rolle Waters, etc., on a fine July day, when the water is as clear as crystal and the surface as smooth as glass: it is then useless 
to attempt the wet fly method, and yet perhaps some four hours later, when the water is thickened by a passing thunderstorm, the wet fly is the only one likely to secure trout-that is, until the water clears sufficiently to allow the dry fly to be once more seen by the fish.

And if sport is wanted, and opportunities of fishing are few, it would be a mistake for the dry fly man to reel up his line when a temporary thickness of the water shuts out his fly from the ken of the fish, and so prevents his fishing with a dry fly. If the rain has been a warm one the trout are sure to be feeding toward the bottom of the stream, and probably on drifting matter, such as the drowned sub-imago, etc. It is much wiser, therefore, for the angler to put on a wet fly cast, and, sinking his flies well below the surface, to fish his way down-stream; he is very likely to pick up some good fish, instead of losing half, or perhaps more, of his precious day's fishing. And now, as we have finished our luncheon, I will show you yet another way of taking a trout before I go home.

You can see that not a fish is moving; everything is baking hot. The sub-imago is sheltering amid the grass, and the pupa amid the weeds; both dislike this bright and torrid glare, and while the former is getting ready for his joyous but very brief honeymoon existence, the latter is clinging to his wavy and shadowy retreat, and waiting for the impulse which is to send him, despite all dangers, jigging up towards the surface to loosen the wings which are fretting within his mask. 
Do you see that deep hole, right up-stream, where the water glides smoothly by that sun-smitten rock ? Well, I am certain that there is at least one trout in its shade, and, therefore, I am going to throw my fly on the rock, and then slowly pull it until it drops off into the deep water. Watch! There, I made no splash with my line, and my fly has alighted just on the edge of the rock, and well in sight of any fish which may be lurking in the cool and delightful depths below. See, I pull it gently, it slides down the rock, tumbles into the water, and floats beautifully downstream. A little ring spreads out, and dies away. Ah, what a rise ! but I have him. See how he bores down; he has some retreat, possibly a hole at the base of the rock, but out he has to come, and, finally, after a stubborn fight, he, too, goes into my creel. Now take the rod, as I must be getting home. Shorten up the line. No, you are winding the line up too carelessly. Always wind a line firmly on the reel, or you will perhaps at a critical moment be in difficulties owing to the line overrunning itself. That's better! The next two or three hours' fishing will be poor ; therefore fish the rise if you see one, but also all the places in which you think it is possible fish may be lying. Keep well out of sight, and go gently with my rod, and " Good luck and a taut line to you !" 


\section{CHAPTER III}

Hints to the student-Hasty judgments-The natural fly-The Ephemeridæ-The Trichoptera-The Perlidæ-The SialidæThe Diptera-The rise-The best time to fish-The evening rise-Keeping the line clear-Changing the fly after darkFishing by moonlight-Bulging trout-The senses of a troutThe vision of a trout.

\section{Hints to the StUdent}

IT is of no use to read books in order to determine your actions when actually fishing. Common-sense is the most valuable guide. No two days are alike, and at each step the fisherman is confronted with an absolutely new combination of circumstances. This is perhaps one of the greatest charms of dry fly fishing. To read is good, because it shows from the personal knowledge of others that no two experiences of the same writer are absolutely alike, and no hard-and-fast axioms of fishing lore can invariably be followed. The attendant circumstances must guide the immediate actions of the moment.

\section{Hasty Judgments}

Always be charitable; never discredit a reputed trout stream because you have been unlucky on one or two 
occasions. "No fish in the river" is a rash statement to advance because, after one or two visits, no fish have been caught, or possibly seen. A futile visit to a stream and a hasty opinion thus formed may be regretted. I remember, by the kindly courtesy of a French landowner in Normandy, taking a day on his stream, in which he told me were many trout. I had been doing well all the week, but on this day I had the poorest luck, and, therefore, hastily concluded that the stream was almost barren of trout. Consequently, on one memorable day on which the May-fly was dominant, instead of going with a friend who was fishing this stream, I went farther and fared worse, and found, on meeting my friend in the evening, that he had enjoyed a glorious day's trouting. I still regret losing that excellent day, and consider that, as regards any water, first impressions are not always the soundest.

\section{WATER INSECTS}

The water insects whose flying appearance is copied by the artificial fly makers are classified as follows: The Ephemeridæ, the Trichoptera, the Perlidæ, the Sialidæ, and the Diptera. In order that the student may be able to tell to which of the above five families the flies he catches in his butterfly-net belong, it will be advisable to remember the following characteristic position of the wings of each family when the fly is alive and at rest.

The Ephemerid ж.-The wings rise upward from 
the shoulder in vertical planes above the body, generally touching each other as they rise from the body, and when floating down-stream these delicate insects can easily be recognized : their wings are like the sails of a fairy yacht afloat on some dreamland sea.

The Trichoptera and the Sialid $\approx$ (the Alder).The wings run backward from the shoulder, and lie alongside the body, meeting, tent-shaped, at their upper edges, and gradually diverging in the posterior direction.

The Perlid ж.- The wings are placed in a flat position, running backward from the shoulder in horizontal planes, and crossing or overlapping one another over the body.

The Diptera. - The wings generally, like the Perlidæ, are placed in horizontal planes; in most cases they do not overlap, but diverge from one another, as in the common bluebottle.

There are over 200 different species of water beetle, the numerous family of the Notonectidæ, besides the larvæ of the above flies, etc., upon all of which trout exist; and, therefore, the wet fly fisherman may well imitate other forms of sub-aqueous life, apart from the larval, the pupal, or other conditions of such flies. Of such lures "Corixa" and the fresh-water shrimp are perhaps the best.

\section{The Ephemerid a}

The sub-aqueous existence of one of the Ephemeridæ occupies the greater portion of its life. From the period at which it leaves its egg until it becomes a flying insect 


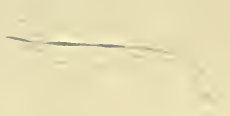




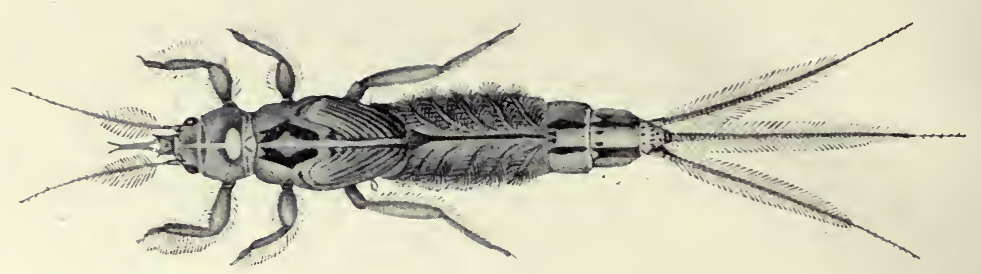

FIG. I.

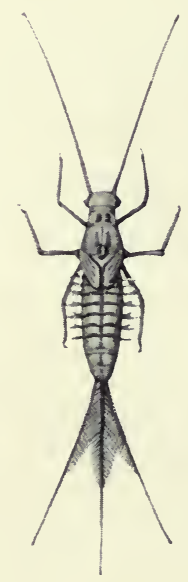

FIG. 2.

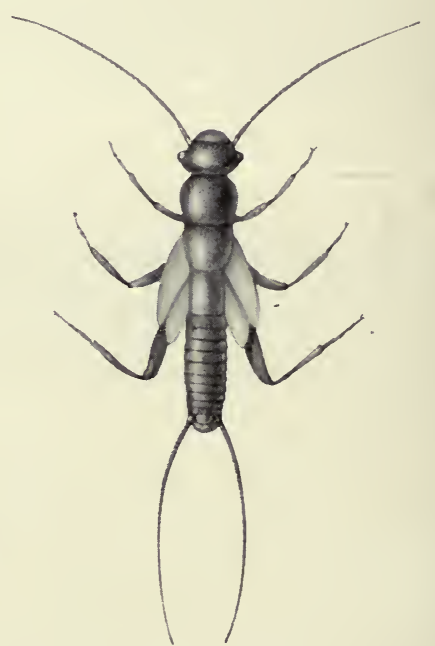

FIG. 3 .

FIG. I.-Ephemera vulgata (May-Fly), twice natural size, ready to assume its subimago or semi-final flying existence. Note the wing as seen under the pupal mask.

FIG. 2.-Ephemera, Clö̈on rufulum, twice natural size, ready to assume its sub-imago existence. Note the wings.

Fig. 3-Perlidæ, Nemura variegata-Small Red Stone-Fly-(Old Joan). $2 \frac{1}{2}$ times natural size. The larva is shown just ready for its metamorphosis into its imago or perfected flying existence Note the wings.

These wings are full sized, but are most delicately packed under their small envelopes, as shown above.

\section{Copyright.]}


it is undergoing a gradual metamorphosis, and, like the Perlidæ, at no time does it assume the real pupal condition-that is, the dormant chrysalis stage -common to the Trichoptera, Sialidæ, and the Diptera.

It should therefore, strictly speaking, only be alluded to as being in a larval condition until it becomes a subimago, but for distinction the latter period of its larval condition may be termed pupal. It is at about this latter period that it begins to be of most interest to the fly fisherman, and, with the kind assistance of Mr. Chas. O. Waterhouse, of the South Kensington Museum, I have been able in Plate XIV., Figs. 1 and 2, to give two characteristic views of its appearance just before the sub-imago state. The beautiful illustrations on Plates XIV. and XV. were drawn for me by Mr. Horace Knight, of the Natural History Museum. Fig. 1, Plate XIV., shows the pupal stage of the larva of the May-fly, Ephemera vulgata, twice its natural size. Fig. 2 represents the pupal stage of the larva of Cloëon rufulum, a fly resembling the Red Quill. The larval period of the different Ephemeridæ lasts from one to two years.

There are several varieties of the larvæ, corresponding to the several kinds of Ephemeridæ, and in each the appearance and the habits differ-some crawl, some burrow, and others, again, swim - but in all the varieties their larval appearance alters as they attain full size, and beneath the transparent integument covering their bodies can be discerned the gradual development of 
the wings, thorax, and legs, which will be used after the metamorphosis of the flying condition.

When the larvæ are fully ready for this change, they leave the haunts in which they have hitherto spent their existence, and swim to the surface. When there the mask-like membrane, under which the wings, etc., have been visible (see Figs. 1 and 2, Plate XIV.), splits open, and, supported on this shell as on a raft, the insect gradually frees every part of its body and unfolds its wings. As soon as these wings are dried and the body is clear of its shell, the sub-imago, as it is now called, flies to the nearest bank, where it shelters itself amid the grasses, leaves, etc. It is commonly known in this state as a dun, and it appears at various times, when the weather is favourable, in the vicinity of the water during a period of from one day to two or more weeks, flying with the breeze, generally down-stream. In this stage of its life it can be easily recognized by its comparatively heavy, drifting flight, and its dull, semi-opaque appearance. By the aid of a watchmaker's glass, cilia will be seen covering the surface, and forming a fringe to the posterior margin of its wings.

The sub-imago stage of its life, which is very brief in some cases, is finally forsaken when the entire membrane of its body and wings again splits open and is discarded, and the insect then assumes its perfected stage as the imago or spinner.

It is now fully matured and enters into its bridal existence, which lasts but a few days. In this stage it is to be seen in great numbers where the heat is not 
excessive and during the evening hours. Its wings are now gauzy and its body lighter and more brilliant in colour. It is easily recognized as it soars, floats, and sinks in the ambient summer atmosphere.

The following are some of the well-known forms of the Ephemeridæ: Olive Duns, Duns, Blue Duns, Autumn Duns, Blue-Winged Olives, Iron Blue Duns, Red-Quill Duns, Red Spinner, Jenner Spinner, Mayfly, March Brown, etc.

\section{The Trichoptera, or CAddis-Fly}

These insects, unlike those of the Ephemeridæ and Perlidæ family, undergo a distinct metamorphosis during their sub-aqueous existence.

The larvæ of the Caddis-fly may be divided into two distinct classes. The one class, after leaving its egg, spins a cylindrical sheath, which forms its future home, and to which it attaches small stones, sand, wood, etc. ; these cover and mask this case, and at the same time act as ballast. The case thus forms an armourlike protection against enemies. The larva uses this sheath as a movable residence, and from the open end its head, thorax, and legs protrude and provide the motive power, the weak and maggot-like body being always enclosed and protected by the armourclad case, which it drags about from place to place. After various enlargements to suit the growing condition of its body, the larva enters and partially closes the open end of its case ; it then commences its pupal 
existence-i.e., it becomes a chrysalis, and finally, when the chrysalis stage is over, it tears open the $s a c$ covering which has protected it during the dormant existence. Swimming to the surface, it either supports itself against some floating object or makes its way to the bank. The skin then splits open and the insect enters the imago stage direct, the pupal skin being generally left in the water.

The other class of larva of the Caddis-fly makes a permanent home by spinning a sac, like a bag, attaching it to some sheltered spot, and covering it with stones, etc. It leaves this home in search of food, and when the pupal stage approaches, it partially closes the aperture and undergoes a pupal phase similar to the one above described, before it assumes its imago existence. Some well-known forms of the Trichoptera are as follows : The Red Sedge, Silver Sedge, Orange Sedge, Grannom, the Welshman's Button, the Cinnamon-fly, the Sand-fly, etc. In Plate XV. will be seen two exquisite drawings of the larva and the pupa of the Caddis-fly by Mr. Knight, magnified about five diameters.

Fig. 1 is the larval condition of the Phryganea, one of the Sedge family.

Fig. 2 is the pupal stage of the same water insect.

\section{The Perlid a : The Stone-Fly}

The sub-aqueous existence of the Perlidæ after leaving its egg and until maturity is reached consists of a crawling and swimming larval condition lasting 
PLATE XV.

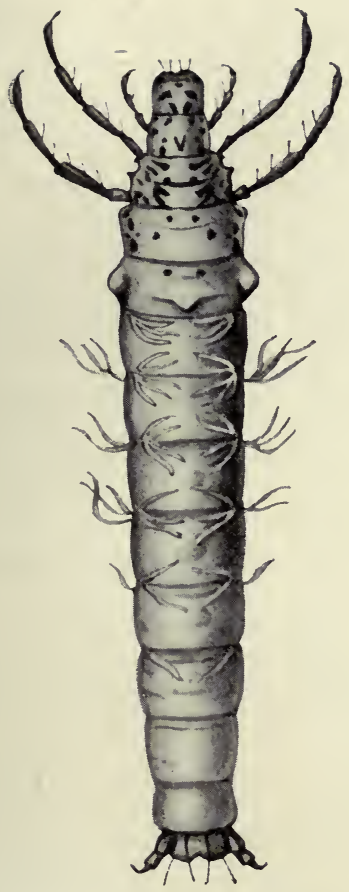

FIG. I.

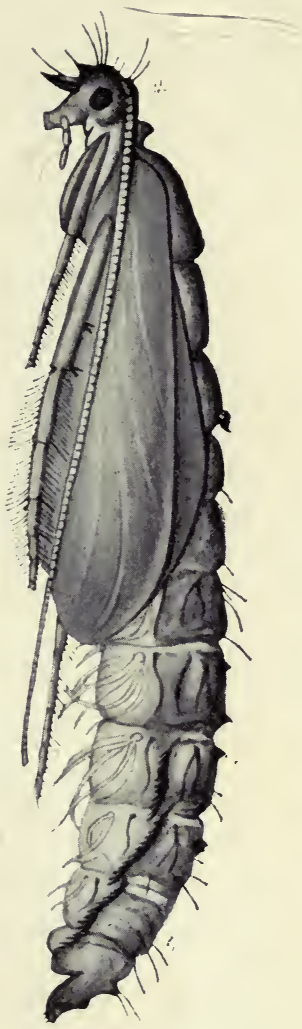

FIG. 2.

The Tricoptera or Caddis-Fly in its Larval and Pupal Conditions

Fig. 1. - The Larva of Phryganea (Sedge-Fly), five times natural size. This larva spins a cylindrical tube, and when it reaches maturity closes the end and enters its pupal existence (see page 80).

FIG. 2.-The Pupa of the same Fly, ready to tear open its pupal envelope and to enter its imago or perfected flying existence.

\section{Copyright.]}



several months, during which phase it gradually matures and attains by progressive changes a state ready for metamorphosis. When this is reached it swims to the surface, crawls ashore, attaches itself to stone, rock, or timber, and undergoes a direct metamorphism into its imago existence.

Its appearance at first is delicate and pale, and it appears to have a great difficulty in flying; but its colour soon darkens, and it grows stronger on the wing.

In Plate XIV., Fig. 3 shows the larval stage of the Perlidæ Nemura variegata (Old Joan), magnified about two and a half diameters. The characteristic wings of this water insect are to be seen on either side of its body, and the larva is shown just before it undergoes its metamorphosis.

The following are some well-known forms of the Perlidæ : Stone-fly, Yellow Sally, etc.

\section{The Sialid a : The Alder}

The sub-aqueous existence of this form of insect life is purely larval.

The eggs are laid by the female Alder on grass, rushes, etc. When the young larva is hatched, it crawls into the water and continues its existence more or less in the shelter of the mud until it is ready for its pupal stage.

It then leaves the water again, and burrows in the earth to pass its pupal existence; it there assumes the 
condition of a chrysalis or pupa. Changing from the pupal to the flying imago condition within the shelter of this retreat, it crawls to the surface and finally takes flight.

The best known form of this fly is the Alder.

\section{The Diptera, or Two-Winged Fly}

The very numerous varieties of this class of insect preclude more than a brief reference to those forms which the fisherman is most likely to copy as artificial flies. These are : the Black Gnat, the Oak-fly, the Spider-fly, the Cow-dung, the Golden Dun, the Hawthorn-fly, and the Claret Smut, sometimes known as the Red Quill Gnat.

The larval and pupal characteristics of these flies differ widely, and the student can do no better than consult entomological works on this and the other families of water insects.

For choice, I should recommend to the student Mr. Frederic M. Halford's work, "The Dry Fly Entomology."

\section{The Rise}

Trout rise to the fly at all hours and during all weathers. In the early moments of dawn, during the hottest hour of an autumn day, as the sun sinks, as darkness descends, and during the stilly hours of a midsummer night, distinct and noticeable rises of trout may be witnessed. If, however, I had to select 
any particular four hours during the whole season in which to fish, I think I should choose the hours between 10 a.m. and 2 p.m.

The cause which leads to the rise-that mysterious impulse which suddenly quickens the trout world into the activity of feeding time-has, so far as I am aware, never been satisfactorily explained; it is, therefore, with some diffidence that $I$ advance a theory which I have held for some time as to this important problem.

I consider that one common cause of the rise is the sudden impulse of the pupæ of the Ephemeridæ to ascend to the surface and take wing.

Fishing one day with the Grannom on that stretch of the Axe controlled by the Shute Arms Hotel, Seaton Junction, I had by noon creeled several trout, when a furious rise of the fish commenced in my neighbourhood.

To my surprise, neither the rising trout nor the dace would look at the Grannom, and after many fruitless casts I decided to change my fly. This I did several times, but with no success, until at last I noticed a small fly on the water.

By the aid of my small butterfly-net I captured the fly, which turned out to be an Iron Blue in its subimago state, and the first I had seen that season. Hastily putting one on my cast, I was into a fish at my first throw, and although the rise only lasted some twenty minutes longer, I got seven other good fish. When the rise ceased there existed a big batch of Iron 
Blue in the air, but the few solitary rising fish took no further notice of the Iron Blue Duns, which rapidly disappeared. I tried it, however, for some time longer, but eventually I replaced my Grannom, and caught several other trout before going home.

Before putting on the Grannom, however, I examined the food in the latest caught fish, and found that the upper part of its gullet contained a great number of nymphæ or pupæ of the Iron Blue in their most advanced stage, several specimens having their wings already unfolded.

I am inclined, therefore, to think that, owing to some altered condition of the water or atmosphere, the pupæ of the Ephemeridæ, moved by one of those mysterious impulses which occasionally influence the insect world, had risen to the surface to assume their sub-imago existence, and that this general movement was followed by the excitement of the fly feeding fish.

Since that occasion I have corroborated the theory I then formed by examining the food of the fish caught during the rise, and have found that it consists, as a rule, of a greater number of the pupæ than the subimago of the existing hatch. I have also noticed the trout during a rise taking the pupæ below the surface, and have seen the trout following pupæ up, and taking them just as they reach the surface of the water.

I do not claim that this suggestion will account for all the general rises peculiar to trout, but $I$ think that in many cases it will be eventually proved to be caused 
by some initial movement of the pupæ towards their next metamorphosis. A few heavy drops of rain are followed or accompanied by a rise; this rise may be produced by an upward movement of the pupæ in response to the meteorological influences at work. Again, certain summer evenings, at about the same hour and for a similar period, generally as the sun sets, will produce a general rise; this rise, so well known to fishermen, is, as far as I can see, to be accounted for only by the cooler temperature inducing a general change from the pupal to the flying state of certain small water insects. The rise of the pupæ to the surface excites the fish, which feed on the swimming insects alone, either as they rise to the surface or after they get there, to the disgust of the fly fisherman. This evening carnival of the trout is invariably accompanied by an enormous hatch of small flying Ephemeridæ, probably the ones which escape from the surface of the water to which they have risen. Again and again have I witnessed the water at such times fairly boiling with the rising fish, but it has been seldom that I have been successful in landing even as much as a brace of fish, though after this excitement has subsided, my Coachman, Silver Sedge, etc., have proved most deadly.

I am inclined to think that bulging may be produced by a similar cause-that is, by the activity of the sub-aqueous entomological life.

The method by which the latest food taken by a trout can be determined is by holding the trout in 
one hand, and, with a firm upward pressure of the fingers of the other hand along the lower sides of the abdomen of the fish towards the gills, expressing, or forcing into the mouth, the latest food swallowed by the trout, which may then be examined. Should this, however, not succeed to the satisfaction of the angler, the knife can be used to open the upper part of the gullet or stomach, in order to discover of what this food may happen to consist.

\section{The Best Time to Fish}

The forenoon is, in my opinion, the most fascinating time for fishing; there is no arrière-pensée as to coming darkness, the whole day is before one, the creel is light, and the anticipations and hopes of sport are keen.

As proving from my own experience the varying times of the day at which big trout may be caught with the dry fly, I give the following extract from some latter day fishing diaries :

1893.*-The Wye, Bakewell, noon, cloudy, 2 pounds 6 ounces, Olive Quill.

1903.-The Test, Nursling, noon, bright, 4 pounds, May-fly.

1905. $\uparrow-T h e$ Otter, Devonshire, 9 p.m., calm, fine, 1 pound 10 ounces, Coachman.

1905.*-The Otter, Devonshire, 5 a.m., light breeze, fine, 1 pound 6 ounces, Red Quill.

1905. - The Irfon, Llangammarch Wells, noon, fresh breeze, bright, 1 pound 6 ounces, Stone-fly.

1899.*-The Wutach, Black Forest, 11 a.m., baking hot, 2 pounds

* These fish were caught by fishing the stream, no rise guiding me as to the fish.

$\dagger$ On Mr. George Peppin's water at Harpford. 
2 ounces, Olive Quill. (Caught on the edge of a stream, in about 4 inches of water.)

1899.-The Arcque, Normandy, 4 p.m., gale, cloudy, 3 pounds 10 ounces, May-fly.

1897.*-Mountain stream, Norway, 2 p.m., baking hot, 4 pounds 11 ounces, May-fly. (No May-fly known there; quite calm, August, dibbling.)

1892.-Lake near Felide, Norway, midnight, June, 4 pounds 2 ounces, Silver Sedge.

\section{The Evening Rise}

Although some hours cannot be regarded as favourable ones in which to fish, still, trout will rise at floating food at all times during the night or day.

After a bright and hot day during the summer months, the sub-imago stage of life will be assumed by many water insects, while innumerable imago forms of insect life will float or soar through the ambient air in the delicate mazes of their bridal dance. The trout at these times indulge in their usual evening carnival, presumably busy amid the ascending nymphæ, or perchance feeding eagerly on some smut-like flying insect. After this is over they settle down with serious supper intentions, and continue feeding at intervals, sometimes well on into the small hours of the morning. As darkness deepens, and before the full moon has risen to keep her vigil and illumine with her silvery enchantment the first sweet slumber of Nature, the fisherman, who has perhaps had a bad day, may be tempted to fish on, regardless of dinner consideration

* These fish were caught by fishing the stream, no rise guiding me as to the fish. 
or of losing his last train. By facing west he can still detect the rise of feeding fish, and even if fish are rising close to the opposite bank and out of sight amid its shadows, the sound of the rise will very frequently guide him in making an accurate cast, and eventually landing a big fish. The rise of the fish at his fly will in most cases be seen, felt, or heardseen, because a comparatively big ring will be caused by a rise, and on the slopes of the attendant ripple the glint and reflection from the western sky will be detected, even amid the blackness of the shadows under the opposite bank; heard, because the evening rise of a fish at a floating fly, owing to his more limited vision at night-time, is frequently more sudden and less dignified, and therefore, in most cases, more clearly audible amid the general hush of Nature; felt, because the fisherman's line at night should be as short and straight as possible, and when the fly is taken by the fish the tug will in most cases be distinctly noticeable.

\section{Keeping the Line Clear}

A word as to casting and fishing when daylight has ceased and before the moon makes her appearance. In order to keep your line clear in casting, bring the rod back a little to the left of the vertical, and return it slightly to the right, or vice versa. This should effectually prevent fouling, always allowing plenty of time for the line to extend itself behind. The line should, however, be drawn through the fingers every 
few minutes, in order to make certain that it has not fouled. When a breeze is blowing across your line, always bring your rod back to leeward, and return it to windward of the vertical plane in which you are casting.

\section{Changing the Fly after Dark}

Now as to the greatest difficulty of all-the changing or replacing of trout flies on the cast after dark. This is a difficulty which has on more than one occasion robbed me of the charm of redeeming the ill-fortune of a poor day, when the very audible but invisible activity of the trout was telling me of a long delayed and anxiously expected rise.

In the dark, with no lantern and no one to help, the chances of replacing a lost fly are infinitesimal. After many trials I have succeeded in designing a small portable electric light which effectually overcomes this difficulty. This light can be suspended round the neck, lies flat on the breast, and, when turned on by means of a switch, sheds a bright and constant beam of light full on the hands, etc. It is cheap, light, and has a two candle-power lasting for hours. It can be recharged by dry cells in less than two minutes. This light is only wanted at rare intervals, and never for more than three or four minutes; its use permits the angler to continue his fishing however dark the evening may be. A full description of the lamp is given on pages 280 and $\mathrm{xxv}$. 


\section{Fishing By Moonlight}

And now the moon has risen and is lighting a path of silvery brightness on the placid waters of the trout stream. You are wading, and the stream is broad, the banks low, and the water where the sedges cast a deep shadow running in depth from 2 feet to 8 feet. Watch this path of glory as it lies before you, until you see a small speck of darkness appear, followed by a single tiny ring which quietly opens out round it-a rise which would not, perhaps, have been noticed in the daylight, though probably caused by a good fish. Now throw your Silver Sedge just above, and let your fly float down right over the place in which you saw the rise, and you will get your fish, probably with less trouble than in daylight. The pall of night is your background, and therefore the fish are less able to see you ; they are not so suspicious, nor so prone to seek the shelter of the weeds or the entanglements of their retreat, and until they see you they will not know from which quarter comes the galling restraint of your fly.

\section{Bulging Trout}

Trout may at times-such times being generally bad for the dry fly fisherman-be seen feeding on the nymphæ of water insects. On these occasions, although the trout are rising to the surface, they take little or no notice of the natural or artificial fly on the 
water. When the trout are showing the dorsal fin and part of the back above the water, they are then said to be bulging. If the fisherman finds that the trout, in these circumstances, persistently refuse to feed on the floating fly, his best plan is to change his cast, and fish up and across stream with a short line and two or more single-winged flies. They should, if possible, resemble the nymphæ on which the trout are feeding, and should only be sunk a few inches below the surface, the spasmodic swimming action of the nymphæ being imitated as closely as possible by a series of very small jerks given to the artificial fly as the cast is drawn through the water toward the fisherman.

I have found that a medium Olive Quill body and heckle, with a single pair of the lightest starling wings, is extremely useful. On one bulging day, when fishing on a delightful chalk stream in Normandy, I gave up any attempt to attract the fish, which were showing up in all directions, with the dry fly, and by adopting the above method secured quite a respectable basket of fish. I have since then, under bulging conditions, adopted this plan with success. Mr. Halford recommends a Gold-ribbed Hare's Ear, and though I have never offered one to a bulging fish, I think them well worth trying, the gold ribbing being most likely the attraction. Alders have, I believe, often been used with success when trout are persistently bulging. 


\section{The Senses of Trout}

I think it may be accepted as a fact that fish can distinguish the flavour of different kinds of food, but, as far as I am aware, it has not been decided whether their olfactory organs are affected, or whether they possess a sense of taste only. The use of paraffin may cause a more rapid rejection of the artificial fly by the trout, but whether it might not be advisable to apply an odour to the body or heckle of a flysimilar to that of the real fly-remains to be proved. Fishermen have claimed that certain flavours are beloved of trout, but the result of personal experiment in the application of such flavours to the body of a fly is a branch of fly fishing still very much open to original discovery. I have experimented with various essences, and considered that I met with success by mixing two or three drops of the oil of aniseed with my paraffin-oil. This suggestion may be of some use to my readers, and perhaps induce them to continue such experiment until some perfect mixture has been discovered.

Trout are undoubtedly sensible to colour distinctions, and, as far as my own experience is concerned, I am confident that they can detect the most subtle differences in the shade and tint of the different parts of the various water insects on which they feed.

I do not consider that trout can appreciate sound as we know it; rather are they gifted with a fine sense of all vibratory motion. Sound is communicated by 
the vibration of the air or other elements, but similar vibrations of these elements can be produced without sound, and the trout may, therefore, depend on the tactile nerves rather than on the auditory ones. If trout were capable of hearing, I do not think that wading would be so productive of good results as it undoubtedly is. The noise of one's brogues on the pebbles can be distinguished when the ear is submerged for considerably over half a mile in perfectly quiet water in rivers, and for miles in lakes.

\section{The Vision of a Trout}

Although it is supposed that trout cannot see an object which is situated directly behind them-that is, in the direction of their tails-the angle at which their sight is limited behind each shoulder has, so far as I am aware, never been discussed.

It can be assumed that this limit of sight is a variable one, depending on physiological characteristics, and also varying at different periods, according to the seasonal changes and the age and condition of each fish.

From my own observation of trout I consider that, if the eyes are assumed to be the centre of the horizontal plane in which the fish is lying, it can see in that plane from a point right ahead to an angle of about 60 degrees behind each shoulder. In other words, that any object situated in the 300 degrees of the forward part of the horizontal circle surrounding 
it may be visible, while any object situated in the remaining 60 degrees of that circle must be invisible as a general rule. Mr. Sheringham reminded me that trout can apparently see at times directly behind themselves. I admit that trout do become aware of a man's presence at times, when in the supposed zone of invisibility, but not in the plane in which the trout is lying. It will generally be found that an object thus seen by the trout will be elevated at some height above the surface, and the bulge of its shoulders would not intervene between the eye and the object, as it would if the object and the trout's eye were in one-plane.

In Diagram 7, if A B C D represents the horizontal plane in which the trout is lying, $\mathrm{E}$ the eye, and $\mathrm{T}$ the tail of the fish, its eyes are naturally diverted upstream, and it can see when in this position any object in the unshaded portion A B C E D, in its own plane, and cannot, certainly without moving its position, see any object in the shaded portion $\mathrm{C} \mathrm{E} \mathrm{D}$, and hence it is that the dry fly fisherman, when within this latter zone, can generally approach his fish without being detected.

In any vertical plane passing through the eye of the trout, however, a different range of sight has to be considered, and an entirely new factor presents itselfthis is the refractive influence of the water on all rays entering it. I need not here enter into the optical laws of refraction, but will ask my readers to accept as a fact that the vertical range of the vision of a 
trout, as regards all objects external to the water, is confined to the interior of a hollow cone, the apex of which cone is situated at the eye of the trout, and the sides of which rise upward at an angle of 42 degrees

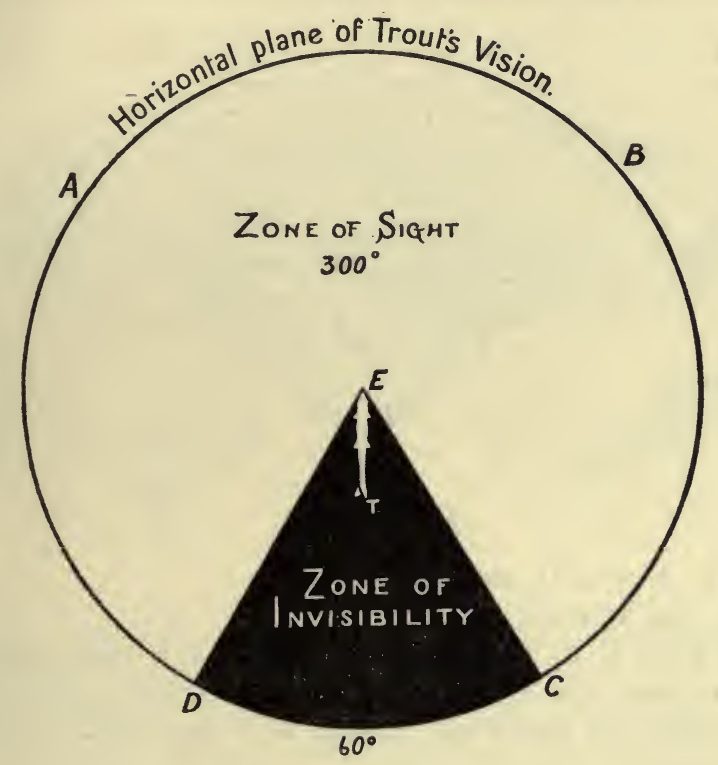

Diagram 7.

A B C D, horizontal plane of trout's vision;

E T, trout;

D A C B, horizontal zone of trout's sight.

to the surface of the water. So far as the fish is concerned, within this hollow cone-which, therefore, subtends an angle of 96 degrees in every upward direction-is confined the view of all objects within the 180 degrees vertically above the water. In other words, the trout sees, as it were, all objects above the surface of the water from the bottom of a well, the 
mouth of which subtends over its head an arc of about half that in which these objects really exist, and consequently, the comparative size of these objects must be relatively smaller in view of their being cramped into the smaller field of vision.

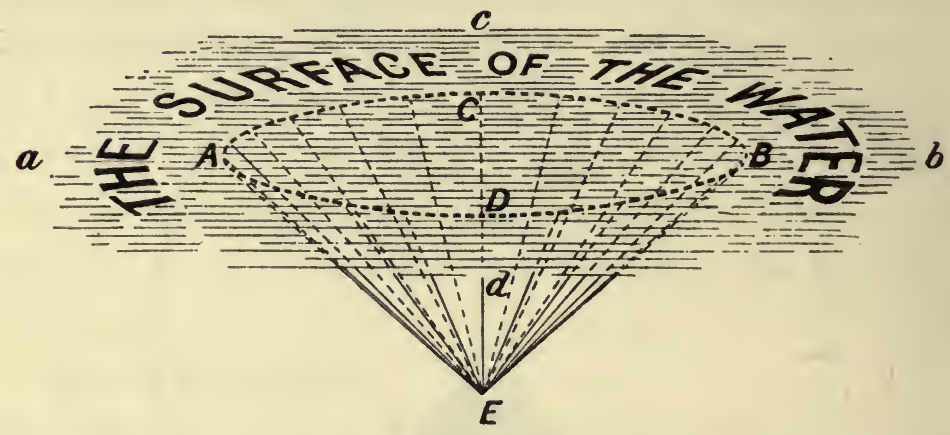

Diagram 8.

$a c b d$, A B C D, surface of water;

$\mathrm{E}$, the eye of trout;

E A, E B, E C, E D, the upward cone within which is confined the trout's sight of all objects above the surface of the water within the range of the trout's vision.

In order to make this perfectly clear to my readers, I have shown two diagrams.

In Diagram 8, $\mathrm{E}$ is the eye of the fish, from which rises a vertical cone $\mathrm{E} \mathrm{A}, \mathrm{E} \mathrm{C}, \mathrm{E} \mathrm{B}, \mathrm{E} \mathrm{D}$, the sides of which cut the surface of the water, as shown at A B C D.

All rays of light from objects above the water which reach the trout at $\mathrm{E}$ must enter the water within the circle A C B D. Let A E B (see Diagram 9) be a vertical section of the cone in Diagram 8 , cutting the 
surface of the water at A B. Then the rays of light from $\mathrm{M} \mathrm{N}$ can only be seen by a trout situated at $\mathrm{E}$ when they enter along the dotted lines $\mathrm{N} B \mathrm{E}, \mathrm{M} b \mathrm{E}$, and the fish sees $\mathrm{M} \mathrm{N}$ as in the direction $b \mathrm{~B}$, and also relatively reduced in size to $b \mathrm{~B}$.

Objects immediately over the trout will suffer least

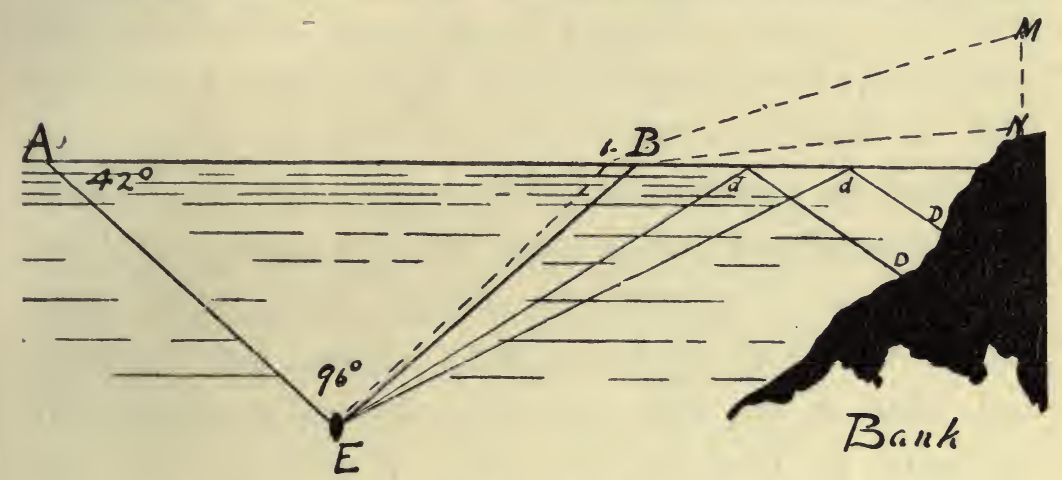

DIAGRAM 9.

A E B, a vertical section of the hollow cone in Diagram 8, cutting surface of water at A B.

$M N$, any object on land, such as a man.

$\mathrm{E} b \mathrm{M}, \mathrm{E} \mathrm{B} \mathrm{N}$, the lines along which the rays of light from the man $\mathrm{M} \mathrm{N}$ will reach the fish.

$\mathrm{E} b, \mathrm{E} \mathrm{B}$, the direction in which the trout will see the man.

$\mathrm{E} d \mathrm{D}, \mathrm{E} d \mathrm{D}$, the lines showing the under surface of water, acting as a mirror to the trout of all objects under the water and outside the cone E A, E B.

from the influence of refraction, but their shape and size will suffer the more as they leave the zenith, and objects on the horizon will suffer most, etc.

To the trout the full moon as it rises will appear as a small horizontal line of light 42 degrees above the real horizon, and it will gradually assume its circular shape as it approaches the zenith. 
It will thus be seen that the nearer an object is to the water level when outside the water, the less will be the angle which it will relatively subtend to the fish; in other words, the lower the position of an object when at equal distances, the smaller it will appear to the fish.

This important fact is taken advantage of by the fisherman, who, although he may not understand the optical laws of refraction, has learnt from experience that, in order to avoid scaring the fish, he must crouch as much as possible and thus reduce his height, and that an overhead cast is more likely to scare a fish than a side cast. Not that he escapes being seen when within the limit of the trout's vision, but his bulk and that of his rod are then generally insufficient seriously to frighten the fish. Wading is for this reason the best method of approaching fish. Although a man's size is relatively reduced the more nearly he approaches the water level, still, in ordinary circumstances, he is clearly visible on the trout's horizon when within that part of the zone $\mathrm{D} \mathrm{A} \mathrm{B} \mathrm{C}$, Diagram 7. If, then, this appearance is accompanied by an invariable agitation of the surface, or the violent appearance of lines or flies over a trout's head, even the most unsophisticated fish will quickly learn to associate these two phenomena, and be increasingly ready to take fright when a man is seen. Hence the necessity for caution when approaching a fish, and delicacy and finesse when casting on the part of the fisherman-not only on his own account, but out of consideration for his brother anglers. 
All other downward rays coming to the eye of the trout, save those which enter the are subtended by the cone of the trout's vertical vision, are external to the cone, and are either from the submerged portion of some floating object, or the reflections from the under surface of the water of sub-aqueous objects, the water, in this latter case, acting as a huge mirror of all bodies below its surface (see $\mathrm{E} d \mathrm{D}, \mathrm{E} d \mathrm{D}$, Diagram 9).

It may be taken for granted that, in ordinary circumstances, when a fisherman can see the trout the trout can see him, with the exception of three factors, however, which must always be considered:

1. The amount of light falling on either.

2. The glint or glare in the eyes of one or the other.

3. The background of each.

1. The first may be considered as sometimes favouring the fish and sometimes the angler.

2. The second factor will be mostly in favour of the fish; the fisherman gets most if not all the glint and reflection from the surface, though the glare of the sun must handicap the fish to a great extent.

3. The third factor is the background, which, however, is almost invariably in favour of the trout. A dark background is of the greatest importance to the fisherman when approaching a fish, and a skyline behind is always to be avoided. If, when fishing from the banks, he has no near background, such as a wood, a hedge, a wall or tree, or a cliff, etc., he should get near to the water level and as much behind the fish as 
is possible. Wading, again, for this reason, will be the most advantageous position for the fly fisherman.

It may be argued that the appearance of the waders below the surface, when within the zone of the lateral vision of the trout (see the unshaded portion of Diagram 7), will scare the fish more than the appearance of the fisherman above the water. This is not so, however, for the rays of light from the fisherman on the bank, say at 40 feet distance, would lose nothing in passing through the air until they strike and enter the water (as at $b \mathrm{~B}$, Diagram 9 ); they will then only have some 3 to 6 feet of water to pass through before reaching the fish. A certain amount of light will be undoubtedly lost, even in this small distance, owing to the density of the water, but the vertical depth of the fish below the surface of any trout stream will never be sufficiently great to prevent all rays reaching it. This density of the water will cause a very rapid diminution of the rays from any sub-aqueous object, as horizontal or vertical distance is attained; and while objects may, in favourable circumstances, be still visible to the fish 25 feet away in any horizontal direction within the zone of its horizontal light, they may in calm, still waters be taken as being unnoticeable in ordinary circumstances at a distance of about 30 feet. In rapid running water the rays from any object will be still further lost or deflected by the eddies, etc.

From my own experience in a diving-dress in the clear waters of the Torres Straits, which were undis- 
turbed by any ripples, eddies, etc., I found that all objects in the horizontal plane were invisible to me beyond a distance of about 20 feet: the head of a shark coming towards me would be visible at about 17 feet, while its tail would at the same time be quite invisible and lost in the misty wall surrounding me. It may be, therefore, confidently assumed that the wader, even when faced by the trout, will, as far as his waders are concerned, be unnoticed by the trout at a distance of from 25 to 35 feet.

I wish to acknowledge the help of my brother, Dr. Philip Egerton Shaw, D.Sc., Nottingham College, who assisted me in writing "The Vision of a Trout," and preparing the diagrams. 


\section{CHAPTER IV}

Pisciculture-Temperature-Trout and the close season-Times of spawning-Close season too short-The Board of Conservators -The appearance of trout-What sort of flies to use-The cap as a fly-holder-Moths-Dry fly fishing with three fliesThe dry fly fisherman's flies-Knots used when fishingWet fly fishing up-stream-Striking-Wet fly fishing-Weeds - Long-distance casting - Fungus on grown fish-Ambidexterity-Spinning for trout-Where to fish.

\section{Pisciculture}

THE scientific development of the most delightful of all sports-namely, fly fishing for trout-has produced a corresponding advancement in the breeding of these beautiful and sporting fish, and no book on trout fishing would be complete without a reference to fish culture. Pisciculture as an occupation, if wisely and scientifically pursued, will not only create a fascinating and absorbing interest for the one who takes it up, but it should, under favourable circumstances, become a remunerative and sound commercial business. Although dating back to the early Egyptian dynasties, fish culture received its first great impetus in the middle of the eighteenth century, when the possibility of artificially fecundating the ova of fish was discovered by one Stephen Ludwig Jacobi, of Hohen- 
hausen, in Westphalia. It was not, however, until 1837 that fish culture was inaugurated in Britain by a Mr. John Shaw, who fecundated the ova of salmon and reared the young fish. During the last forty years the United States have, more than any other country, recognised the importance of this industry, and by giving it a generous monetary support enabled the United States Fish Commissioners to establish and provide many important fish hatcheries throughout the States. Mr. Livingstone Stone, a deputy Fish Commissioner of the United States, has written a book entitled "Domesticated Trout," which, though originally published some years ago, is written up to date, and in its latest edition* may be regarded as a work of the greatest interest and value; indeed, it is impossible to read this book without becoming deeply interested, not only in the trout, but in the possibilities of their wonderful and scientific cultivation.

Trout farms are becoming numerous in England, and I wish to impress on the student the advisability of not only reading and studying the literature of trout breeding, but also, by personal visits to every troutrearing establishment in his vicinity, gaining a practical knowledge of the fish on which he will in the future rely for his most beloved and exciting sport.

It is of the utmost importance to secure strong and healthily reared yearlings and two-year-old fish for all streams, lakes, and ponds which are being restocked,

* Published by the Fishing Gazette, Ltd. (see p. vi.). 
and the more nearly the conditions in which the fry, the yearlings, and the two-year-old fish are reared, approach those of nature, the better will the results be. Mr. Stone, guided by his own experience and that of every trout-breeding establishment with which he had, either as manager or commissioner, been brought into contact, is strongly opposed to risking breeding ponds in the channel of any stream or river, and advises the artificial construction of ponds, fed by artificial races. These ponds, he thinks, should be small and compact, lined with wood, and freed from any danger of floods, etc.; and he recommends the use of water plants as affording shelter and food for the trout.

These ideas, sound as they undoubtedly are when the dangers above enumerated are considered, have been followed more or less by English pisciculturists, and the logical consequence of these artificial surroundings has been a loss of the many natural advantages of the other method - that is, of having trout pounds situated in the channel of recognized trout streams.

The want of the natural food carried by a good trout stream, and of the plentiful supply of fresh running river water, the reliance on artificial food, the vicinity of the keepers, the feeble current, etc., all tell against the trout reared under such conditions. For one thing, I am confident that trout reared under these conditions and accustomed to be hand fed, do not, when they are taken to stock other waters, rise to the fly as freely as they would had they been accustomed to depend more on natural food during their early life. 
For another thing, the trout do not grow so quickly, and again, they are not accustomed to the natural food on which they will have to live when they are liberated. The best food for trout, as long as a plentiful supply is available, is undoubtedly water insect life in its varying stages. Small fish, such as minnows, gudgeon, etc., are the next best food, although trout, when fed on this latter class of food, frequently develop cannibalistic tendencies, while probably the food least beneficial, in an all-round sense, is the animal food on which hand-fed trout have frequently to depend.

Again, the loss of the strong, plentiful and naturally running waters creates a less developed, less powerful, and less healthy fish.

Taking the stock fish of the ordinary trout-breeding establishment, the length of time which it takes them to recover from their breeding operations is the greater owing to this artificial and restricted flow of water. Fungus is not so easily shaken off, neither are the wounds and abrasions of the breeding-time so quickly healed. It may be accepted as a fact that trout should have plenty of water, plenty of space, and plenty of food, and the more natural the conditions of these three factors the better the results in trout breeding.

To those, therefore, who may be inclined to devote their attention to trout breeding, I would strongly recommend the adoption of breeding pounds situated, when possible and where safe, directly in the by-paths 
of some portion of the best trout stream available. As an instance in point, I can refer to the Itchen Trout Breeding Establishment, in Hampshire.

Some years ago Mr. E. V. Corrie, one of the keenest of fishermen, conceived the idea of placing his breeding pounds directly in the flow of the Itchen River at Lower Chilland, Itchen Abbas.

With the exception of the hatcheries themselves, in which spring water is used, all the troughs, boxes, pounds, etc, are directly treated to a plentiful supply of river water; the fry-i.e., the young trout-immediately after passing out of the alevin or yoke-sac period are brought up directly in the life-bearing and cool waters of the Itchen, and the consequence is that, both as yearlings, as two-year-old fish and onwards, the size and healthiness of all the trout are phenomenal.

In order to illustrate the natural conditions of these remarkable breeding pounds, I have been able, by the kindness and courtesy of the present owner, Mr. G. R. Bryant, of Lower Chilland, to show my readers in Plates XVI., XVII., and XVIII., the succession of these pounds as they occur in the bed of the stream.

Plate XVI. shows the upper pound in which the stock fish (from 3 to 5 pounds) are kept. The river is here screened off and so controlled by hatches that the entire flow of the River Itchen (here a considerable stream) can be poured through the stock pounds. These screens across the course of a rapid river such as the Itchen of course require most careful and constant attention, it being one man's work to 


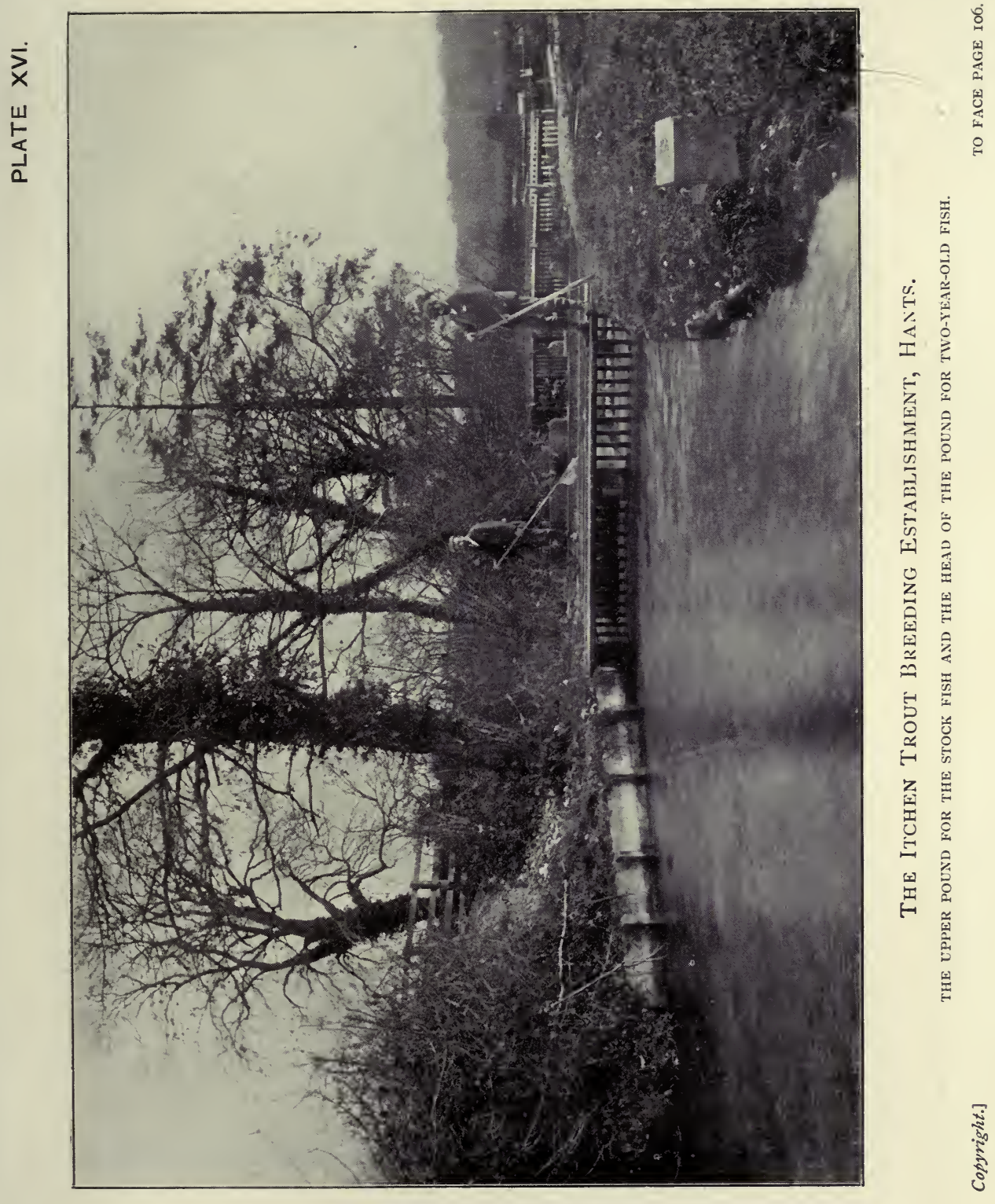



attend to them, but the advantages to the fish are so great as to be deemed well worth this expense. The surplus current of the river runs over a weir to the right-hand side of these pounds above the upperi.e., the most distant-boundary seen in this view; the keepers are shown as standing on the lower boundary of the pound. The fine wire screens can be seen if this plate is carefully examined.

The dangers of floods and of the blocking of these screens are reduced to a minimum. Immediately below these screens are kept the 12-inch fish, which thus get the full force of the stream and become very strong and vigorous.

Plate XVII. shows the pound some 200 yards in length devoted to two-year-old fish, the natural advantages of which must be apparent even to the tyro.

Plate XVIII. shows the home stretch devoted to 8-inch fish. At the lower end, near the hatcheries, the river is divided into three other pounds, into which the stock fish are drafted during the breeding season, and others in which certain drafts of fish are kept prior to being dispatched to their final destination in some other water.

On the lower side, carefully screened, are situated innumerable small canals, into which the river water is directed, and in these the varying classes of fry of the brown and rainbow trout are reared. It is, of course, in these lower breeding ditches that there is the problematical danger of flooding. Mr. G. R. Bryant, the present proprietor, whose house is seen 
to the right, and his keeper, Mr. Clinker, scout the idea of such a danger. Floods are practically unknown in this portion of the Itchen, owing to the rapid flow of its waters and the vicinity of its source. The author suggested to Mr. Bryant that many of the weaker fry must be forced by the rapid current against the lower screens in these breeding canals or boxes, and thus destroyed. "That," said Mr. Bryant, "is exactly what happens, and we thus get rid, by natural means, of the small percentage of weaklings, and retain none but healthy and vigorous fish."

To show the richness of the Itchen water at this place, the following extract from a letter written by Mr. E. Valentine Corrie will be found most interesting :

$$
\begin{aligned}
& \text { "Lower Chilland, } \\
& \text { "July 10, } 1900 .
\end{aligned}
$$

" The weather was remarkably hot, and the heat only occasionally tempered by a south-west breeze, just strong enough to cause some ripple when it pressed against the run of the stream. For two weeks previously trout had been very difficult to take, and when I waded into the shallow water immediately below Chilland foot-bridge, I scarcely expected more than a brace or so of $1 \frac{1}{2}$-pounds fish. The rise commenced shortly after 10.30 a.m., and trout came well to a medium-sized Olive. Very quickly I had three nice fish, and as I saw large numbers of them taking up their feeding stations behind the bars of weed which had been left across the wide shallow, and judged that an extra big day might be in store, I returned to the house and directed that some of the fish-cages in which the Chilland Fishery trout are stored before being sent on a journey should be taken down to the shallow, and placed in the water near below the place where I was fishing. The rise of fly was never very strong, but continued all day, and by 4 p.m. I had landed fourteen and a half brace of trout averaging over $1 \frac{1}{2}$ pounds apiece, and placed them in the storing cages. Of course, a great many fish of less weight also came to hand, but were at once returned to the river. Of the 


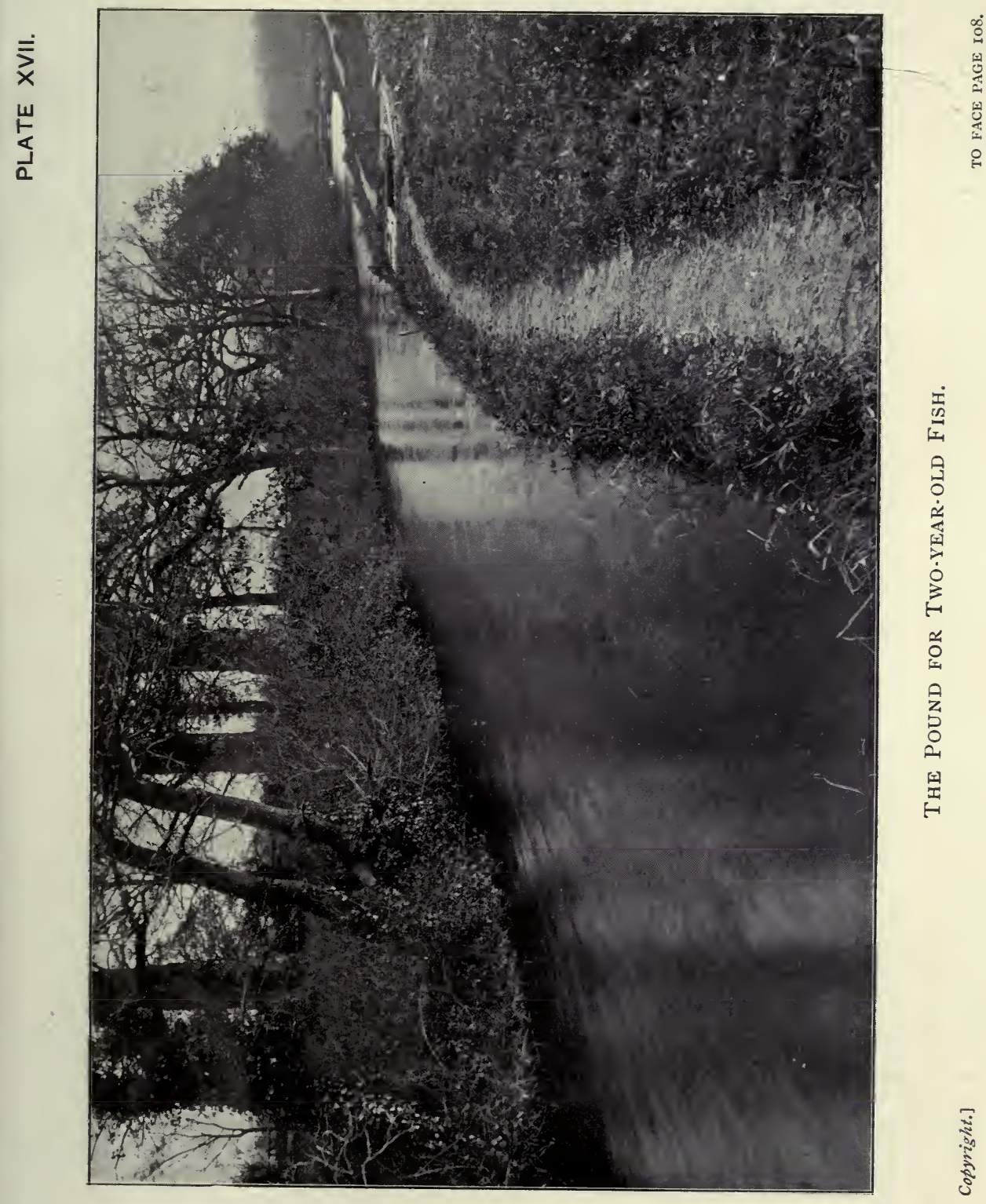



twenty-nine trout in cages, I liberated all females, only retaining male fish that appeared to have reached or passed their prime. This work was done at leisure after the rise of fly ceased, and I had ample time to sort out and knock on the head fish which were better out of the stream. I think the most remarkable incidents of the day's fishing were the variation of the kinds of fly that hatched out, and the trout's determination to only look at the artificials which were the same colours and sizes as the natural flies. This was about the best day's fishing I ever had on the Itchen. The trout fought very well indeed-well enough to try strength of tackle to its utmost. Nearly every fish when hooked rushed past me, straight down-stream towards deeper water, where the short waders I was wearing did not allow of pursuit. I might have returned to the bank and so got below hooked fish, but the shallow was so clear that much movement on my part must have cleared fish in all directions, so I simply played the fish against the stream, and was fortunate that I had no breaks and very few holds gave way.

$$
\text { "E. V. C." }
$$

A river, then, which can support such a wonderful number of natural fish is eminently suited for trout rearing, and the trout which are reared at Lower Chilland breeding pounds fully establish the advantages which I claim for such a method. There are probably not many rivers in England so favourably situated in every way to produce such happy results, but if there are such a system is well worthy of trial.

Another excellent trout-breeding establishment is the Norton Fisheries, Baldock. These fisheries have a never-failing water supply from very large springs situated immediately above the Fisheries. They have a very well arranged system of sluices, and the whole water is absolutely under control. There are upwards of a hundred different ponds for fry yearlings and twoyear-olds. A speciality of these fisheries is that wild spawners are largely used from the mill river below, 
but 300 stock Rainbows and 500 stock Brown Trout are also used. These domesticated fish are fenced off in another portion of the river above the mill (see Plate XVIII.). The circumstances surrounding are admirably calculated to produce a strong and healthy stock. The water contains a very large amount of natural food, flowing as it does through extensive beds of watercress and other food-producing weeds.

Some 70,000 Fario fry are reared annually and fed on natural food peculiar, I believe, to these Fisheries, but the particulars of which I am not permitted to disclose. These Fisheries are within an easy distance of London.

In the Kennet Valley Fisheries, which rear, principally on Natural Fish Food, a very fine and healthy twoyear fish for stocking rivers, they make a specially prepared Food for streams in which there is a scarcity of natural food, common to some rivers in early spring. They also supply waterside and aquatic plants of all kinds, including trees, etc., which will afford cover for the angler and shade and insect food for the fish; plants suitable for river margins and shallow water; and. other varieties for the deep water of lakes and rivers, etc.

The Influence of Temperature, Etc.

Variations in the temperature of the air and water exercise a most important influence on aquatic life.

The relative increase in the temperature of water 


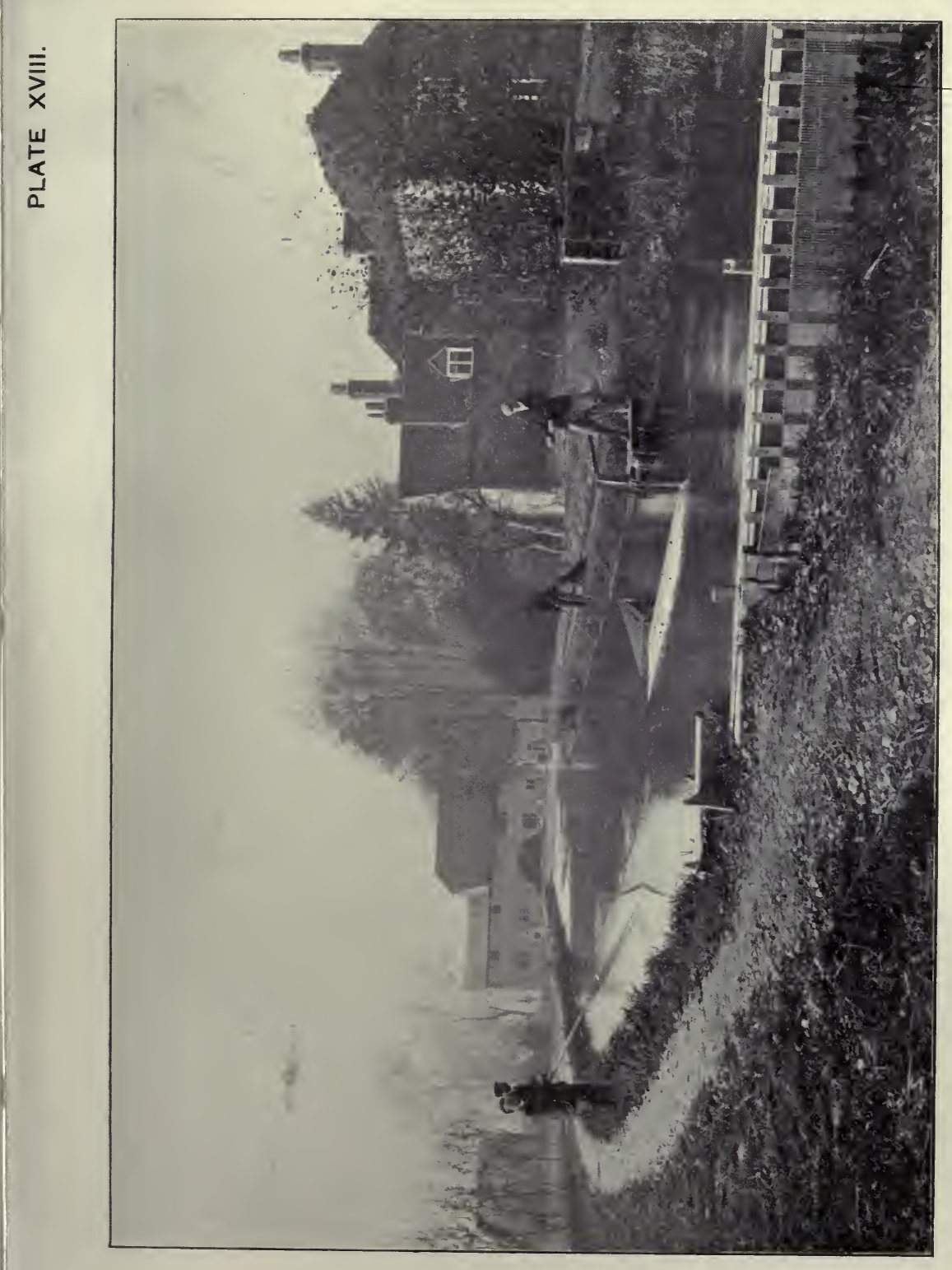

吾 



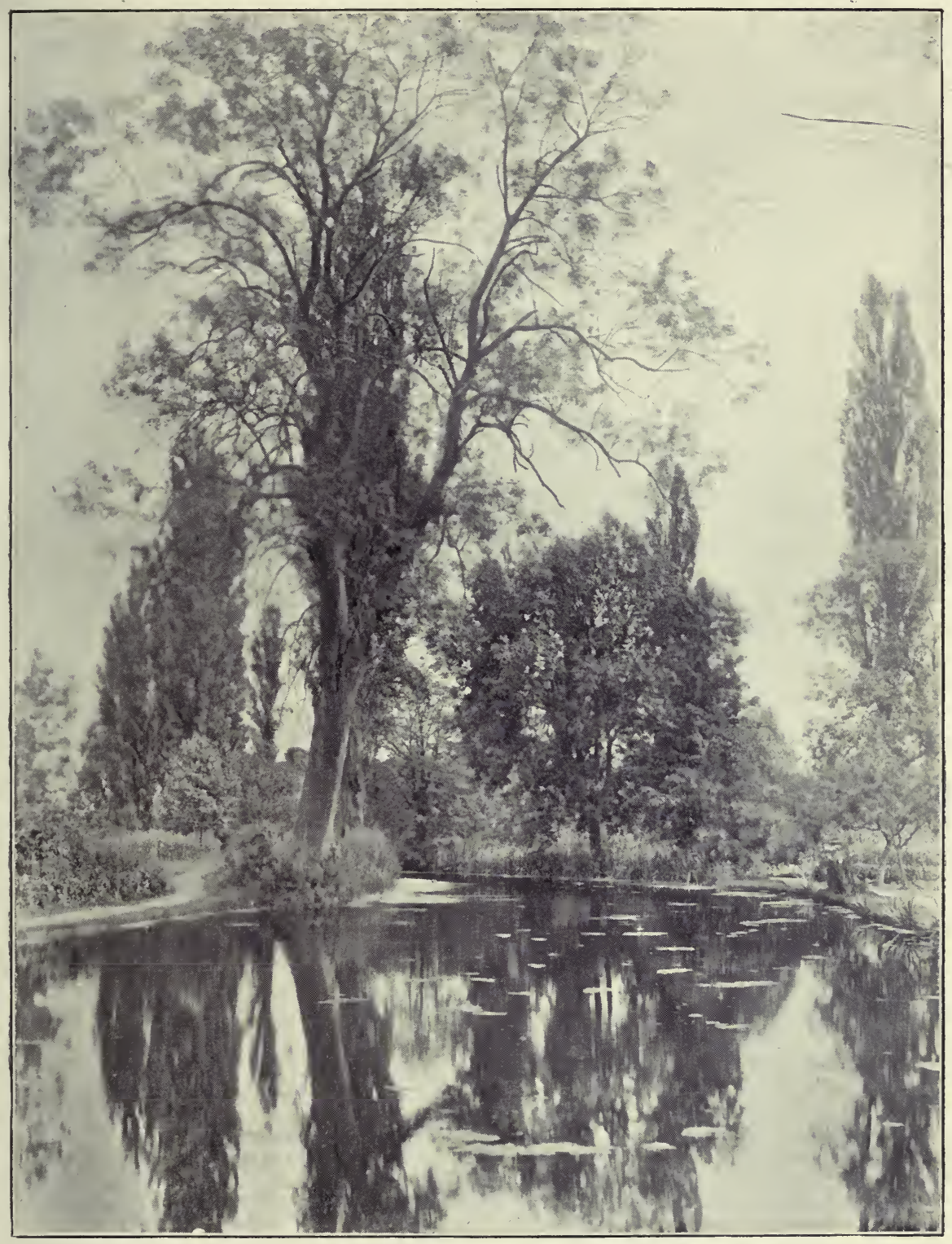

River IVel, Norton Fisheries, Baldock. 

assists and quickens the incubation of all sub-aqueous eggs, and hastens the metamorphosis of all insect life.

Mr. Livingstone Stone is decidedly against the establishment of breeding pounds in the natural bed of streams, but his objections are due to the dangers connected with such a locality. Trout, he admits, will flourish ${ }^{-}$most when placed in strong-running, natural trout water, plentifully supplied with natural food, and he also admits the difficulties of regulating the temperature of water conveyed in aqueducts. I consider that so long, then, as the owner of a hatchery is secure against floods and natural dangers, the natural food and temperature of productive trout streams will secure the most favourable breeding of his trout.

Under favourable circumstances the rapid growth of a trout is extraordinary. Trout from the upper waters of the Dart, where natural food is scarce, and the fish in consequence are small, quickly grow to a very large size when placed in the more productive waters of ponds and reservoirs. Trout will feed better in fairly temperate weather than when it is very cold, and a rise in temperature after a cold spell is productive of good sport, due to the improved appetites of the fish, to the greater activity of insect life, and sometimes to the recovery of trout after spawning. Trout lose their desire for food as the spawning time approaches, and though they commence feeding after it is over, they do not regain their full feeding powers until the warm spring weather is reached. My experience of trout has convinced me that they acquire an increase of 
feeding power, and, naturally, a more rapid power of digestion, in the spring months, and that, in consequence, they increase more in weight in the four months between April and August than during the rest of the year. These months, then, are the time for the fisherman.

\section{Trout and. The Close Season}

I am inclined to think that to the majority of trout fishermen the natural history of the Salmonidr is as a sealed book. Fishing to them is but a pastime to which the most delightful hours of their outdoor life are devoted, and save during the moments which are spent in the actual pursuit of this sport their interest in these game fish seems to disappear.

The life of the trout during the close season, for instance, is practically unknown to the average fisherman, and while the necessity of observing such a period is recognized, the wisdom of the limits imposed by the various fishing associations is but seldom considered, and receives but a small proportion of the criticism which is deserved by so momentous a subject.

Are trout sufficiently protected by the present limits of the close season ? In order to strengthen my own impressions in this matter and to avoid the possibility of mistake, I have recently written to the managers of several breeding establishments, to gentlemen interested in trout breeding, and to those in 
charge of various trout fisheries, asking them to give me their experience as to the period which covers the loss of appetite prior to spawning, the dates on which the trout in their immediate neighbourhood commence and cease to spawn, and the length of the period taken by trout to recover from their spawning operations.

\section{Times of Spawning}

From the information which has been kindly placed at my disposal in answer to these letters, it may be taken as certain that the general limit of the period during which wild and domesticated trout spawn is from October 1 to the end of January, although trout are known to spawn as late as the middle of February. Mr. Walter Bailey, of the Midland Counties Fisheries, Malvern Wells, informs me that he has taken eggs from wild brown trout as late as February 11. The average period during which most trout spawn, however, may be accepted as occurring between October 25 and January 12, the temperature of the weather and the amount of water in the rivers considerably affecting even this early or late spawning season. Trout in their natural condition suffer a loss of appetite commencing from eight to three weeks before spawning, this loss of appetite depending to a considerable extent on their condition towards the end of the fishing season. If the trout have experienced a warm summer, with plenty of food in the 
shape of insect life, their condition early in the autumn will be good, and a more extended period of fasting may be expected prior to spawning. In some cases they begin to feed immediately after spawning, and if the circumstances are favourable will be clean and in good condition from two to three weeks afterwards. If, however, the conditions are unfavourable, they may not commence to feed for several days after spawning has ceased, and their complete recovery may be relatively delayed if the weather be unfavourable. Hard frost will also check and interrupt the actual spawning operations.

The importance of a careful consideration of the above facts when deciding the limits of the close time will be better appreciated when it is thoroughly understood that, from the time the fish begin to lose their appetite prior to spawning until they have entirely recovered their condition after spawning, they are unclean and not fit for human food.

Those fish that do happen to feed as their spawning operations approach-and this may happen during the open season-appear to suffer at times from a disease of the intestines, and are afflicted with worms. Strict laws should therefore be enforced in order to prevent the possibility of the trout being captured and destroyed prior to their spawning, or when their condition renders them unfit for human food. 


\section{Close Season too Short}

It is the opinion of many fishermen that trout fishing opens in many districts at too early and closes at too late a date. The fisherman whose experience has extended over many districts, and who has fished early and late in the season, will recall the frequent capture of ill-conditioned or dirty fish towards the close and at the beginning of the different seasons. These are fish which have not recovered from, or which have already begun to feel the influence of, the spawning season. Such fish should, of course, in all cases be returned to the water, but the chances of killing or injuring these fish should in no case be permitted.

The wild fish instinctively cease to feed as their spawning season approaches, though the domesticated fish will continue to feed, if permitted, up to the time they are ripe. This loss of appetite in the wild fish is accompanied by a change in their appearance. Generally speaking, the female fish becomes sluggish and more discoloured than the cock fish; the cock fish retains its activity, and in some rivers becomes brighter on the sides as the mating season approaches.

Meteorological conditions affect the time of spawning, and also affect the length of the period in which it takes a trout to recover after the spawning operations are over. This is especially so in the wild fish. Even in the same districts spawning conditions vary very considerably; not only the temperature of the 


\section{EARLY FISHING ON WELSH RIVERS}

atmosphere, but the temperature of the water in two neighbouring streams, will produce a relatively early or later spawning season, as the case may be. The locality of the rise of each river should be considered, as well as the rise of each of its tributaries. The snowfall and the meteorological circumstances of each season should be carefully considered twice a year, and the hard-and-fast period selected for the opening and closing of the trout-fishing season should therefore be modified by the peculiar circumstances of each river and each season. Trout fishing can be legally pursued between February 1 and October 2, except in those districts in which the conservators have wisely extended the length of the close season. It is unnatural, foolish, and unsportsmanlike to permit fishing during periods in which ill-conditioned fish can be caught; but at the present time many rivers are deprived every season of a considerable quantity of ova, and suffer the loss of many ill-conditioned fish owing to an insufficiently extended close time. For these reasons alone it is advisable that the close season in many districts should be still further extended. Many of the early fish caught in the Welsh rivers during a hard spring, for instance, are as unfit for human food as is the kelt before he has visited the sea. The fish on the first warm day are ravenous, and at such times they will take any bait, no matter how unskilfully it may be offered to them. As a natural consequence, the rivers lose many of their best fish before the latter are in a condition either to fight 
properly or in a mood to discriminate as to the choice of their food.

\section{The Board of Conservators}

The opening of the trout-fishing season is regulated by the fishing conservators, and if the gentlemen controlling these associations could only be induced, in the interests of the rivers they control, to consider the causes which lead to the depopulated condition of certain rivers in June and July, it is probable they would defer the opening day from the middle of February to the middle of March, or even later. I have noticed that local fishermen on many Welsh streams seem to regard their legitimate fishing as over by the end of May, and judging by the big creels which they are able to obtain in February, March, and April it is little wonder that they leave the rivers and the few remaining trout during the summer months to the anxious attention of their visitors, whose dry fly but too frequently falls on waters from which nearly every trout of takable size has disappeared. It must be evident that with late spawning fish and a very hard January, February, and March, it is a mistake to permit trout fishing to open in February, or at any rate until the great majority of fish in each particular river have recovered their condition. Rivers in which the trout spawn late are said to produce the best results, as the alevin emerges into the world under more favourable conditions as far 


\section{APPEARANCE OF SPAWNING TROUT}

as temperature and weather are concerned; but in any district, whether it be relatively early or relatively late in its spawning, contradictory as it may seem, the early spawners produce the best results.

Captain T. R. Morse, of the Kennet Valley Fisheries, a very keen observer, has communicated an interesting method, which I believe may be regarded as a new one, of distinguishing on sight between the sexes of the trout. The cock fish, he claims, can be easily distinguished from the female fish during the spawning season by the fact that the adipose fin is more developed, thicker and stiffer than in the hen fish.

During the open season the reader may probably find it difficult to distinguish between the sexes of the trout. As stated above, it is claimed that the cock fish has a longer and stouter adipose fin; there is a bluntness about the nose and head of a cock fish, although this bluntness is lost as the spawning season approaches. At this time the colour becomes more vivid on the sides; and the belly of the fish, both before and behind the ventral fin, has a decidedly square appearance in the cock fish. The hen fish at this time loses some of her colour, and grows big with spawn, but does not acquire the squareness in the underneath part of its body peculiar to the cock fish.

River weeds are of the greatest importance in order to provide food for trout. The weeds which should be introduced and which best encourage the growth of the water shrimp, perhaps the most valuable natural food for trout, are the Ranunculus and Water Celery. 


\section{The Appearance of Trout}

The colour of the trout changes rapidly in relation to his local surroundings. If a dark trout be taken from under a bridge or from some deep shady portion of the river, and placed in a shallow enclosure with light-coloured gravel at the bottom, he will at times change to a much lighter colour within the hour. A trout which inhabits a river one side of which is deep, over-shadowed, and with a dark bottom, will when on that side of the river be possessed of a dark colour; but if he should during certain hours of the day cross the river and lie on the opposite side in sunlight, on a shallow, gravelly bed, he will rapidly lose his dark colour.

\section{What Sort of Flies to Use; When and Where To Use Them}

The most important problem which the angler has to solve when he gets to the water-side is as to the fly which is being taken, or going to be taken, by the trout.

The natural flies, the fancy flies, the best patterns of these flies for the various rivers, the hours of the day, where such flies are most killing, have already been most fully discussed by others, and the works of Sir Edward Clarke, Halford, Dewar, Hutchinson, and Pennell are not only most delightful reading, but are full of interesting information on these subjects. 
The student cannot do better than obtain the standard books on fly fishing, and if there is one I can specially recommend it is "Fishing," edited by Horace C. Hutchinson, and published by Country Life.

This literature will not only prove most interesting, but by reading it the learner will acquire a general idea of the natural flies which are recommended by these writers.

The fly fisherman should always, before going down to his stream, consult the Field and the Fishing Gazette, and in their weekly reports from the different rivers he should find what flies are killing at the latest moment. He must make sure that he has among his other patterns at least a dozen of each sort of flies mentioned by these papers as being used and as doing execution on the water he proposes to fish, or on some of the neighbouring streams. When he reaches his river he should, as soon as possible, discover which of these flies are on the water and being taken by the fish, and the result then rests with him.

It is just here that the great usefulness of a small, light, and collapsible butterfly-net must be impressed on the student; no article after the rod, the line and flies, the reel and the fishing-net, is more important to the dry fly fisherman. It is often impossible, and always difficult, to catch the elusive winged insects which are floating by on the water or flying rapidly past without such a net. With a net, however, little or no time is lost, and fly after fly can be easily and quickly netted and examined, and then compared 
with the artificial flies in the student's fly-book, until he has finally determined on the correct fly to use.*

One of the difficulties which the beginner will experience is to determine the size of the flies he wants when ordering them from the makers. The new number of flies which commences from $000,00,0,1$, 2,3 , and 4 are those commonly used. To facilitate the correct ordering of the flies, I have engraved these exact sizes in facsimile on the side of the knife previously mentioned on page 67 . When, therefore, a fly is caught by the brookside, if it be placed exactly over one of the engraved hooks on the knife handle, the student will see at once which sized fly he has to order. This will enable him to order the correct fly by wiring the number and name of the fly to the maker who supplies him, thus : "Send me by first post one dozen Red Quill size 0_"

\section{The Cap as a Fly-Holder}

A good place to keep the fly which you have just taken off your line is undoubtedly the cap. In this position the flies dry quickly, are secure, out of danger, and always very handy. The flies placed in the cap during the day can be sorted and replaced in your fly-book or fly-box when you get home. The only drawback to this plan is that in wet weather the hooks, if allowed to remain in the cap as it dries, are likely to rust. Flies in the cap are also apt to excite * See the Ephemeridæ Fly Net, page xvi. 
attention, and hints from friendly strangers that "Your hat, sir, is covered with feathers," etc., have been frequent in my own experience. Quite the most droll remark on this subject was made to myself, and is illustrated in Plate XX. When I was coming home from fishing one day on the top of a tramcar, a fond mother kept her children quiet for some time by an entomological discussion as to the nature of the " tame" flies grouped on my fishing-cap.

\section{Moths}

Moths constitute a very real danger to the security of all artificial flies, and during the off season camphor should be freely used. My dear old friend the late Dr. Wiblin, one of the keenest fishermen and kindest of men, gave me a few years ago a big case of specimen flies, which Mr. Halford had especially arranged for him. An assiduous maid, intent on removing all extraneous matter, carefully dusted this out, and left the valuable case absolutely unprotected. Alas ! the moths entered and committed considerable havoc before I discovered the evil.

\section{Dry Fly Fishing with Three Flies}

Now we will suppose you have just arrived for the first time at a stream for a few days' fishing. It is an ordinary trout brook, and you may not have any one with you to suggest the correct fly to fish with.

Your Ficld or Fishing Gazette may have told you that 
PLATE $X X$.

THE LAST STRAW.

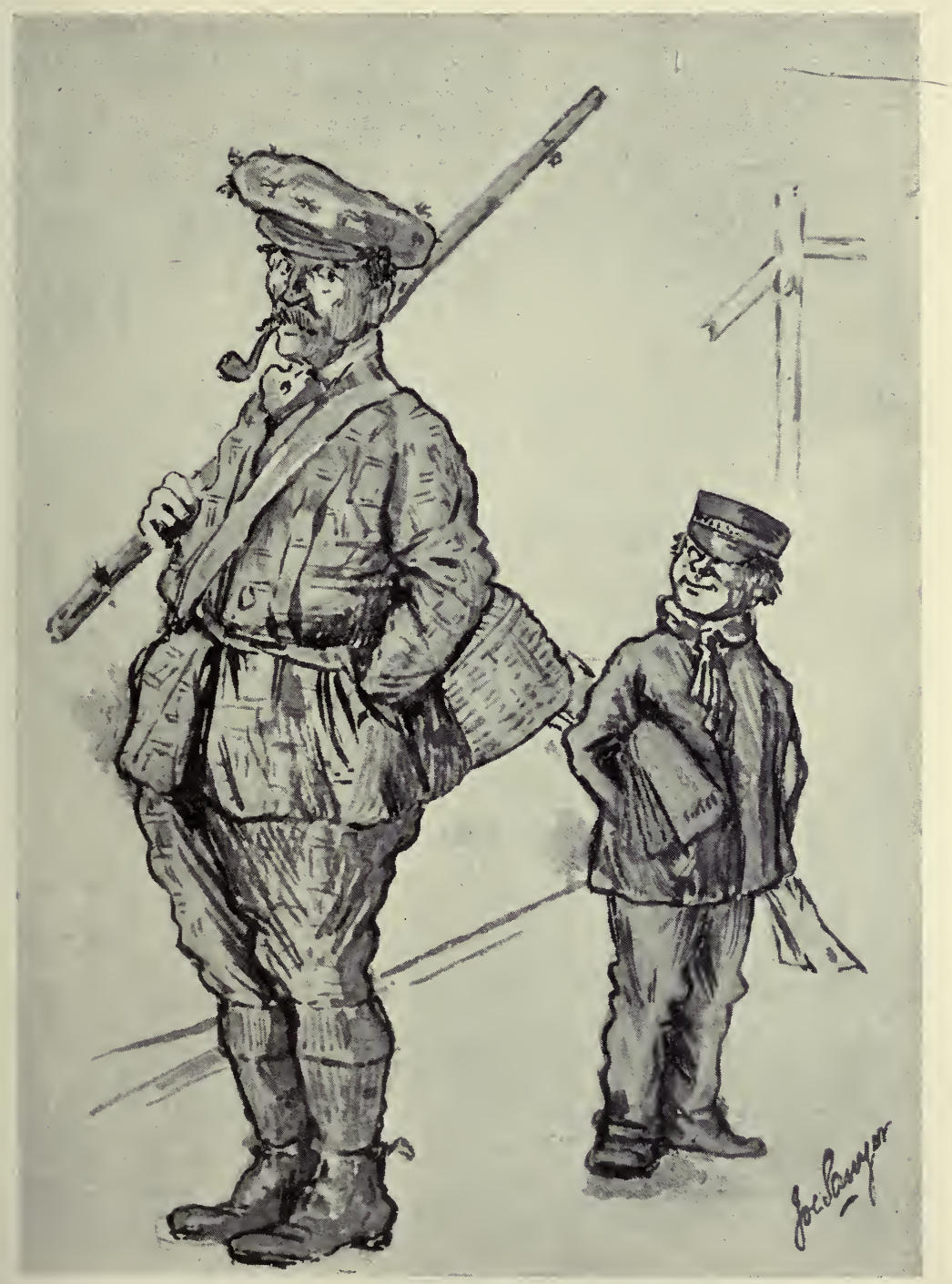

NEWSPAPER Bor (to May-fly fisherman, with no luck, but many fies in his cap):

"Hexcuse me, Sir, But your 'At is Hall Hover Hinsecks!" 

Black Gnat, the Blue Quill, and Olive Quill are being taken on the water. But there are no flies visible, and the trout are not rising. How, then, are you going to determine the correct fly to use ? It is by no means a bad plan-although not usually adopted-in order to save time, to place one of these flies, say the Olive Quill, on the end of your cast; then, 3 feet up the cast, with a very short end, attach the Blue Quill, and again, 3 feet further up, a Black Gnat. Oil the cast and each fly, and treat this cast of three flies as you would a single dry fly cast, and fish up-stream. I have often, by adopting this method and fishing the likely spots, discovered a fly which the fish will take, and by discarding the other two and fishing dry fly with the remaining one, have saved much time and caught fish which I should not otherwise have taken.

Even when the fish are rising, it is often difficult to find out the definite fly which they are taking, and when, for experimental purposes, you may, as above advised, be fishing with three dry flies and happen to catch a rising fish, examine the food in the upper part of his gullet. The chances are that the sub-imago form of some water insect will be found there, as well as the pupæ of the same insect, and if the fly on which you have taken this fish does not secure you trout when it is fished as a single dry fly, try a specimen of the sub-imago found in the fish's gullet. 


\section{Dry Flies}

I should advise you always to get " eyed doublewinged" flies, the eye of the hook turned down. Use a large fly in preference to a smaller one. Never buy flies with the gut tied to the hook when eyed flies are to be had.

There are many days, mostly in fine weather and clear, calm water, which require the floating fly to be in the most perfect condition possible, while on a few other days, and in perhaps rougher water, the more fluffy and knocked about the fly be, the more deadly it appears to become.

When hesitating as to the sizes of any fly it is better to choose the large one, even on such educated waters as the Itchen and the Test.

But it must also be remembered that educated trout may easily be "put down" by a fly larger than the natural fly to which they are accustomed.

\section{Knots used in Trout Fishing}

Hardly a book on fishing has been written which has not dealt with the subject of the knots which are used by fishermen when fastening their line to their casts, fastening two parts of a broken cast together, attaching a dropper to the cast or the gut to the hook. I shall deal, therefore, with this subject in the most elementary manner. The knot which of all others may be considered the fisherman's knot is the overhand knot (see Diagram 10, Fig. 3). This is the simplest form 


\section{THE OVERHAND KNOT}

of knot, and yet it is one on which practically all the fastenings depend. The best method, in my opinion, and the one I recommend for attaching the end of the cast to an eyed hook, is to pass the end of the gut through the eye of the fly, and then to form this overhand knot round the unthreaded portion of the gut, so that the end lies alongside and pointing up the cast

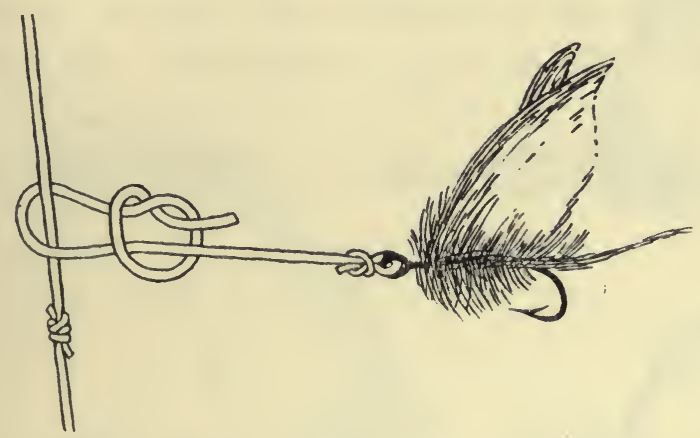

Fig. 1.

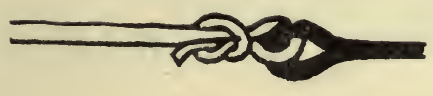

FIG. 2.

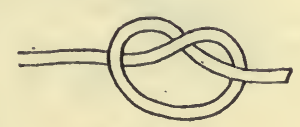

Fig. 3.

Diagram 10.

Fia. 1.-Method of attaching dropper to line.

Fig. 2.-Overhand knot drawn taut on the eye of hook.

Fia. 3.-Overhand knot loose.

(see Diagrams 10 and 11, Figs. 2 and 4). It is drawn tight as it stands, and is then pulled down to the eye of the fly, and the end cut off. This forms the safest knot which can be used on small flies, and is the one I invariably adopt (see Diagram 10, Figs. 1 and 3).

There is, however, what is known to the sailor as the half-hitch, which is shown in Diagram 11, Fig. 6. If 
this half-hitch is slipped down over the eye of the fly, and drawn taut, the knot shown in Diagram 11, Fig. 7, results. It is the neatest possible knot if it can be put on well below the eye and made without injuring the fly. If this knot is used with small hooks, or ones in which the wings are close to the eye, it is a difficult,

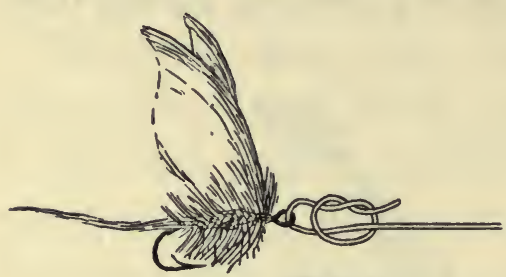

Fig. 4.

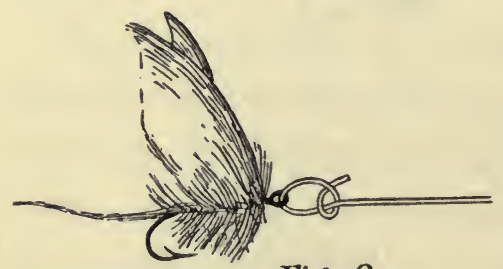

Fig. 6.

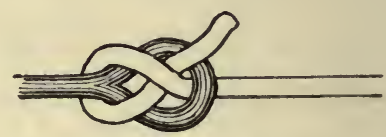

Fig. 5.

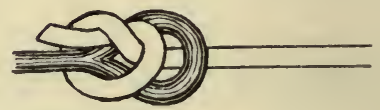

Fig. 7.

\section{Diagram 11.}

Fig. 4.-Overhand knot tied round unthread part of cast.

FIG. 5.-The same slipped over eye and drawn taut, forming the sheet bend.

Fra. 6.-The half-hitch.

Frg. 7.-The half-hitch after it is slipped over eye and drawn taut.

matter to avoid injuring the wings of the fly. It will be seen at once by Diagram 11, Fig. 7, that the end of the line will lie down close alongside the body of the fly. A common method of using the overhand knot is shown in Diagram 11, Fig. 4. This knot is slipped down while loose over the eye of the fly, and drawn 
taut, the result of which is shown in Diagram 11, Fig. 5, and is known to the sailorman as the "sheet bend." This knot, in my opinion, is not a very good one, more particularly for the wet fly fisherman, as a bubble of air is frequently retained by the short end above the eye of the hook, which gives an unnatural appearance to the fly or insect. In addition to this, the end cannot be cut too close, or it will slip through the eye of the hook; and

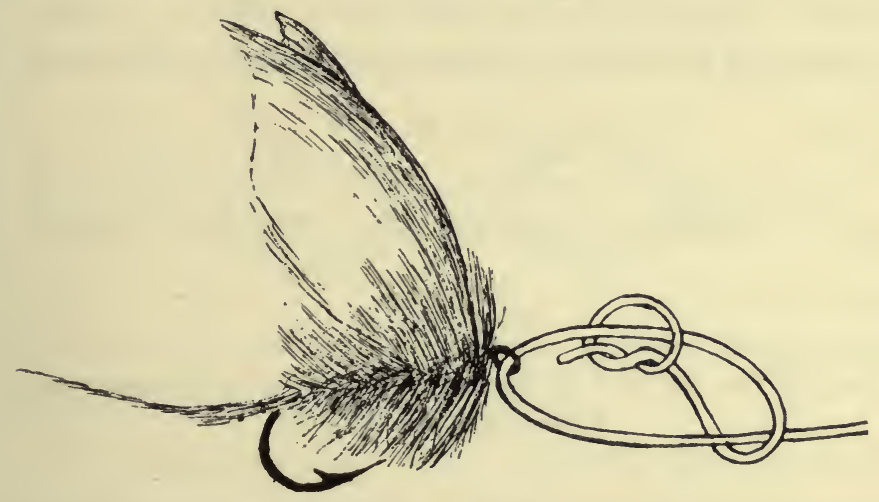

Diagram 12.

Showing a method of using the overhand knot for large flies.

another disadvantage is that the point of the gut sticks out in an objectionable manner. When the half-hitch, however, is used as described above, the end of the gut can be cut close off. It lies more nearly into the body, and does not hold the bubble of air, but the greater care is necessary in putting it on, and while it is by no means a bad knot, I think the one I recommend much the better.

For bigger hooks, as large as May-flies, this overhand 
knot can be used as in Diagram 12. To make this knot it will be seen that the knot is made round the threaded part of the gut, and not, as in Diagram 11, round the unthreaded part. The knot is then drawn taut, and the end cut off short. The noose thus formed is drawn taut on the unthreaded part, and is then pulled down, so that the knot thus made slips down to the eye of the hook.

If two ends have to be joined, one overhand knot is tied, and the end of the other part passed through the knot, and this end tied in an overhand knot round the

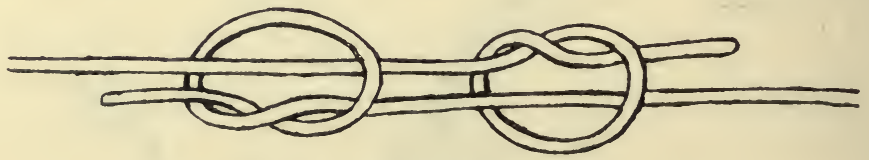

Diagram 13.

Showing the method of joining the ends of two pieces of gut with overhand knots.

other part (see Diagram 13). Notice how the ends come out. All that remains to be done is to draw these two overhand knots taut on the piece of gut they enclose, and then draw the two knots together. This makes the neatest of all joins, but for additional security, and so that the end of the gut can be cut absolutely short, a double turn can be given to each overhand knot before it is drawn taut.

When attaching a dropper to a cast, the best way is to make a fairly large overhand knot in the short end of gut attached to the fly, and to pass the fly through this knot, enclosing the cast in the loop thus 
formed. The overhand knot is then drawn taut, and the loop thus formed is placed at the spot at which the dropper has to hang, the loop closed by pulling on the fly, and the end cut short off (see Diagram 10, Fig. 1).

\section{Wet Fly Fishing Up-Stream}

As wading is almost imperative in open water when wet fly fishing up-stream, a short rod-about 9 feet 6 inches-should be used; but when casting from the bank, either up or down stream, a longer rod is advisable.

The wet fly is most useful in the earlier and colder months of the year, but it is not every one who cares to invite rheumatism or endure the cold inseparable from wading during March and April.

When fishing up-stream with the wet fly, the line, after the flies have touched the water, should never be slack. The tail flies should never be allowed to sink more than a few inches below the surface, the first dropper only an inch or so, and the upper dropper should skim the water. The cast being made, the rod should keep the line straight as the flies come back with the stream, and a slight jigging motion should be imparted to them. The rise of the fish is almost invariably seen, and success depends, therefore, on four things-the choice of flies, the fisherman's quickness in striking, his ability to throw a light line, and his knowledge of a fishing stream. This method of 
wet fly fishing is not only highly successful, but far more interesting than fishing down-stream. Wading is almost a sine qua non, as the bank is too conspicuous a place for the angler; and this is the drawback, for the line must be fished short, and he must of necessity, from having to use a short line, be closer to his fish than in dry fly fishing. The greater the stream lore of the fisherman, other things being equal, the greater will be his success. Rising fish should induce special attention. Wet fly fishing up-stream possesses many of the charms of dry fly fishing, and as a sport it comes next to it in scientific interest and pleasure. The object of jigging the wet fly when in the water is to imitate the action of the nymph or pupæ when swimming. The object of letting it float steadily down with the current is to imitate the drowned sub-imago. Hence, when drowned sub-imago are not present, and the pupæ are being taken by the trout (any captured trout will readily solve this point), a series of little checks should be given to the drifting flies by tiny jerks of the point of your rod. After a thunderstorm, when numbers of drowned sub-imago are coming down and the pupæ probably not moving, it is better to adopt drifting.

\section{STRIKING}

If the fly at which the fish rises is near the surface, the motion of the fish, or perhaps the fish itself, can be seen, and the strike may therefore be made at the time the touch is or should be felt. When, however, 
the fly is well below the surface, as is mostly the case in wet fly fishing down-stream, the first intimation the fisherman gets that a trout has taken one of his flies is the pluck or pull at his fly. In the latter case, if the fish is hungry, an immediate strike may force the fly into the mouth of the fish before the fly is rejected. In most cases, however, this pluck means either a hooked fish or a missed one. The pluck in itself is quite sufficient to hook the fish, and therefore, in so many as eight cases out of ten, the hooking of a fish with a wet fly down-stream cannot be claimed as being due to any skill or quickness in striking; while in at least eight cases out of ten the fish hooked with a dry fly or wet fly up-stream may be fairly claimed by the angler as due to his skill in striking.

\section{Wet Fly Fishing}

When three or more flies are being used on a cast, the question as to the best distance which should separate them is an important one.

In wet fly fishing down-stream a long cast of, say, 9 feet, should be employed, and more space can be allowed between each fly than when using a short cast of 6 feet for wet fly fishing up-stream.

If the flies which are being used are of a large pattern, plenty of room should be allowed between each fly, but this space can be reduced as the cast becomes finer and the flies smaller. In discoloured water, again, a shorter distance between each fly is advisable 
even when using a fairly large pattern of fly. In selecting the tail $\mathrm{fly}$, the one most likely to attract the fish should be used, and the droppers, as the other flies are called, should be attached to the cast by a length of gut, not more than 3 inches from the cast to the fly. Single-winged flies should be used, with a fairly stiff heckle. I think one gold-ribbed fly should always be used on a cast. Experience acquired on any particular water, tempered by the size of the fly and the condition of the water, will be the best guide as to the arrangement of your wet fly cast.

The smaller the fish you expect to meet, the finer should be your line, your cast, and your flies. Each day on which you fish should most certainly add to your knowledge and experience, and maybe to your skill. The weather may be unpleasant, the fish shy, your luck villainous, but never be discouraged; your luck must turn, the fish must feed, the sun must shine, and you must catch fish. Bad luck at the card-tables may be ended by a no-trump hand and a big slam. The poorest day's fishing may be concluded with the capture of a record fish. As an instance of patience and wrist play, I recall an experience of a connection of mine, the late Rev. Daniel Hughes, of Ruthin Grammar School, who, in April of 1872, while trout fishing with an 11-foot rod in Carnarvon, using a silk-and-hair line, hooked a salmon of 32 pounds on a medium-sized March Brown, and, after a most exciting struggle lasting over six hours, finally secured his fish ! 


\section{WEEDS}

You may well ask me! If these weeds are sodangerous and so often rob the fisherman of his fish, why are they left in the river ?

There are several considerations which have to be taken into account with reference to the water plants or weeds in a trout stream. The owner has to consider the necessity of keeping open his water way and preventing these rapid-growing plants from choking up the channel of his stream, a fault which would lead to the flooding of the adjacent property, damage to the river-banks, and the probable loss of many good fish.

On the other hand, he has to remember that these weeds, when kept within certain bounds, are most beneficial to trout life, forming shelter and refuge to the trout, not only from mankind, but from the otter, the heron, and other enemies, and providing a neverfailing supply of natural food, as well as acting as filters and natural purifiers of the waters in which they exist. The Ephemeridæ and other water insects are always plentiful in weedy rivers. The fresh-water shrimp, one of the principal foods of the trout, abounds and multiplies amid the shelter of the weeds. Several trout-breeding establishments make a regular business not only of supplying fly larvæ, fresh-water shrimps, and other water insect life, but of cultivating and supplying the best weeds and water bushes for trout streams. Riparian owners, therefore, who wish to 
afford shelter or create a natural food-supply for their fish would do well to remember this fact. Among the establishments which are known to myself as supplying a good class of weeds are the Itchen River Trout-Breeding Establishment, the Norton Fisheries, Baldock, Herts, and the Hyde End and Kennet Valley Fisheries.

The Riparian owner must also take into consideration the valuable effect which the water plants have in checking the down-stream flow of the water in the dry seasons, and by this natural damming action keeping a plentiful supply of water in streams which would otherwise soon run very low (see Plates XXI. and XXII.). These two photos were taken on the Axe, near Seaton Junction, and the influence of the weeds on this stream can be at once realized, both as regards the plentiful supply of insect life and also as damming up and filtering the water of the river.

Weed-cutting and dredging should always, therefore, be restricted within reasonable limits.

The only water on the Colne, near Uxbridge, with which I am acquainted was, at one time, thoroughly ruined by the unthinking action of the Thames Conservancy, who, at the most inopportune time of the year, absolutely ploughed the river-bed entirely clear of weeds, leaving it shelterless, foodless, and fishless, save for a few stray fish which were lucky enough to escape death, mutilation, or banishment, but which soon fell victims to the nets of the local poachers.

This wholesale weed destruction does not, however, 
PLATE $X X I$.

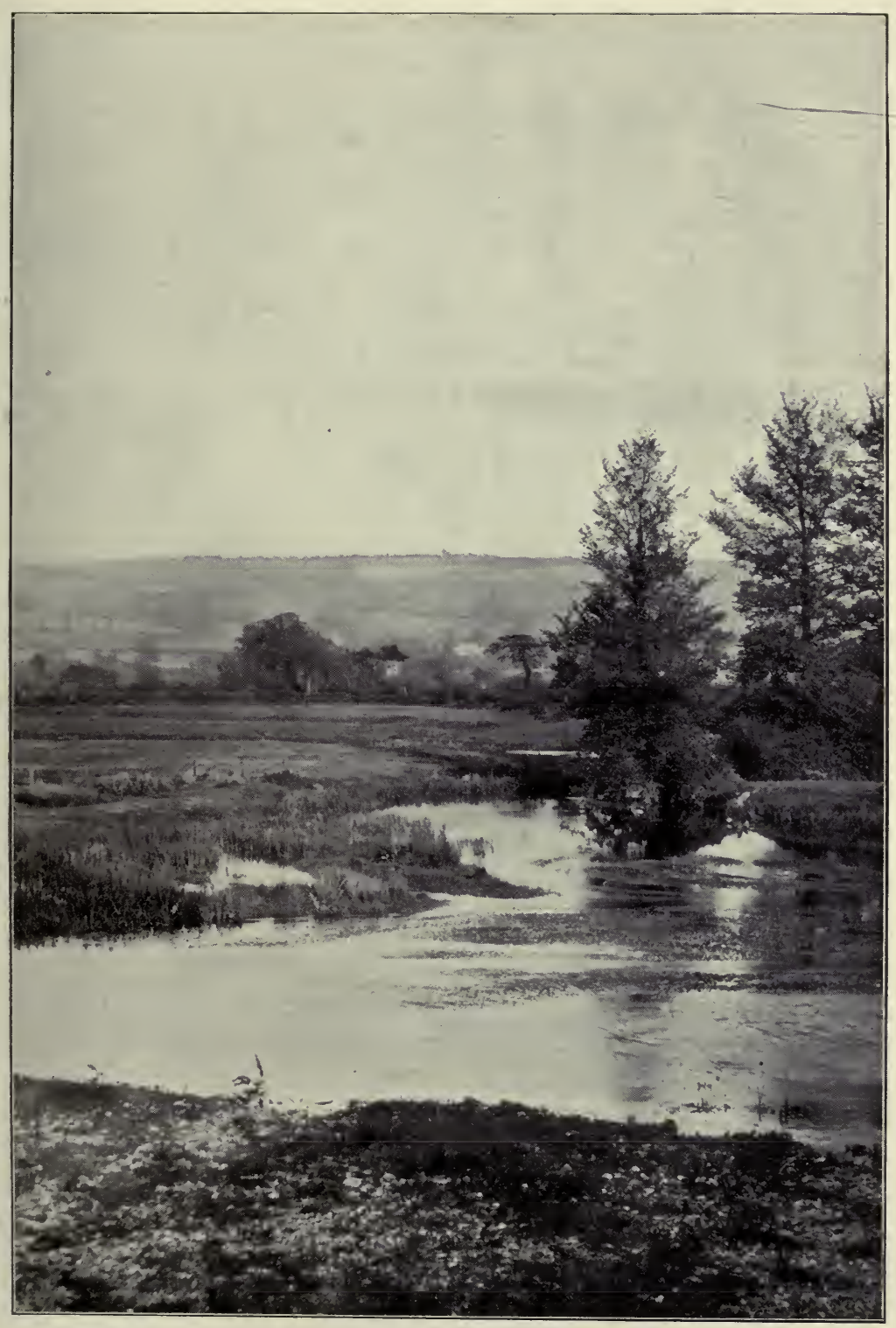

A Natural DaM of WeEds.

[Photo by the Author. AT THE MEETING OF TWO CHANNELS OF THE AXE, 

do any good to the Thames or the Thames Conservancy, as, instead of the weeds being left in the Colne to check the flood water, this river's volume is increased, and a much more rapid and dangerous addition is therefore made to the already swollen waters of the Thames.

Always remember that in very weedy water it is better to let a trout go up-stream into the tail of a bunch of weeds than to pull him down-stream, and let him get sideways into the thick of such a danger. A fish which may seem hopelessly entangled in weeds and brushwood may with patience and nerve be ultimately creeled.

\section{Fungus on Grown Fish}

A trout may be caught at times suffering from a fungus or a growth on the head, shoulder, or other part of the body. The student will be well advised, after netting such a specimen, to destroy it at once, taking care not to return it to the water or place it among his clean fish. Mr. Stone has proved that fungus can at times be cured by dipping the fish in a strong solution of salt, but that, when left alone, it appears invariably to kill the fry, and also any weak fish which are not situated in healthy and rapid water. Ordinary fungus is a vegetable growth which attaches itself to any bare spot on the trout's skin, caused by a wound or the accidental loss of slime. The natural slime on a trout protects the skin from fungus in exactly the same manner that Peacock 
Paint protects the bottoms of iron ships from barnacles, etc. The fungus is in itself harmless, but it sometimes contains worm-like parasites of microscopic character. These harbour themselves in that portion of the fungus near the skin of the trout, and are continually eating into the tissue of the fish. The mouths of these worms are armed with tentacles, with which they can adhere to any portion of the trout's skin which may be unprotected by slime.

If the worms be killed by salt solution, the fungus then disappears. If, however, any portion of the living and malignant fungus be returned to the water, it will carry with it a percentage of these deadly and contagious worms, and hence the necessity of its absolute destruction for the benefit of the healthy trout in the same stream. Mr. Thomas Clinker, the manager of the Itchen Trout-Breeding Establishment, considers that there are two kinds of fungus - the one malignant and epidemic, and recurrent in places where the surroundings are unhealthy and the water-supply feeble; the other universal, but comparatively harmless. I quite agree with this view, the real harm being due to the parasitical worms, which may or may not exist in the ordinary fungus. The bare places caused by the fry nibbling one another are an ever-present source of danger to these small fish. 


\section{AMBIDEXTERITY}

The student should be able to use either hand when manipulating his rod, reel, or landing-net. There is fortunately no difficulty in doing this when once the science of casting is acquired, while there exist many sound reasons in favour of such ambidexterity. Many a good rising fish and many a difficult but likely spot in the stream may be reached by him alone who can cast with either hand.

There is always the danger of a disabled right or left hand or arm, and even when both arms are sound there are times when a change of hand is not only pleasant but necessary. I remember in 1897, while fishing on the Wutach, getting an acute attack of fisherman's elbow in my right arm, and for several days at a time the ability to use my left hand in casting enabled me to enjoy my sport with comfort and pleasure, when to use my right hand gave me considerable pain. The committee of the International Tournament, 1904, very wisely introduced an open ambidexterous competition among their fly-casting events, Mr. Lauri Hardy, of the firm of Hardy Brothers, being first, and I having the good fortune to be second. Mr. Hardy's average with six casts, using each hand alternately, was 27 yards. The contest was exceedingly interesting, and it is to be hoped that it will be repeated at the future tournaments. 


\section{Long-Distance Casting}

While not wishing to minimize the importance of being able to cast a long line, and of successfully hooking fish when doing so, this ability by no means stamps any person as a good or skilful trout or salmon fisherman.

Unfortunately, we have at present no means of deciding the championship other than by a test as to distance in casting.

Style, delicacy, accuracy, and variety should enter into the competition, and points should be allowed for each class. The greatest aggregate number of points obtained should decide the championship.

\section{Spinning for Trout IN the Summer Months}

As many of my readers may possibly be anxious to try spinning for trout, a few words on that by no means easy method of taking fish may be welcome. There is a great and distinctive difference between the man who uses a minnow in the discoloured waters of the early spring months, and allows the tumble and rush of the river in which his lure is cast to do the work for him, and the man who delights in the difficulties of catching fish in dead, low, clear water, with a natural minnow and a tackle consisting of at most two triangles and a lip hook, and the finest of traces.

The greater difficulty and the more interest must 
centre in the last-mentioned method of spinning, which, when used in clear water, in an almost empty stream, and in the blazing sun of a summer month, requires an even greater skill than that required to cast a dry fly with the requisite subtlety and delicacy under similar conditions.

First as to the rod: The rod as supplied by most makers is, as a rule, of far too stiff a type, for it is as necessary to feel the line and the minnow when spinning as it is to feel the line and the fly when fly fishing. The rod should have an action similar to, or be in fact, a stiff fly rod, and it should, of course, be fitted with the most easy-running rings.

The reel will depend on the method of castingwhether the bait be cast from the reel, or from slack held in the hand. In the former method some form of Nottingham reel is necessary; in the latter an ordinary fly reel is perfectly suitable; but for either method a good Nottingham reel will be all that is required. The line should be either a very perfectly dressed one, or (which I prefer) an undressed silk as fine as is consistent with necessary strength. The trace should be 2 or $2 \frac{1}{2}$ yards long, furnished with at least two double swivels. Spinning flights are supplied in so many different patterns that it is impracticable to describe them all, but the fewer the hooks the better. A lip hook and a triangle at the tail will be sufficient in fine water.

The minnows should be small, not more than 2 inches in length, and as bright and fresh as obtainable. 
Now, as to the actual working method of catching fish with this tackle, I cannot do better than give the method used by a cousin of mine, Reginald Downes Hughes, in his own language, as follows :

"The minnow must be held at the end of sufficient line to reach to the reel. Draw off with the left hand, say, a couple of yards. Swing the rod steadily and absolutely without any jerky motion in the required direction, letting the slack in the left hand run through the rings. Cast up-stream, and immediately the bait reaches the water, which it should do without splash, start drawing in the line again with the left hand down or across stream, but slowly enough to let it sink as deeply as possible, while avoiding weeds, snags, etc. In this way search every inch of the water as carefully as you would with a fly, remembering that, as a rule, the larger the fish the more disinclined he is to be tempted. Having once become capable of casting delicately with this short length of line, which, however, is generally sufficient where wading and fishing up-stream, you can, in order to command a larger area of water, gradually learn to draw off more slack line, either letting it fall on the ground where clear of weeds, etc., or, better still, held in three or four coils over the different fingers of the left hand.

"Casting in the Nottingham style necessitates the same steady swing of the rod, but the minnow is cast from the reel. Swing the rod well back, holding the reel with the first or second finger of the left hand, and on commencing the forward cast release the reel. As 
the bait approaches the water again recover control of the reel by pressing a finger of the left hand against the rim of your reel, until, as the bait touches the water, you have stopped the reel action altogether. You should then at once start winding in the line. Casting from the reel is, of course, the better way, as the fish is, when hooked, at once in play from the reel instead of from loose coils; but it is very much the more difficult to learn owing to the tendency of the reel to overrun. It is also more difficult to throw accurately in the desired direction. Should you at first when throwing from the reel find the bait travel waywardly round you and become fast in the back of your coat, it is not necessary to return home in order to find some one to release it, as has been done. A quicker way is to lay down the rod and take off your coat."

In the spinning thus succinctly described my cousin, who is a most excellent fisherman, dwells lightly on the difficulties to be overcome when spinning. One lesson from any experienced spinner should be enough; practice will give accuracy and lightness to anyone determined to succeed.

In spinning for trout, therefore, in fine water, when you expect to eatch the class of trout you would take with fly, the best way is to throw up-stream, and draw down the rapids as quickly as possible, not using a very long line. In fishing for pike, however, and the large cannibal trout, the bait should be thrown across and slightly up-stream, and worked as slowly as possible 
across and down-stream, the bait being finally brought to the bank at your feet. Pike and big trout are lazy, and won't move an inch out of their way, and therefore in spinning as in wet fly fishing every inch of the water should be searched, and for the bigger fish more slowly than for the smaller ones.

In casting your spinning bait down-stream the Nottingham reel should be used, and a longer line is necessary. The lure should be cast across that part of the stream you wish to fish, and be drawn back and across the current, the pressure of which will impart the necessary spin to the minnow.

\section{Where to Go}

Trout fishing as a sport is rapidly taking a leading place in public favour, and if as much attention were given to the advertising and letting of our trout streams as to salmon fishing, grouse moors, and deer forests, fishing for trout would soon become a pastime pursued only by the very rich. It is possible, however, to obtain very excellent trout fishing on terms moderate enough for persons of very moderate means.

There are four sources of information open to the would-be fisherman - "The Angler's Diary," the Field, the Fishing Gazette, and the retail fishing trade. "The Angler's Diary" should be in every fisherman's hands, its general information being not only very extensive but reliable.

The two papers I have mentioned are instructive, 
and their fishing notes are always interesting, while the leading tackle makers can always be consulted, and from their long experience are fairly good judgesas to fishing possibilities. In some localities excellent hotel accommodation, good fishing, shooting, eighteenhole golf-links, and lovely scenery, are to be had.

Excellent accommodation is afforded by the Lake Hotel, Llangammarch Wells. Shooting over several thousand acres of mountain, moorland, woods, etc., is reserved for visitors. Salmon and trout fishing in the River Irfon, a tributary of the Wye. Over two miles of this river flows through the hotel grounds, and is reserved for visitors. Recently the weir at Cilmery, which undoubtedly was prejudicial to the run of salmon, has been opened, and a good salmon season may in consequence be anticipated.

The hotel stands at an altitude of 600 feet on the slope of the Eppynt Hills. The Llangammarch Golf Club has just been formed, and the links which are adjacent to the hotel leave little to be desired. There are also bowling-greens, croquet and tennis lawn.

The curative waters give the same benefits as is afforded by the celebrated springs of Nauheim and Kreuznach.

\section{Elan Valley Fisheries}

Fishing in the reservoirs of the Birmingham Waterworks, streams and lakes in the Elan Valley, Rhayader, is very excellent, and the average weight of the fish taken is rapidly increasing. The waters consist of four 
reservoirs, with an area of about 864 acres, several natural lakes with an area of 134 acres, and upwards of 30 miles of rivers and streams. Good hotel accommodation can be obtained at Rhayader. In 1906 the total number of fish caught on the various waters was 5,252 , the heaviest fish weighing 2 pounds $14 \frac{1}{2}$ ounces. Fishing shelters are put up during the season as garages for motors and cycles, stabling for horses, and depositories for lunches, extra fishingtackle, etc. Particulars can be obtained from Mr. John Jones, Estate Office, Rhayader.

\section{The River IveL}

Excellent fishing can be obtained at the Norton Fisheries Club water, some two miles in length, and which will extend in 1908 nearly four miles, the owners having bought up the exclusive rights of the water belonging to the three neighbouring mills. The River Ivel is thoroughly well stocked with fish ranging from 1 to 4 pounds. A limited number of rods are taken every year at thirty-six guineas each. From its vicinity to London, it affords an admirable opportunity to fishermen living in town, who require good fishing within an easy distance of their homes. The fishing opens on April 15 and closes on October 31. 
PLATE XXII.

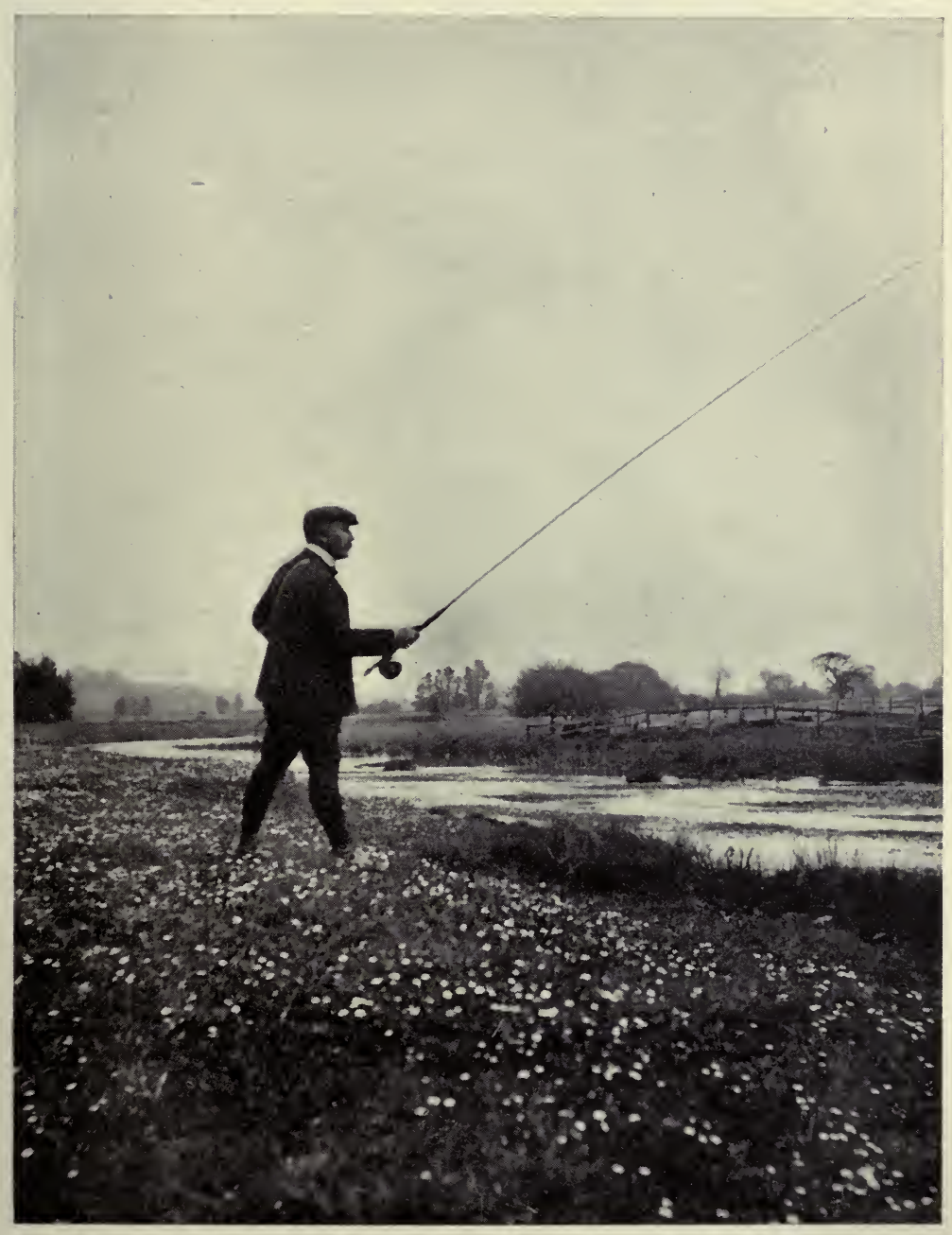

Mr. Shaw Fishing on the Axe in May. 

Axe River, Somerset

A pleasant and comfortable hotel, possessing several miles of good trout fishing on the Axe River, is to be found in the Shute Arms, Seaton Junction. The trout average about 10 ounces in weight, and run up to $1 \frac{1}{2}$ pounds. Two pictures of the river are shown in Plates XXI. and XXII. It is advisable to book rods and beds at this hotel in advance, as only a limited number of rods are available.

\section{Kennet Valley Fisheries}

Very good trout fishing can be obtained within an easy run of town on the Kennet Valley Fisheries, whose waters are about nine miles in extent. Tickets can be obtained by the day, week, month, or season, and good accommodation will be found conveniently adjacent to the different fisheries. For particulars, apply to Captain T. R. Morse, Riverside, Hungerford.

\section{Scourie Lake, SutherLandshire}

For those who like varied fishing, and can afford to travel some distance from London, the Stafford Arms, Scourie, Sutherlandshire, possesses many advantages. Excellent sea trout and brown trout fishing is obtainable ; a large number of boats are kept for sea fishing, and some forty lochs are available during May, June, July, and August for brown trout fishing. There are 
several lochs stocked with Loch Leven trout, averaging about 1 pound each. During 1906 the two best baskets of trout were eight trout weighing 20 pounds and six trout weighing 18 pounds taken with fly.

The scenery is magnificent, there is excellent sea bathing, and the hotel is situated close to Handa Island, which is noted for the richness of its bird life.

To those who like a comfortable hotel and lake fishing the Hotel Lake-Vyrnwy can be safely recommended; the fishing is good and the hotel overlooks the water.

The North, West, and South of Wales are full of good localities. In the North of Scotland and the West and North of Ireland free fishing can be obtained, and good fishing easily acquired at a small cost. Norway, Germany (especially in Baden), France, Spain, the Austrian Tyrol, Sweden, etc., will all repay a visit; in many places exceptionally good fishing will be found. If I have any favourites abroad, they are the chalk streams of Normandy, or those of the Black Forest.

But I must, after all, give my adherence to the British Isles. For many years to come most excellent and cheap trout fishing will be obtainable in this dear old motherland by those who know where to go, and while they will find it will cost them less than going abroad, they will be spending their money among their own people, the trout will be as game, as beautiful and as plentiful as in any other country, and the scenery and accommodation will be in most cases better. 
If, however, my reader should fail to discover any suitable place in which to fish, I shall be delighted to assist him from the knowledge gained by my personal experience.

I have, however, been frequently written to by the readers of the first edition of this book not only as to fishings for trout and salmon, but also in regard to shooting estates, deer-forests, etc. This has induced me to mention the few places which I know, and which possess good fishing, etc.; but the letting of shooting estates, salmon rivers, etc., is not in my line of business, and I think, therefore, it would be of some advantage to the reader if I mentioned an agency well known to myself, which makes a special feature of sporting properties.

The agency is known as the Club Shooting and Fishing Agency, 19, Hanover Square, London, W., which is managed by Messrs. Tennant, Ross, and Wallace, Limited.

The gentlemen controlling this agency are sportsmen themselves, and they are thoroughly reliable and trustworthy. Their charges are moderate, and I cannot suggest any estate agents to whom those in want of salmon, sea-trout, brown trout fishings, etc., or shootings of any description, can better apply. With their practical knowledge and wide connexion they are in a unique position to afford every assistance to those placing themselves in their hands. 


\section{The Broken Rod}

The fisherman is likely at some time or other to fracture or spring the upper or middle joint of his fishing-rod or some other portion of his kit.

If he should happen to meet with this misfortune he can with very little loss of time and without difficulty repair the most serious fracture or injury.

I keep a repair-case in my fishing-bag, which I have found to be most useful. It is a small cardboard box which contains all that is necessary to make the adequate repairs ; it is small, compact, and handy, the contents of which should not cost more than sixpence.

There is a small tube of strong liquid glue or cement. This cement should be odourless, non-poisonous, strong, and should dry rapidly. There are also some 50 yards of the strongest and best black thread, and several lengths of various-sized goose-quills.

If the fracture is a long splintery break of any wooden implement, you first squeeze a little cement over the surfaces of the two fractures, and then fit the two ends of the broken parts together. You then place a few turns of thread around the fractured parts, no knots being necessary, as the thread will adhere to the rod. By the time you have done this the cement on the thread will be dry, and the parts held firmly together. You now cut two suitable-sized sections of the quills, smear a little more of the mixture into the concave surface of each quill, and press these firmly on the rod over the fractured part. A turn of the 
thread will hold them while you select, if required, another quill, and treat it in the same manner, placing the last quill firmly on the top of the ones already on the rod. All you have now to do is to whip the thread firmly and evenly round the rod over the quills, putting a little cement on the thread or upper quills as you do this. By the time you have put the repair-case in your fishing-bag and lit your pipe, you will find that your rod is absolutely sound and fit for use. If the break, however, is a clean, short one, whittle the two ends until they fit closely and diagonally, put the cement on the two surfaces, and proceed as before.

If the rod be a cane one, it will not be likely to break, but merely to spring, most often in two or three segments on one side. In such a case, place two quills on the weaker side of the rod and one on the other. These, combined with a good strong whipping over all, will render your rod perfectly fit for use. If you care to make a neater job when you reach your fishing quarters at night, a little hot water will dissolve the cement, and you can then make a more perfect mend of the break, and quite sufficient to last until you see your rod-maker again.

It may be necessary to place a third or fourth section of the quills on the rod, but as they fit closely together and are very light, they don't in any way interfere with the pleasurable use of the rod. The quills can be softened by soaking them in hot water.

If you have not broken a part of your own rod, 
others may not have been so lucky, and you can help them, and, as the revered father of Huck Finn said, "a good action ain't never forgot." I remember meeting a man wandering beside a trout stream in Devonshire who told me he had knocked off fishing for the day, having broken his top joint. Luckily, I had my repair-case with me, and, to his delight, in about fifteen minutes' time his rod was spliced, and he was fishing again, and, as he told me afterwards, my repairs lasted him the whole season. His gratitude resulted in friendship, of which I was only deprived when he, poor fellow, met with the fate of many other gallant men during the late Boer War.

The beauty of this method of splicing or fishing a rod is that if only a little cement is used, it dries while the splice is being made, and the rod is then usable. 


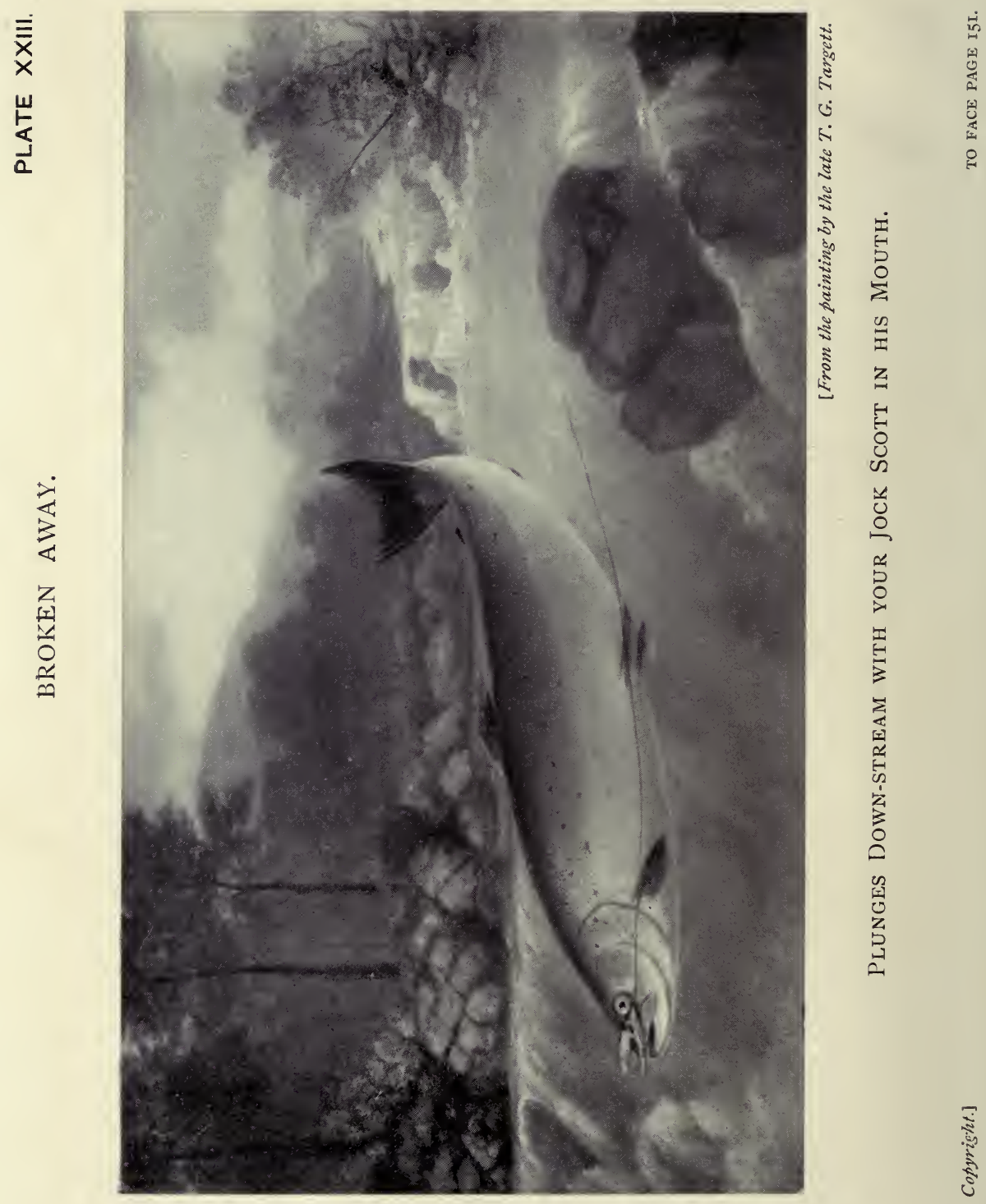


\section{CHAPTER V}

The instincts of the salmon-The life of the salmon-Redds-The deposition of the ova-The dangers to the ova-The appearance and life of the ova-The alevin and its birth-The parr-Its appearance and life-The smolt-Its descent to the sea.

The Instincts of the Salmon: the Good Fairy of the SAlmon's Life

From the moment it leaves the friendly shelter of the redd, amid the pebbles of which it has hatched, has absorbed the yolk-sac attached to its body, and passed from the alevin to the parr stage, the life of the salmon is full of interest to the naturalist, peril to itself, and danger to the water insect and smaller life with which its parental stream abounds.

No watchful care guards its early days or assists its first attempts to obtain food or the shelter so necessary to its tender and defenceless condition. As it emerges into the rush of the stream from the comparative safety of the redd, a tiny inch of delicate but perfect fish, it is swept into a world teeming with watchful and ever-voracious enemies. It is by no means helpless, and instinct teaches it to dart at once for the protecting shelter of the nearest root or pebble. In every after moment of its eventful life, in every 
fresh danger, until it attains to its full growth, it is to the natural wisdom of its own instinct that it owes its safety. This instinct is the guiding influence of its whole life, and is as vivid and compelling in its alevin state as when, a full-grown salmon, it rubs your Jock Scott from its jaws against some pebbly bottom, or saws through your cast against the rugged rock at the foot of which you have perchance permitted it to sulk, and plunges down-stream with your broken trace trailing from its jaws (see Plate XXIII.). Strengthened though this instinct may be by afterexperience, it represents to the salmon an equivalent for the parental education so wonderfully and carefully imparted to most animal and bird life, and to all humans prior to the age of maturity.

No education, indeed, no matter how complete, could compensate the salmon for the absence of those mysterious impulses which influence its life, which cause the smolt's migration from, and return as a grilse or salmon to, its native waters; the wisdom which directs the salmon as it leaps for the first time up and amid the dangers of the towering fall, which sends a wounded salmon away from the deadly contact of the fresh-water micro-organisms to the healing power of the salt water, or guides it back to the mouth of its own particular river after wandering over the trackless bottom of the ocean.

The following remarks anent the habits and life of the salmon will, perchance, contain some matter new to those who may be, either from experience or study, 
familiar with the life history of the salmon; but it is written mainly for those who may be anxious to acquire some general information as to the fish they are so anxious to capture, and with the hope that such knowledge as I have acquired during many years of fishing experience may be of use to them when they find themselves face to face with some unexpected difficulty or problem connected with salmon life. The basis of those theories which offer some new solution for well-known phenomena associated with Salmonidæ are suggested by the most probable and natural influence of their own instinct as affecting their actions.

\section{The Life of the Salmon}

If the reader should, in the early spring, be wandering beside the upper and more shallow waters of any salmon river, his attention may possibly be attracted to certain mounds of gravel rising from the bottom of the stream. He will observe that these mounds are kept clean and free from mud by the sweep of the current in which they are situated, and to which they offer some resistance.

These gravel mounds are called salmon redds, and they are formed by the male and female salmon to cover and protect the ova deposited by the female fish.

During the autumnal and winter spawning season the female fish, after first scooping out a hollow trough 
in the gravel and driving out all muddy or weedy sediments by fin and tail action, deposits her ova in the depression she has thus made. Her ova, which are to a certain degree sticky, will adhere to the gravel when deposited, and are immediately fertilized by the attendant male salmon, after which both fish proceed to fill up this trough with gravel, and continue to pile it on until the eggs are safely buried some 2 or more feet below the top of the redd. If fertilization does not take place the egg absorbs water, becomes opaque, and loses weight. It is in this manner that these redds are formed, in order to protect and bring to a safe issue the result of the spawning operations. It is instinct alone which teaches grilse in their first run to take exactly the same precautions for the safe hatching of their ova as that described above, and adopted by salmon in their first* or subsequent spawnings.

Having performed these duties, the salmon become kelts, and remain as such until they reach salt water, and again become clean fish.

The river is bright and clear, cold and swift, and it will be seen that, however much the sedimentary deposit of the winter months may have covered the bed between the redds, these have in most cases, owing to their elevated position, been preserved from the smothering and pernicious effects of the mud and

* Salmon not infrequently fail to ascend a river to spawn in their grilse stage-and the first spawning of a fish may be after having attained to its final adult salmon stage. 
silt. Here again the instinctive wisdom of the parent fish in thus elevating the redds above the bottom of the stream will be recognized. The elevation of the gravel causes the necessary percolation of the running waters of the stream amid the pebble stratum in which the eggs are deposited, and at the same time washes out any deposits of mud or silt so fatal to the life of young fish.

No matter how cold and empty the river you are watching may appear, hundreds of thousands of tiny lives are healthily pulsating beneath these streamswept redds, and steadily, as the temperature of the river rises, are becoming daily more capable of breaking through the elastic covering which now encloses them, and of emerging as alevin amid the crevices of their pebbly surroundings. Even here, while yet in the egg in the apparent security of their redds, their tiny existence is continually threatened. Fish may root them out; the larvæ of the stone-fly, caddis-fly, Mayfly, and dragon-fly, may penetrate the crevices of the redds, and seize them in their voracious grasp; the water-rat and moorhen may gobble them up, floods may destroy them, or droughts may leave the redds high and dry, and the ova exposed to frost or dry air. All these dangers are possible, and many of them but too common.

But haply none of these dangers may disturb the eggs in the redds we are observing. Each egg is now in itself a separate and detached entity, and as such is individually affected by its own particular and 
immediate surroundings. In appearance it is a tiny opaque elastic ball less than $\frac{1}{4}$ inch in diameter, of which any gallon measure would hold some 25,000, about the number deposited by a 27-pound salmon during any one spawning season; and yet, think you, what possibilities may lie in any one such minute atom ! As I write this I have lifted my eyes from my paper, and they have rested on the skeleton head of my 50-pound salmon (see Plate $\mathrm{XL}$.), and as I recall the splendid fight made by that grand old veteran, and speculate on the past glories of his life, it seems difficult to picture him as being once but one of the wee, small atoms now pulsating beneath the gravel bottom we are considering.

The temperature of the water in each salmon stream is the principal factor which dominates the period for which the young salmon remains in the egg.

\section{The Alevin}

This period will, of course, vary with the particular warmth or coldness of each stream : with a temperature of some $43^{\circ} \mathrm{F}$. the eggs may hatch out in about 100 days, while with a temperature of $36^{\circ} \mathrm{F}$. the eggs will take about 115 days. It is supposed that after about 160 days the egg may be considered dead, or incapable of producing live alevin. This I am inclined to doubt, Nature under adverse circumstances extending life and preserving the vitality of the eggs, even in the moist atmosphere of a redd exposed by 
the lack of water in a rainless season. Cold retards, but does not rob the ova of their vitality after this period has elapsed, so long as the eggs are moist and in a moist atmosphere. From ten to fifteen weeks may, however, be taken as covering the average period of incubation, provided that no abnormal circumstances arise to check the process. At the end of this period the walls of the egg break down, probably owing to the growth and strength of its inhabitant, and the alevin emerges. It is supposed by some that the young fish nibbles its way through the shell. As, however, the mouth of the alevin is not capable of any noticeably muscular action sufficiently great to effect this until at least some time after leaving the egg, I think this must be a purely analogous supposition based on the known action of young birds, etc. For a period of about five weeks the alevin generally remains hidden amid the crevices of the gravel and pebbles forming the redd. After it has left the egg its food is provided by the yolk or umbilical sac attached to its body, which not only hinders its movements and compels it to remain within the shelter of the redd, but provides it with sufficient food to sustain life and add to its strength and growth.

\section{The Parr}

Here again a higher or lower temperature plays an important part in shortening or lengthening the alevin stage of the salmon fry. At the end of this stage, 
the time of which varies from five to eight weeks, it has greatly increased in size, and measures from 1 to $1 \frac{1}{2}$ inches in length. As the last vestige of the sac disappears the alevin existence is ended, and the parr stage is entered upon. The tiny fish now begins to feed upon the minute water insects, etc., surrounding it as it slowly works its way upward or outward by gentle degrees to the surface or side of the redd, whence as it emerges it is possibly at once swept away by the current, and unless it can find some immediate shelter will most probably fall a victim to its numerous and watchful foes. But, tender and inexperienced as is the young fish, he is by no means lacking in wisdom. Instinct guides him, and, luckily eluding his many enemies, he finds his way to the nearest shelter, of which he immediately takes advantage, and happily secures below a pebble or under a root a safe and comfortable home for the early days of his parr life.

It will be, then, in the shallows of this river, near his original home, that he remains until the following, or perhaps the second or even the third, spring after his birth.

\section{The Appearance of the Parr}

His growth is very rapid, and he gradually assumes the delightful beauty and colouring by which the parr is recognized. Four months after leaving the egg he will measure $2 \frac{1}{2}$ inches, and in six months $3 \frac{1}{2}$ inches. 
$\mathrm{He}$ is slimmer, more graceful and more beautifully bright than the troutlet, but with the exception of the posterior or adipose fin, which has, unlike that of the trout, no shade of vermilion edging it, he is similar to a troutlet of a like size. The transverse finger-marks common to the parr, about eleven in number, are frequently found on young trout, while the bright vermilion spots so dearly beloved by all trout fishermen are previous to the smolt stage of the salmon also common to both fish.

The food during the parr period consists of the water-insect life surrounding him (both in its swimming and flying existence), the young of other fish, worms, small eels, and water shrimps; and when the supply is plentiful he will have gradually grown, until in the following spring his length is from 5 to 7 inches, and his weight from $2 \frac{1}{2}$ to $3 \frac{1}{2}$ ounces.

\section{The Smolt}

In the first, second, or third spring succeeding his appearance as an alevin a gradual change takes place in the parr as his smolt stage approaches. He seldom rises at a fly, his appetite appears to cease, and his body gradually becomes covered with silvery scales. The beautiful markings disappear beneath this new and protective armour, and during these spring months he and the other parr who have also changed their appearance and entered the smolt stage, urged by that instinct which has so far guided them in safety, turn 
their heads with one accord and make their way rapidly to the sea.

Mostly, following the sides and shallow parts of the stream, but in the dangerous rapids, keeping well down in the river channel, they go towards the sea; flashing like bolts of silver, plunging down the cascades and shooting over the caps of the big falls, they pass gradually from the purer and colder waters of the upper river into the muddy and warmer waters of the tidal reaches, whence they finally emerge into the cool, food-abounding paradise of their ocean inheritance. 


\section{CHAPTER VI}

The physiological change of the parr into the smolt-The natural arguments in favour of the earlier change of the male parrThe smolt's life-Appetite and growth in salt water-The grilse and his return-The run up to the spawning-groundThe dangers of the ascent-When injured-Arrival at the spawning-bed-Selection of a mate-Spawning-Making the redds-Appearance of the grilse-The kelt and the wellmended kelt.

A CONSIDERABLE difference of opinion, however, exists as to this change of the parr into the smolt-not only as regards the percentages of fish in each year's hatch which leave in the spring of the following or succeeding year, but also as to the sex of those which change during these years.

It has so far been impossible to determine this question with certainty, even in regard to the results of each particular year's hatch of domesticated alevin. How much more difficult is the problem where wild fish have to be considered. As regards wild parr, their change into the smolt stage should bear an intimate relationship to the particular locality and the food, as well as to the meteorological conditions of each season. In unconfined water, therefore, close observation can 
only attempt approximate conclusions as to the times at which the parr of any particular season's hatch change into the smolt, or as to the sexes affected at the various times of this change. It may be assumed that the meteorological conditions affect the periods over which the parr stage extends, and it is not improbable that the male parr is, as a rule, the first to leave that state.

One reason for this may be that the male parr is physiologically more advanced than the female. It has been proved that a 2-ounce male parr is quite capable of fertilizing the ova of a full-grown salmon of 30 pounds weight, but the female parr or the female smolt does not spawn until its return from the sea. I venture to suggest, therefore, that it is not improbable that, under favourable conditions, if it be assumed that the sexes are evenly divided in each hatch, then about 80 per cent. of male parr will undergo the smolt change and migrate during the first succeeding spring - that is, out of 100 male and female parr, 40 male parr will migrate in one year ; that 80 per cent. of both sexes remaining, or 48 fish in every original 100 fish, will migrate as smolts during the autumn or in the second spring, and the balance left behind, about 12 in every 100 of each hatch, will migrate in the following autumn, or in the third spring after being hatched.

Smolts migrate during the autumn months, but beyond this being known as a fact no absolute knowledge has so far been obtained as to the numbers, 
sexes, or conditions of such autumn migrations, although it may be surmised that in the first autumn they are probably female fish.

\section{The Aim of Nature}

There is, so far as I know, no evidence to disprove this suggestion, while there are many arguments in favour of its consideration. Nature and the laws of natural selection are opposed to inbreeding, the aim of Nature appearing always to favour the union of the sexes of different stocks. The migration, therefore, of the male fish in the first spring will, on his return from the sea, throw him into contact with the female of another generation, and most probably of other parentage, and so on. It is the belief of many that each shoal of grilse ascending a river is composed of the one or the other sex.

As is only natural, a considerable diversity of opinion exists, some authorities considering that the female parr changes into a smolt before the male, but this reverses the order of the physical development of the sexes.

It may be assumed that a minority of parr in any one season's hatch migrate after one year's river life, that a large majority of those left behind as parr migrate after two years, and the small remainder, probably the weaker ones, after the third year.

But, whatever may be the approximate facts, food and temperature will be a serious factor in the 
development of the smolt and of its migration to the sea.

We will now follow the smolt of the first year as he darts with a multitude of his fellows from the river into the sea.

$\mathrm{He}$ has at this time all the well-known characteristics of the salmon both in appearance and habits, and he is yet but a little fellow who has to depend entirely on his own resources during his three to five months' stay in salt water. Luckily for him he is full of life and vigour, and his river training has given him wonderful speed and quickness, while his good fairy, Instinct, is always with him.

\section{The Smolt in Salt Water}

Nothing is definitely known as to the wanderings of the smolt after reaching the sea, either as to the period which elapses before he leaves the company of his fellow-smolts, or of the distances to which his travels thereafter extend. What we do know is that the chemical properties of the salt water are most favourable; that his enemies are numerous and voracious, and that his food is plentiful and wonderfully nourishing, and his appetite abnormal ; that, escaping from the ogres of the wonderland in which he travels, he increases in size and strength in a most remarkable manner; and that after satisfying his feeding instincts and stuffing to repletion, he is called by his fairy godmother, and guided amid the hills and valleys, 
the trackless plains and forests of the ocean floor, back to the home he left. It is possible that, as he nears his destination, some perceptible flavour of his own river may entice him nearer; but whatever the ties may be which draw him home, he will be found in the autumn months a full-grown grilse of from 3 to 6 pounds in weight, with numbers of other grilse of his own season, in the lower reaches of the salmon rivers, waiting for a further call to take them away back to the upland stream of their birth.

\section{The Grilse or Salmon}

Here again meteorological conditions affect his movements, and when the condition of the water in the river up which he has to ascend is favourable, his instinct again sets him going. It is now that all the strength and stamina won during his salt-water experience is required to carry him safely through the perils and the difficulties of the up-stream run. Not only has he to elude the wiles of the fisherman and the onslaught of the otter, but he has to fight against the bewildering turmoil of the rapids, and the more deadly and difficult ascent of the falls down which as a smolt he plunged so gleefully a few months before. It is here, faced with the thundering fury of the towering fall, that the difficulties and dangers of his journey culminate. It can only be this evercompelling instinct which not only nerves him in his first ascent to encounter such a danger, but also 
prompts the tremendous effort, and indicates the only place in the descending waters which he must strike in order to gain the haven above.

But with the grilse or the salmon in his initial run up-stream the attempt is made, and though some may be killed and others stunned and torn, yet the rest conquer, and-instances of the survival of the fittestare soon proceeding on their way up-stream. It is on this upward journey that the grilse of 4 pounds may perchance pass the tiny smolts of 3 ouncesmembers of his own redd and hatched from the same batch of eggs-on their way down to salt water.

\section{Its Return when InJURed}

When hurt in his upward course to the spawning grounds, instinct again impels immediate action. Stronger and more imperative than spawning is the instinct of self-preservation. Fatal would be a stay in fresh waters with that gaping wound in his silvery side, for most assuredly would the zoospores of the dreaded saprolegnia enter the abrasions in his skin, and speedily destroy him. It is only in the healthgiving waters of the sea that a cure can be effected, and instinctively, therefore, will the grilse or the salmon turn and make his way to the sea whenever his scales are destroyed and his skin torn. Thus it is not unlikely that the occasional stay of the grilse in the sea until he attains the growth of a salmon may be accounted for by accidents which happen to 
him on his first spawning trip, and compel his return to the sea.

Salmon appear to be more irregular than grilse, both as to the time of their return and also as to the river they ascend; but the ascent of both grilse and salmon is affected by the state of the water in their river. The early or late ascent peculiar to different rivers-by which they are known as early and late waters-is entirely due to the condition of such rivers, and their natural temperature and local climate. Each river may again vary as regards the average date at which salmon run, being earlier or later than the average date as the river varies in the volume of its flow. The running of salmon will again vary, being early or late in accordance with the annual variation of the season in each river. Some few salmon enter the rivers as fresh fish as early as January, and continue to run up till late in the spawning season.

\section{Spawning}

At last our grilse has reached the gravelly beds of the upper stream of his own river. Natural selection, attended by combat, will decide his mate, and the female salmon lying on her side, when her condition is ripe, will with lateral movements of tail and fins, sweep the sand and fine gravel away from her body, and thus form a hollow trough, into which she proceeds to deposit a proportion of her ova, the male fish 
meanwhile acting as guard, keeping off other male fishes and also the predatory attacks of troutlets, parr, etc. Directly the female has finished each batch of ova, the male darts over and fertilizes them with his milt, and as soon as possible they sweep gravel over and bury the ova to a depth of at least 2 feet, thus forming the redds above described. The time covering the spawning season in an average stream is from six weeks to two months, the earliest comers being, as a rule, the first to spawn.

\section{The Kelt}

The male and female grilse or salmon, which have lost enormously in weight, and are now in the kelt stage, leave for the sea in the early spring, recuperate, and, maybe, return as full-grown salmon of from 7 to 10 pounds the following autumn.

It is an interesting fact that the larger a salmon becomes, apparently the less regular it is in its visits to its native water, and in rivers such as the Gula, which lies to the south of the Namsen River, large salmon, evidently Namsen salmon, are not infrequently caught. The Gula salmon are small fish, and when a big fish is caught it is invariably looked upon as belonging to the Namsen.

Mr. George Beck, a very experienced Norwegian fisher, caught in 1906, on the Roystad stretch, the largest salmon ever caught on the Gula River, and although this was not a marked fish, it is the universa] 
opinion that it was a Namsen fish. Its weight was $44 \frac{1}{4}$ pounds, and it was caught on an extremely large Wilkinson.

The appearance of the grilse is similar to that of the salmon when fresh run, the back and upper part of the head being dull bluish black, running into a bright silvery hue on its belly and sides, the dorsal and adipose fins and the tail being all dark. As kelts the older fish grow more discoloured than do the younger ones, and form a disgusting comparison with their own fresh-run condition. Kelts are known as foul fish, and are unfit for food. While in this state they are very voracious, and kill quantities of river fish. In appearance they are a dull and dirty-looking red. They seem at first to be exhausted and spent after spawning operations, but often recover a considerable amount of condition before reaching the sea, in which case they are known as "well-mended kelts." 


\section{CHAPTER VII}

Feeding in fresh water-Rejection of food when caught-Aggressiveness of salmon-The sustenance of salmon in fresh waterA new theory-Analogies drawn from other fish-The gastric juices of salmon-Facts advanced on other theories-Important evidence as to food in salmon's stomach in fresh water-Other views of this evidence-The gastric glands discussed-A general view-Another theory-Stoning a pool-Salmon entering fresh pools-Actual fishing and non-rising fish-The record take of salmon.

A GREAT deal of literature has been devoted to the problem affecting the clean salmon's pursuit of all moving objects after it has left the salt water, and various explanations have been advanced to account for its apparent appetite in fresh water prior to spawning. The structural changes of the entrance to and exit from the stomach of a fresh salmon prior to spawning appear to preclude its taking food therein, and there have been few authentic cases of a proved clean fish ever having been discovered in fresh water with food in its stomach.

A well-mended kelt may, of course, be taken for a clean salmon, and if food is found in its stomach it may induce a contrary belief in the mind of a person unable to discriminate between a well-mended kelt and a clean salmon. I think it may be accepted that 
kelts do feed in fresh water, but not for some time after spawning.

A salmon when in fresh water appears to pursue and take in its mouth any moving or novel object which it sees, unless the object be too big, or the salmon be frightened or warned by some previous unhappy experience. What is the reason for this action? Some, ignoring the physical changes in the alimentary regions, declare that the salmon takes the food into the stomach, but that directly it is hooked, or finds itself in a net, it discharges the entire contents of the stomach.

\section{Rejection of Food when Captured}

Mr. H. Cholmondeley-Pennell advances, as a possible solution of the empty condition of the salmon's stomach when caught in fresh water, this theory of the rejection of all food, and instances a case where 716 salmon caught in a net-in salt water-were seen to discharge quantities of small eels as the net approached the shore. This, however, only affects the fish in salt water and when their stomachs are in the normal food-absorbing condition, and therefore this evidence of Mr. Pennell's does not help matters.

\section{Aggressiveness of Salmon}

Salmon in fresh water do not appear to be hungry, but rather savage, and their attitude is more aggressive than voracious. The leaf floating on the surface of 
the stream is seized, bitten, and rejected; the lure of the fisherman is seized, and, so far as my experience goes, is never swallowed. I have never hooked a clean salmon, even when spinning with the natural minnow, save in the mouth, and generally in the tongue or jaws ; and I have never heard of the triangle being found embedded save in the mouth or upper part of the throat of a clean salmon. It is certain that when a salmon is feeding it neither masticates nor attempts to masticate its food; indeed, its teeth are unfitted for such a process, and directly the prey is seized it is swallowed. This alone should dispel any belief in the theory that a clean fish feeds in fresh water; for if it did so, the bait, when it was seized, would be immediately swallowed, and innumerable cases would occur in which the salmon would have to be cut open in order to liberate the hooks attached to the lure. One powerful argument which has to be met is, that salmon are frequently caught with worms as bait, and if the hooks to which these worms are attached were found in the stomach of the salmon, an even stronger case would have to be answered; but as far as my information goes, these hooks are not found in the stomach. Eels, worms, and larvæ are as great a source of danger to the salmon ova and alevin as any other denizen of fresh water, and thus their destruction by the salmon might be as natural as that of small fry. The salmon, when entering a river, attacks the larger-sized objects, which are seized and lacerated by its teeth, and as it approaches 
the spawning ground this occurs with nearly everything seen, no matter how minute the moving object may be.

\section{The Sustenance of Salmon}

Salmon, it has been affirmed, when in fresh water, live on their cream-that is, the adipose matter distributed through their body-until spawning operations are over, even as the hibernating animals live on their fat until their winter is over. The loss of the appetite of the salmon is natural when the object of their visit to fresh water is remembered-that is, to spawn. The insect and fish life of a river is insufficient to sustain an inrush of healthy feeding salmon with an appetite such as is common to these fish when in salt water; hence if their appetite continued all living creatures in the fresh waters of the salmon river might possibly be destroyed, and the salmon would not, in succeeding years, leave the salt water, where food is plentiful, and enter an empty river, however strong their spawning instincts, and for this reason-an appetite would imply a necessity for food, which food would in such a case be unobtainable. Thus their sexual duties would be unperformed in fresh water, and if they attempted to spawn in the sea, their ova would be killed by the saline action of the water. Nature appears to moderate the appetite of the smolt in fresh water, and instinct then prevails, and the smolt flies to the sea, where he recovers his appetite. When 
salmon have recovered their strength after spawning and increased in size, Nature takes away their appetite, instinct prevails and they run up the rivers to spawn.

\section{A New THEORY}

What, then, causes them to pursue and seize all the moving objects they encounter prior to spawning ?

It has been shown that the guiding loadstone of their life is instinct, and instinct in this case makes them destructive. A similar impulse pervades all Nature, and teaches the parent to destroy or to drive off any possible foes that are likely to endanger the safety of its young. Salmon enter fresh water for one purpose alone, and instinct teaches them that all moving inhabitants of fresh water constitute a future danger to the well-being of the defenceless young which they must leave behind. Their instinct therefore compels them to pursue, capture, and destroy all the forms of life existing in the waters which will be the future home of their young, and which life may endanger the existence of their ova or fry. Even in the smallest of the fish tribe, our dear little bright sticklebacks, this instinctive desire to attack and destroy all possible dangers to their young is recalled in the delightfully simple rhymes of Father Tuck's "Little Pets" series :

"For if some fish or other thing

To harm our nest draws near, We bravely bite and fiercely fight,

To save our babies dear." 
I have, when well concealed from sight, while watching salmon, quietly thrown in preserved minnows, worms, and snails. These have been seized, chewed, and, as far as I could see, invariably rejected by the salmon. Nature, despite its immutable laws of supply and demand, is rarely destructive for destruction's sake, and the salmon's attack on moving objects is actuated by the absolutely natural law which dictates the safety and survival of the species.

\section{Analogies drawn from Other Fish}

Herring, mackerel, and other salt-water fish, cease to feed as spawning operations approach.

As the spawning season of trout approaches they lose their appetite and their condition, and though at times food is doubtless swallowed and enters the stomach of the trout, it appears to lead to trouble, frequently to disease of the intestines. The natural condition of the trout's stomach is opposed to the reception of food during the season in which its sexual activity exists, and it is easy to understand a similar state of things as regards salmon. The very few cases in which it is stated that food has been found in the stomach of clean salmon when in fresh water may be regarded as the exceptions, which justify the contention that salmon and trout cease feeding when about to spawn. 


\section{Other Theories}

Those who hold that salmon feed when in fresh water account for the accepted emptiness of their stomachs as being due either to the immediate assimilation of the food they swallow, owing to the powerful action of their gastric juices, or else to the assumption that salmon vomit forth the contents of their stomachs directly they are hooked or netted, and before being handled. This school of thinkers admit, however, that the appetites of the fish are less when in fresh water than in salt, and that food is but seldom found in the stomachs of salmon save when they are taken in salt water. If the appetites of salmon are stronger in the sea, and if food is partaken of in greater quantities than when in fresh water, it follows that the gastric juice should, when the fish is in salt water, be proportionately more rapid in its action and more powerful in its character, in order to enable the fish to assimilate the greater amount of the food they then take. Only, however, on the reverse assumptionthat in fresh water the gastric juice is increasing instead of diminishing in its power-can the members of this school of belief explain the phenomena in which they believe, while still having to admit, that, those isolated cases in which the gastric juices have had no such rapid solvent effect, are the only evidence advanced by them to prove their contention.

I remember reading the report of a commission on this subject many years ago, which either directly or 
indirectly stated that the functional duty of the coats of the stomach and the intestines ceased after the salmon had left salt water. The report went on to say that the stomach and alimentary canals contracted and diminished in their dimensions.

In order to justify his belief that salmon feed while in fresh water, a contributor to the Fishing Gazette recently advanced the following facts: In the first instance given by this gentleman a salmon of 14 pounds - presumably a fresh-run fish-was killed and taken home, and on being opened was found to contain a rat in his stomach. This rat-which is the evidence that salmon feed in fresh water-must have been swallowed some time before, but it had not, apparently, suffered from the attack of the gastric juices which this writer claims as being so powerful a solvent that "any food that is swallowed is almost immediately assimilated." Neither had it been vomited out, as it should have been if the vomiting theory held by others of his opinion could be accepted as accurate.

In the second instance, he states that a huge kelt was captured in his presence which had in its mouth a partially swallowed $\frac{1}{4}$-pound trout, perfectly fresh and apparently just seized. The head and shoulders had been reduced to a mere pulp, and he considers that the rapid action of the salmon's gastric juices accounted for the pulp-like condition of that portion of the trout even before it reached the stomach of the salmon, for he states that the tail end, from the dorsal fin, was uninjured. The trout in this instance cannot 
be taken as proof that the salmon swallows food, but only that he would like to, and apparently makes the attempt while in fresh water. Now, if the salmon's stomach was in the normal feeding condition this small trout should have been completely swallowed by the huge kelt, even as the rat was swallowed by the small salmon; in which case not the head only, but the whole of the trout would have entered the stomach of the salmon, and would have been reduced to pulp. Salmon have repeatedly been found with full-sized herrings in their stomachs. If they are capable of swallowing full-sized herrings, it is obvious that a huge kelt would have no difficulty at all in swallowing a $\frac{1}{2}$-pound trout. The rat, however, found completely in the stomach was uninjured. These contradictions may be taken as samples of the proofs (sic) and arguments advanced to show that not only do clean salmon eat and swallow food, but that this is the aim and object of their onslaught on all living and moving life in fresh water. Two totally dissimilar results of swallowing, or attempting to swallow, food are advanced to prove this theory, in neither case achieving the desired result.

A fish will often seize another which is too large for it to swallow. A fish so seized enters the throat of its captor head first, and apparently sticks in that position; fish have been at times caught on a lure in these circumstances. The head and shoulders of the smaller fish, when it is removed from the larger one, are either more or less reduced to a pulpy condition, or at least show signs of decomposition, and it 
has always appeared to me to be an open question as to the causes which have produced this condition in the smaller fish. The contributor to the Fishing Gazette mentioned above considers it due to the action of the gastric juices, and if this is so these gastric juices must have been in the throat, and not in the stomach; he ignores the effect of the vomeral bone and teeth, throat pressure, and muscular action, to say nothing of the laceration of the other teeth.

\section{Important Evidence}

While fishing Mr. George Beck's stretch of the Evanger River, Norway, in 1899, Mr. Arthur Wellington Naylor hooked a fresh-run 20-pound salmon forty miles from the sea, and having no lice on it. The triangle of the lure which he had been using was fixed in the upper and lower jaw of the fish, completely closing its mouth. After the fish was gaffed, the tail of a parr 4 inches long, half digested, was seen protruding from its mouth. This happened in July. This evidence is important. The parr had apparently been swallowed, and the fact that no sea-lice were on the salmon argued that the salmon had been some days out of salt water. It is by no means an uncommon thing for salmon to clear forty miles of the lower stretches of a river with sea-lice on them. I myself have killed salmon fifty miles from the sea having sea-lice on them. The deduction which can be made from this fact 
is that this particular salmon had been some little time in fresh water; that either during that time or after it left salt water it had swallowed a parr, which when hooked it had endeavoured to discharge; but, owing to the fact that its jaws were firmly held together by the triangle, the parr could not pass between themaltogether a remarkably strong argument in favour of the assumption that salmon do at times take food, swallow it, and partly digest it, while in fresh water.

\section{ANother View of this Evidence}

On the other hand, it may be argued that all fresh-run salmon do not have lice on them; that owing to a spate on which the salmon may have "run" this parr may have been taken near, if not in, salt water; and that, owing to the entrance of the salmon into fresh water immediately afterwards, the gastric glands of the stomach had begun to cease their work, and consequently the parr was still in an undigested state when the salmon was caught by Mr. Naylor, forty miles from the mouth of the river. In "Fishing," which is a beautifully illustrated work published by Country Life, and edited by Horace C. Hutchinson, Dr. Kingston Barton asserts that " he has conclusively proved that the digestive organs of salmon taken by rod and line, and examined by himself, are in their normal condition." This is undoubtedly most interesting evidence, but there is a very prevalent opinion among fishing men that the intestines, the entrance to and the stomach itself contract, 
and the gastric glands cease gradually to perform their functional duty, when a salmon enters fresh water.

\section{The Gastric Glands of Salmon}

Dr. J. Kingston Barton states definitely that the digestive organs of salmon taken with rod and line, and examined by himself, were "absolutely normal." This from such an authority appears conclusive, in so far as the healthiness and normality of such organs are concerned, but it does not of necessity imply that these organs were active, or inclined to be active; while healthy, their powers might still be in abeyance. If the digestive organs of a hibernating animal were examined, they would undoubtedly be found in a normal condition, as would the digestive organs of Dr. Sacchi during the course of one of his long fasts.

If, indeed, the gastric glands of either the bear or the doctor were actively discharging their contents on to the delicate tissues of an empty stomach, it is certain that the bear would not sleep, and that the doctor would not rest during the fast. The gastric glands may be regarded as the wholesale manufacturer, by chemical process, of easily assimilable food for the retail demand of the digestive organs ; in other words, as the agent in preparing the nutritive portion of the food for conversion into blood. In certain physically or mentally unhealthy conditions of life, the gastric glands will at times discharge gastric juice after the 
stomach has emptied itself, generally causing thereby insomnia and stomachic trouble.

In healthy fresh-run salmon we may assume that the digestive organs, though normal, are merely inoperative. The salmon have ceased to feed, the stomach, etc., becomes empty, and, as a consequence, exhibits a very natural contraction, sufficient to cause a difficulty in receiving food. On this latter and important point many writers seem to agree, while a small minority of fishermen continue to assert that the stomach does receive food, and that the salmon does in reality continue to feed when in fresh water. A feasible suggestion has been advanced by Dr. Barton to account for salmon apparently coming on the feed when in fresh water. He says: "Knowing that the digestive organs are only in abeyance, one can easily understand why a tired and slightly hungry fish will dash at a morsel that simulates some food of its liking."

The italics are mine. Is there any evidence that a salmon is hungry? If there is, I imagine the question would be solved.

This is an ingenious idea, but it is open to criticism. Salmon continue to feed for many days after they have entered a new pool, and that in most cases long after any physical exhaustion, produced by the effort, would have disappeared. It also appears probable that the digestive organs being simply in abeyance, the food swallowed (and it would be if the entrance and to the stomach were in their normal receptive con- 
dition, and not contracted) would be at once attacked by the gastric juices, and be passed on in due course to the intestines. In which case the vigilance of the scientific examiner would frequently be rewarded by discovering food and its products in the stomach and intestines of the salmon. Dr. Barton himself can, however, only give one such instance.

\section{A General View}

Salmon, like trout, may feed prior to and when spawning, and they may or may not at such times swallow food. Their gastric juices may sometimes act with lightning result, then again at others, as in the case of the rat, be inoperative, and they may both feed and swallow during a period when others of their kind cease feeding ; but such isolated cases as are advanced, even if they be considered as proved, should be regarded as exceptions tending to prove a general rule. But that salmon do not feed, in the general sense of the word, prior to or during their spawning operations is, I think, acknowledged by most people, and hence my theory, that their pursuit of fresh-water life may be due to the instinctive desire to preserve their species from future danger, may be worthy of some attention.

\section{ANother Theory}

It may also be a reasonable supposition to imagine that the salmon, whether hungry or not, and whether capable of swallowing or of assimilating any food he 
may seize, may be still influenced by the feeding habits which have been so strongly developed during his visit to salt water, and that, continuing his attack on all moving objects, he unconsciously fulfils a natural duty which tends to the future safety of his young.

As the salmon leaves the salt water, the larger bait he takes would be accounted for by the greater size of the inhabitants of the tidal waters.

\section{Stoning a Pool}

Salmon, like all other fish, mistrust a moving object outside the water, but seem to exhibit a curiosity when smaller objects, such as spinning-bait, stones, moving leaves, flies, etc., enter their pool. Stoning a pool frequently results in the salmon, as fishermen say, "coming on the feed," so long as no one is visible to them on the bank.

The salmon see the air bubbles made by the bait or the stones, feel the vibration of the water, or perchance hear in their own way the noise of the stone falling on the pebbles under water, and, although they may have appeared dull and listless at the time, they frequently become alert and excited, and at once attack the first moving object they see, apparently imbued with an instinctive desire to destroy the possible enemies of their future young, and to whom they may reasonably impute the disturbance in the water. To watch salmon in a pool is an easy matter if the 
right spot is selected, and if the spectator approach with the greatest caution and remain apparently immovable and as much concealed as is possible.

\section{When Entering Fresh Pools}

It has been repeatedly noticed that when salmon are running up a river they display remarkable activity during the first few days after reaching any fresh pool. This cannot be due to an appetite forgotten during the final days of their stay in the lower pool, and resuscitated in response to the exertion of reaching the new water, because the run between these pools has on several occasions been particularly noticed, and it has not been of such a character as to exhaust the fish, and create a temporary demand for food. As a more likely explanation, it may be assumed that their instinctive desire to destroy the possible enemies of their young may be brought into renewed activity by their new surroundings, and when they find that they have demolished the river life in the new pool they will be naturally suspicious as to any fresh moving objects which they see, especially if there has been no alteration in the water, such as a spate, etc. Salmon which have apparently gone off the feed will, when a spate occurs and the water begins to go down, commence to "feed." This, again, can hardly be due to the reaction attendant upon exhaustion, for the salmon have left the more rapid portions of the stream during the spate, and will have been resting 
in the less troubled back-waters of the river. It will most probably be due to the fact that they become aware of the fresh forms of life brought down by the spate, which they feel impelled to destroy, and consequently a spate may for this reason occasion their renewed activity.

\section{The Salmon Fly}

The correct solution of the problem as to the appetite or otherwise of salmon when in fresh water should have a very decided influence on the selection of flies with which they are to be tempted. If it be an appetite which induces the pursuit of the lure, then taste will have to be considered as an important factor, and the fly to be used should be one which, when it is cast in the particular water to be fished, appears in the guise of the most familiar and best-liked food upon which the salmon has most recently been feeding. The great difficulty, however, which will beset the fisherman is that, among the extraordinary variety of lures presented to the salmon, there are but few which can be claimed as favouring the appearance of any wellknown or favourite food of the salmon, and he will, therefore, be obliged to depend on the experience. gained in the particular locality in which he is fishing for the most likely fly to use. If, on the other hand, it may be (as I advance) that destruction is the motive which induces the pursuit of a moving object by the salmon, then the particular colour, size, and shape 
should be selected which will most readily and naturally attract the attention and excite this destructive impulse of the salmon.

It is recognized that certain peculiarities of colour are more favoured by the attention of the salmon in some than in other rivers, although the natural life existing in the different waters is identically the same.

It has occurred to me that this partiality by the salmon for certain colours in certain streams may be due to the different effects produced on the subaqueous appearance of water life by the geological strata of the country affecting the bed and the banks of the river, the natural differences of the foliage and the vegetation through which it passes, and its altitude above the sea.

Cloud and sunshine, clear or thick water, sunlight or shade, reflection or shadow, depths or shallows, forest or open country, rapid or slow current, will all be varied by the above factors, and natural phenomena will, therefore, tend to alter at least the appearance, if not the colour, of the subaqueous life in different waters. Whatever purpose the salmon has in his pursuit of a moving object, it is certain that unless scared by former experience, he will most readily attack the object which has the most natural appearance and movement.

As the ever-varying influences of natural and meteorological phenomena will affect the colour of moving objects, as hunger may not be the reason of 
its attack, and as destruction, from whatever cause it arises, certainly is its result, the colour of the lure appears to be of secondary importance to its having a natural movement and being of a natural size, and the latter factors should therefore, in my opinion, be the basis dominating the appearance of the lure which should be chosen.

Favourite flies on any river are the result of past experience, and should always be tried, especially when fish are "running." "Custom may, however, stale their infinite variety" to fish which have been some time in the river, or in any particular pool, and such lures may become for this reason the least effective, and patterns which are not usually fished on such streams should be tried, and will often be found effective.

\section{Actual Fishing: Non-Rising Fish}

It may occur to the reader that if salmon, while in fresh water, be actuated by an instinctive impulse to destroy all the possible enemies to their future young, they but too frequently display a considerable disinclination to respond to this call, and the lures with which he endeavours to awaken their conscience to this duty, and incidentally to effect their capture, are, as a consequence, disregarded.

There are, however, several circumstances which may explain this apparent lapse of duty on the part of the salmon. In the first place, it is certain that 
salmon are not exempt from the natural laws which affect all living creatures. They require rest, and for this reason alone it is little wonder that they may at times neglect the instincts of hunger or destruction, whichever they may be, though perfectly conscious of the presence of the moving life around them.

In the second place, it can hardly be supposed that they are lacking in the wisdom which teaches the majority of created beings to avoid objects which have occasioned them pain, and which threaten danger.

In the third place, those inhabitants of our rivers and seas comprised in the families which are attacked by salmon, although progressing in a variety of different ways, are yet affected by the natural phenomena of the currents, etc., which they have to encounter, and it is assumable that salmon will naturally avoid meddling with moving objects which do not conform to certain laws of progression through the element in which they travel.

Salmon may be roused from their inactivity at times by disturbing the pools in which they lie. Flies and lures can be altered to colours and varieties which may not recall to the salmon previous unpleasant experiences, and a variety of different casts may be made, which may cause the lures presented by the fisherman to the salmon to assume a more lifelike appearance and progress through the water. It cannot, therefore, be too strongly urged upon him who would be successful that a constant change in the methods of 
fishing any pool may be advisable, and a frequent change of flies when the salmon are not taking well desirable. While dealing with this aspect of salmon fishing it is by no means a bad plan for the fisherman to fish up and across stream if no success can be obtained by the ordinary method, in which case the line must be drawn through the water by reeling in, lifting the rod, or moving the point down-stream. I would go still further, and advise the fisherman to make an occasional cast as with a dry fly. I have hooked salmon on the Test with a May-fly, and I believe my experience is by no means uncommon. Salmon frequently take the March Brown when fished wet, and I believe they would do so were this fly fished dry.

\section{The Record Take of Salmon}

When staying with Mr. Arthur Millington Naylor as a fellow-guest of Mr. George Beck in 1897, and after a hard day's elk shooting in the Namsen Lake country, he told me the following particulars of his record eatch of salmon, which bears directly on the possibility of taking fish when every circumstance seems to be against you, and also on the fact that salmon will "feed" whenever they enter any new stretch of water in their up-stream journey, and that this cannot be claimed as due to that exhaustion which is considered by many fishermen to account for the resuscitation for recuperative reasons of the feeding 
instincts of the salmon, for in this instance the run was only a distance of one mile, and their already decreasing appetites might still have been in existence; but the destructive instinct seems to me to offer an equally feasible explanation of the freedom with which they took the lures.

Mr. Naylor, with Messrs. Hansard and Probyn, had taken the fishing on the Grimersta River, on the island of Lewis, N.B.; but, owing to drought, the salmon could not run to the upper water and the lochs. The river between these lochs and the sea was "vera sma'," while in the sea at the mouth of the river an immense number of salmon had collected; some of them, as could be plainly seen, appeared to be developing some disease on the head and body-fungus-like white patches began to show themselves-while large numbers were found dead at low-tide. It was seen that unless rain came, the chances of the fish "running up " were nil.

It occurred to the party that in order to get the fish to run and to save their lives (sic), that if the channel of the river was deepened as it left Loch Langlabat, the head loch of the river, and situated about nine miles from the sea, and if a dam was made below the first of the four smaller lochs, which was about 100 acres in extent, and within one mile of salt water, a spate could be engineered which would bring the fish up the first loch.

Labourers were obtained, and every one setting to work with a will, the upper channel was deepened and 
the outlet from the lowest lake was checked by a substantial earthwork dam, which, after bringing the water in it to about 1 foot above its former level, was suddenly destroyed, and an artificial spate was created, which went tumbling down the short lower length of the river and into the salt water in which the salmon had been so long waiting, producing an immediate run of shoals of salmon to the lake above, where they remained for some weeks.

It was permissible to fish only one rod per day on the first beat, which included the first loch in which the fish had collected. The total take for the six days at the end of August following this artificial spate were 338 salmon and 71 sea trout, the average weight of the fish being 6 pounds.

On the 23rd of August Mr. Naylor killed thirty-one salmon, on the 27th the rod which fished the loch got thirty-six salmon. On the 28th Mr. Naylor had the record catch, taking fifty-four salmon in nine hours, and Mr. Hansard caught forty-six fish the succeeding day, and the next day again, the 30th, Mr. Naylor killed forty-five salmon, all these wonderful records being made with the fly.

No record was made of the salmon lost or which came "at" the fly during these busy days, and but little wonder can be felt at this, for when a man has an average kill of one salmon to every ten minutes throughout nine hours' fishing he has little time for other matters. The record is in itself a wonderful instance of endurance. 


\section{CHAPTER VIII}

Boards of Conservators and their influence-The double-handed rod-Salmon and trout netting-Salmon fishing-A sagging line-Method of fishing the river-Hauling for salmon-Using a spinning line-Your first salmon-The rise of the salmonGaffing-Necessity of learning how to cast-The position of the salmon reel-Casting.

\section{BoArds of Conservators and their InFLuence}

\section{Netting for Trout and Salmon}

THAт netting for salmon should, in the interests of the rod fisherman, the fish, as well as that of the netting industry, be restricted by extending the weekly close time, will no doubt meet with the approval not only of my readers, but of all those who have the interest of our salmon rivers at heart.

Far too many salmon are taken when entering the lower part of each salmon river, and it is my firm belief that not only the pastime, but the industry itself, is being seriously injured owing to the enormous percentage of the salmon which are annually caught in the nets when entering the river for spawning purposes.

The weekly close time for nets should be lengthened in order to permit a sufficient number of fish to run 
the gauntlet of the net and of the rod fishermen, and to get to their spawning ground. This would, in the first place, give the riparian owner some more proportionate share in the numbers of fish which are attracted to the river, and, in the second place, create a sufficiency of parr to keep the stock of returning fish up to its former numerical value.

The upper water of each salmon river is the golden goose which provides the future supply of salmon, and without which there would be no parr, no smolts, and, in consequence, no return of grilse or salmon. The oldest rights of a salmon river are those which were conferred by Nature on its upper waters ages before netting had been dreamt of. The primitive resident near such waters subsisted on the fish which Nature so lavishly sent to his larder, and had, in consequence, learnt to depend on the fish caught in his own streams for a portion at least of his food; the gradual lessening of this food-supply by the netters has been an evil which, owing to the difficulties of any combined action, the former have been unable to resist, and the greater proportion of fish, which should have enriched their own streams and supplied their wants, have been taken to feed others and provide an industry for a few, who in reality possess no other rights than those which are common to all. The common law of England and Wales gives every person an equal right to fish for salmon in navigable tidal waters, and to the riparian owners alone an equally defined right of fishing in the waters passing through their own lands. 
In no case does it give anyone the right to prevent the natural passage of the salmon up the river, and thus to deprive the riparian owners of their unalienable privilege conferred by the natural run of salmon to their own water.*

There has been a constant conflict between public and private interest in this matter. So early as the Magna Charta all fishing weirs and fixed nets were abolished, except on the sea-coasts. Later on fixed nets were repeatedly declared illegal, and their creation was prohibited by statute in the Salmon Fishing Act of 1861, which forms the basis of the regulations at present in force. Fixed nets were definitely abolished except where legal rights to maintain them could be conclusively proved. It must, therefore, be evident that fixed nets are incompatible with the maintenance of the various rights of fishing under the common law, and it follows that when any net fishing is carried on ruthlessly in narrow rivers, such as the Tyne, during three-quarters of each week, during which time in ordinary weather no salmon succeeds in passing the netters, a very serious wrong is being done to the upper waters. The portion of the river netted may be only one-tenth of the length of the river up which the salmon would run, the number of persons employed in netting only one-hundredth of those who have a natural claim, or who are otherwise personally interested in the rivers-such as the riparian owners, gillies, boatmen, keeper, inn-keepers, etc.-and yet, forsooth, the far

* See Appendix, Salmon $v$. Trout. 
smaller number of individuals thus interested in netting in this small proportionate part of the river are permitted to entirely stop, not only at one point, but throughout the nettable portion of the river, for three-quarters of each week, all the salmon which in the natural order of things would enrich the greater portion of each river. A most important Act-that of 1873-enacts that each Board of Conservators may make the by-laws for the regulation and improvement of fisheries within its own limits.* As there may be many of my readers whose knowledge of the Boards of Conservators, and the laws under which they are elected, is limited, the following synopsis of these laws may be useful :

\section{The Boards of Conservators.}

After "The fishing district" has been settled by the Secretary of State (formerly for the Home Department, then Board of Trade, and now Board of Agriculture and Fisheries), a Board of Conservators is formed, under the Salmon and Trout Fishing Acts of 1865 and 1873 , in the following manner :

A joint committee of three members of each of the County Councils (instead of Quarter Sessions) of the counties comprised in "The fishing district" meet, and settle upon how many members the Board shall consist and the number to be elected by each County Council ; then the County Councils elect their representatives.

* See Appendix, Salmon $v$. Trout. 
In the Wye Board, for instance, three are selected from Montgomery, Cardigan, Brecknock, Radnor, Hereford, Monmouth, and Gloucester, and these twenty-one members constitute the Board.

In addition, there are the ex-officio members, with these qualifications :

1. Anyone who is the owner or occupier of a fishery or fisheries in the fishing district, assessed to the poor rate on a gross estimated rental of $£ 30$ a year, but in no case shall both owner and occupier be entitled to act at the same time.

2. The owner of lands in a fishery district of an annual value of not less than $£ 100$, having a frontage of not less than one mile on one side or half a mile on both sides to any salmon river, having the right to fish, and having paid licence duty during the last preceding fishing season.

The ex-officio member, before he takes his seat at the Board, must make a declaration as to his qualification, and anyone wilfully making any false declaration, or acting before having made such declaration, shall be liable to a penalty not exceeding five pounds.

3. Representatives of a public fishery.

On the Wye Board there are none, and I doubt very much whether there are any in England and Wales.

Note.-The ex-officio members are, as a fact, in a majority, but the difficulty is to get them to attend. The elected members nearly always do so, and, consequently, in many cases, being men indifferent to sport, and 
having no interests in common with the riparian owners or those interested in the welfare of the river and in the continuance of sport, the latter interests are neglected and the river suffers.

- Much good has been done, and far more good would follow if the elected of the County Council on these Boards were in all cases men who were selected because of their knowledge of the subject, and not owing to political considerations, and it would be of considerable value if the ex-officio members could be induced to take a more active part in matters which should concern themselves.

It is for these Boards to move in the matter of the interests confided to them. No local authority could be more useful, no influence so important; and, great as is the good which they have already accomplished, much more remains to be done. Unfortunately, when it comes to voting on such questions as the close time, the appointment of additional bailiffs, the cheapening of licences, the elected members on some of the Boards appear to think more of vote-catching than of the true interests of the salmon and trout rivers which they control. I was told by the late chairman of a well-known Board of Conservators that on one of the Welsh rivers, and one which has been greatly improved of late years, most of the elected members on the Board are dead against having any water-bailiffs at all during the spawning season.

This from those who control the rivers in a country where poaching and illegal fishing flourish seems 
almost incredible; but that it is so, is a fact. As I have shown, the majority is most commonly formed by the elected members, many of which are neither fishermen nor naturalists, but who by their numbers in attending the meetings control the voting of each Board.

Licences should be made dearer, a much more rigid control should be exercised by an increased number of bailiffs, and the close time should be extended. (The influence of the elected members is frequently exerted in the opposite direction.) The result would be better fishing and increased revenues. Netting for trout should be made criminal; the close time for weekly salmon netting should be extended. Every genuine fisherman would benefit from such legislation, whether he be the man with the five-guinea rod or he who cuts his willow and fishes with a worm. The evils caused by the gentleman of the moonlight net,* the limethrower, and the raker-out of spawning fish with sharpened steel implements, should be minimized as much as possible. The wholesale destruction of salmon before they enter fresh water and trout by netting is, in my opinion, a crime which in the long run must prejudicially affect the whole industry. It is for the various Conservancy Boards to justify their existence by a fearless and determined effort to legislate for the future good of the many and for the welfare of the waters they control. $\uparrow$

$$
\begin{aligned}
& \text { * Only too common in Wales. } \\
& \dagger \text { See Appendix, Salmon } v \text {. Trout. }
\end{aligned}
$$




\section{The Double-Handed Rod}

The use of the double-handed trout and salmon rod is nearly always confined to the wet fly method of fishing. The fly or flies are mostly fished across and down stream, and are generally thrown to an angle of about 50 degrees across the direction in which the current is flowing. The flies are sunk below the water, and drift down-stream round towards a point immediately below the fisherman, his object being to make these flies work in such a manner as to be easily seen, and to vary the appearance they present to the fish. It is necessary to keep a straight line between the submerged flies and the point of the rod

\section{Salmon Fishing: A Sagaing Line}

When fishing from the bank it requires careful study and a good deal of skill on the part of the fisherman to prevent the sagging of the line due to the varying currents in the river across which it is cast. If the line has fallen straight in the desired direction, and there should be a tendency of the line to sag downstream after the forward cast, the fish, when in a certain position, may possibly detect the casting line before they see the lure. A short up-stream motion of the point of the rod, immediately after the fly has fallen on the water, will cause an attendant up-stream curve of the line, and if the rod is kept pointing well above the direction of the fly until it has swept down 
into the full force of the current, much will have been done to avoid the objectionable sag and its consequences. A small jigging action of the rod in a slow current is advisable, as the fly sweeps round to a position below the fisherman; but in rapid water and with a very long line it is not of very great use, as this motion is lost before it reaches the fly, and the pressure of the stream prevents the feathers of the fly from opening.

When the river is rapid on one side alone, if the river can be covered with one cast, it is well to fish from that side of the river which possesses the most moderate current, the fly being cast across the slacker water to the side on which the more rapid stream exists.

When a river is rapid in the centre and slow towards the sides, the more directly the line is thrown across the current and into the slacker water on the other side, the greater the sag. When fishing such a stream, if wading is impossible the fisherman should cast his fly well down-stream, in order thus to avoid some portion of the sag. If, however, the river is nearly uniform in its current from bank to bank, a cast can be made at a much wider angle, the line being thrown almost at right angles to the bank, the rod held well up, and but little sag need be anticipated. Wading is to be recommended for the facility with which one can fish a stream to the greatest advantage. It permits the fisherman in most cases to choose his own position for casting; he can, in consequence, generally 
avoid the danger of his line sagging, or having to make his casts from a position which might endanger the safety of his gear. If a river is not wadable, and has a broad, rapid current in the centre, the fisherman should content himself with fishing the rapid water and his side of the stream, casting the fly well over but within the rapid portion of the river, and allowing it to come round into the slacker water towards his own bank.

\section{Method of Fishing the River}

When the fisherman has fished a cast out, and has satisfied himself that no fish is likely to take the fly, he can again cast over the same water, either higher or lower, as he may think necessary. By standing on one spot and gradually increasing the length of the line, a very considerable amount of river can be covered, the shortest length always being used in the first cast. If the line has been fished straight and down-stream, and no fish have been moved after repeated efforts, it is by no means a bad plan to try the same water, but to allow the line to sag. If a slight downward belly of the line be now permitted, it will-at any rate, over a certain portion of the water fished-present the fly to the fish with an altered appearance and a different speed. In heavy water it is advisable to allow the fly to sink as much as possible below the surface, and it is not an uncommon plan to put a shot on the trace above the salmon fly. 
This does not appear to me to be an unfair method of fishing : the object is, of course, merely to bring the fly to the notice of the fish. If the fish be lying well down to the bottom, and the water be thick, a fly coming down the stream near the surface would easily escape their notice. This question of leading a fly is, however, one which is frequently condemned by those who consider that it is opposed to legitimate fly fishing; it suggests to them a relationship to lures forbidden on certain waters. The object, however, of the salmon or trout fisherman is to capture fish by lures which are meant to represent some form of water insect life, and the various flies which are thus used are meant to be presented to the fish. If the fisherman, therefore, chooses the only method of doing this by placing shot on his cast, I sympathize with his effort, and not with these objectors, who are perhaps adopting an attitude having a greater relationship to their own ethics and ideas as to legitimate fishing, than to the absolute merits of the case. Personally, I dislike throwing a line to which shot are attached, but if my fly cannot otherwise reach the notice of the fish I am anxious to capture, I should not hesitate to use shot.

\section{Your First Salmon}

No kill is quite equal to that of the first salmon; no thrill can exceed that which runs from the butt of the fisherman's rod to his brain as he braces his muscles 
to resist the first rush of a fresh-run salmon, or feels the long downward strain on his rod, and hears the screech of the reel as his first fish plunges downstream in its initial rush for safety; no tension is more delightful than the first twenty minutes spent with a clean-run salmon; and no satisfaction, so far as the sport is concerned, can possibly exceed that felt by him as the gleaming silver sides of his first salmon emerge from the water on his gillie's gaff. The vigour of the sport, the grandeur of the scenery, and the revivifying atmosphere of his surroundings, form a tonic to the system far more pleasant and of infinitely greater value than any the pharmacopœia is capable of producing. The struggle between the salmon and the fisherman is more severe, longer, and the result more uncertain than that between the trout and man, and during the time the struggle lasts no one would deny that salmon fishing is infinitely superior to trout fishing. It is during all the other hours of these two sports that the latter may with justice claim precedence, and, day in and day out, there are many who prefer dry fly fishing for trout.

\section{HARLING}

This method of presenting the lure to salmon can best be adopted in large and rapid rivers which are otherwise unfishable. Harling is perhaps the most killing but by no means the most interesting method of presenting the lure to the notice of the salmon, 
the skill, at any rate until the lure be taken, depending on the manipulation of the boat by its two oarsmen. The fisherman sits in the stern of the boat, with his back to the bows. He has generally two rods, one over each quarter of the boat, and with about 30 yards of line out on each. The rods are fixed at right angles to each other, and kept in this position by shoes in the bottom of the boat for the butts and cleats on the gunwale of each quarter for the lower joint of each rod to rest in. A spoon is generally used as a lure on one rod and a fly as lure on the other. The lines are allowed to drift down-stream behind the boat, which, starting at the head of each stretch, and the boatmen pulling slowly against the stream, is permitted to drop very gradually down the river. By the experience and judgment used in keeping the lures at a constant and best possible speed through the water, and moving in sweeping curves from bank to bank of the river across which the boat is being pulled from side to side, the lures are presented to the salmon, etc., in a more or less perfect manner.

The music of the reel and the pull on the rod at once informs the fisherman that he has a fish "on," and he, seizing the rod on which the salmon is hooked with one hand, passes the other rod with the other hand into the ready grasp of the after-boatman, who having already thrown his oar on board, is waiting to receive it. The fisherman then proceeds to play his fish, and while the after-boatman reels up the line on the spare rod, the other keeps the boat going. As 
soon as an opportunity offers the fisherman lands and plays his fish from the bank. The 50-pound salmon mentioned on p. 242 was killed in this manner.

\section{SPINNING FOR SALMON}

In fishing any pool, the speed at which the lure has to be drawn through the water is a matter of considerable importance. The line should be so cast that the lure commences to spin directly it enters the water, and a constant rate of speed should, if possible, be given to it-not too fast and not too slow. If you intend to vary the speed of each cast, it is better to impart the greater spin in the first casts, and gradually reduce this speed.

Don't attempt to cover too much water when casting-cover it, but without pressing. The best results can be obtained only when keeping the muscular action under perfect control. Never expend your last half-ounce of force in any athletic effort; always keep something up your sleeve-in other words, don't press.

The variation of the speed of the lure when fishing a pool is effected in two ways. The first and better way is to keep the rod in its correct up-stream position, and with the lower hand slack out or reel in the line. The second is by moving the rod point. As, however, there must always be one best position for the rod when controlling the speed of the lure-preventing sagging -and while expecting a rise, any movement of the 
rod away from this position must of necessity be inadvisable if the speed of the lure can be otherwise controlled.

\section{The Rise of the Salmon}

Probably the most anxious moments of the salmon fisherman's experience are those which chronicle the rise of the salmon at his fly, and it is well for the beginner to be in all senses ready for this event. During each cast the eye should be alert, the rod pointed at an angle of at least 25 degrees away from the position of the fly, the line clear to the reel, and grasped firmly between the upper hand and the rod. You need not, as in dry fly fishing, strike in order to hook your fish. Except when the fly is stationary or being drawn down-stream, the salmon should be allowed to fix the barb in its own mouth-i.e., to hook himself-before a counter-strain is employed. Following the rise, except in the two cases just quoted, the fisherman should merely brace himself for action and keep perfectly still. If a quick stroke is made as the rise is perceived the fly may be pulled from the still open mouth of the fish, or jerked out before the hook is in a position to enter the flesh. The salmon will, on closing his jaws, if time be given, shift the fly with the tongue toward the teeth preparatory to lacerating it. If the barb of the hook during this action happens to meet the skin either of the tongue or jaws of the fish, the salmon will in most cases be 
hooked. There will always be sufficient pull on the hook itself, owing to the plunge of the fish or the drag of the line, to ensure the barb penetrating directly its point is checked by the skin. The salmon will undoubtedly sooner or later eject the fly unless the barb touches and becomes fixed in his mouth. The drag and resistance of the rod and line will be sufficient to drive it well home. If, therefore, the rod is kept stationary the strain on the fly will be quite sufficient to hook the fish, and should the barb never be in a position to enter the flesh the fly will be rejected by the salmon naturally, instead of being jerked out of the mouth by a strike, which would effectually scare the fish, and maybe prevent its tackling any other flies presented to it later on.

So long as an object be moving, the salmon will invariably attack it with a rush; but should the object be stationary in the water-i.e., floating with the current-he will take it at times as gently as a big trout would take a drifting worm as it enters his favourite and shady pool. In this latter case, directly the first intimation is conveyed to the fisherman that the fly has been touched an immediate and steady pull at the line should be made.

When the strain on the rod proves that the fish is hooked, the point of the rod should be kept steady, and the strain on the line should never be relaxed under any circumstances. Nọt only is this necessary because the fish may be lightly hooked, or hooked on the bone, but also with the idea of exhausting the 
fish, and keeping him away from the dangers of the river, and, finally, in order to bring him out into the most convenient back-water or quiet pool. Keep as much strain on your line as is safe, but do not frighten a salmon down-stream into dangerous water by being rough. If a fish sulks get below him and try a fresh strain on the rod.

\section{GafFing}

Always, if possible, take a gillie or local authority when first fishing a salmon river, and it is most probable, therefore, that when bringing in your first salmon you will have some one with you to gaff your fish; but if not, keep at your fish until you have him beaten. Get into the water, bring your rod up overhead and backward with your left hand, handle straight up, and as you draw your fish in towards you slip the gaff quietly over his back, point sideways, just before the dorsal fin, turn the point right down, and with one strong and determined pull bring the point into his side, and drag the fish to the shore.

Never, never under any circumstances attempt to take your lure from the mouth of the salmon until he has received his most complete quietus-i.e., until the salmon is incapable of motion. Place your rod carefully in some safe position, and, using the lancet in the disgorger of your knife, liberate each hook from the flesh. Keep the mouth of the fish open with the butt of your priest while doing this; then weigh 
your fish, and put the exact weight, time of day, name of lure, the appearance of the fish, and the name of the pool down in your pocket-book. You will remember the rest if necessary when you get home.

\section{Necessity of Learning how to Cast}

The difficulties which are met with on an ordinary river can best be overcome when your methods of casting are perfect. It is therefore of the greatest importance not only to know how to cast, but how to cast in every style. Bearing this in mind, the reader may, I hope, be induced to devote a little time to the following attempts to describe the various casts as used by myself. There can be no question as to the difficulty of attempting to write on such a subject, but it must be done, and if a little patient attention can be devoted to the matter it will, I hope, repay the effort.

When actually fishing the adaptation of any perfectly learnt method in order to overcome a difficulty is a far more simple matter than trying to create an entirely new method in order to surmount any such difficulty. The object of all casting is to get your fly to alight in some desired and definite place. To be able to do this to the best advantage the line must first be more or less extended, as far as the tip of the rod is concerned, in the opposite quarter. The smallest curve of the line behind a vertical rod will, however, suffice for a forward cast (see Plates XXV. and XXVI.). 
Natural dangers, such as trees, bushes, cliffs, etc., and artificial difficulties, such as telegraph-poles, barbed wire, etc., will prevent at times not only the overhead cast from being performed, but also nearly every variation of the curved cast. Yet there will always be one variation at least which can be adopted in order to bring your line sufficiently back to be easily and accurately cast forward. The more completely the line can be thus brought back, the better the result in the forward cast. There is no place from which a fisherman cannot cast his line so long as he can bring his rod either upright or back sideways - at least so far as the edge of the water by which he stands, and so that, between his rod and the object, a clear path is open for his line in its forward movement.

The axioms and principles of casting with a twohanded rod are identical with those which I have dealt with under the head of "Trout Fly Casting," the difference between the two being that, instead of the elbow acting as the pivot of the backward and forward cast, as in the single-handed rod, the pivot of the double-handed rod is situated at a point midway between the two hands, and so long as this point of the rod is maintained as the pivot, the hands can be relatively raised or lowered in any direction in the plane or curve taken by the rod in the various casts to which I shall allude (see Diagram 14). 


\section{The Position of the Salmon Reel}

In salmon fly casting, if the fisherman uses most commonly the right-hand cast-that is, the cast in which the right hand is uppermost- the rod is brought back over the right shoulder, the handle of his reel should be facing the left hand, for he can then most readily use it without shifting his right or upper hand. The butt of the rod rests either in the belt socket or against the body, while the left hand easily controls the line and reel. If the left-hand cast is generally used, the handle of the reel should face toward the right. If both right and left hand casts are equally employed in casting, then the position of the handle of the reel may be left to individual choice.

\section{Casting}

By the term "cast" I include all the movements made by the single or double handed rod in lifting the fly from one place and casting it to the same or any other desired position on the water. Every variety of cast may, for convenience, be grouped under two heads. The first may be called the straight method, and the second the straight and curved method.

In the former the rod and line travel in the same plane, with a distinct forward and backward movement. In the latter the rod and line combine the forward and backward actions in one continuous movement, 
made in one or more planes, and invariably connected with some curved motion of the rod.

The first method is easily described and drawn, as the casts are invariably made in one plane. The great difficulty, however, of drawing diagrams relating to any curved casts is that these casts have to be made in one or more planes, which are connected by curves, while the artist has only one plane on which to show these various movements, and for that reason the latter are diagrammatically somewhat more difficult to explain. The casts which may be grouped under the straight variations include the overhead cast, with extended back movement of the line, the side cast, the Galway cast, and the wind cast.

The casts which may be grouped under the straight and curved are the overhead cast, as made in the method described in the pages immediately following, and all the varieties of the loop cast (see Plate XXXIV.), a common form of which is known as the "Spey"; any alteration of a cast from one quarter to another in a single continuous movement; and any cast in which a danger has to be avoided within the radius of the backward straight cast. 


\section{CHAPTER IX}

The right-hand overhead cast-The left-hand overhead castShooting the line-Casting a salmon fly when wading from the bank-Changing the direction of the cast-The left-hand cast to the right-The right-hand cast to the left-The Galway cast-The right-hand side-cast-The left-hand side-castCurved casts - The loop cast-The Spey throw-The author's variation of the Wye cast-The use of a variation of the Wye cast-Diagrammatic illustration of this cast-A 50-pound salmon-A few additional maxims for fishermen.

\section{The Right-Hand Overhead Cast-Two- HANDED RoD}

We will assume that the student is practising either on a lawn or over water, and that his object is to learn how to cast his fly towards any definite mark. In order to make the backward cast, the first position of the body should be as shown in Plate XXVIII. The right foot should point towards the object, the weight of the body being evenly distributed between the two feet, the right shoulder advanced, and the reel being about midway between the two hands. In the preliminary practice the upper hand should, when holding the rod, enclose the line above the reel, the thumbs should be extended along the rod, and the 



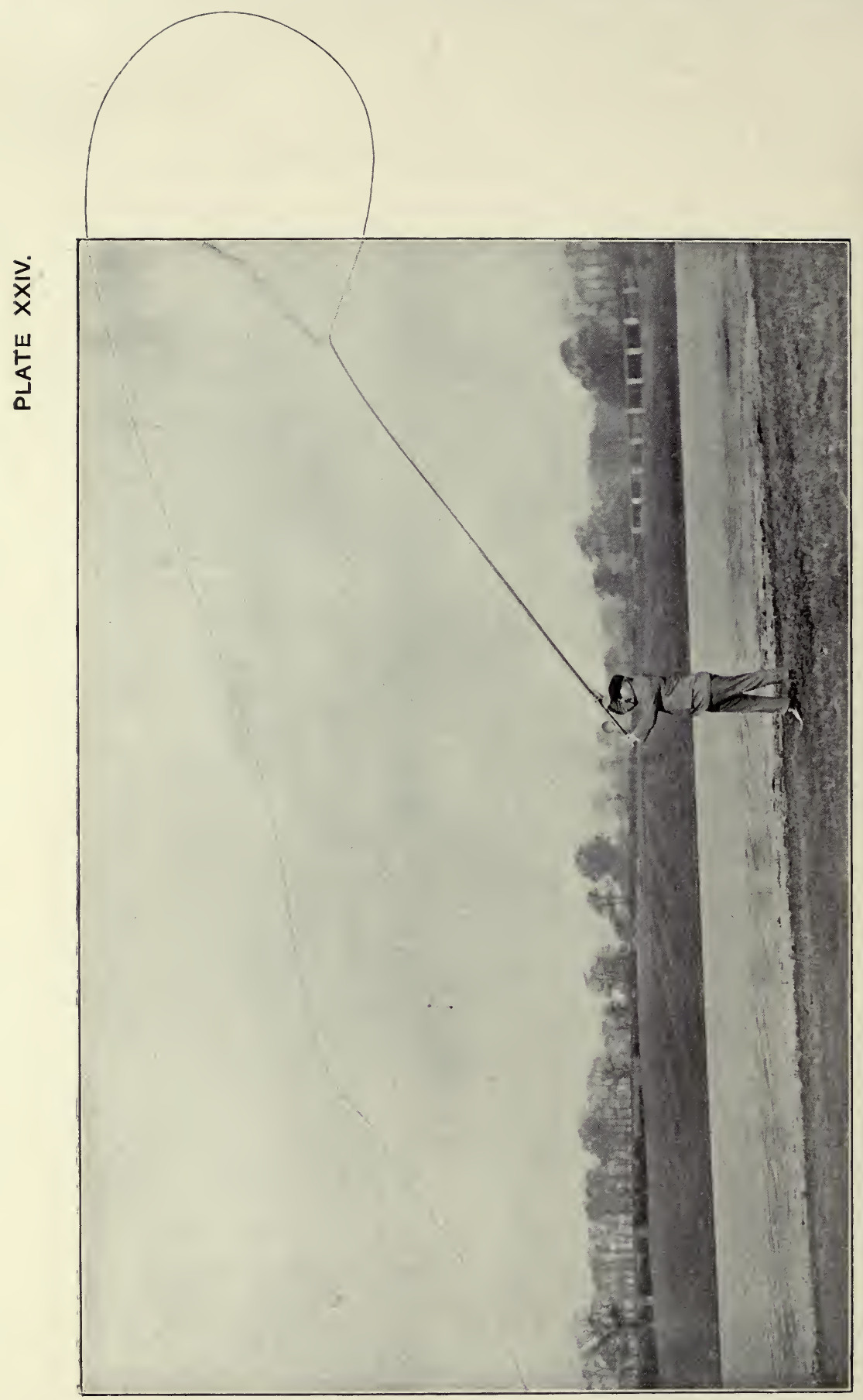

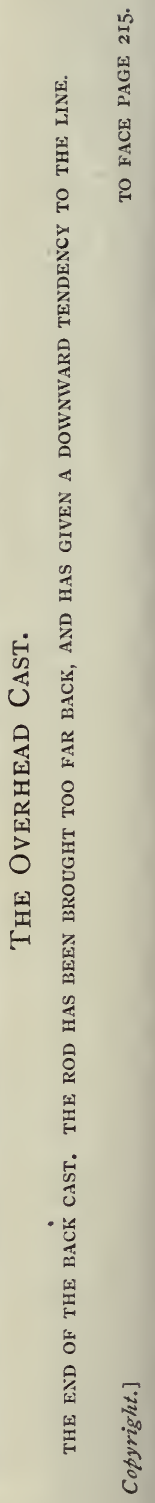


line should run out in a straight line in front of the student.

If the left foot is foremost, the back cast can perhaps be as easily made, but it is against the experience of every sport, and it most certainly detracts from the command over the forward cast. The right hand dominates the cast, therefore the right side and right foot should be in such a position as will give the greatest power and assistance to the right-hand forward impulse.

The object is not to throw the fly as high into the air as possible, but to a point opposite to that at which it has to alight.

Assuming that this practice is taking place downstream on running water, the point of the rod should be lowered well towards the water prior to making the back stroke; the current will then take out all the slack line, and as the rod is steadily raised to an angle of about 50 degrees the line will rise well to the surface of the water (see Diagram 14, Fig. B). The backward action for the salmon rod is then precisely similar to that used in the backward action of the trout rod, the force applied to the line being a pull which increases in strength as the rod goes back, culminating as the butt of the rod passes the vertical, the reel being the pivot of the backward action of the salmon rod, instead of the elbow (see Diagram 14). The rod should come to a sudden stop at an angle of about 35 degrees behind the right shoulder (see Plate XXIV.). The line is here shown as curling back, 
but the whole curve is unfortunately not included in the plate, as it would perhaps have shown more clearly the result of a slight fault in the back cast. In this photograph I have brought the rod too far behind the shoulder, to an angle of nearly 50 degrees instead of

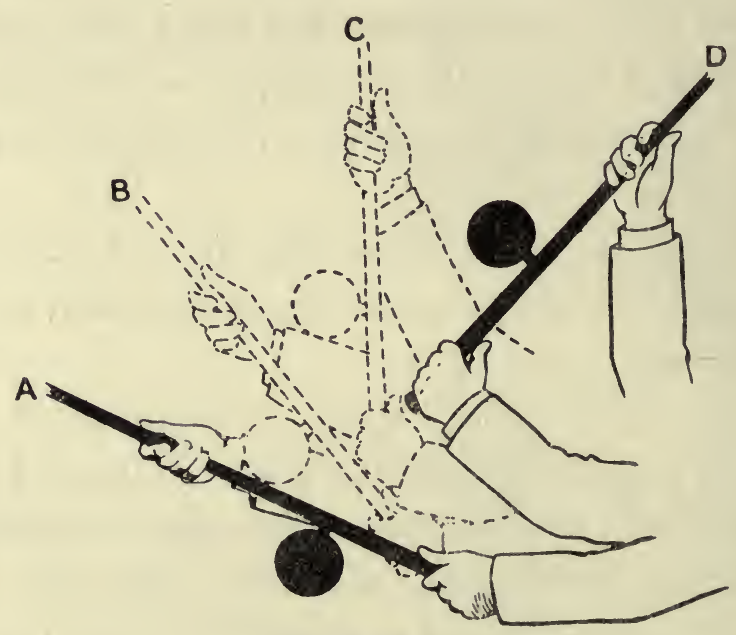

Diagram 14.

Figures A, B, C, and D show the movements of the arms and rod in the backward cast.

$A$, the general elevation of the rod when fishing.

$\mathrm{B}$, the angle to which the rod has to be raised.

B, C, D, the switch of the rod in its backward action.

$\mathrm{D}$, the angle at which the rod pauses before commencing the forward stroke.

35 degrees, and the line has in consequence contracted a downward tendency of the lower part of the loop in its backward progress, this fault affecting the line in the forward cast which follows it (see Plate XXV.), the line being too low in its forward movement. This 


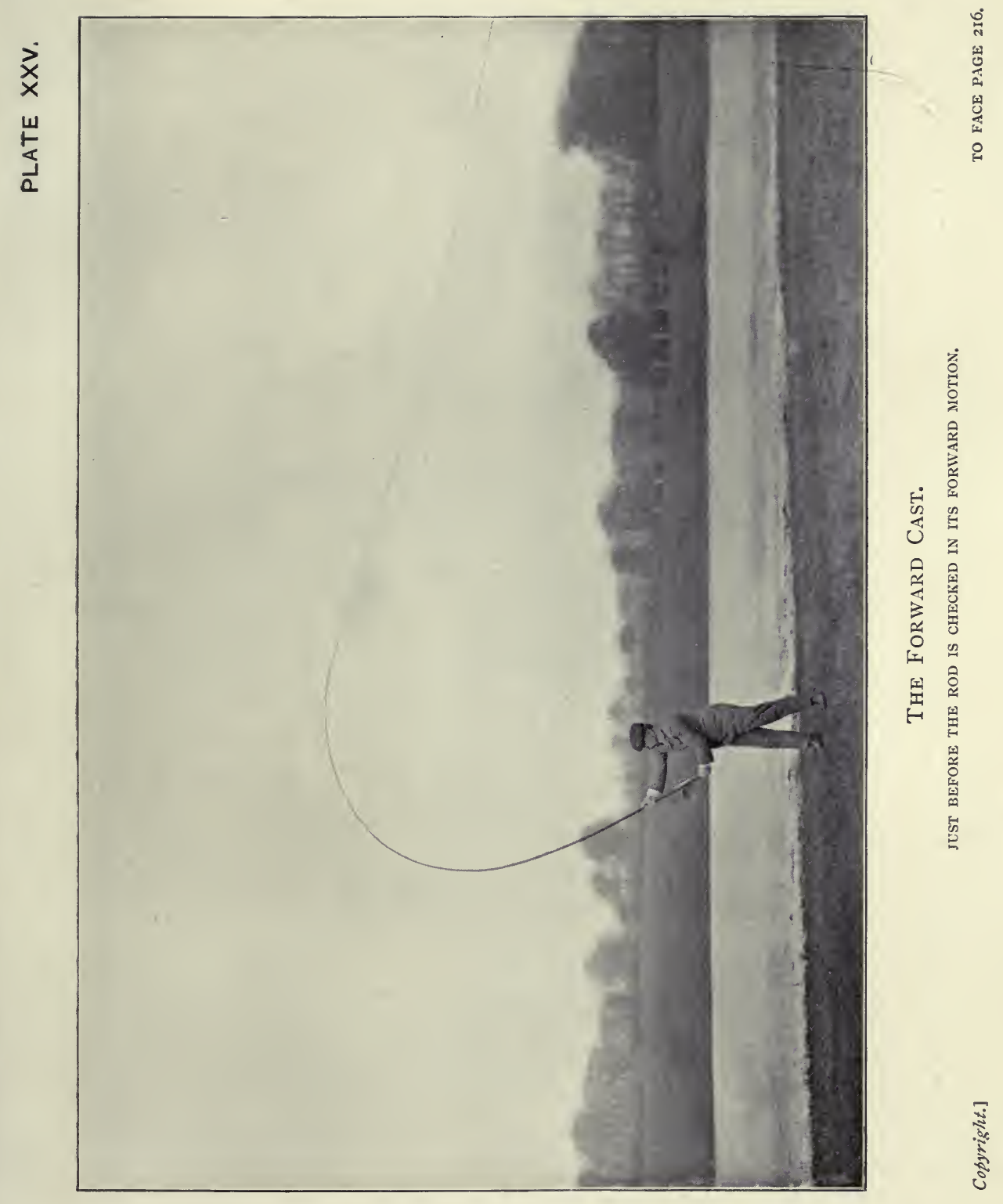



fault is continued to the final position of the forward cast (see Plate XXVI.). For a correct position of the arms, hands, and rod at the conclusion of the back cast, see Plate XXIV.

It is advisable during the back stroke to raise both hands, the left hand being brought nearly to the level of the chin at the end of the stroke (see Diagram 14, Fig. D). The power is obtained by an elbow action of each arm, the right hand being brought backward and the elbow bent out, and the left hand thrust forward, the shoulders being squared as this movement is effected.

If anything, the forward action of the lower hand should be used with greater force in the backward stroke of the rod than should the upper hand. The lower hand should not be extended to the full length of the arm, but should be brought to a sudden stop ere this be reached, and the upper hand should be lifted well up and be stopped before it reaches the perpendicular line of the shoulder. In the same way the forward action of the upper hand in the forward stroke should be checked when the angle of the rod is within 40 degrees of the horizon, and the lower hand brought back to its original position (see Plate XXVI.) close to the body. By this action the imaginary clay fixed to the top of the rod would be jerked alternately backward and forward, and a perfect action of the line will be obtained.

The rod is checked at the end of the cast with a jerk, and the line will then curl backward over the top of 
the rod. A pause is necessary to allow the line sufficient time to extend itself behind the fisherman, at the end of which pause the forward cast should be made, the right shoulder being advanced, the right arm extended (see Plate XXIV.), and the left hand lowered and brought into the body as the stroke is made, the left arm, with the elbow out, being then close to the side. The angle at which the rod should be checked in the forward cast varies, the thrash down being extended further when a head wind has to be encountered. The rod should, as the line shoots forward, be lowered (see Plate XXVI.).

\section{The Left-Hand Overhead Cast}

In this cast the left hand should be above, with the thumb pointing up the rod, and the right hand below, the left foot and shoulder pointed forward, and the action of the rod and the motion of the arms being similar to the right-handed cast, the hands merely changing their places on the rod. The lower hand in both of these casts should control the backward action of the rod, and care must be taken not to permit the right hand to travel behind the shoulder (see Plate XXIV.). The hand here is too far behind. I think until the correct backward and forward motion of the rod has become a matter of habit, a great assistance in order to obtain the correct rod action is to think of my suggestion made under the head of "Trout Fly Casting," 


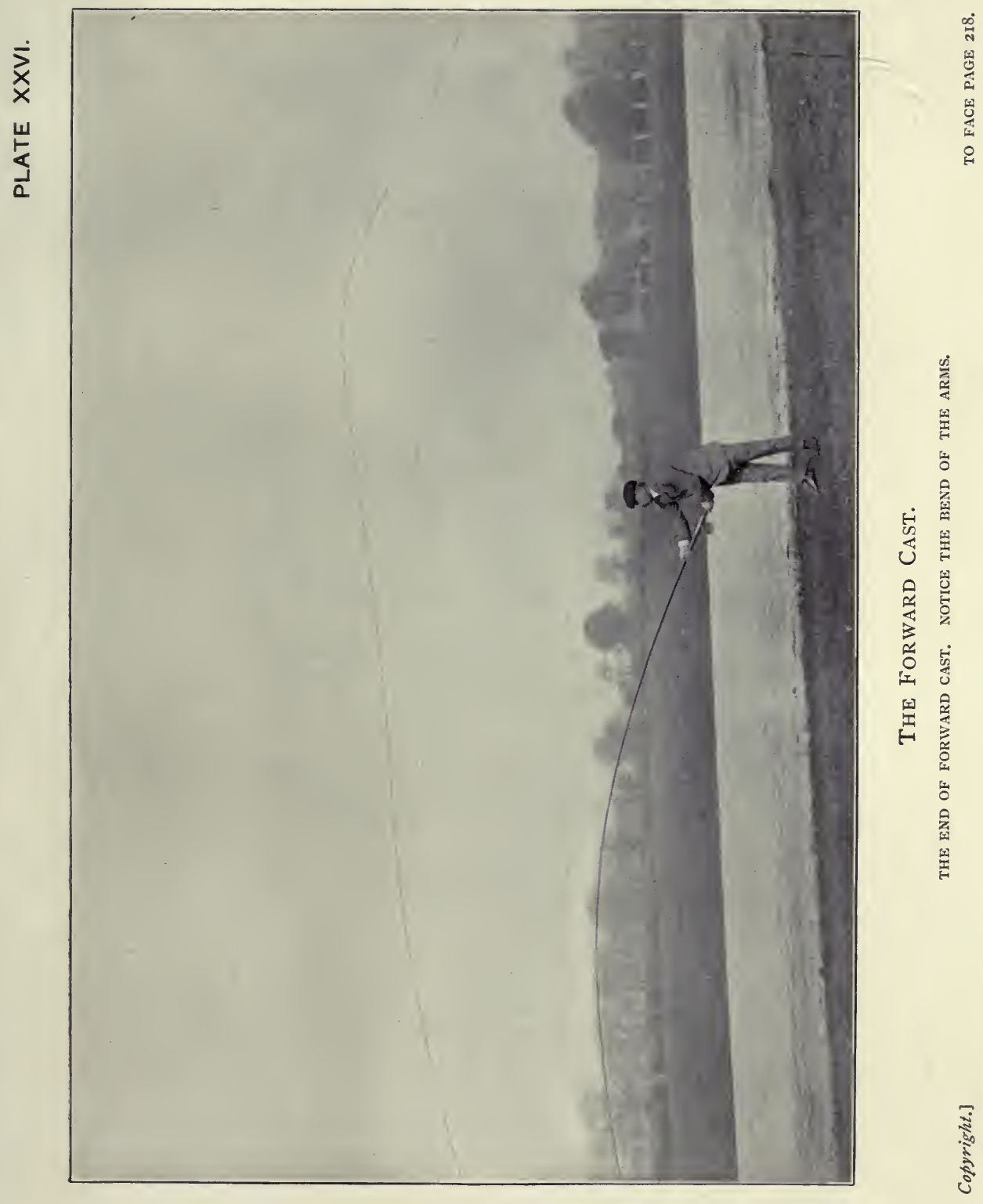



as to there being a portion of clay pressed on to the tip of the rod, which has to be jerked forward or backward off the rod in a horizontal direction. The greater the force of the wind against the fisherman the more forward should be the impulse, and the greater the effort which must be made. The jerk is in reality the sudden stopping of the forward motion of the rod at the moment of its greatest tension (see Plate XXV.). The rod must never be jerked at the commencement of any stroke, but drawn, the force gradually increasing up to the final effort; the rod must then be suddenly checked but not stopped. The hand or hands must always tightly grasp the handle at the conclusion of each of the backward and forward motions. This grasp will of necessity produce a rigid wrist, and should therefore assist the sudden check which is so important. When a correct action is obtained the beginner will find that at the conclusion of this forward impulse the line will shoot forward and cause a certain length, which can be held in the fingers of the lower hand, to shoot through the rings and lengthen the forward cast. In order to permit this extension, the line should be released, when the rod is brought to a stop in the forward cast, and, if necessary, fed up toward the lower ring with the left hand, the rod resting in the butt-rest in the belt of the fisherman. A most useful article for the fisherman is a leather belt which is provided with a socket, into which the butt of the rod is slipped, the lower hand being then free to manipulate the line or use the reel. 
If, therefore, the backward motion of any cast, whether straight or curved, has been properly made, and if the correct forward motion be then given to the rod, the impetus imparted to the line will be sufficiently great to pull through the rings of the rod from 1 to 3 yards of the slack line between the hand and the reel, provided always that the amount of line which has been lifted from the water in the back cast is well within the limit of the thrower's capability. This is known as "shooting the line." When fishing it secures the following advantages : a greater length in the cast, less exertion to reach the desired spot with the fly, greater accuracy, and a lighter line. The line will only shoot, however, when the correct forward action of the rod is made. If any two men compete one against the other with similar rods and lines, he who can shoot the most line in the forward cast-so far as this forward action alone is concerned-will be the better fly thrower. As with golf, so with the salmon rod : don't press. It is knack and not strength which achieves the best and most accurate casts. Never exert your last pound of strength; keep well within the limit of your power. A correct action is perhaps the most important art in fly casting. At the finish of any cast, if there is any slack line hanging below the upper hand and the winch reel up at once; never have any slack line before the winch when expecting a rise. 
Casting a Salmon Fly when Wading, or from an Open River Bank

When picking up the line and fly from the water to make a fresh cast across and down stream, the rod and body action should be similar to that employed in altering the direction of the cast when using a trout fly rod (see Diagrams 5 and 6 ). If, for instance, the fresh cast has to be made to the right of the position from which the line has been picked up, a left-hand swing of the rod behind the body should be adopted, and the line returned vertically (see Diagram 5). If, on the other hand, the fly has to be cast to a position to the left of that in which it was picked off the water, a right-hand sweep of the rod behind the body should be made, and the rod and line brought over the head vertically forward to the desired spot (see Diagram 6).

\section{To make this Left-Hand Cast to the Right,} the body should be facing down-stream towards the position of the submerged fly, and the rod held at an angle of about 25 degrees above the water, left hand up. The first object is, so long as the banks are open and no dangers about, to get the line more or less extended in a curve to the opposite quarter to which it has to be cast, and the better way to effect this is by a circular backward swing of the rod to the left, the body at the same time turning so as to face the spot at which the fly has to alight. The circular back 
movement of the rod, which is similar to that made by the trout rod (see p. 53), should be continued as the body turns, the rod rising upward behind the fisherman to an angle of about 30 degrees from the perpendicular (see Diagram 14, Fig. D), when the forward cast should be made in the ordinary way. The two points to be specially noticed in making this cast are-first, that the whole movement of the rod must be a continuous one, and, secondly, that the body movement must be made in sufficient time to ensure that when the rod reaches the position shown in Plate XXXI. the forward cast can then be immediately made.

To make the Right-Hand Cast to the Left

To make the right-hand cast (see Diagram 6) the rod, right hand up, should be brought back to the right, and as this movement is being made, the body should swing round to the left to face the direction in which the fly has to be cast. The circular side sweep of the rod should be continued as before in a gradually ascending spiral until the rod is pointing immediately behind the fisherman, in a similar position to Plate XXXI. The forward cast is then made. The line in both these casts will follow the point of the rod in its side movement, and as the rod is raised upward the line will curl out towards the opposite quarter to that at which the fly has to alight.

The fly can be picked up and returned to the same spot by a similar stroke, when the ordinary back 



\section{PL.ATE XXVII.}

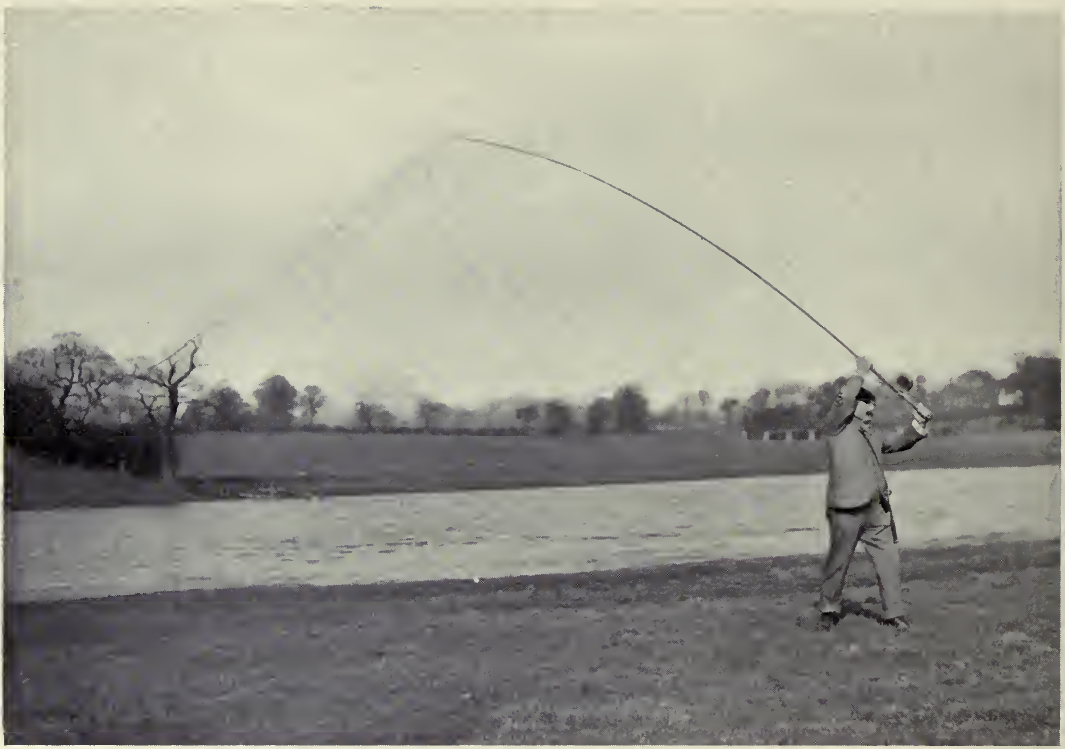

The Galway Cast.

AFTER THE BODY HAS TURNED IN ORDER TO MAKE THE BACK CAST, AND BEFORE THE Copyright.] RIGHT FOOT HAS BEEN BROUGHT FORWARD,

\section{PLATE XXVIII.}

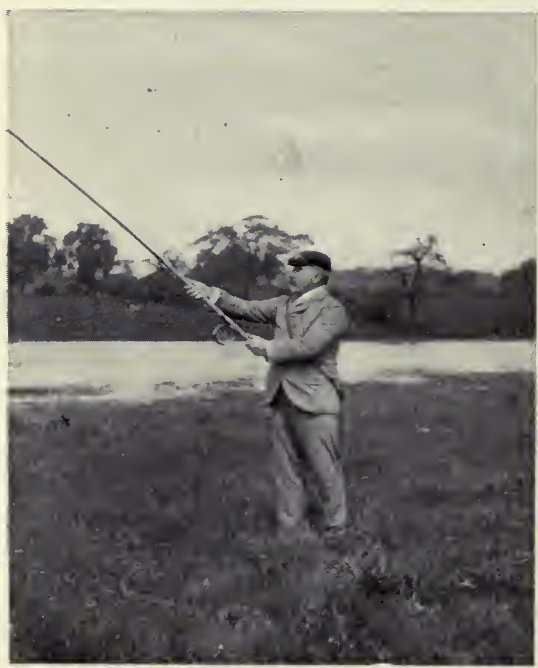

The Galway Cast.

CORRECT ATTITUDE FOR COMMENCEMENT OF THE GALIWAY OR ANY VERTICAL OVERHEAD CAST

Copyright.] BACKIWARD.

THE END OF THE BACK CAST: THE TURNING MOVEMENT FORWARD IS JUST ABOUT TO BE MIADE.

Copyright.]

TO FACE PAGE 223. 
cast would have to be made against the wind ; the body does not have to move, however. When the wind is blowing across the direction in which the fly has to be cast exactly the reverse motion has to be made. The line is brought back overhead, and in a continuous movement the rod is dropped down to the right or left and brought forward again into the eye of the wind. These casts are merely variations of the cast used by Wye fishermen, and, I dare say, common to most rivers in which salmon fly casting is done.

\section{The Galway Cast}

This effective cast can perhaps be best made as follows: The rod is first raised to an angle of about 40 degrees (see Plate XXVIII.); the body is turned completely round to the left (see Plate XXVII.). The hands, arms, and rod-which have been held, as shown in Plate XXVIII., with the thumbs up, knuckles down, right arm straight out, left arm bent, and the reel below the rod-twist half round as the body turns, and as shown in Plate XXVII. During this movement the position and direction of the rod remain almost the same, the point merely rising about 10 degrees in the air, so as to keep in touch with the line; but the thumbs and reel now reverse their position, the reel being on top and the thumbs below, the left arm being more or less extended forward, and the right arm being raised well over the right shoulder, the elbows of both arms altering their position as the body turns 
(see Plate XXVII.). The right foot having been brought forward, the backward cast is made, but with a forward action (see Plate XXIX.). While the line is travelling in the direction to which it has to be extended the body again turns round to the left to its original position, facing the place at which the fly has to alight, the rod's direction, as before, remaining unaltered, and exactly the same alteration of the rod, thumbs, hands, and arms again takes place, and the rod, arms, hands, and reel are as in Fig. 4, Plate XXX. The right foot again swings forward, and as the line will by this time have fully extended itself, the forward cast is made, its finish being as shown in Plate XXVI. The position of the feet should be carefully noticed in Plates XXVII. and XXX., which are those positions assumed immediately before the backward and the forward strokes are made, and before the right foot has been brought forward. In Plates XXVII. and XXX. the feet are shown leaving the ground preparatory to the forward cast being made, the line being seen extended.

The Galway cast is a very pretty one, and is of great use when an opening occurs amid the trees behind the fisherman, and when such trees are within the radius of the back cast of his line and a loop or curved side cast cannot be made. In casting backward in the ordinary overhead manner it is nearly always impossible for the fisherman to guide his line accurately, and were such an attempt made when the open space is small, the backward cast would result in the line and fly hitting the trees instead of being directed 
PLATE $X X X$.

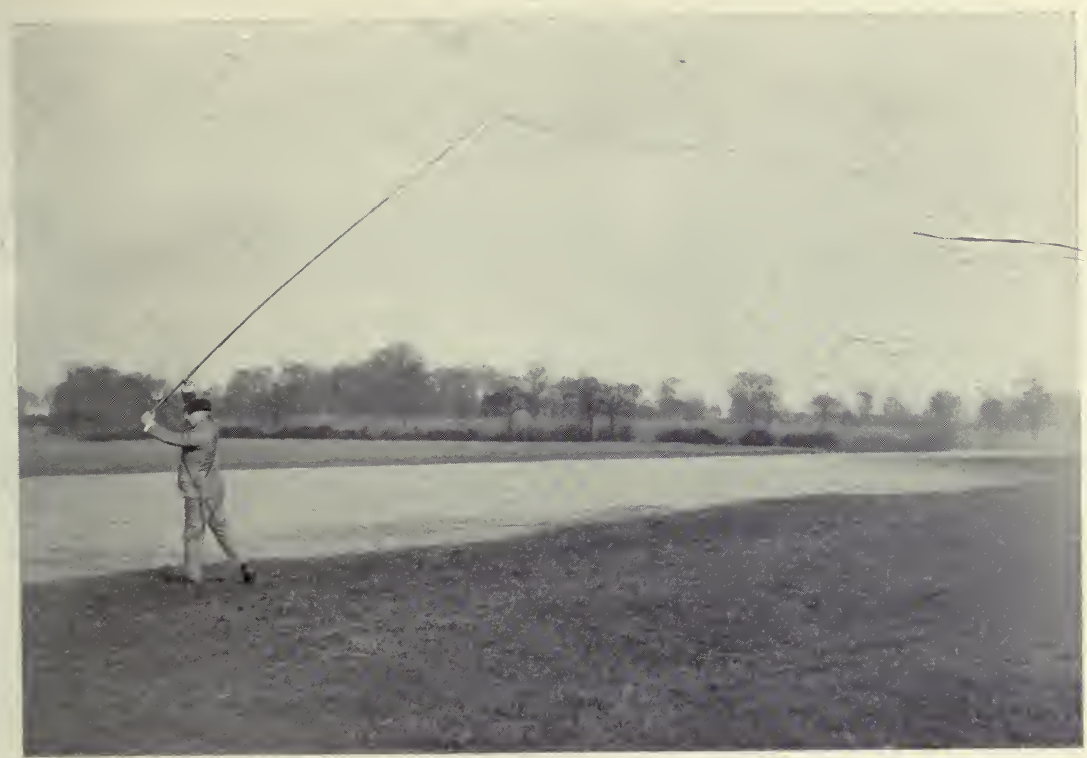

The Galway Cast.

THE BODY HAS NOW TURNED FORWARD AGAIN, BUT THE RIGHT FOOT HAS NOT YET BEEN BROUGHT FORWARD.

Copyright.]

\section{PLATE XXXI.}

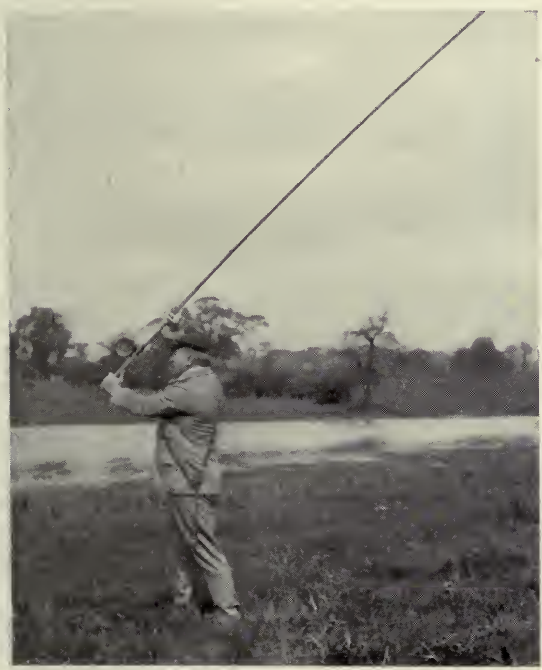

FORWARD CAST.

CORRECT ATTITUDE IN GALWAY OR ANY VERTICAL OVERHEAD FORWARD CAST.

\section{Copyright.]}

PLATE XXXII.

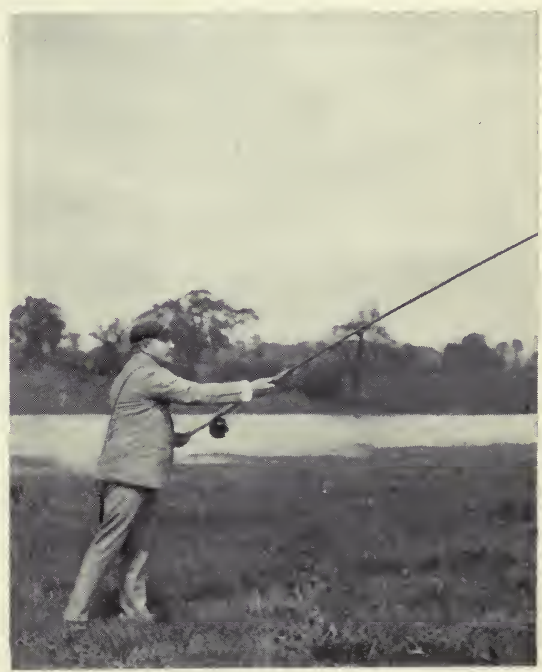

SIDE CAST.

CORRECT ATTITUDE WHEN COMMENCING THIS RIGHT-HAND SIDE CAST. NOTE THE RIGHT FOOT.

Copyright.]

TO FACE PAGE 224. 

safely through them. By turning the body round before the back stroke is made the line can be accurately directed, so as to avoid the danger of striking or being hung up on the branches of the trees on either side of such an opening, and if in the forward cast the turning of the body is correctly timed, the forward cast can be made with great accuracy and perfect security.

\section{The Right-Hand Side Cast of the Two- HaNded Rod}

In order to make the backward stroke in this cast the position should be as in the side cast of the single-handed rod, the right foot pointing at right angles to the direction to which the fly has to be cast. The rod should be lowered well towards the water, and then moved about 40 degrees to the right-hand side, and when this position of the rod is reached (see Plate XXXII.) the body should turn to the right hand, and the side movement of the rod continued backwards to an angle of about 30 degrees behind the direction in which the right foot is pointing, and to an elevation above the horizon of about 40 degrees. The rod action is similar to that used in the side cast for the trout rod (see p. 22). A pause is made in order to allow the line to extend itself, and the fisherman should during this pause turn his body to the spot at which he wishes his fly to alight, the forearms and the rod remaining stationary. The forward cast should then be made. 
The body action must, however, precede that of the rod in the forward cast of the two-handed rod. During the backward cast the point of the rod should rise gradually and evenly to its position behind the body, but in the forward cast the rod should be moved in a more horizontal direction, in order that the line may be able to extend itself before it touches the water; the action of the arms in the side cast, instead of being made in a vertical plane, will be made in the plane in which the rod moves, the pivot, however, being in the same position of the rod as in the overhead cast.

\section{The Left-Hand Side Cast}

Here the position is reversed, the left hand being uppermost, and the body turning to the left instead of to the right. In all respects, however, the action is similar to the right-hand cast. The side cast is useful when the backward or forward stroke has to be made against the wind.

\section{Curved Casts}

If the rod with a short line be held upright, and by a continuous wrist and elbow action moved in a circle horizontally above the head, the line will follow the action of the point of the rod, and circle round in a continuous loop. The greater the force applied, the longer will be the line which can be made to follow 

PLATE XXXIII.

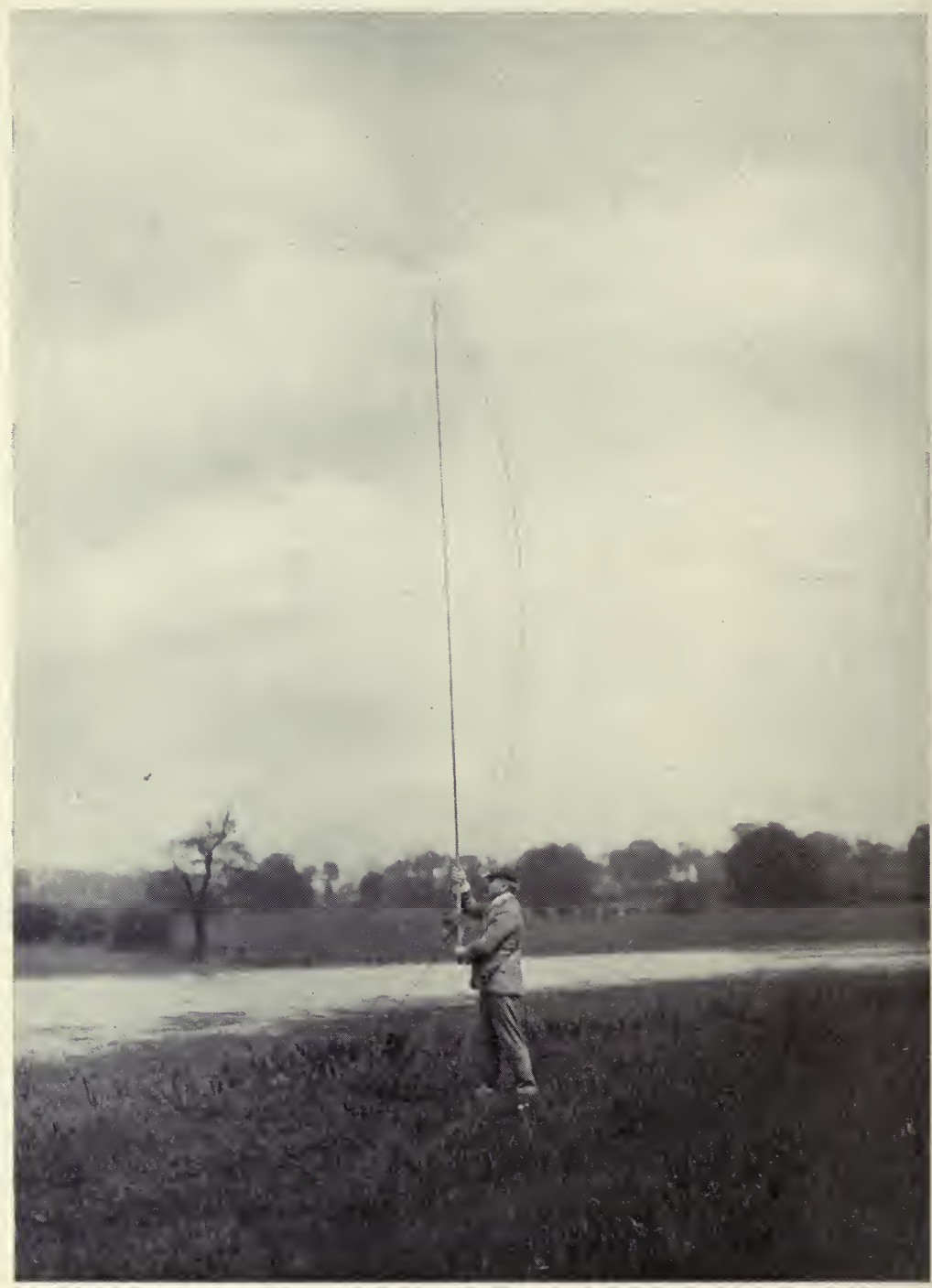

The Vertical LOOP CAST.

COMMENCING THE FORWARD SWITCH. 
the point of the rod in this loop, but directly the downward thrash is applied, the line will at once leave the circular curve in which it has been travelling, and will follow the direction which the point of the rod has taken. There must, however, be no pause in the motion of the rod, the curved action must always be made in a steady swing, which is merged into a direct cast, towards the spot at which the fly has to alight, and to which the body should be turned. It must be evident, therefore, that the alteration to this circular movement should, if possible, be made when the rod has arrived at a position behind the shoulder, and similar to that in Plate XXX. Such a cast would naturally be classed under the second method of casting mentioned on p. 213. It is not, of course, necessary to adopt this elaborate method of making a circle or circles in the air when casting a fly, but it is useful to practise, and to remember that in making all curved casts a portion at least of a complete circle is required, and that after making this particular portion of the circle, whether in a horizontal or vertical plane, the rod should be as much as possible in the position behind the shoulder for making the usual forward overhead cast. The body must, if necessary, have been so moved prior to the forward cast as to be facing the required position. 


\section{The Loop Cast}

The cast which is known as the loop cast is one in which a complete loop should be made with the line, and although the point of the rod does not describe so complete a circle as that taken by the line, yet its whole movement is a circular one which is directly responsible for this result.

If the position in which the fisherman stands with regard to natural or artificial dangers does not permit his rod coming behind the vertical line of his back, either in the side or the overhead casts, the line may still be extended in front of him by making the loop cast. The fisherman must face his extended line as it lies on the water, and if he wishes to cast to the right of this position, the rod, held left hand up, is brought steadily back to a nearly vertical position slightly over the left shoulder, and as the line comes back in a slight curve behind the rod (see Plate XXXIII.) to his left side, well clear of his shoulder, he turns towards the direction in which he has to cast. As the rod attains the vertical position the elbows should be raised, and as the line curves in a loop behind his rod (see Plate XXXIII.) the upward movement should be continued into a circular forward thrash down from the elbows, which are advanced slightly and drawn downwards slightly and backward toward the body as the rod is checked at an angle of about 20 degrees above the horizon. If the cast is properly made, a perfect loop will run along the water, unrolling itself ${ }^{n}$ as it goes, finally extending the 


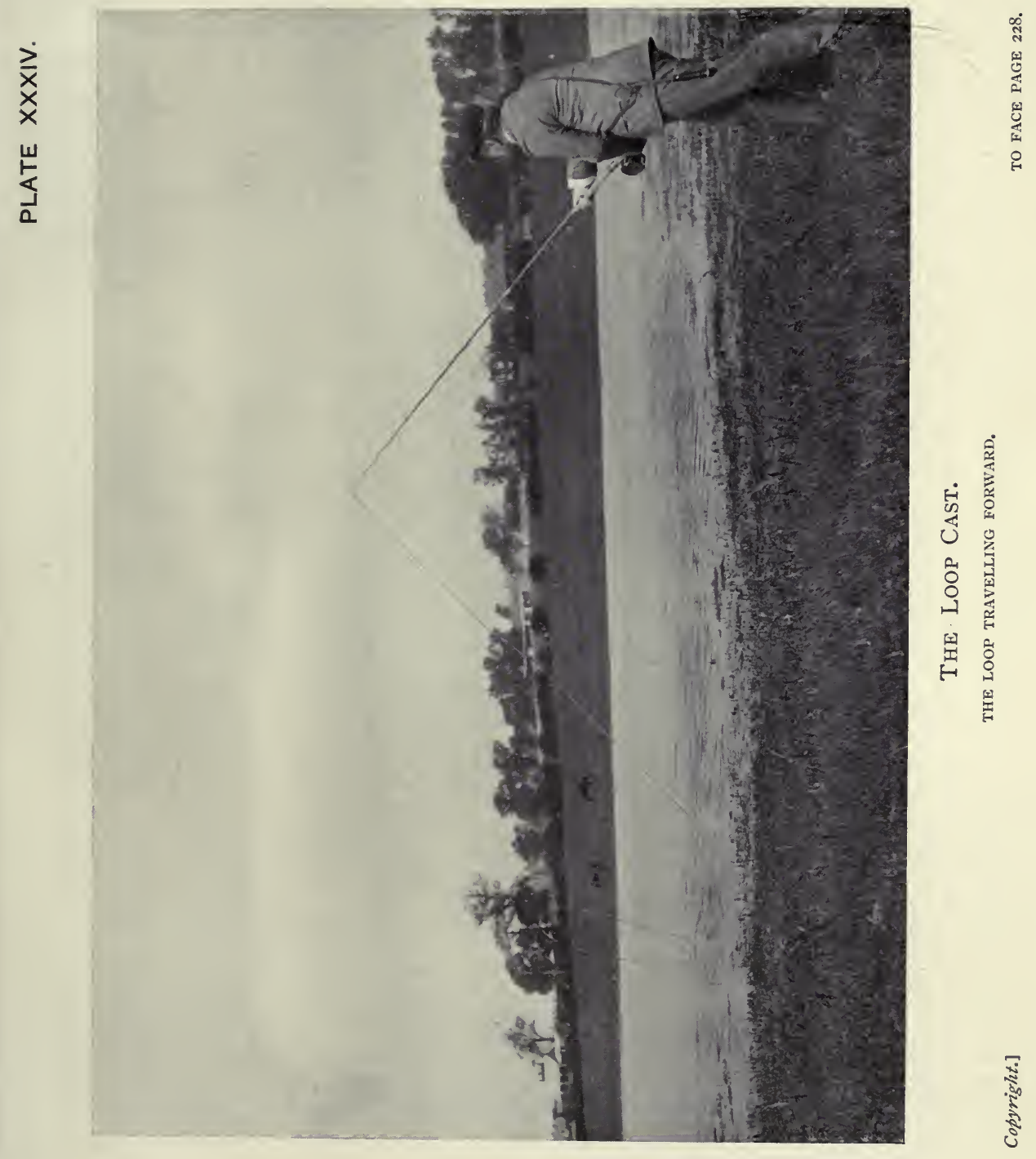



fly at the extreme end of the line (see Plates XXXXIV. and $\mathrm{XXXXV}$.). If he wishes to cast to the left, the rod must be held right hand up, and brought back to the right shoulder, etc.

The motion of the arms is most important, the usual forward motion of the hand being continued, the final effort being made with a circular downward curve; the elbows are slightly lifted and advanced as the forward stroke is made, and at the point when the final effort should have shot the clay off the rod tip, the elbows are brought slightly down and back. It will thus be seen that although the loop is made in very nearly one plane, it in reality comes distinctly under the head of the straight and curved casts, the backward motion being in one plane, but the point of the rod being continued in every respect as a vertical curve in its after movements. Indeed, if this motion were not somewhat in the nature of a circle the forward loop would not be formed.

\section{The Spey Throw}

The river from which this method of throwing the fly takes its name, and on which, from Loch Spey to the Moray Firth, it is principally used, is one of the most noted salmon rivers in the kingdom, and the cast has become famous as much for this reason and on account of its reputed difficulty, as owing to the general acceptation of its merits.

The Spey manner of throwing the fly is as simple in 
method as it is effective in its results. To make this cast in the best orthodox style, one should have the advantage of at least three factors, which are natural to, or artificially used on, the Spey. These are-a rapid river; a long, heavy, spliced rod, having a very pronounced bend backward of the top joint; and a very heavy line; and so long as these three factors exist, the Spey throw simply requires the knack of making a cast which is in itself quite as simple as the overhead one. Its greatest admirers cannot claim that it has the merit of placing a light line on the water, and if the disturbance of the surface of the water by the line be considered a fault, the Spey cast certainly sins in that respect more than any other form of throwing a fly.

If the water is smooth, and if the salmon are shy and alert, warned by previous experiences on the run up, or have been some time in the river, then I would certainly prefer that some other method of casting should precede me in the pools I intended fishing, and whenever I can use the overhead salmon cast, I certainly prefer it to all other methods.

Although its most finished exponents are unanimous in declaring that it is extremely simple to make this cast, yet it is by no means an easy cast to describe, and this is borne out by the difficulty which seems to have been experienced by writers when endeavouring to describe the modus operandi of those who use it. It is probably owing to the common principle forming the basis of the cast that the many variations adopted have been claimed as being the Spey cast. The Spey 


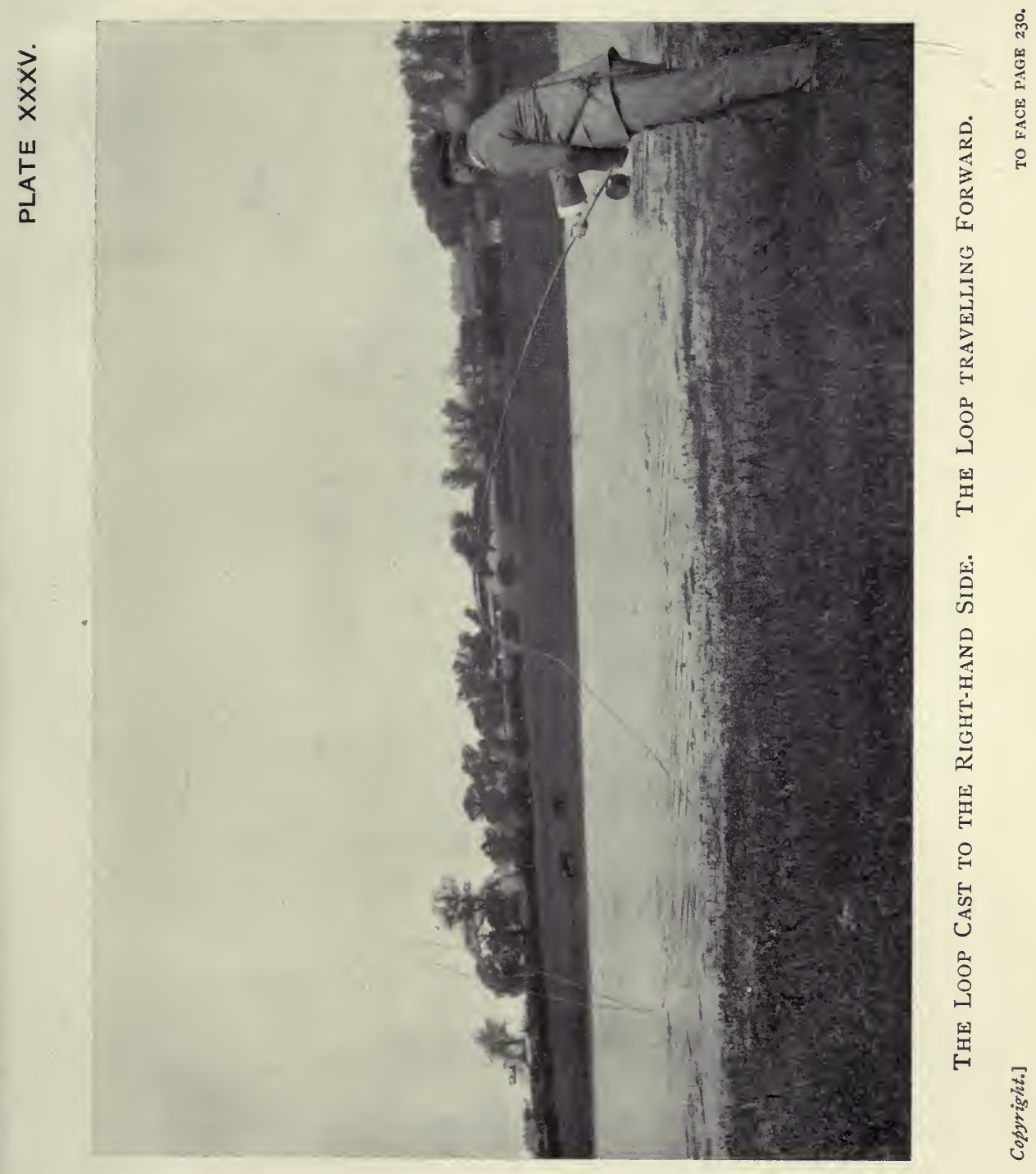



cast is, after all, but a variation of the perfect form of the loop cast, which I have already described, and which latter can be successfully made with any rod and line, and on any water, but in using which cast it is an impossibility to shoot the line.

Under the heading "The Loop Cast," I showed how a line could be extended in a forward movement when dangers existed to either side and behind the fisherman. The rod was raised vertically, and when a slight curve had been allowed to form behind the rod (see Plate XXXIII.) the rod was brought forward, and a perfect loop of the line (see Plate XXXV.) was sent out, picking up the line from the water as it unrolled itself on the surface; and finally extending the fly at the extremity of the cast. It is precisely by means of a similar impulse made more or less to the side that the orthodox Spey cast is made. The rod is not, however, brought back vertically over the head, but after being raised sufficiently high to clear the greater part of the line from the water, it is swung well backward to the right or left side, and returned forward toward the desired spot in one continuous action (see Plate XXXVI.).

As in the loop cast, the object is not to extend the fly behind the fisherman, or to take it off the water, that is, until it is lifted by the forward travelling loop. Hence the rod must not impart too much impetus to the backward movement, just sufficient to lift the line well to the surface of the water, and to bring back enough line to either side of the fisherman, to ensure 
that when the forward thrash of the rod is made, a sufficient belly of the line will exist to carry enough impetus to pick up in its forward curl all the line lying on or in the water.

The strength put into the backward sweep depends on the length of the rod, the length and weight of the line, and the amount of loop which is going to be permitted to extend itself behind the fisherman.

The motion of the rod in the Spey throw may be described as a continuous underhand up-stream sweep of the rod to either side, which is more or less quickly and forcibly returned in a higher plane either as a side or vertical forward cast. The body, prior to the forward thrash, should be turned to face the direction in which the fly will have to go.

In making the Spey cast, every consideration has to be given to the surrounding circumstances, and to the position of the fisherman, whether he be wading, standing on a low clear spit of land, or fishing from a broken and rough bank, and hedged in behind with various dangers. The action of the rod must in any case be continuous, and while it is most frequently returned somewhat as in the side stroke, and without raising the upper arm above the shoulder (see Plate XXXVI.), yet it can with advantage be brought upward and forward over the shoulder as in the overhead cast.

In either case, the object is to send the line forward without permitting it to extend itself backward, and the rod in the forward action, when coming abreast of the fisherman with a gradually increasing motion, 


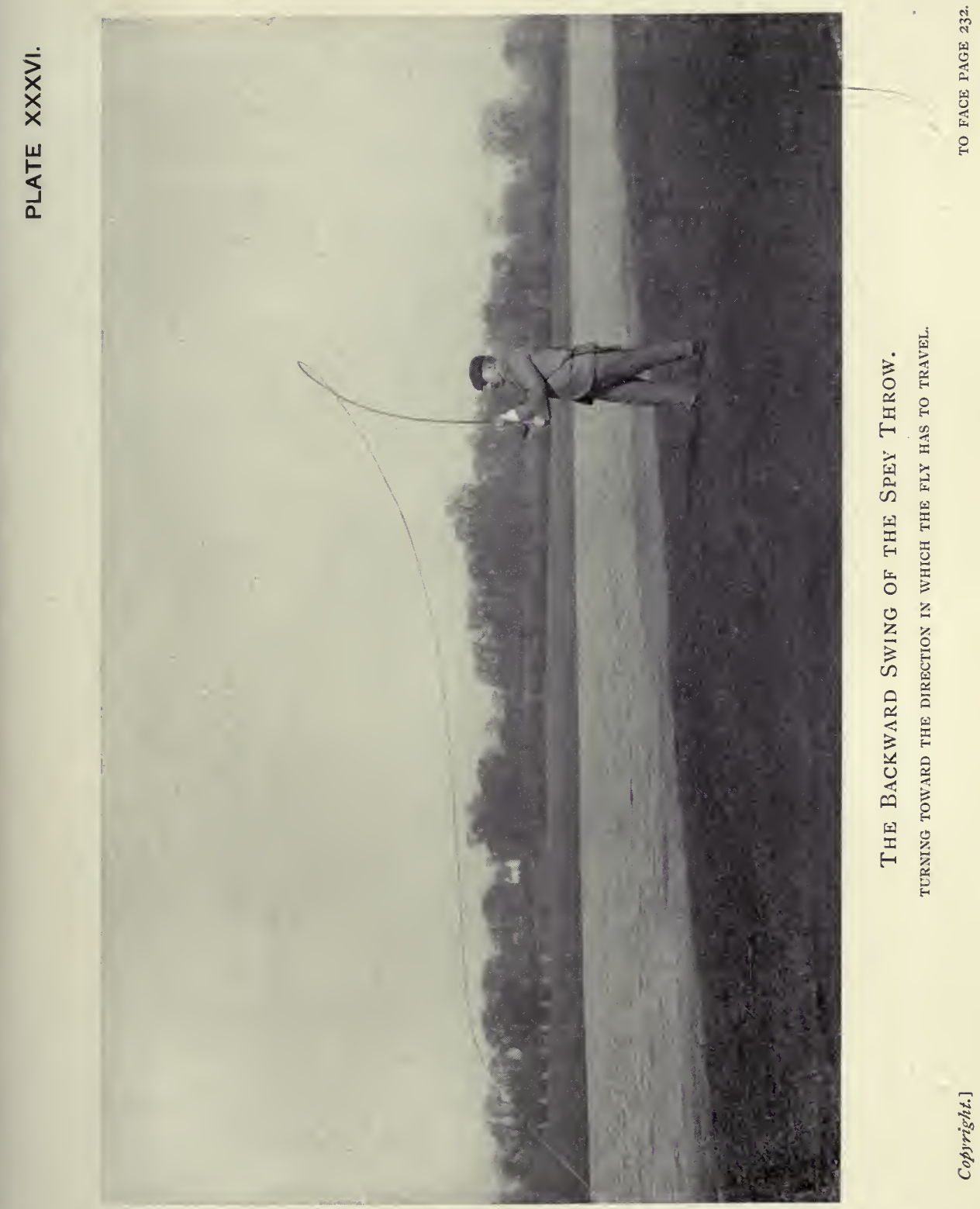



must be receiving the full force of the forward effort. The effect of this impulse will cause the line to curl forward either on or over the water in a more or less continuous loop, and the distance at which this loop can be forced to pick up the line will depend on the strength and ability of the thrower, the weight of the rod and line, the action of the rod, the perfection of the forward motion, and the relative manner in which the end portion of the line and cast is resting on the water. It will depend on the position of the rod at the moment the forward impulse terminates as to how much of the line will loop forward in the air or on the water. On the Spey, fishermen prefer to allow the most, if not the whole, of their line to drop on the water before the fly alights. This forward and downward tendency of the belly of the line is caused by the forward impulse of the rod being carried down towards the water.

There are certain places in most of the salmon rivers where the Spey cast, or a variation thereof, is an easy means of surmounting the difficulties with which the fisherman is confronted.

\section{The Author's Variation of the Wye Cast}

The following cast, which I have found extremely useful when wading in shallow water, etc., and by which the backward extension of the line can be regulated, comes under the head of curved casts, as will be seen by a reference to Diagram 15. This diagram 
has been divided into four sections, in order to more fully demonstrate the action of the rod (see Diagrams $16,17,18,19)$. The motion of the rod in this method of casting may be described as an underhand circular cast, made in one continuous swing. This style of casting, which I think will be found efficacious and easily acquired, is based on the elements of lessons given

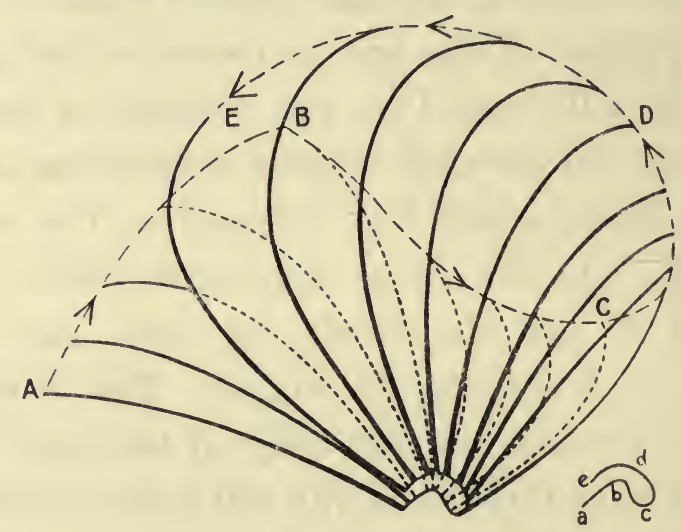

Diagram 15.

$\mathrm{a} b \mathrm{c} d \mathrm{e}$ show the motion of the upper hand.

to me on the Monmouthshire Wye thirty-six years ago, by the late Edwin Ballenger.

The rod in the first place rises upward, more or less in front of the fisherman, to an angle of about 70 degrees above the horizon (see A B, Diagrams 15 and 16); it is then brought down sideways (see B C, Diagrams 15 and 17), and backward, in a right or left hand swing, the rod point following the dotted line, as shown in diagram, being continued upward more or less behind the fisherman (see C D, Diagrams 15 and 18) to an angle of about 
30 degrees from the vertical, and is concluded as in the overhead forward cast, from D to E (see Diagrams 15 and 19), the rod and line moving forward and downward

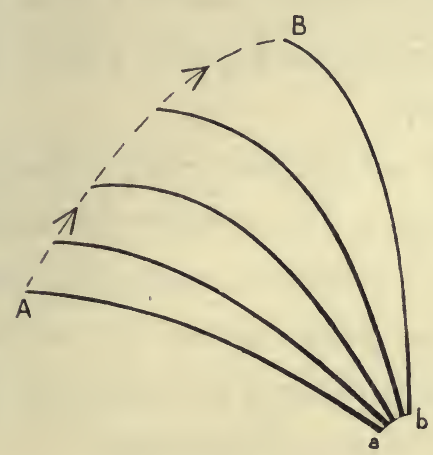

Diagram 16.

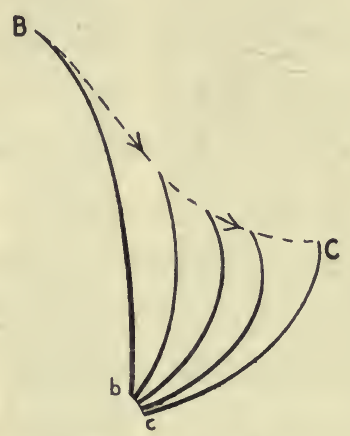

Diagram 17.

in a vertical plane. The body during the downward and upward movement (see B C and C D, Diagrams 15, 17,

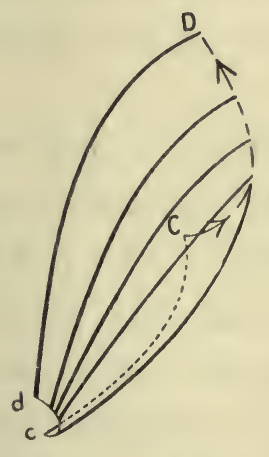

Diagram 18.

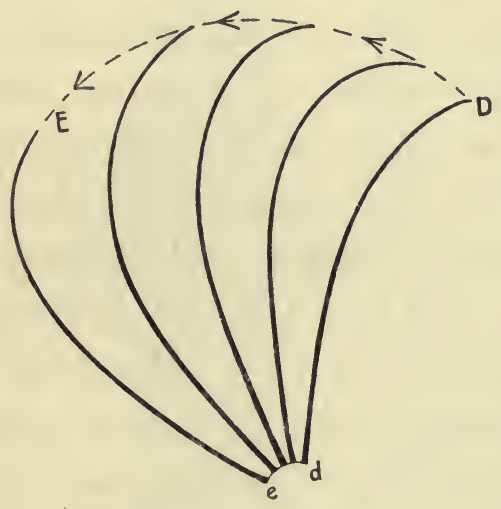

Diagram 19.

and 18) turns toward the spot to which the fly has to be cast. As the rod travels backward and upward in this circular movement, the line forms a more or 
less extended vertical curve behind the fisherman (see Plates XXXVII. and XXXVIII.). The line in its backward passage can be checked by being brought into contact with the water, which contact can be controlled by the force given to and path taken by the rod in the backward sweep.

This cast, when made with a long line and a danger at a short distance behind, must of necessity be made with a rapid upward and forward impulse (see Plate XXXIX.), and this impulse must be carried well forward, causing the line to travel more or less on the surface of the water in its forward progress.

When the bank or other danger is at a more considerable distance away, a more leisurely upward and forward motion may be made, and the line will extend itself well behind (see Plate XXXVII.), and can be returned as in the overhead cast. The line can thus be extended by shooting, which is one of the advantages of this method of casting.

When making this cast for the first time, a moderate length of line should be essayed by the fisherman, and in the backward and downward sweep of the rod its path should be regulated by the surrounding circumstances. The line following the rod point will make a more or less extended curve behind him, and following the forward motion of the tip of the rod forward, the fly will land in the place desired. The fly may or may not in this cast pass behind the fisherman, its path depending on the length of the backward loop (see Plate XXXVIII.). In making this cast, the speed of the 


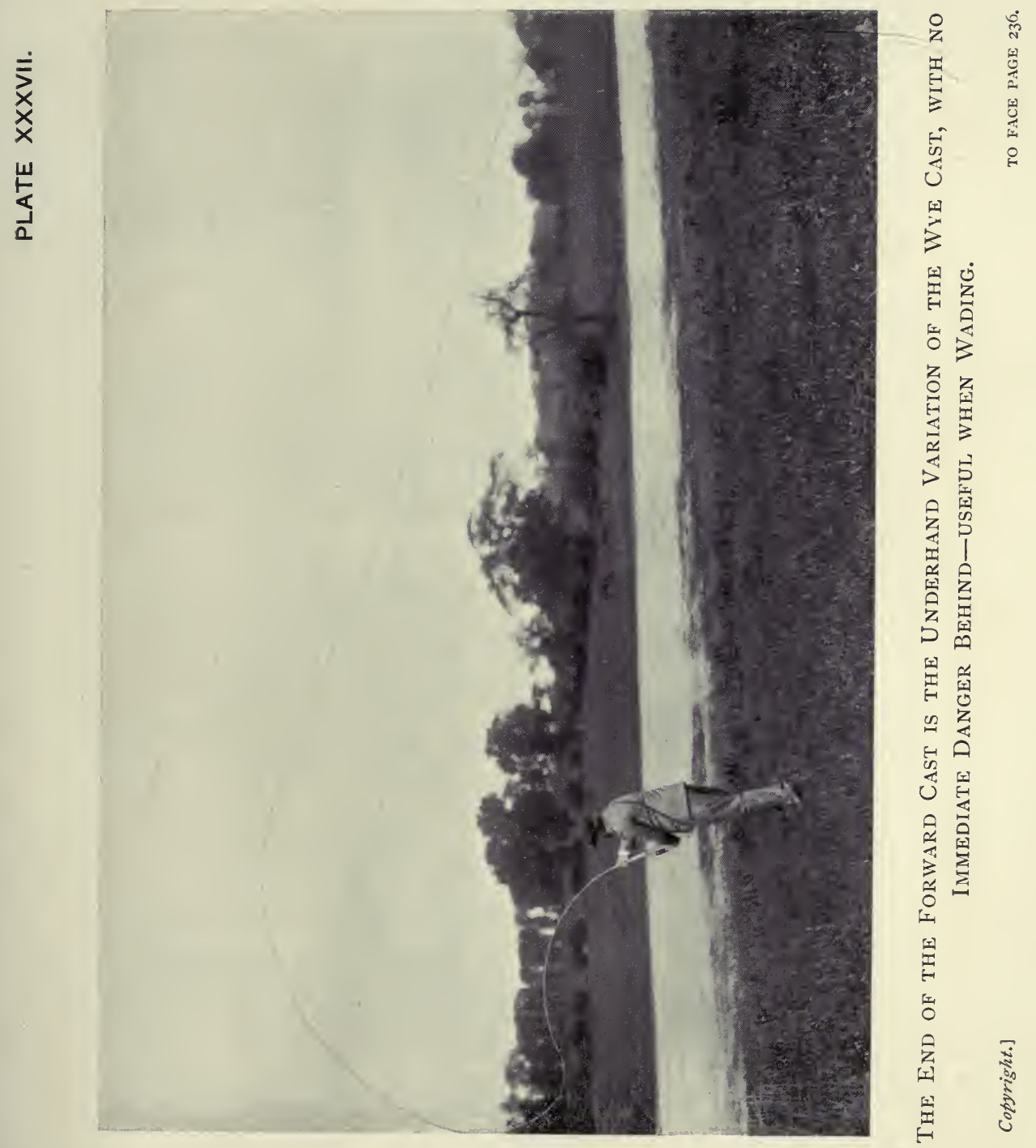



rod in its upward and overhead forward movement is responsible for the length which the loop takes behind the fisherman. The length to which the curved line extends itself behind will always be diminished in size in relation to the increased speed with which the upward and forward motion of the cast is made (see Plates XXXII., XXXVIII., and XXXIX.), and this will be at once apparent when it is remembered that after the downward and backward sweep of the rod, the line, as the rod moves upward again, will be flying backward in a curve. The more rapidly, therefore, the rod concludes the upward and forward movement, the less time will the line have for forming this loop behind the fisherman, but the more complete will it be in its forward movement.

The cast can be made at any angle between the vertical and horizontal; it can be used to alter the direction of the cast, or to avoid dangers behind or on either side.

\section{The Use of the Wye Cast}

We will imagine that we are fishing in Norway, and standing on the left bank of the Namsen River, below the Fiscum Foss. High above our heads you can see the river as it sweeps over the edge of the falls, and appreciate its immense volume of water as, thundering in our ears, shaking the rocks on which we stand, and covering us with spray, it plunges downwards a sheer 200 feet into the head salmon pool below. If you look 
across the water toward the pine-crowned cliffs, which run from the falls down-stream to the bottom of the rapids guarding the approach to the river on the opposite side, you will notice how the surface of the river, as it leaves the troubled waters of the head pool, is broken in its first smooth glide by that brown and grey rock some 30 yards from that on which we are standing, and some 20 yards from the precipice opposite. There, at any time between May and September, resting after his journey from the sea, in the eddy of that rock, so long as it shows above water, will generally be found the latest fresh-run salmon in this part of the river. If you can present your fly in an attractive manner, you will probably find him in a taking humour, and when happily you may be lucky enough to gaff him, and try the same cast over again later on, you will probably find another fish in his place.

You will see at once that you cannot cast for that salmon in any other position save from the jutting slippery and spray-drenched rock on which we stand; and to make such a cast more difficult, 20 yards behind us rise the precipitous walls of the river channel, against the iron sides of which the overhead or side cast backward of the line will most assuredly bring your Durham Ranger with disastrous effects.

To present your fly attractively, your cast should be sufficiently long to drop the fly 3 yards at least beyond the rock, so that it will then sweep round from the farther side, and appear just over the salmon's position. 
This, however, means a fairly long throw, of 33 yards at least, and although you can shoot the line, it is still evident that the wall behind will preclude your extending the line in that direction for the remaining 30 yards.

We cannot use the Spey throw from our only standing-place, for you will see how those low-lying rocks run out into the stream below us, and our fly, in the up-stream drag of the Spey cast, would most assuredly come to grief among them.

The axiom that " the line must follow every motion of the point of the rod," suggests a way out of the difficulty. We must make a curved cast which is a variation of a cast used on the Welsh Wye, and one which is most useful when fishing from a coracle.

The line, at the moment in which you make the final forward cast, cannot be extended backward, or it would hit the rocks behind, and therefore it must be curved at the psychological moment, and every portion of the line in this curve behind you must be under the influence of a continuously applied circular sweep.

The wind is up-stream from the left side, and this will help you in making the cast to the right. You first get out about 20 yards of the line by the vertical overhead cast across the stream, and then proceed as you lift your line to curve it up-stream and backward by a strong circular underhand sweep of the rod to the right (see Diagram 20), bringing the rod behind you in a continuous swing, but gradually raising the point 
of the rod in a spiral upward movement until it has attained the position H D (see Diagram 20). The line will now be extending itself in a curve behind you, and immediately opposite the rock you wish to cast over, and you therefore turn this upward swing of the rod into a forward overhead cast, shooting as much line as you can. You must repeat this process before or immediately after your fly has touched the water, and

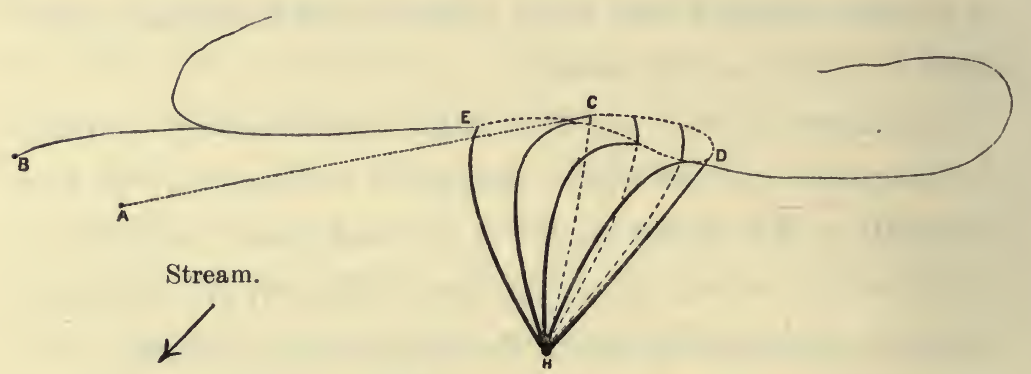

Diagram 20.

$\mathrm{H} \mathrm{C}$, the rod at the commencement of the final cast.

$\mathrm{C} \mathrm{A}$, the line before it is brought back in the final cast.

$\mathrm{H} \mathrm{D}$, the rod at the moment of making the forward cast.

C D E shows the path of the top of the rod.

$\mathrm{B}$, the place to which the fly has to be thrown.

in two or three casts you will be able to get your fly to drop on the further side of the rock. The line following the path your rod has taken will confine itself to a more or less extended curve, and will, if the stroke is done properly, have never approached the dangerous face of the cliffs behind you. When the cast has been properly made, you will be rewarded by seeing your fly falling lightly on the far side of the rock, and may be, as I have seen, a fish plunging upward, and then down- 


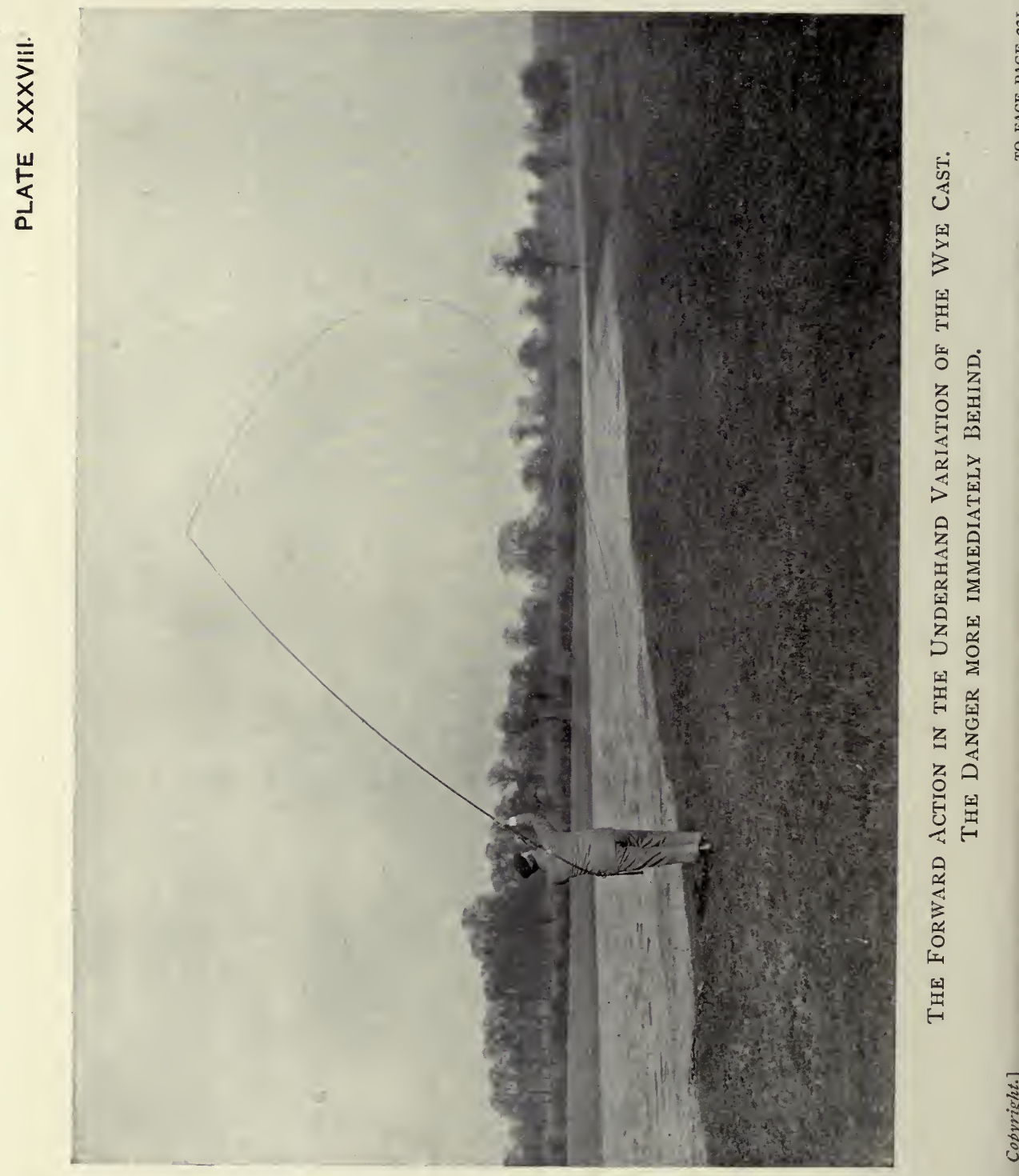
ward, with your fly in his mouth. You will feel the ecstatic and electric thrill as the first strain of the salmon comes on your line, and thank Providence that your Durham Ranger has not been snapped in half by the rocks behind you.

The above cast is so very useful that a diagrammatic illustration will be of service to the reader to illustrate the rod action described above (see Diagram 20).

We will suppose that the rock over which we have to cast is situated in the direction B on the left-hand side of the page, that the precipice behind is situated to the right hand of the page, while the river flows toward the left-hand lower corner, as shown by the arrow, and that the reader is standing above the level of the rod in the right-hand corner. The line is brought back from $\mathrm{A}$ by a right-hand side sweep of the rod, the point of the latter following the dotted lines CD, and the line which has been extended toward A has been lifted from the water, following the point of the rod, and has been brought back as shown in the curved line from D. The rod has been gradually raised until it reaches $H \mathrm{D}$, and from this position it has been carried onward in a forward overhand. stroke, D E towards B, at which we are aiming. The line following this direction has been projected towards $\mathrm{B}$, as shown in the curved line from $\mathrm{E}$. 


\section{A 50-Pound Salmon}

It might perhaps illustrate the uncertainty of salmon fishing and the reward which will at times repay a patient wait on the river-side if I describe the good luck which attended my enforced stay on the Namsen River at the end of the 1897 season. The late Mr. Merthyr Guest had very kindly placed his house at Gartland, and his stretch of the Namsen River, at my disposal. I had been entertaining a party of my friends, who, owing to previous engagements, or because the water had been too fine to fish, had one by one left me, until on the 23rd of August I found myself alone, to pay off servants, and see that the house was properly closed for the winter. I had arranged to follow two other friends further into the interior and join them in elk shooting.

On the very night, the 23rd, on which the last two visitors left Gartland a heavy downpour of rain commenced, which made their journey up-country extremely unpleasant, but which, to my great delight, brought down the Namsen River in spate.

On the 26th of August it was fishable, and I was lucky enough to kill over 200 pounds weight of salmon in the next three days, killing on the first day, among a lot of other fine fish, one which scaled just over 50 pounds. This was a fine old cock fish, which, had he been fresh-run, would probably have scaled 60 pounds. He was killed at 5 p.m. on August 26th. This splendid salmon measured exactly 4 feet in length, 27 inches in 
PLATE $X X X \mid X$.

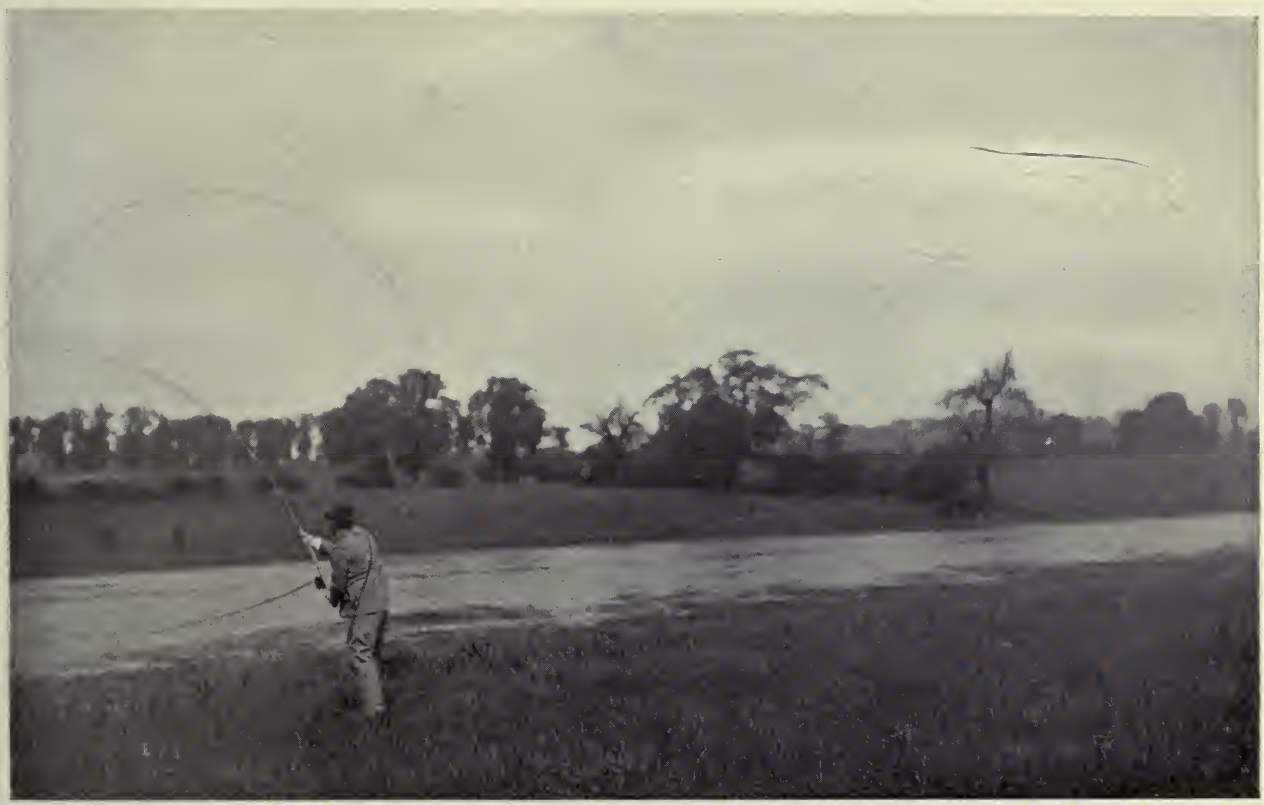

The Forward Action of the Side Loop Cast when the Danger is immediately Behind. THE LINE HAS BEEN TOUCHED UP.

Copyright.]

PLATE XL.

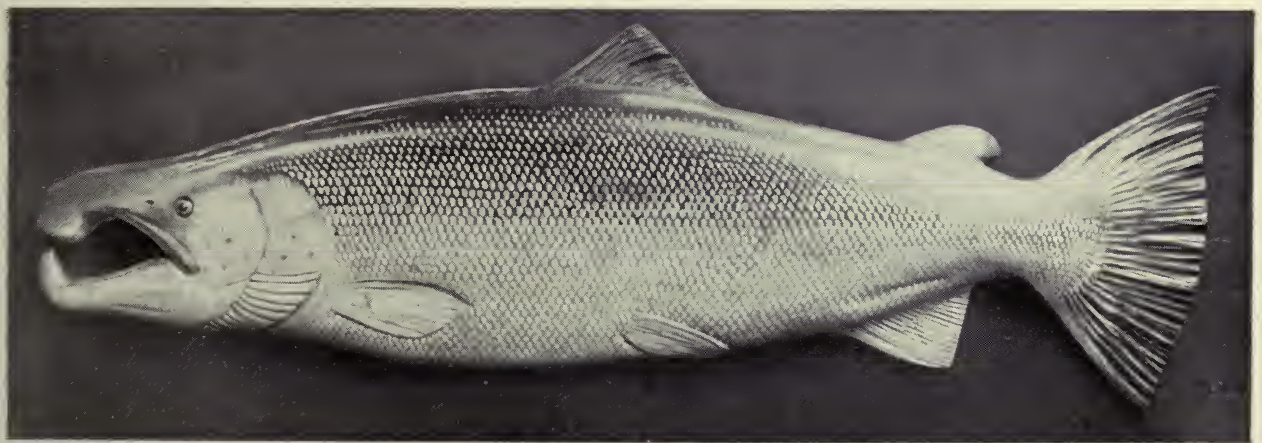

Model of a 50-Lb. Namsen Salmon killed by the Author in August, 1897, on the Namsen River, Norway.

Copyright.]

TO FACE PAGE 242. 

girth, and the span of his tail was $13 \frac{1}{2}$ inches, and he had the biggest head I have ever seen on a salmon. He was caught on a medium-sized spoon with a 17 -feet Castle Connell rod. He took the lure with a tremendous dash, the reel screaming as the fish went spinning downstream ; but, luckily for my nerves, he gave me a chance after taking out 100 yards of line, and I was able to turn him towards the bank. After trying a short run up-stream, he made another dash towards the centre of the river, and then another down-stream rush, until he sulked in about 10 feet of running water. Pulling in to land, I attempted to move him; but for fifteen minutes he lay like a rock, sulking, if ever a fish sulked, and only a surge now and again told me I had a fish, and not a world, on my line. I might have turned him down-stream, but my Norwegian strongly advised me not to do so, as danger existed but a short distance below. So it was a case of wait. Meanwhile, my eyes were beginning to play me tricks : the high pine-clad banks commenced running up-stream at express rates whenever I lifted my eyes from the rapidly running river at the spot where my fish lay, and on turning them on any motionless object the same curious optical delusion occurred. My man, Isaac, now planted a stone or two below the salmon, and after fifteen minutes' sulk, he made a move towards me up-stream, and then a dash across the river, we having to follow in the boat for some 300 yards. He then came down again and we got him into a big backwater, in which I managed to keep him, and finally, after a very anxious 
struggle, I had him beautifully gaffed, and lying on the bank.

He took forty-five minutes to kill, and out of that time he sulked for fifteen minutes among some dangerous rocks in a deep run, about 70 yards from the bank on which we finally landed him. I also killed two fish over 30 pounds with the fly (Jock Scott and Popham), besides losing another very big one, and finished off the day by killing a 22-pound clean-run salmon with many sea-lice on him. It was a coincidence that the late Mr. Merthyr Guest, M.F.H., should have killed in the same pool on July 20, 1894, a 64pound salmon, the length of which was 4 feet $3 \frac{1}{2}$ inches, but with all other measurements similar to the one just described. Mr. Guest's fish was almost the biggest salmon killed on a rod at that time. I killed on this water on September 10, 1896, a clean-run salmon of 24 pounds. This will serve to show that a river has every chance of giving good sport until the close of the season, provided always that the rain is forthcoming, or that there is sufficient water in the river to bring the fish up. Our party had been waiting for rain for over three weeks, and we had been amusing ourselves in almost any way but salmon fishing. August is as likely to be a wet month in the North of Norway as it is to be a dry one, and the salmon continue to ascend the river until the close of the season (September 14). From the drawing I made and the measurements taken of the salmon, the model shown in Plate XL. has been made. The mouth, which is 
open, gives a good idea of its extraordinary head, and was modelled from the head of the salmon, which I brought back to England in pickle (see Plate XL.).

\section{A Few Additional Maxims for Fishermen}

1. If it be possible, always keep a taut line when a fish is hooked.

2. Always play your fish from the reel.

3. Keep your rod well up when playing the fish.

4. A constant and delicate wrist action secures a lightly-hooked trout, which otherwise would be lost.

Look to the point of your trout and salmon hook frequently, and always carry a small file in case the point becomes blunted.

The salmon fly which is most deadly is that which is fished on the straightest line.

A slack line leads to danger, and it also prevents your bringing pressure at once to bear on a fish which has taken the fly.

Movement can most easily be given to the fly at the end of a straight short line. With a long line much of the impulse given to the rod will be lost ere it reaches the fly. This is especially so when wet fly fishing.

When fishing the lower reaches of any salmon river, and when the water is discoloured or the river full, heavy rods, lines, and lures can be used, and with advantage; but when the water is small and as clear as 
gin, the lighter the rods, tackle and flies, the greater should be the success in getting fish.

While the colour of a salmon fly is undoubtedly of some importance in securing fish, the size of the fly, in my opinion, is of even greater consequence.

Sir Edward Grey says: "The art of throwing a fly well cannot be taught by description; it may be seen and watched, but it can only be acquired by practice and a capacity for taking persistent and well-ordered pains."

There is no sounder authority on the subject of trout fishing than Sir Edward Grey. I believe, however, that he is mistaken in the first sentence quoted above. But I should like to add to the quotation these words, "when properly instructed," and in vindication of this point should like to refer my reader to the remarks referring to instruction in fly-casting made in the final advertisements in this book. 


\section{CHAPTER X}

The necessities of the fisherman-The rod-Length-PliabilityWeight and action of the rod-Makers and makers of rodsThe fly fisherman's knife-Wading and waders-Basket creels and fishing bags-Salmon and trout lines-The oil-bottleThe salmon and trout reel makers-Spinning-The fly hook -The cast-Trout and salmon flies-Fly books-MuscatolBinoculars-Gear-case-Gaff-The landing-net-Waterproofs -Fisherman's spectacles-The fly-net and fisherman's lamp.

\section{The Necessities of the Fisherman}

I HESITATED about writing this chapter at all. It is certainly of the utmost importance to a beginner, and useful often to an old hand, to get good appliances for his art or craft, and to know where to go for them. In giving such information, however, an author lays himself open to suspicion of self-interest, and I am not anxious to incur the risk of this, especially as one or two of the appliances I recommend are my own invention.

But since the various friends I have consulted all advise me to include the chapter, I do so, and hope the reader will believe it is done only in his interest, and in the desire to make the book complete.

I trust I may, therefore, be regarded as a friend worthy of thanks for mentioning a few special articles 
and certain patents or makes of those fishing articles, most of which they will of necessity require.

The advertisers are those firms with which I have been in the habit of dealing, and whose goods are, from my own personal knowledge, thoroughly trustworthy and useful. It must not be supposed, however, that I advise my reader to leave the tradesman with whom he has been accustomed to deal, and to patronize any one of those whose advertisements I insert. The trade is an honest one, and my experience is naturally limited, and therefore, if satisfied with his present treatment, he will be well advised to continue his custom where he is well known.

But there are specialities and patents which deserve to be known and which cannot be purchased from all dealers; these I have specially mentioned when well known to myself.

It is a pleasure to draw the attention of my readers to the fact that, with one exception, the articles I mention are English-made, and to think that in my favourite sport we are almost entirely independent of foreign manufactured goods.

\section{The Rod}

The student when purchasing a rod, even when he has the help of an experienced friend, should consider which method of fly fishing he is prepared to adopt, and whether he is going to fish up or down stream. 
When selecting a rod for either method the action and balance of the rod is of the greatest importance, and, to determine these points, the rod, with the reel attached, should be grasped in the hand, or hands, as usually held, and switched backward and forward in the horizontal plane with the eyes shut.

The shorter the distance at which the trout rod appears to extend beyond the hand, judging by the feel alone, when thus held and moved, the better. The shorter the distance which the salmon rod appears to project beyond a point midway between the two hands (the pivot point), the better the balance, etc., of the rod. The dry fly rod when held horizontally should not incline downward at the tip. The purchaser of a rod should remember that the wrist and arm, unless fatigued, will not readily detect either a faulty action or a badly balanced rod-such faults will, however, become painfully apparent after a few hours' fishing.

The length and the stiffness or the whippiness of the rod chosen should depend on the river, the size of the fish, and the different methods of fishing.

In dry fly fishing and fishing up-stream, the rod selected should be fairly stiff, as the hooking of a fish depends on the initiative of the striker, and after a trout has taken the fly, the sooner the strike is made and the wrist action communicated to the hook, the better the chance of establishing a relationship between the trout and the rod. The more whippy the rod, the 
longer the time occupied in communicating the wrist action to the hook.

In fishing down-stream, the rod will most often hook the fish by its own delicate mechanical action, and it becomes a more effective machine when its whippiness is one of its pronounced features.

\section{The Length of the RoD}

It is when bank fishing that a long rod is most useful. The dangers are then multiplied, and the aid of a long rod after the fish is hooked frequently prevents breakage. With an 8-ounce rod from 9 feet to 9 feet 6 inches long, a fly can be cast up to 25 yards, a distance sufficient for all trout fishing, and therefore the only reason for a longer and heavier rod is that the user has a greater power in keeping the fish from danger spots, such as those immediately under the bank on which he stands. This last danger is obviously minimized when wading.

The weight of the rod is not of the first importance. It is in the balance and action of the rod that its value lies. The movement of the tip of the rod should be felt in the wrist, and if that is so, any weight of rod under 10 ounces will not be noticed. The reel and spear should balance the length of the rod when grasped by the handle. 


\section{Pliability of the Rod}

Unless the elasticity be relatively proportioned to the strength or thickness of every part of the rod, an unequal strain must fall on that part in which the springiness is in excess of this relationship.

Should such a part exist, then that portion of the rod will suffer, and an imperfect action will be the result. Pliancy should be in constant ratio to the taper, that is, to the strength of the rod when well built.

This does not infer that the pliancy should increase in a regular ratio as regards the distance from the butt.

When testing a rod by switching it backward and forward in a horizontal direction, careful attention should be given to the bend of the rod as it moves from side to side, and by comparing the action of various rods a good selection can be made. The lower part should begin to show its pliability about 9 inches above the handle.

I cannot too strongly impress on my reader the very great difficulty of choosing in any shop the rod which will best suit his strength and style when fishing. Careful attention to the hints I have given will materially assist the purchaser, but otherwise he will, unless very experienced, be in the hands of the dealer, whose strength, ability, taste, and desires may not always be similar to his own. In selecting rods for my pupils, I found that at first I was often mistaken in the first 
estimate I formed when making a preliminary selection in a fishing-tackle shop, and that the practical trial on a lawn frequently modified my first impression. It is only by rigidly applying the rules $I$ have laid down that a correct judgment can be made. Rods rejected by experts will in the natural order of commerce be offered to novices; a heavy, ill-balanced rod will frequently disgust the beginner, and cause him to abandon a sport which would have been a constant delight, not only as regards his every-day enjoyment, but as filling with pleasant reminiscences the storerooms of his memory.

\section{Various Rods aNd Makers}

In all cases I should advise the reader, when buying a rod, to try three or more specimens of the particular rod he is anxious to obtain, for although the rods of any well-known pattern are as nearly alike as it is possible to make them, still no two rods are exactly similareach having its own particular points of merit or demerit. Do not condemn a particular make of rod because one of that make does not happen to suit you, and, on the other hand, do not purchase any rod before carefully trying its balance and action.

I think that the great success of Hardy Brothers of late years entitles them to take precedence when dealing with the subject of split-cane trout rods. Indeed, it is hardly necessary for me to draw attention to their very many good points, as nearly every 
description of rod can be obtained from them. I owe my success at the International Casting Tournament of 1904 to the use of their split-cane rods.

\section{SALMON RodS}

In salmon rods, the "Special," a cane-built steelcentred rod with bridge rings, made in any size from 15 feet upwards, is a rod which is admirably balanced, easy to use, and throws a remarkably good line. It is one of the best cane-built rods in the market, is fitted with all the latest improvements, and is quite up to Hardy Brothers' excellent standard.

I have at present more of C. Farlow and Co.'s rods in my possession than any other make-some of them, indeed, are very old favourites. I have always considered their greenheart rods the best in the market.

Farlow's " Perfect," a greenheart salmon rod weighing about 23 ounces, and 14 feet in length, is about the best greenheart salmon rod I have ever handled. Its price is $£ 215 \mathrm{~s}$., and it can be made in all sizes up to 18 feet. It has a most delightful action, is well balanced, and throws a good line.

\section{Trout and Salmon Rods}

Hardy Brothers, working from my specification, built a 9 feet 9 inches rod for me last summer which I have the greatest pleasure in recommending. It is fitted with all the latest improvements. Their 
new patent joint was tried for the first time on this rod, and has proved a great success. The butt-end of the upper joints slips directly into the socket of the lower one, and is secured by a pin in the former actuated. by a spring, which rises through the latter. The injury done to the delicate construction of the upper joints by the severe strain of twisting out the butts when suction and other joints are used is thus avoided. The bridges along the rod cannot get out of position by the various joints twisting, and the rod is easily and quickly taken to pieces. At my suggestion the bindings of the rod above the handle are exactly 1 inch apart and numbered from 1 to 15 , so that a means of measuring the fish caught is always at hand.

It is elegantly finished, with solid silver reel fittings, agate rings on butt and top, bridge rings throughout, and is contained in a light bamboo case.

As I was to a considerable extent responsible for this rod, and as it is one of the best I have yet handled, I have permitted Hardy Brothers to name it the "Shaw" Rod. Its cost is $£ 5$ 10s., and its weight 7 ounces.

Hardy's " Alnwick Greenheart," a 9 feet 6 inches dry fly greenheart rod, in three pieces, and having two tops, is most excellent in balance and well finished. It is fitted with bridge rings, lockfast joints, cork handle, spear, and agate top ring.

Farlow's "Perfection" is a 9 feet 6 inches split-cane rod, weighing about 7 ounces, which is quite one of the best-made rods I have used; it is elegantly finished 
and has a beautiful action, is well balanced, casts a good line, and is a good all-round rod.

Farlow and Co. are also the agents for the celebrated "Leonard" rods. I have a 9 feet "Leonard" weighing $3 \frac{7}{8}$ ounces, which $I$ won at the International Tournament; it is the best rod of this weight I ever used.

J. Bernard and Son, of 45, Jermyn Street, make an excellent rod called the "Fairy." This rod, 8 feet 6 inches long, weighs from 5 ounces to 6 ounces ; the price is $£ 410$ s. It is well named the "Fairy," and it is a capital rod for a lady, having a perfect balance and action, a most comfortable cork handle, and, when fitted with the Itchen reel and Bernard's special-made tapered silk line, is a pleasure to use. This rod can be built to order in different sizes up to 10 feet 6 inches.

Westley Richards, of Birmingham, sell an excellent double-handled trout rod, called the "Panama." The rod is light, well built, well balanced, and has an excellent action. It is strengthened by a system of cross-sectioned silk wrappings. The silk is flat and shrunk on the rod, and almost invisible. This system of sectional wrapping in silk is strong, and lighter and neater than the steel ribbing used on Foster's very excellent "Dovedale" rods.

The "Panama" is made either for salmon, grilse, or trout rods, and is excellently finished.

Ogden Smith's, the "Warrior," is a double built throughout cane rod, 9 feet 9 inches in length, and made either in two or three joints, is light and power- 
ful, has an excellent action, and is well balancedaltogether a very sound and delightful rod. Messrs. Ogden Smith keep this rod in order for three years free of charge ; price, $£ 55 \mathrm{~s}$. with rod case.

The "Multum in Parvo" rod made by Jas. Ogden, of Cheltenham, is a cheap but excellent rod, made with blue Mahoe wood or greenheart, with cork handles. It is to be had in sizes from 8 feet to 10 feet 6 inches, and it is a light and at the same time powerful two-joint dry fly rod. The price is $£ 1$ ls. It has a permanent spear fixed on the butt.

Holbrow and Co., of 40, Duke Street, among many excellent rods, make an especially good and cheap trout 8-feet greenheart rod at $£ 12 \mathrm{~s}$. I have used this rod continuously, and it is as light to handle as a "Leonard." It is well balanced and strong, and can throw a remarkably good line.

The Junior Army and Navy Stores sell a very good close-whipped greenheart rod, called the "Test." Its length is 10 feet, it weighs about 10 ounces, and its price is $£ 115 \mathrm{~s} .6$ d. ; a very useful, well-balanced, and pleasant rod.

Among other rod-makers whose rods I have used and found always of the best are those of Eaton and Dellars, and Enright and Son, of Castle Connell.

Gamage and Co. sell a very excellent little spinning rod. It is perhaps a little stiff for trout, but for pike and sea trout, etc., it is admirable. It is made of split cane and fitted with agate rings throughout, and costs $£ 33$ s. 
At the end of the season rub wooden rods carefully with fresh mutton-fat, and don't keep them in too dry an atmosphere.

\section{The Fly Fisherman's Knife}

No article becomes more endeared to the average man than a good knife. To the fisherman a knife is

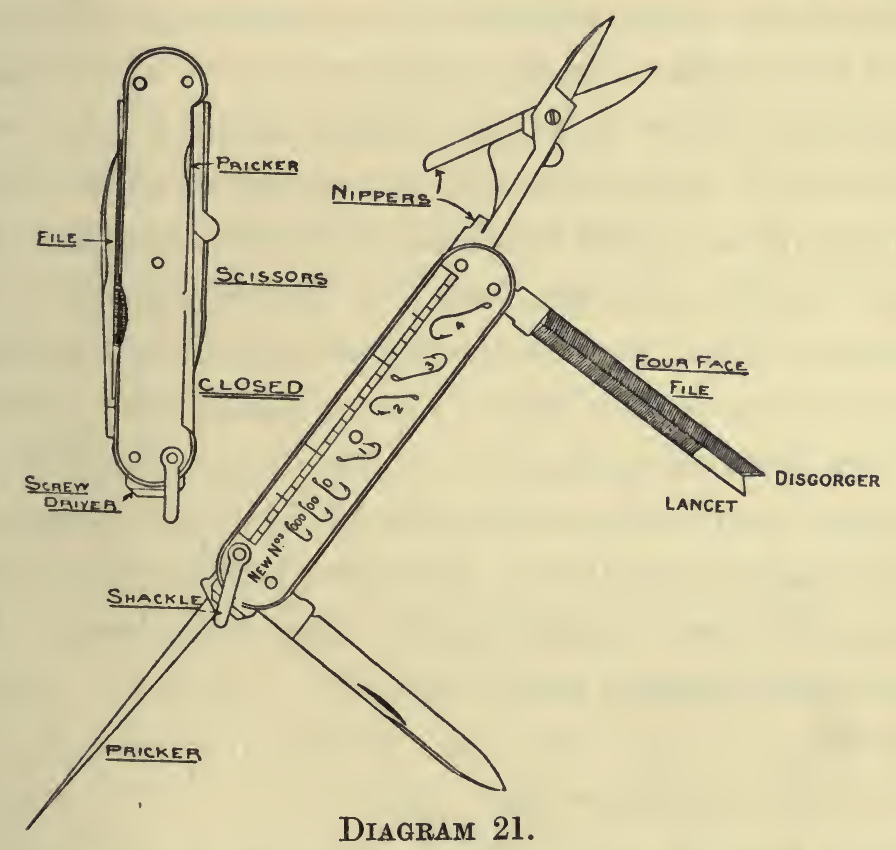

The fly fisherman's knife contains all the tools required by the fisherman. Weight, 2 ounces. Length, 4 inches. Thickness, $\frac{1}{4}$ inch.

indispensable, and in the knife shown in the diagram he is able to obtain one which contains all the tools he is likely to require at home or at the river-side. It is 
light, thin, and can be carried comfortably in any pocket; furthermore, it is made throughout of the best material. I have already shown in Chapter XI. the usefulness of this knife.

The blade, which acts as a file, lancet, and disgorger, makes an excellent manicure tool, and the file is so admirably tempered that it will cut through hardened steel with ease. I have experienced a considerable difficulty in easily picking out any particular fly from among its fellows in my fly-box, and to obviate this difficulty I have had the various tools in the knife magnetized, so that, whichever implement of this knife is being used at the moment, it can be applied to the particular fly required, and this fly will be easily and securely raised, by itself, without the other flies being disturbed or lost. This excellent idea I owe entirely to Mr. Foster Hardy, of Hardy Brothers. I make no apology for recommending this knife to my readers, as it is claimed by all who have purchased it to be the best and most desirable knife they have used. For further particulars, see p. xxxi.

\section{WADING}

Cold should not affect the legs through the waders.

Always wear thick woollen socks and drawers under the wading trousers in any stream in the early months of the year, and always when in cold water streams. Waders should be sent to the makers for repairs or overhaul when they show the least sign of leaking. 
Strong waders are always advisable; the lighter cloths used, though perhaps less cumbersome, are liable to tear at the touch of a thorn or barbed wire.

If you are strong, youthful, and robust, wading without waders in shallow or warm streams in summertime will not hurt you, so long as no chill is felt, but as the influences of Anno Domini increase, it is best to take no risks and to wear reliable waders.

As the non-fishing months are many, you should send your waders to the makers to be overhauled when the fishing season closes; you will then be prepared in plenty of time for the next.

In wading always remember to have a few eyelet holes punched and protected in the sides of the brogues near the sole; this permits of the water leaving the brogues when the wearer is on land. J. C. Cording and Co., of Piccadilly, whose waders, etc., I have always found most excellent and reliable, have adopted these holes in their fishing brogues for some time. Cording's wading-boots, a combination of fishing stockings and light leather goloshed boots having handsewn soles, are the most comfortable wading articles to be had. The dampness caused by perspiration is entirely eradicated by the use of their special thin indiarubber stockings; these when taken off are readily dried, and the interior felting of the boots remains perfectly dry. 


\section{Basket Creels and the Fishing-Bag}

The basket creel has been so generally improved that it is sold in greater numbers than the fishing-bag.

The advantages which the bag possesses over the basket are as follows :

It is neater in appearance.

It is rainproof, less noisy, less cumbersome, and quite as light.

The bag is not so prone to slip round and capsize its contents when the wearer stoops.

When one is running or moving quickly, the bag does not emit that incessant jingle which the creel, filled with a heterogeneous mixture of the various articles of tackle, flask, luncheon, the fish, etc., is so prone to make; while the contents, unlike the articles in a midshipman's chest, which are always on top and yet never at hand, are so placed and arranged in their numerous pockets and receptacles, in a properly constructed fishing-bag, that they are all and each available at a moment's notice.

The fish are generally kept in a detachable watertight canvas bag. The bad point about fishingbags is the stowage of the fish. If the fish-bag is kept between bag and wearer, it is awkward and hot for the wearer and bad for the fish; while if it is in front of the bag it is in the way, and is exposed to the sun, etc., etc.

On the other hand, a creel is cooler to wear, better to keep the fish in, and modern improvements have 
eliminated in a few of them some of the disadvantages I have mentioned.

A combined creel and fishing-bag is, however, the best for general use, and will eventually supersede the fishing-creel or fishing-basket. There are several combinations on the market, but they are all open to improvement. One of the best combinations which I have so far seen is the "Curragh," manufactured and sold by Hardy Brothers. It is light, handy, and useful.

In order to satisfy my own wants, I designed a combined creel and fishing-bag, and had it made up by Bernard and Co., of 45, Jermyn Street.

- The above firm considered the design sufficiently good to register; the new idea has caught on, and the demand for this combined creel and fishing-bag is daily increasing.

The creel is broad-bottomed and cannot capsize; it has a large and cool holding capacity for trout, is easily cleaned, and it is light. The bag is removable in a moment, and rests on the ledge of the basket. It is divided into convenient compartments, and has plenty of room for sandwiches and other necessities. The whole affair is free from jingle, and is very light and comfortable to wear ; it is cool both for the wearer and the fish, and the pocket and its contents can be reached with the greatest ease. (See p. iii.) 


\section{Trout LINeS}

In choosing a line the student will be well advised to accept the advice of the rod-maker of whom he purchases his rod, whose experience will be a good guide in such a matter.

For trout fishing get a double-tapered line for dry fly fishing, and one not too light for your rod. The line should be soft and pliable, with a smooth indiarubber-like touch. Always remember that the life and usefulness of your rod, your reel, and your line will depend on the care and attention you give them. Always unreel your line after a day's fishing, and leave it either on a winder or in coils to dry during the night.

Remember that the taper of your line is its most delicate and most valuable part, and do not be rash in cutting off the ends.

The lines I recommend are :

Farlow's double-tapered, soft-dressed trout line, in length from 30 to 40 yards, and costing from $10 \mathrm{~s}$. to $15 \mathrm{~s}$. , is one of the best lines made, thoroughly strong, and delightful to use.

The "Corona," the most carefully made and excellent double-tapered trout line, is specially made by Hardy Brothers, and though expensive it is well worth the price asked.

The "Houghton" double-tapered special fly line, made of the finest silk, has a beautiful polish, and its flexibility and feel are perfect; this, too, is made by Hardy Brothers. 
The "Bernard Special" line is of excellent quality and strength.

Eaton and Dellars, of No. 1, Bury Street, Ogden Smith, and Westley Richards, of Birmingham, make excellent, well-finished 30-yard double-tapered trout lines.

\section{SALMon Lines.}

The makers mentioned above can be relied on for their salmon lines. The "Kingfisher" line, sold by Mallock of Perth, is an especially good line, moderate in price and good in quality. If I have any choice, however, it is for Hardy's "Corona" salmon line.

\section{The Oil-Bottle.}

The ingenious method of wrapping an ordinary 1-ounce bottle of odourless paraffin in blotting-paper suggested by Mr. Marston in the Fishing Gazette is an excellent idea. The blotting-paper absorbs any oil, and prevents it from soiling the coat when the bottle is suspended in the ordinary way from the upper front buttonhole, and offers a ready means of taking the superfluous oil from the fly.

C. Farlow and Co. have for some years sold a small box with a porous felt, which is first saturated with oil, and on which the fly can be easily and quickly oiled. No escape of the oil is possible.

Hardy Brothers have just produced an excellent pocket bottle for the same purpose. 


\section{The Reel}

Reels, during the last few years, have more than kept pace with the scientific advance of rod-making, and those now in use, and sold by most tackle makers, can be considered as almost perfect.

The prices of good trout reels vary from $5 \mathrm{~s}$. to $60 \mathrm{~s}$. I am inclined to recommend a modern up-todate wooden Nottingham reel, with strong attachments to the saddle; it can be purchased at all tackle shops. The barrel should be large, the action simple, the break pleasant. If the barrel is detachable the parts are easily kept clean. I never enter a tackle shop, however, without breaking the Tenth Commandment, and wanting some of the excellent forms of reels which I see. I have nearly every kind of reel in my possession, and the only ones I object to are small ones which have a small barrel and slow winding action.

\section{Salmon Reel}

The "Perfect" reel for trout or salmon, made by Hardy, with ring guide, in all sizes from $3 \frac{3}{4}$ to 5 inches, cannot be beaten by any reel in the market. It is delightful to use, and is especially strong and well made.

Farlow's patent lever winch is a most excellent reel, admirable in its power and mechanism. It has a most convenient regulating screw on its outside for 
regulating the pressure on the check. It is made in any size from $3 \frac{1}{2}$ to 5 inches. Its price runs from 42 s. to 70 s., according to size.

\section{Trout Reels}

Personally, I prefer a $3 \frac{1}{2}$-inch "Special Perfect" reel, made by Hardy Brothers, of Alnwick and Pall Mall, and consider it as near perfection as possible. This reel should be carefully treated, and the delicate mechanism must be kept clean and well oiled.

The "Silex" can be recommended when spinning for trout, salmon, pike, etc., alike, and for whichever kind of fishing it is used it is equally delightful. This reel is also the patent property of Hardy Brothers, but I think it can be ordered through any dealer.

Bernard's "Itchen," $2 \frac{1}{2}$ inches, is quite one of the best little trout reels I have used. Its weight is only 4 ounces; it has a big barrel and very pleasant action. Price 17s. 6d.

Another very excellent reel is the improved "Corbett" salmon reel by Bernard and Co. The price for the 5-inch size is $£ 2$. It is made of some special composition which is as light as ebonite, but is capable of standing the roughest usage. It is fitted with a silent check, as well as the ordinary click check, both of which are easily manipulated.

The Coxon "Aerial" reel is a very well finished and excellent Nottingham reel, of which the mechanism is 
delightful. It is made by S. Allcock and Co., of Redditch, and sold by most dealers; its price ranges from 20 s. to $30 \mathrm{~s}$.

The "Sun" Nottingham reel, sold by Farlow and Co., is quite one of the best for trout fishing. Its diameter is 3 inches, and it costs $21 \mathrm{~s}$.

Holbrow's 3-inch unbreakable trout reel at 26s. is thoroughly strong and reliable. It can be obtained in any size up to 5 inches. The metal is unbreakable; it is as hard as gun-metal and as light as aluminium. It is fitted with repeating rollers, which permit the line to be reeled in with remarkable speed.

An attractive-looking reel which has recently been placed on the market has an entirely new principle for regulating the resistance of the check. The brake is applied in a very simple and effective way by a cone pressing out two parts of the $\mathrm{V}$ spring against the spindle. The $\mathbf{V}$ is loose within the spindle, and is easily taken in and out. The brake works both ways, against the fish and also against the fisherman, and for this reason it may not commend itself to every one. It is well finished and can be purchased in all sizes.

\section{The Silent Reel}

Some fishermen's ears are so attuned to the melody of Nature that the friendly, cheerful, and, to my ears, musical tone of a well-regulated brake on the winch seems out of harmony with their surroundings. To please such ears, Hardy Brothers have produced a reel 
having a silent brake, which can be easily and quickly adjusted to the requirements of each individual fisherman. If good workmanship and design are a recommendation, this reel should become popular with those who like to use a silent winch. Dry the interior mechanism of your reel with an old silk handkerchief, and keep it carefully oiled with the best machine oil.

\section{SPINNING FOR Trout}

In certain streams in the Northern Counties, in Scotland, Wales, Ireland, and Norway, spinning is permissible. The art of spinning is a delightful one, and the biggest fish are frequently caught by this method-especially with the natural minnow. Level gut traces fitted with two single swivels at least should be used.

Single-handed trout-spinning rods, fitted with any good spinning reel and undressed silk lines, with swivel traces, will give the angler most excellent sport, and though the pleasure and the science are not so great as when fishing with the dry fly, the results are frequently happier.

\section{The Fly Hook}

The fly hooks which I recommend are the "Pennell" turned-down eyed hooks, the turned-down eyed "Model Parfait"-a hook invented in France, but 
now sold by most English tackle dealers-and the "Hall" eyed hook. There is little to choose between these; they are all good.

\section{The Cast}

A very instructive and interesting article has appeared in the Fishing Catalogue of Westley Richards this year (1907), which is well worth the study of fishermen. The merits of unbleached and undrawn gut, in my opinion, are rather overaccentuated, and I should certainly advise the student to depend on the bleached, drawn, and polished casts supplied by the best makers. Every length of gut in each cast should be well and carefully knotted, and no ends should be noticeable when the cast is drawn through the hand; each length should be of even thickness throughout, round, translucent, and smooth to the touch.

Always use the finest tackle consistent with safety, and in choosing your casts and traces I can give no better advice than to go to no dealer but the best. I have obtained excellent casts from all the following firms: Bernard, Hardy Brothers, Farlow, Westley Richards, Eaton and Deller, Ogden Smith, etc., and alas! I have also been at times disappointed. In spite of every care, even the most careful retail dealer may at times be unable to guarantee every cast he sells, and I should never condemn any good dealer for supplying me with a few faulty gut casts. 
A make of cast which can be obtained from most dealers is the "Hercules" cast. So far as my experience has gone, I have found these casts good both in quality and durability.

The cast for dry fly fishing should be 3 yards in length, tapering to the finest limit of safety. This limit should be decided by the state of the weather, the water, the time of the year, and the size of the trout inhabiting the water in which you are fishing.

Remember that the strength of the cast will be determined by its weakest length.

Experience will decide the degree of necessary strength for the fine points, and when new streams are tried the advice of a local fisherman or your tackle maker may well be sought.

Always have at least half a dozen casts of fine and medium gut in your box when away from a tackle shop, also a plentiful supply of fine gut points, 15 to 18 inches in length. During the day when fishing keep one cast in your damping-box, and always where possible soak a new cast for at least thirty minutes in lukewarm water before using it. Insufficient soaking or too much soaking may render the best gut unreliable. Keep your casts in a round flat metal castbox, such as is sold by all tackle makers, and always between white flannel. The dyes used in coloured material, etc., have very frequently a deleterious effect on gut casts or traces.

Sunlight and light generally is ruinous in its effect on gut. Your spare casts should never be left exposed 
to the light, and for this reason should never be wrapped round outside the fisherman's cap, and the rod when not in use should be placed in the shade.

Before using your cast, every length should be carefully examined and tested. The gut should slip easily and smoothly between the fingers; it should exhibit no bright isolated patches, being of a uniform colour and tint throughout its length. Always remove your casts at night from the damping-box.

I prefer a very light blue, green, or brown tint for the colour of my cast.

\section{Trout and Salmon Flies}

The ability to tie a trout or salmon fly is undoubtedly an advantage to the fisherman. It is an interesting study, and to many a delightful occupation.

It is by no means difficult to acquire, and among the many volumes written on this subject I can recall no better guide than the second edition of a small book published by the Fishing Gazette, entitled "How to Tie Flies for Trout and Grayling,"* by Mr. Harry C. McClelland, which deals with the entire subject of hooks, material, and flies. Both as regards salmon and trout fly-tying, however, it is better to have a few preliminary lessons in the art, especially so in the case of salmon fly-tying. Mr. E. Holbrow, of Holbrow and Co., Duke Street, is, I believe, the sole remaining

* Published by the Fishing Gazette Co. 2s. 6d. net. 
representative of the old master rod-makers in London, and is one of the most experienced fly-tyers who gives lessons in this useful art.

\section{Salmon Flies}

I must confess here that I have not a sufficiently extensive experience in using the flies of one-tenth the number of those who provide salmon flies for their customers. The salmon flies which I have used have been those made by Farlow, Hardy, Mallock, Holbrow, and Ogden of Cheltenham, and so far I have been invariably satisfied by the excellent value obtained.

\section{Trout Flies}

If there is any fly-tyer in the world who may claim a premier position, it is undoubtedly Mrs. Richardson ; her trout flies are, in my opinion, unbeatable. They are small as a rule, but most beautifully made. This lady makes, I believe, for Mr. Ogden Smith, and this will account for the excellent qualities of the flies of this well-known firm.

Farlow and Bernard both make a most perfect fly. For delicacy and perfection it is hard to choose between them, but in the smaller kind of eyed flies I think Bernard's are hard to beat; while Farlow's trout flies, especially the finer and larger kinds, are superlatively good. Hardy Brothers sell most excellent flies, not perhaps so small or delicate as Farlow or Bernard, 
but strong, useful, and attractive. I have some thousands of artificial flies, the greater number of which are Farlow's.

Mr. James Ogden, of Cheltenham, makes a remarkably good artificial fly, and lays himself out specially to imitate any natural fly sent to him.

The reader should never forget that each fishing centre has at least one local tackle dealer, and that such tackle maker is the best authority to whom to apply for information as regards the best flies to use. Therefore it is well when fishing a district new to the fisherman that he should take advantage of such local knowledge and give the flies most commonly recommended in each district a trial.

\section{FLy-Books}

The "Winchcombe" combined eyed fly and cast case is a very compact, strong, and light case, capable of holding sufficient flies for the longest day's trout fishing. The flies are well protected. It is bound in pigskin, and is one of the most convenient fly and cast books I have used. The price is only 8s. 6d., and it is made by James Ogden, of Cheltenham.

The "Onsight."-Ogden Smith, of Knightsbridge, make a most excellent fly-box and cast-case in japanned tin. It is strong, well made, and the most useful metal case I have yet seen. There are ten separate divisions, each capable of holding twentyfour flies. The tops of these divisions are transparent, 
so that the various flies can be seen at a glance before each is opened. Its price is $10 \mathrm{~s}$. $6 \mathrm{~d}$. It also has a compartment with cast-damper, and a combined scissors and tweezers. The size of the case is 5 by $3 \frac{1}{2}$ inches by 1 inch, so that it can easily be carried in any pocket.

\section{How to circumvent Midges, Sand-flies, Mosquitoes, etc.}

My experience, as far as insect pests are concerned, has been an extensive one, ranging from the Ti-Tree swamps of North Queensland to the estuaries and bays of New South Wales; from the swamps of South America to the Gulf of Florida; from the low veldt of South Africa to the estuary of the Nile; from the Campagna of Italy to the North of Norway; and in all these and many other regions flies have worried my sensitive skin until life became for the time being wellnigh unendurable.

I had tried many preventives against the fly nuisance, but had not so far found one which was pleasant to use, permanent, and effective.

Seeing a notice in the Fishing Gazette regarding a preparation said to be a certain protection against the objectionable familiarity of the above noxious flies, I sent to Mr. Frank Rogers, 327, Oxford Street, London, W., for a spray and bottle of his "Muscatol," and found that, instead of having to smoke like a furnace to keep off the objectionable torments who will at 
times insist on giving my head, hands, and ankles the benefit of their too pressing attentions, I simply spray on a delightful and cooling scent, which effectually keeps them off. In the interest of my readers, either when fishing, shooting, sketching, land-surveying, etc., I can most sincerely recommend "Muscatol," and consider that this clever invention deserves all the pleasant things which were said about it in the Fishing Gazette and elsewhere.

\section{BINOCULARS}

There will be occasions when the use of the butterflynet for securing floating or flying Ephemeridæ may be impossible or inadvisable. To give one such instance-a trout lying in a perfectly glassy backwater may often be observed steadily rising and sucking down certain flies which are floating downstream; such a fish may be taken if an artificial fly is delicately presented to him, but your chance of securing him will be reduced to a minimum unless you present the right fly at the first cast.

It is essential to discover this fly, also to keep out of sight ; below you the water is too deep for wading, and the flies beyond the reach of your butterfly-net.

The use of a strong and light pair of field-glasses is on this, as on other similar occasions, most useful. Concealed below your fish in the long grass, with such a pair of binoculars you can easily discover the sort of fly the trout is taking, and also any fly beyond the reach of your net. 
L. K. Leon, of 167, Piccadilly, has just brought out a field-glass called "The Queen," which magnifies over five diameters, and has an adjusting centre by which the glass can be instantly adapted to whatever may be the distance between the eyes, thus keeping the "field" absolutely straight; while another improvement is a retaining focus, which, once regulated, remains fixed whether the glasses be shut down or drawn out. In appearance the new glass is exceedingly neat and smart-looking, and it is of the lightest possible weight.

With this glass I can easily distinguish the fly which I see floating on the water at a distance of 30 or 40 feet from the bank.

\section{Gear-Case}

The "Dee" tackle-case, invented by Mr. Bryes Leake, and sold by J. Bernard and Co., is one of the best all-round cases $I$ have seen. It is made of the stoutest butt leather, fitted with a spring lever lock, and is divided into a variety of trays and compartments, specially designed for the salmon and trout fisherman. It is light, strong, and well arranged.

\section{The GafF}

This important and useful weapon is made either on the telescopic principle or as a combined gaff and wading-staff. When selecting one, some consideration will have to be given to the circumstances under 
which you are going to fish. If attended by a gillie or a friend, the latter kind of gaff is always preferable. In dangerous water it can be taken from your companion and used not only to test the bottom, but to steady yourself against a rapid stream. The bottom end of such a gaff should be shod with a steel point. It can also be suspended from the shoulders by a strap.

When you are unattended, however, a telescopic gaff is advisable. There are several varieties of this gaff, but the most useful will be that one which hangs securely within reach with the hook uppermost, and which can be immediately detached and extended ready for use.

The fisherman who has to gaff his own fish will probably have enough to do in playing his salmon without having to trouble himself as to a refractory gaff.

Hardy's "New Zealand" gaff is a very convenient and safe form of telescopic gaff.

Sir Hubert Maxwell's folding gaff, sold by Farlow, is also very convenient and safe to carry.

In handing the gaff to another person, for obvious reasons it is always safer to hand it hook foremost.

\section{The Landing-Net}

The landing-net should be of such a description that it can be unhooked, opened, and extended with one hand, as it should be used whenever a fish is landed. It should be carried, when not in use, well out of the way, and yet in the most handy position, and the 
web of the net itself should be as high as possible from the ground, and so placed as to clear the brambles and other dangers. The handle is all the better for being telescopic, the extension of the upper part being checked by a lever key, etc. A telescopic handle is most useful, as it can be used short when wading, and can be at once extended when fishing from a high bank. The lighter the landing-net the better, so long as strength or balance is not sacrificed. Landing-nets are many, and in every well-known tackle shop good landing-nets are to be purchased.

A good net I have used, and which I now use, is the "Eclipse," made by Hardy Brothers, who, at my suggestion, fixed a spring check on the handle. This check is most convenient, as it controls the extension of the inner tube, and prevents the telescopic handle from extending when wading. In their recent catalogue I notice this net is made without this check, but it can no doubt be added if necessary.

Farlow and Co. supply an excellent little net, invented by His Honour Judge Percy Gye. It is cheap, light, and very handy. The last one I used was taken out of my hand by a crocodile during the rainy season while netting a tiger-fish in the Sebakwe River, Matabililand.

\section{WATERPROOFS}

Burberrys are so well known that it is hardly necessary to emphasize the many excellent points of their goods. One of the most useful articles they sell, in 
my opinion as a fisherman, is their "Slip On." It is very light, comfortable, and easily carried when not in use, and absolutely rain-proof. I have used this waterproof when fishing in heavy rains during the whole day, and it has kept me perfectly dry.

The advertisements of Rowland Ward and Co. will be found on $\mathrm{p}$. viii. I have invariably found their work most excellent.

I would also draw the attention of my readers to the advertisements of the Llangammarch Wells Lake Hotel and other hotels, and to the excellent accommodation and fishing they offer.

\section{Sight and the Influence of AnNo Domini}

As the years roll on and as Nature begins to exact her toll on our faculties, the difficulty of threading the fine points of our cast through the minute eye of our trout fly will perhaps be more and more noticeable, and we shall find that in order to do so we have to hold our fly and our line, etc., a little further and further from the eye.

An observant friend will probably say, "Ah, my boy, it's glasses you're wanting !" and the penalty of age will then perhaps for the first time be recognized.

Our oculist will tell us that we must wear glasses, etc.; and when we get to our stream we shall then begin to find that the ordinary form of glasses, while 
they restore our sight, become in other respects an intolerable nuisance.

Not only do they occasion the loss of time, but they are continually being mislaid and frequently injured.

Pince-nez are perhaps the handiest form of glasses to wear, but even these invariably get in the way, the hand, etc., continually catching in the silk cord, and the glasses being jerked off the nose. Spectacles are too much trouble, and take too long to place on the nose when the crisis of a "rise" is on, and the fly has to be changed, etc. After a variety of experiments, I have invented and patented spectacle-frame attachments which can be fixed to the cap, and which can be riveted or readily attached to the arms of any pair of spectacles, and by means of which the spectacles when not in use are kept on the peak of the fishing, bicycling, or shooting cap, the fez, or the smoking-cap, etc.; a single motion of the hand places the spectacles on the nose, or replaces them securely out of danger on a hook placed on the front of the cap, which hook prevents the glasses from coming down.

In both positions they are absolutely secure, and the cap can be lifted from the head with the usual ease when the spectacles are on or off the nose.

The advantages of these glasses are many, and will be readily appreciated not only by sportsmen but by all short-sighted persons. The framework of the glasses can, of course, be filled with any kind of lenses, and attached to any cap, etc. Personally, I can safely say that I have found this arrangement of the greatest 
possible comfort, not only when fishing, bicycling, etc., but when indoors. The plate on advertisement page xxvi. shows these glasses when in use, and also when placed in perfect safety on the peak of the fishing-cap.

In this plate the patent arms are shown as riveted to the ends of the arms of the spectacles, but the patent arms can be purchased with self-attachments, so that one end can be at once readily fixed to the cap in any desired position, and the other with equal ease fixed to any part of the arms of an ordinary pair of spectacles -in which case the unnecessary ends of the arms of the spectacles between such point and the ears should be filed off, and the spectacles kept permanently on the cap.

\section{The Fly-Net and Fisherman's Lamp}

The usefulness of these articles has already been described in Chapter III., and further particulars can be seen on advertisement pages.

\section{Conclusion}

In conclusion, I trust that this book will be of assistance to many, and of offence to none, and that while following the paths familiar to all fishermen, I may be pardoned for depending almost entirely on my own experience and ideas in the matter of "The Science of Dry Fly Fishing and Salmon Fly Fishing." 


\section{APPENDIX}

\section{SALMON VERSUS TROUT ON THE HAMPSHIRE AND OTHER STREAMS}

The Salmon and Fresh Water Fishing Bill introduced by Lord Carrington into the House of Lords has as its primary object the improvement of the present salmon industry by stopping, if possible, the rapid decrease in the number of salmon visiting certain of our rivers. There are some clauses, however, in this Bill which have disturbed to no small extent the tranquil security enjoyed by riparian owners and trout fishermen generally, and which clauses more immediately affect those who own or fish on the classical trout waters of the Hampshire streams. Even if this Bill secures the objects for which it has been framed, it will at its best benefit but two or three riparian owners, a very few salmon fishermen, and but a very small proportion of those who are, or who may be, interested in these rivers, while it is feared, and with much reason, that certain clauses of this Bill, unless safeguarded, will result in serious injury to the interests of every other riparian owner, a very large number of trout fishermen, innkeepers, tradesmen, river-keepers, labourers, and a certain proportion of the country-side. It will deteriorate property on which much capital has been spent, and on which property it would otherwise be spent.

That the number of salmon visiting a small portion of the Test has declined cannot be denied, but whether the measures suggested will generally improve this state of affairs, or whether 
in endeavouring to improve it a far greater evil will not be inflicted on the majority of those interested in the river, is the vital point now affecting this question. If certain salmon obstructions are cleared away, salmon will undoubtedly run up in additional numbers to some three or four miles at least of the salmon portion of the river. If they do so, some or many may go higher, and this will mean a possible danger to the rest of the river, which is purely a trout stream.

In order to minimize or avert these dangers the Test and Itchen Trout Fishing Association was formed in April, 1907. This Association represents a very great majority of riparian interests of these rivers, and the committee which has been elected is a powerful and distinguished one, representing the best sporting traditions of the country. The objects of this Association are mainly the protection of the trout fly fishing interests, and it is well that this unrivalled sport should be so ably represented.

In discussing the pros and cons of the situation, which are in many respects applicable to other salmon and trout rivers, it will, perhaps, be better to deal with one of the two principal rivers immediately interested-the Test and the Itchen. I shall, for the sake of the argument, deal with the former.

A very small proportion of this river has been in the past mainly devoted to salmon fishing, and it is admitted by every one that the number of salmon taken by rod fishermen, etc., has materially decreased during the last twenty years.

It is impossible to state to what extent the number of salmon visiting the Test has fallen off, or even to obtain reliable returns from the lower waters of the number of fish killed thereon. On the upper salmon beats-say the Broadlands waters below Romsey-the annual take of salmon on the rod some fifteen years ago was occasionally one hundred per annum; the average annual take for the last five or six years is less than fifteen. This will serve to show the considerable falling off in sport above Nursling, and the necessity of arresting, if possible, this state of annual decrease. 
The salmon fishermen above Nursling are admittedly the principal sufferers, and they attribute their dearth of salmon mainly to the obstruction below Nursling Mill.

Net-fishing in the river used at one time to be most lucrative, but it is now practically abandoned, although it is supposed that illegal netting below Redbridge is by no means unknown. But even if this be true, it cannot seriously affect the question. There are, undoubtedly, fewer salmon in all parts of the river than formerly, and that in this case it is not due to nets is certain. The causes must be sought elsewhere.

It is probable that the general falling off of the salmon in the Test may in part be due to the narrow passage on the Southampton Water and the very considerable disturbance of the water about Southampton. The increased destruction of salmon food-herrings, etc.- - round our coast may be an explanation of this annual decrease in the number of salmon returning to this river, and, most likely of all, as suggested to me by Mr. R. B. Marston, it may be due to the frequent heavy firing at the entrance to the Southampton Water.

The Test may be roughly considered to be divided into three sections : the water below Nursling, the water from Nursling to below Mottisfont-say to and a little above the late Foster Mortimer's water, "the Island,"-and the rest of the Test water above the latter place. The two former include all the salmon fishings, comprising about eight miles of the river; the last, the trout fishing portion of the Test, having a length of over sixty miles.

Just above Nursling Mill the river splits up into two portions, one-the Test River-running through the mill and over the mill-weir to the east, and the other-the Little River-running to the west, these two branches joining again above Redbridge. The Little River is not only very prolific, but as a salmon river is earlier than the Test itself. The fishings below the mill at Nursling consist of two beats, the Nursling and the Testwood waters. 
The owner of the farm-land below Nursling Mill possesses, or claims to possess, the rights to control the hatches of the Little River, in the interest of his water meadows. A very large number of salmon enter the Little River, and are, by the closing of his hatches on that river, forced into the ditches of his water meadows, and as the water is altered from ditch to ditch, they either perish or disappear-some probably go back to sea. That this arbitrary closing of the hatches on the Little River is responsible for much of the evil is undoubted. Not that the hatches are entirely closed : they are open sufficiently to permit a small stream of water to flow, but, as a rule, insufficiently to permit the salmon to run to the water above.

At an inquiry held in 1906 by the Board of Agriculture and Fishing the fact was elicited that there is no approved fish pass on the Testwood beat, the lowest salmon water on the Test, and therefore a large number of salmon are probably unable to get up, except in the time of extensive floods; but no supervision of water has so far been possible, as the land is private on both sides of the river.

Riparian owners of the salmon portion of any river are naturally anxious as to rent, and when an acknowledged obstruction at the head of or near above their own water does not injure the prices obtainable for their own fishing, they may fail to take any vigorous steps to insist on proper passes being maintained. The Board of Fisheries should, however, see that no obstruction exists, and as their bailiffs can with perfect ease step in where strangers are not allowed, they can insist on adequate and reasonable passes being available at all times for the passage of salmon.

This would, in my opinion, satisfy the owners and salmon fishermen on the four miles of salmon water above Nursling.

It was elicited at the above-mentioned inquiry that the water in the Little River is stopped for months togethersufficiently, in fact, to prevent the salmon running until after the rod season is over-and that this has been done under the 
plea of irrigation purposes. It is at present under the statute law illegal to stop the running of salmon, and this appears to be a case in which the law should be enforced, as the salmon are thus practically stopped, and are not permitted to ascend in any quantities above Nursling until the rod season is over, and the salmon rod fishermen above suffer as a consequence.

The newly appointed Hampshire Fishery Board, if influenced by a competent, independent and uninterested public policy, will endeavour to protect the salmon fishermen on the upper part of the river from the action of those on the lower reaches, and will equally endeavour to protect the trout-fishermen above, if permitted by law to do so.

The bailiffs of the Board have, in virtue of their office, the freedom of exercising the most unrestricted vigilance, and, if honest and determined men, will, so far as they are sufficient in number, fulfil their duties. Prejudicial obstruction to the ascent of salmon would possibly become a thing of the past, as hatches, fishing, premises, and methods, would be liable to the unexpected visitation of the bailiff.

Now, the unchecked ascent of the salmon from the tidal waters will no doubt improve the position of the salmon fishing waters below Mottisfont, but it may do more : it may seriously affect the trout water above.

If the salmon obstructions are cleared away, salmon will undoubtedly run up in additional numbers; if they do so, it will mean a possible danger to the trout stream.

At present the statute forbids any stopping of salmon when running, and if, which is possible, the salmon increase $i_{n}$ numbers and threaten to ruin the upper water of a trout stream, no legal remedies can at present be taken. If the law be locally altered under the advice of the Board, and a reasonable understanding be arrived at by all riparian owners, security could be given to the trout waters by the erection of weirs below Mottisfont.

Owing to the limited number of fish which now come into the river and the splendid reaches of spawning-ground between 
Romsey and the tidal waters, the natural run of the salmon may be considered to cease at or below Mottisfont ; but there is always a danger that if the number of salmon increases in anything like the quantity which is possible, the breeding fish will be continually pushed higher and higher up the stream in search of spawning-ground, much to the injury of the trout fisherman. Nature in some rivers imposes barriers which most effectually control the ascent of salmon, but as long as no obstacles exist the salmon will run up. The running upward of salmon when spawning is no idle fancy, and is a direct danger to the trout stream.

When the hen fish has selected her spawning-ground and decided on the place for her redd, she is-so far as my experience goes-but rarely disturbed. Other female fish pass her and seek beds higher up the water (which is the danger the trout fisherman fears) ; the cock fish in his turn, if able to do so, drives other cock fish up-stream, or is driven himself away; and when his duties with one hen fish are finished, unless utterly spent, he proceeds, generally above the scene of his late duties, to fertilize the ova of other hen fish.

It is only natural to suppose that each cock fish requires at least one little place that he can call a redd, and one mate whose company he wishes to monopolize, and therefore during the spawning operations there is no room in his immediate vicinity for other breeding fish of his own sex. Hence the continued ascent of salmon into the upper and more remote waters of the trout stream. It is this danger-a very real one-which naturally alarms those who regard the classical reputation of these beautiful and famous trout streams, and the inviolate sanctity of these rivers as trout streams, an inalienable right and privilege of incomparable value.

The salmon fisherman very naturally wishes to see the threatened ruin of his sport prevented. The trout fisherman, with equally natural desires, wishes to avoid the threatened danger to his trout streams.

If it were possible to form a combination of interests and to 
fight side by side instead of against each other, these legitimate desires could, so far as the Test is concerned, and presumably in other rivers, be achieved, and that at no sacrifice to either party. This is, of course, the difficulty, for the real divergence of interests is at the present moment more between the respective salmon fishing interests than between the respective interests of salmon and trout fishermen.

The views of the owners of each salmon beat cannot be considered as identical. Each owner would very naturally like to see the salmon allowed every facility for running at least as far as the upper waters of his own fishing, but would perhaps consider that this limit (his own water) was a very excellent place to check the upward running of the fish.

This evil to the majority could only be legitimately stopped by amending the law as it at present exists. Strong Parliamentary action might lead to such amendments as would permit the great majority of riparian owners in the common interest to check at some agreed upon place on any specified river any future influx of salmon, unnecessary so far as the salmon industry and undesirable in so far as the trout waters are concerned.

But from whatever cause this decrease arises, the increase in the number of salmon returning to the Test will probably never affect the trout waters above Mottisfont; but it is wiser to consider the possibilities, and to the riparian owners above Mottisfont the possible danger that their waters may be thus affected is very real. Their course seems plain.

In the first place, a mutual agreement between the riparian owners, as regards both salmon and trout, above Nursling would probably result, not only in adequate and combined representation on the Hampshire Fishing Board, but in obtaining Parliamentary sanction for the erection of weirs capable of stopping the run of salmon above, or even below, Mottisfont, should such be necessary. From my own knowledge those interested in salmon above Nursling have no desire to see the salmon permitted so high up the river as Mottisfont. 
The interests below may possibly desire to see the salmon no higher than Nursling Mill itself, and therefore a modus vivendi should be possible which would ensure the best results for all the various interests. At present, however, those interested respectively in salmon and trout fishing are on opposite sides of the camp.

Are the interests, however, of the salmon and trout fishermen antagonistic? If they are not so, then the sooner the fact is recognized the better for both parties. The only argument in favour of permitting salmon to run above Mottisfont, or above Mortimer's Island, which can possibly be used, is that the decrease in salmon is owing to the want of sufficient spawning-grounds in the lower reaches of these rivers. If salmon required more spawning-ground and could only obtain such by ascending these rivers, it might be necessary to allow them to ascend, but to a certain limited extent, and for spawning purposes alone.

But taking the case of the Test as an example, I fail to see how such an argument can be advanced as an excuse for injuring the trout river, or, indeed, any claim made in favour of such a necessity.

Excellent beds for spawning exist up to Romsey, five miles above tidal waters; but a very large percentage of salmon spawn below Nursling, in both the Test and the Little River, and in the remainder in the river as far as the island above Romsey, while the very few which get up to Stockbridge in the winter are not heard of again. There is ample spawningground between the tidal waters and the island above Romsey for tens of thousands of other fish, if there were these numbers to spawn; but, unfortunately, there are no such quantities of fish returning to the river, and the numbers which do return are perceptibly decreasing each year, although the water favourable to, and available for, spawning purposes has not in any way been curtailed. Hence the argument that more salmon would return to the river if more extensive spawninggrounds were opened falls to the ground; and as spawning- 
ground is not wanted, the trout waters should be protected by weirs or by some artificial obstruction.

The falling off in the salmon beats above Nursling is elsewhere to seek, and it is in part due to the obstruction. That the rod fishermen have to suffer from a yearly decrease in the salmon they kill below Romsey is a misfortune which might be lessened if there were less obstruction about Nursling.

The salmon are undoubtedly in the river, and run above Mottisfont as high as Stockbridge (below which former place I think they ought to be stopped); but I fail to see how they can be legally prevented from doing so, unless the law be altered.

On the other hand, I cannot believe that, if it were the unanimous wish of all the riparian owners on a river that some such barrier as I have suggested should be erected, such a project would be allowed to fall to the ground.

If this is admitted by all parties, then it only means the determination of some particular part in the river at which the run of salmon should be checked, and collective action taken, to ensure not only the improvement to the salmon fisheries, but to add to the security of the trout fisherman.

The right of the riparian owner to decide as to the best interests of his own water should be upheld if such decision does not prejudicially affect the rights and privileges of others.

That the right of the individual should be safeguarded has been the basis of English law, but this protection should be exerted with equal force when the rights of many individuals and communities are concerned.

Riparian rights are owned by communities as well as by individuals, and these rights are threatened by the passing of this Bill in its present form.

Why should the few interests which this Bill is designed to assist be catered for at the expense of the many?

In a case in which interests are likely to clash, the rights of the majority should prevail. This is the principle which each successive Government endeavours to instil on the 
Opposition, and so long as they continue in power, the game is with them. Governments are not, however, permanent institutions. Riparian interests are; and, therefore, unless it be to obtain some great good for the community generally, any Bill which deals with dual interests should be most carefully safeguarded in order to prevent a possible benefit to the few from endangering the undeniable permanent interests of the many. 


\section{INDEX}

Accuracy, Preface, 4

Alder, 76, 81, 82, 91

Alevin salmon, 151-157 trout, 102-112

Ambidexterity, 6, 137

"Angler's Diary," 142

Arcque River, 86

Australia, 70

Austrian Tyrol, 70

Bailey, Walter, 113

Bakewell, 71

Baldock, 107

Barton, Dr. Kingston, 180, 181, 182

Beck, Mr. George, 168, 170, 190

Bernard-Shaw Creel and Bag, 260, 261

Black Forest, 70

Black Gnat, 82

Board of Conservators, 117, 193-199

Bryant, G. R., 105, 106, 107

Bulging, 90, 91

Olive Quill for, 91

Hare's-lug, 91

Butterfly-net, 43, 44, 57, 63, 120, 121

Caddis-fly, 79, 80

Cap, the, 51 as a fly-holder, 121, 122

Cast, the trout-

the back, $7,8,9,10,11$

breaking the, 68

final, 28

forward, 12-21

hints, 268, 269, 270

mending the, 68

selection of, 268

side, the, 22,23

steeple, the, 21

strength of, 268

wind, the, 24, 25,26

Casting, attention to, 60

delicacy in, 39
Casting, faulty, 58

lightness in, 39

long-distance, 28

night, 89

lawn, on the, 4

rock, on a, 73

varying direction of, $31,32,33$, 34

Casting salmon fly, Chapter IX., 210, 211,212

curved, 213

straight, 213

Castle Connell, 3

Casts, 268, 269, 270

Casts, salmon, the, Chapter IX. curved, the, 227

Galway, the, 223, 224, 225

loop, the, 228, 229

overhead, the, $214-220$

side, the, 225

Spey, the, 229, 230, 231, 232, 233

Wye, the, 221, 222, 223

Wye variation, 233-237

Catching the fly, 121

Cinnamon fly, 80

Chilland, Lower, 107

Claret Smut, 82

Clinker, Thos., 107-136

Cloëon rufulum, 77

Close season, trout, 112, 113, 114, 115 , 116

Club Fishing Agency, 147

Coachman fly, 85, 86

Conservators, Board of, 117, 193-190

Coquet, 71

Corixa, 76

Corrie, E. Valentine, 14, 15, 106, 107

Country Life, 120, 180

Cowdung fly, 82

Creels, 260, 261

Curragh, the, 261 
Dam, natural, 134

Dee tackle case, 275

Diptera, 75, 76, 82

Disgorger, 54, 257 and Lancet, 257

Domesticated trout, 102

Double-handed rod, 200

Dove, the, 71

Drag, 23, 24, 42

Drowned fly, 46

Dry fly, hints on, 40, 124 fishing, 40, 53, 70, 71

Dry fly fishing, three flies, 122, 123

Dun, the, 78

Autumn, 78

Blue, 79

Golden, 82

Iron Blue, 79, 83, 84

Olive, 79, 86, 91

Red Quill, 79, 51

Early rivers, trout, 116, 117

Elan Valley Fisheries, 143, 144

Elbow as pivot, 7, 8

Enright, Mr. John, 3, 13

Ephemeridæ, 45, 75, 76, 77, 78, 79, 84

Evanger River, 179

Expressing the food of trout, 86

Farlow and Co., Chapter X.

Faults, 54, 55, 216

Felide, Norway, 87

Fellow fishermen, 66 due consideration for, 66

Field, 120, 142

File, 54, 67

Fisherman, necessities of the, Chapter X.

Fisherman's elbow, 137

fly-net, 43,57

knife, 52, 54, 67, 121, 257, 258 lamp, 89, 90

Fishing bag and creels, 260, 261

Fishing Gazette, 120, 142, 177, 263

Fishing, a comparison, 61

Agency, 147

a run, 69

creels, 260

dry fly, 37-40, 70, 71

glasses, 274

hints, $56,60,61,65$

hours for, 86,87

methods of, 37-40

on a hot day, 73

requisites for success, 39
Fishing, for salmon, 200, 201

spectacles, $278,279,280$

the rise, 44

the stream, 46

using reel when, 65

wet and dry fly, 37-40,71, 72 , 131

wet fly, 131, 132

wet fly, down-stream, 131

wet fly, up-stream, 38, 129, 130

where to go for, 142-147

Flies, 43, 79, 80, 119

cleansing, 54

discussed, 43,45

drying the, 54

fancy, 119

floating, 48

natural, 119

replacing after dark, 89

sinking, 37,38

wet, 131, 132

what to use, etc., 120,121

Fly-books, 272, 273

casting for salmon, Chapter IX.

catching the, 121

clearing the, 68,69

salmon, the, 187, 188, 270, 271

trout, the, 270, 271, 272

Fly nuisance, 273

oiling the, 48

Fouling the rod, 10

Fungus, 135, 136

the cure, 136

Gaff, 275

Gaffing a salmon, 209, 210

Galway, the cast, 223, 224, 225

Gear-case, 275

Grace, Dr. W. G., 3

Grannom, 80, 83, 84

Grey, Sir Edward, Preface, 119, 246

Grilse, 165, 166, 167

Gula River, 168

Gut, 268, 269, 270

Halford, 14, 82, 91

Hardy Brothers, 137

Mr. Foster, 258

Mr. Lauri, 137

Harling for salmon, 204, 205

Hasty judgments, 75

Hawthorn fly, 82

Hints, 56, 74

Hooks, blunted, the, 66, 67

various, 54, 267, 268

Hughes, Rev. Daniel, 132 
Hughes, Reginald D. Hughes, 140, 141

Hungerford, 145

Hutchinson, Horace C., 119, 120, 180

Imago, 45, 78, 79, 87

International Tournament, 1904, . . . 137

Irfon, 71, 86

Itchen, the, 71, 106, 107, 134, 136

Lower Chilland, 106, 107, 134, 136

Itchen Abbas, 106, 107

Kelt, 168, 169, 170, 177

Kennet Valley Fisheries, 110, 118, 134,145

Knife, fisherman's, 52, 54, 67, 121 , 257,258

Knight, Horace, 77, 80

Knots, 51, 68, 124-128

Lambourne, the, 71

Lamp, 89

Landing-nets, 276, 277

Langlabat, Loch, 191

Larvæ, 45, 77, 78

Late rivers, salmon, 167 trout, 116, 117

Learning to cast, 210,211

Left hand, 6

Lewis, Island of, 191

Line, the, 262, 263

alive, 17, 28

Bernard, Chapter X.

dead, 28

drying the, Chapter $\mathrm{X}$.

Farlow, Chapter X.

fouling the rod, 10

greasing the, 27

Hardy Brothers, Chapter X.

keeping it clear, 88

lifting the, 29

long, the advantage of, 28

shooting the, 17

smashing on water, 58

suitable for rod, 262

tapered, 27, 28

the, Chapter X.

varying the plane of, 25

winding up, 73

Lines, various kinds, Chapter $\mathrm{X}$. salmon, 262,263

trout, 262, 263

Llandrindod Wells, 146
Llangammarch Wells Hotel, 71, 86, 143

Long-distance casting, 138

Loop cast, 228, 229

Luck, 132

Magnifying glass, 43

Mahseer, 90

March Brown, 79

Marston, R. B., 67, 263

Marston, Mr., 67

Maxims, 245, 246

May fly, 75, 77, 86, 87

Mending a rod, 148, 149, 150

Mid-day rest, 70, 71

Mint, wild, 56

Moonrise, 90

Morse, Captain T. R., 118, 145

Moths, 122

"Muscatol," 273

Namsen Lakes, 190

River, 168

Naylor, A. Wellington, 179, 180, 190, 191, 192

Necessities of the fisherman, Chapter X.

Net, butterfly and fly, 43, 44, 57, 67 , 120,121

landing, 276, 277

Normandy, 70, 91, 97

Norton Fisheries, 107, 134, 144

Notonectidæ, 76

Nymphæ, 87, 91

Oak fly, 82

Ogden Smith, 271

Oil-bottle, 263

Old Joan, 81

Olives, blue-winged, 79

Otter, the Devonshire, 71

Overhead cast, salmon, 214-220 trout, Chapter I.

Paraffin, 47, 92

Parr, the, 157, 158, 159, 161, 162, 163, 194

Pennell, H. Cholmondeley-, 171

Peppin, George, 86

Perlidæ, 75, 76, 80, 81

Phryganea, 80 larval stage, 80 pupal stage, 80

Pisciculture, 89, 90, 102, 103, 104

Priest, 54, 63

Pupa, 43, 77, 78, 84, 85 
Quill, Blue, 49

Olive, 91

Red, 51

Rainbow trout, 110

Redds salmon, 151-155

Red Quill gnat, 51, 86

Reel, 4, 212

striking from the, 60

using left hand, 6

using, 65

various kinds, 264, 265, 266

Reels, silent, 266, 267

Refraction, 94, 95

Rest, mid-day, 70

Richardson, Mrs., 271

Rise, the, 44, 56, 57, 82, 83, 86

advantage of, 56,57

after dark, 88

cause of, $82-86$

evening, 87,88

locating the, 58

moonlight, 90

never mind, 68

Rivers : Arcque, 68, 87

Axe, 83, 134, 135

Colne, 134

Dart, 111

Deveron, 40

early, 116, 117

Evanger, 179

Grimersta, 191

Gula, 168

Itchen, 39, 106

Ithon, 146

Ivel, 144

late, 116, 117

Namsen, 168

Otter, 86

Sid, 71

Spey, 229

Test, 39,86

Tyne, 195

Wutach, 86

Wye, Derbyshire, 71, 86

Wye, Monmouthshire, 71, 86, 196, 197

Rod, 5

broken, 148, 149, 150

dropping point, $63,64,65$

fouling with line, 10

length, 249

lifting the, 27, 215

pivot of the salmon, 211, 216

pivot of the trout, 7

pliancy, 251
Rod, rests for, 41

selecting, 248, 249, 250, 251, 252

stiffness, 249

weight, 250

whippiness, 250

Rods, makes and makers, 252, 253, $254,255,256,257$

power of, 60

spinning, 139, 256

Sagging the salmon line, 200

Salidæ, 75, 76, 81

Salmon, 151-213

aggressiveness, $171,172,174$

casts, Chapter X.

clean, 170

common law, netting, 194, 195

rod fishing, 194, 195

feeding in fresh water, 170-185

first, the, 203, 204

fly, the, 186, 187, Chapter X.

fly casting, Chapter IX.

food, 170-185

gastric glands, 181

injured, 152, 154, 166, 167

instincts of, 151, 152, 153

Kelts, 168, 169

licenses, 199

life of, 153,154

lines, 263

lures, 186, 187

netting for, 193

50 -pound, a, 156, 242-245

poaching, 199

record take of, 190, 191, 192

Redds, 151-155

rising, non-, 188

sea lice, 179

sustenance of, 172

theories as to, $174,182,183$

Salmon fishing, 188-190, 200-203

casts, the, for, 212,213

gaffing, 209

harling, 204, 205, 206

learning, 210, 212

methods of, 202,203

netting, 193

rise, when, 207

rod, with the, 194, 195

spinning, 206

Salmon rivers, early, 116, 117

late, 116, 117

rights of, 194, 195

Salmon $v$. Trout, Appendix

Sand fly, 80

Scissors, 52, 257, 258 
Scourie Hotel, 145, 146

Screwdriver, 67

Sea lice, 179

Sedge, orange, 80,85 red, 80 silver, $80,87,90$

Senses of trout, 92-101

Shaw, Dr. P. E., D.Sc., 101 John, 103

Sheringham, H. T., 94

Shooting the salmon line, 219 the trout line, 17

Shute Arms, 83, 145

Side cast, salmon, 225, 226 trout, 22,23

Sight of trout, 42,93

Smolts, 159, 161-165

Smuts, 87

Spawning salmon, 154, 167, 168

Spawning trout, 113, 114

appearance of, 115

close season, 115

conditions affecting, 115

early, 113

early rivers in, 115, 116, 117

feeding when, 114, 115

late, 113

late rivers in, 115, 116, 117

weather affecting, 115, 116

wild fish, 115

Spear, 47

Spey cast, 25

Spey throw, the, 229, 233

Spider fly, 82

Spinner, 78

jenny, 79

red, 79

Spinning for salmon, 206

for trout, 138, 139, 143, 141, 267

Stock fish, trout, 105

Stone fly, 80, 81, 86

Stone, Livingstone, 103, 104, 111, 135

Stoning a salmon pool, 184, 185

Strike, the, 16, 20

Striking salmon, 207, 208 trout, 38, 59, 130, 131 from the reel, 60

Sub-imago, 78, 84, 87

Sutherlandshire, 145

Tackle case, 275

Temperature, 85, 110

Test, the, 39, 86

Thames Conservancy, 135

Thyme, wild, 56
Torres Straits, 101

Trichoptera, 75, 76, 77, 79, 80

Trout, 49

appearance, 118, 119

breeding, 102, 103, 104-112

bulging, 90, 91

close season, 113, 114, 115

colour distinction of, 92

culture, 103-116

domesticated, 103-116

expressing their food, 86

enticing to rise, 73

farms, 103

fighting a, 55, 62, 65

flies, 270, 271, 272

growth, 111

handling, 53

hearing of, 92,93

jumping, 63, 64, 65

killing, 53

licenses, 199

lines, 262, 263

Lock Leven, 49, 145, 146

missing, 50

netting, 52, 65, 66, 193, 199

playing a, $41,42,52,55,62,65$, 69

position of, 42,44

putting down, 58

rising short, 50

scaring, 39, 99

season, 112

setting up, 69

spawning, 113

spinning for, 138-141, 207, 267

taste of, 92

times to fish, 86,87

vision of, 50, 93-101

Vadheim, 70

Vision of trout, 50, 93-101

Waders, 259

Wading, 258

Walton, Izaak, 2

Waterhouse, Charles A., 77

Water insect, the, 75, 133

Diptera, 75, 76, 77

Ephemeridæ, 75, 76, 77, 78

Notonectidæ, 76

Perlidæ, 75, 76

Salidæ, 75, 76, 77

Trichoptera, 75, 76, 77, 79, 80

Water insects, $45,75,104,105$

hatching of, $45,77,78,80$

Waterproofs, 278 
Weeds, 133, 134 as dams, 134 breeding-places, 134 shelter, 133

Welshman's Button, 80

Wet fly fishing, 37-40, 72, 131, 132 arrangement of flies, 131, 132 down-stream, 131, 132 striking, 130, 131 up-stream, 129, 130

Where to fish, 142, 143, 144, 145, 146 Wiblin, Dr. John, 122

Wind, casting against, 24, 25, 26

Winder for lines, 41
Wrist, rigid, 7, 8, 9, 22, 24, 25, 26

Wutach, 86, 137

Wye cast, 221, 222, 223 the use of, 237-241 variation of, $233,234,235,236$, 237

Wye, River, Derbyshire, 71, 86 Board, the, 197

Wales, 71, 197

Yellow Sally, 68, 81

Yoke sac, salmon, 156, 157 trout, 106

Young, Rev. Hamilton, 40

THE END 


\section{INDEX TO ADVERTISERS}

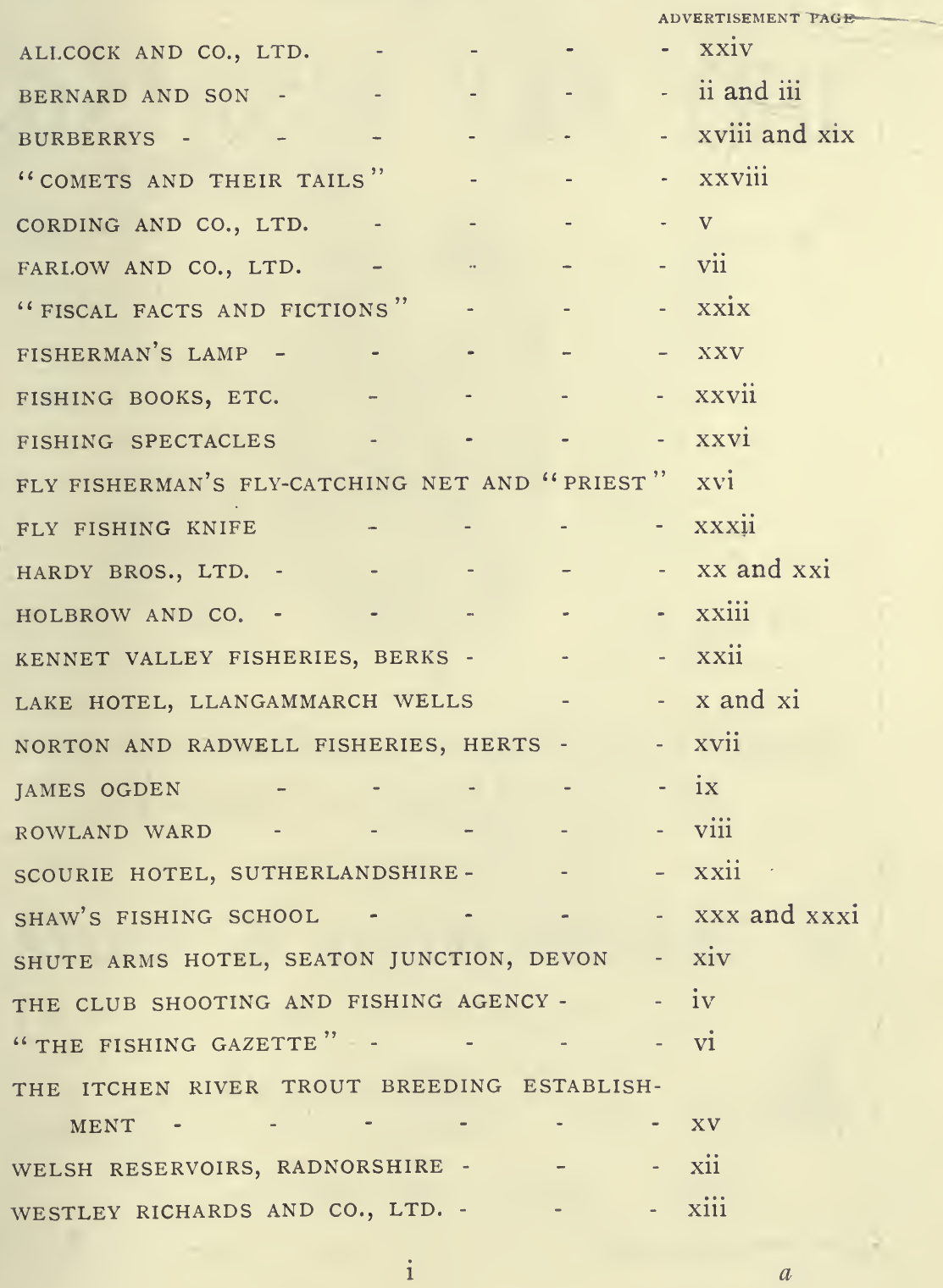




\section{The "FAIRY" \\ OUTFIT FOR}

DRY FLY FISHING.

\section{Best hand made \\ SPLIT CANE RODS,}

$8 \frac{1}{2}$ to Io feet, very stiff in action, and beautifully balanced, with shaped cork handles, and lockfast joints, etc.

Weights $4 \frac{1}{2}$ to $7 \mathrm{oz}$.

$\$ 4$ 10s. Od.

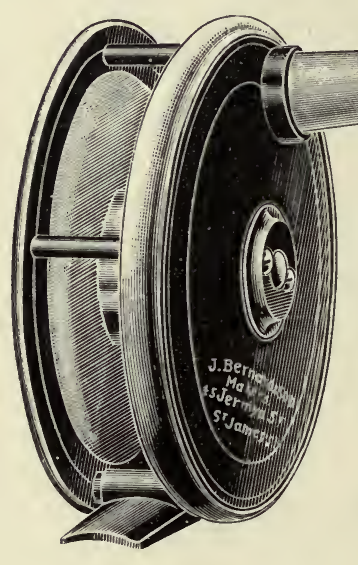

Special "TEST"

REELS

(as illustrated), made from our new metal, very light and strong, .. with narrow barrel and large drum. Sizes :

$2 \frac{3}{4}$ in. 3 in. $\quad 3^{\frac{1}{4}}$ in. $3^{\frac{1}{2}}$ in. $19 / 6 \quad 21 /-24 /-27 / 6$

Weights from $4_{\frac{3}{4}}^{3}$ to $6 \frac{1}{2}$ oz.

Special Double Tapered Oil=dressed Lines, made expressly for these Rods, 10/6 each.

J. BERNARD \& SON, 45, JERMYN STREET,
ST. JAMES'S, S.W.

CATALOGUES FREE.

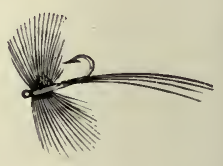




\section{The BERNARD=SHAW Combined FISHING BAG \& CREEL.}

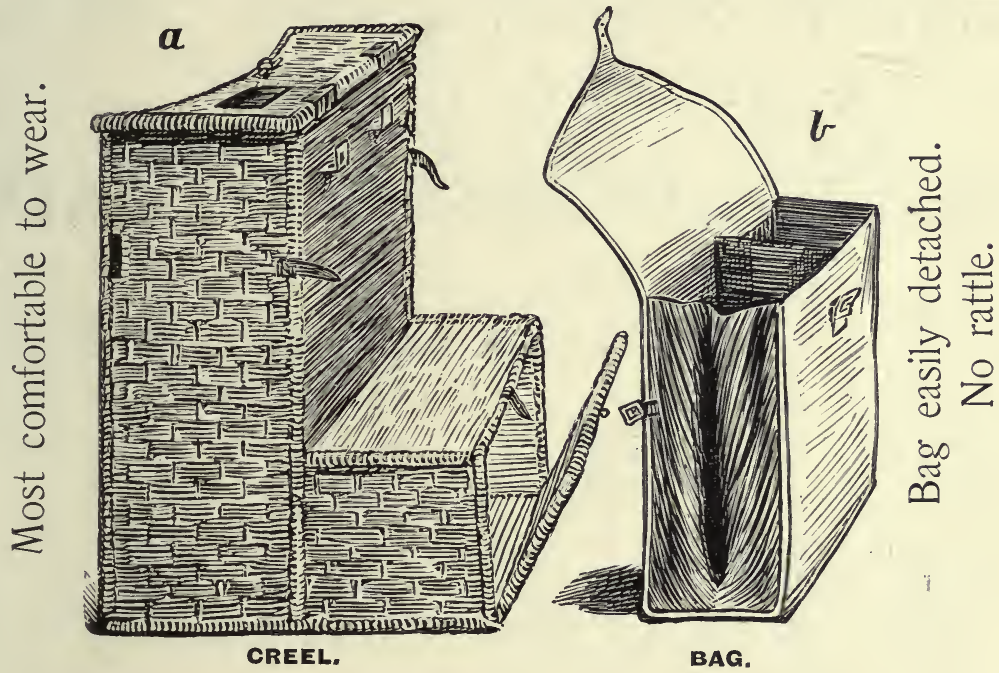

THE MOST CONVENIENT COMBINATION ON THE MARKET.

Easily cleaned. Very light. Perfectly secure and strong.

Cool for fish and for wearer.

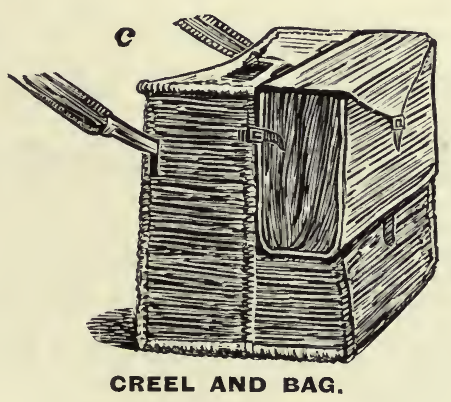

The Fishing Gazette says :

"It is an ingenious idea and very practical."

2

\section{Price 25/=.}

Everything complete.

\section{J. BERNARD \& SON,} 45, JERMYN STREET, S.W. 


\section{For DEER FORESTS, GROUSE MOORS, LOW GROUND SHOOTINGS, FISHINGS,}

ENGLISH, SCOTCH \& IRISH ESTATES TO LET OR FOR SALE, Apply to Messrs. TENNANT, ROSS \& WALLACE, Ltd., The Club Shooting and Fishing Agency, 19, HANOVER SQUARE, LONDON, W. (Next door to the Oriental Club.)

Telegraphic Address: "Fishpond, London." Telephone : 4692 Gerrard.

N.B.-Messrs. Tennant, Ross \&. Wallace, Ltd., make a speciality of Sporting Estates, and the personal attention of the Directors is given in every case. Particulars of Shootings and Fishings to let or for sale are inserted in their Register free of charge.

The Best Book of Reference for Sportsmen and Others INTERESTED IN Scotland IS

\section{THE SHOOTINGS OF SCOTLAND,}

PUBLISHED BY

Messrs. TENNANT, ROSS \& WALLACE, Ltd., The Club Shooting and Fishing Agency,

I9, HANOVER SQUARE, LONDON, W.

150 Illustrations. Special Sporting Map. Of all Booksellers, or of the Publishers. Price 3s. 6d.; or post free, $4 \mathrm{~s}$.

The Publishers have the honour to announce that His Majesty has been graciously pleased to accept a copy of the above work for inclusion in the Royal Library. 


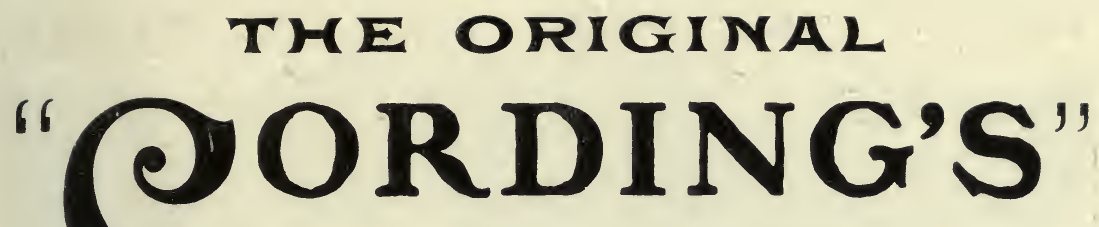

(J. C. CORDING \& Co., Ltd., Estd. 1839),

SPECIALISTS IN

HIGH-CLASS WATERPROOFS

FISHING,

SHOOTING,

General Purposes.

\section{WADING OUTFITS. sear}

MAKERS of

ABSOLUTELY WATERPROOF THIGH, KNEE, and "IDSTONE" ANKLE BOOTS.

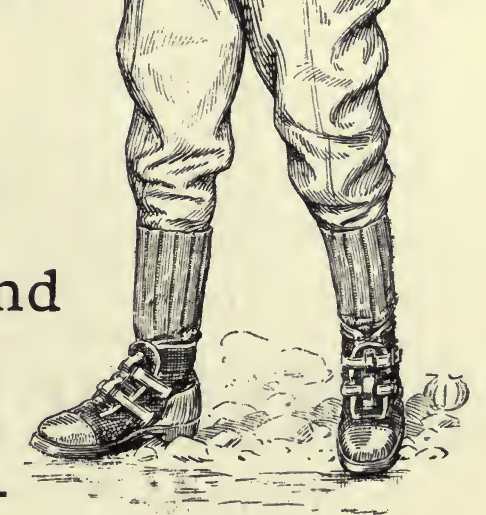

ONLY ADDRESSES:

19, Piccadilly, corner of Air street, w., AND

35, St. James's St., $\begin{gathered}\text { Corner of } \\ \text { Jermyn st., s.w. }\end{gathered}$ 


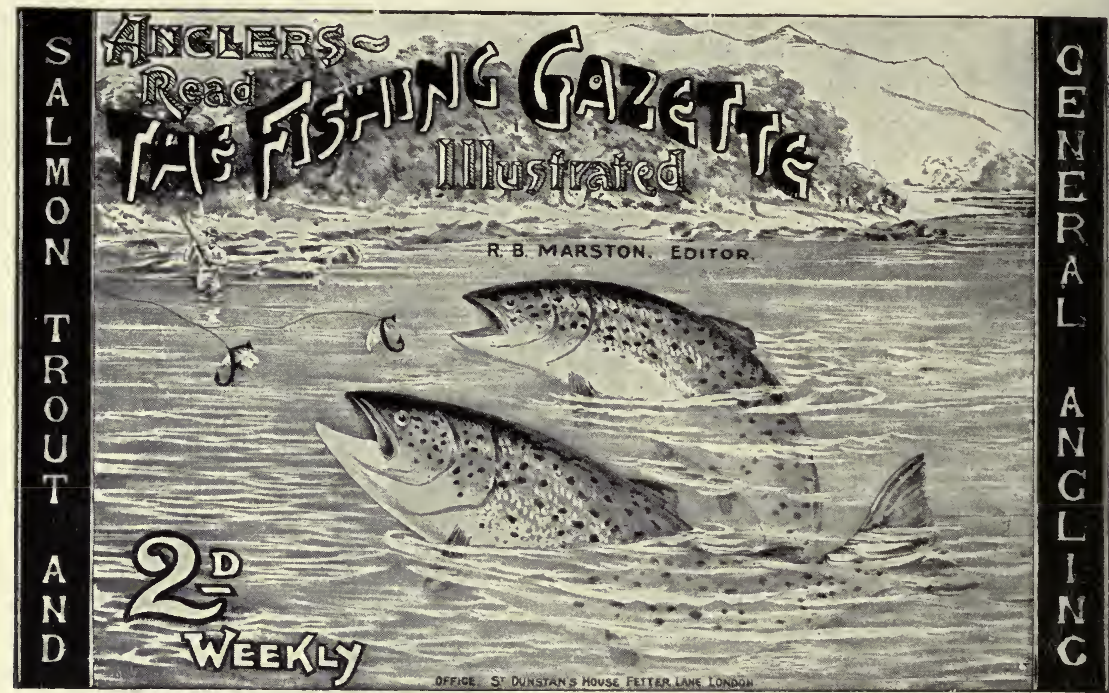

Devoted to Angling, River, Lake, and Sea Fishing, and Fish Culture.

ESTABISHED 1877.

\section{A JOURNAL FOR ANGLERS.}

EDITED BY R. B. MARSTON.

"Under the editorship of Mr. R. B. Marston the Gazette has attained a high standing."-Daily Neres.

"An excellent paper."-The World.

PUBLISHED WEEKLY, PRICE 2 d.

Prepaid Subscription, 10/6 per Annum. To America and the Continent, 12/6 per Annum.

THE "FISHING GAZETTE" contains every week Original Articles, Reports, etc., often Illustrated, on Salmon, Trout, and General Fishing. Reports from the principal Rivers, and Correspondence.

THE "FISHING GAZETTE" contains the latest ADVERTISE.MENTS of the Leading Fishing Tackle Houses, Anglers' Hotels, Waterproof Makers, Fish Culturists, etc., etc.

LONDON : OFFICE OF THE "FISHING GAZETTE," ST. DUNSTAN’S hOUSE, FETtER LANE, FLEET STREET. Can be obtained throngh all Bookstalls and Nerosagents.

\section{SIXTH EDITION. NOW READY. \\ DOMESTICATED TROUT: How to Breed and Grow Them.}

By LIVINGSTON STONE, United States Deputy Fish Commissioner.

One Vol. Crown 8ro. Cloth extra. 367 pages, with good Index. Price 12/6 net, post free. See foot, * **

"I shall take pleasure in recommending this book to anyone who wishes a standard work on troutbreeding."-Hon. SPENCER F. BAIRD, United States Commissioner of Fish and Fisheries.

"An invaluable work for the practical fish-breeder, and all who keep trout in ponds or streams."-Fishing Gazette.

THE FISHING GAZETTE, LTD., St. Dunstan's House, London.

** Please cross Cheques and Post Orders "Union of London and Smiths a/c Fishing Gazette, Ltd." 


\section{FARLOW \& Co., LTD.,}

10, CHARLES STREET, ST. JAMES'S SQUARE, LONDON,

\section{And 191, STRAND, LONDON,}

Manufacturers of First=Class Rods and Tackle.

\section{Farlow's "Perfect" Cork-Handle Greenheart Salmon Rods for Ladies.}

These are made in 3 pieces, $\mathrm{I}_{4} \mathrm{ft}$. and $\mathrm{I}_{5} \mathrm{ft}$. The grips are made of solid cork, thereby dispensing with the wood that is usually left for the grip. The cork handle has a hole bored through it to receive the butt, which is the same size under the cork as above the grip. Consequently the play is continued to the winch, thereby giving greater casting power than ordinary Rods of the same length.

Suction Fittings, Upright Rings, and Revolving Head Rings. Two Tops and Top Case.

$$
\begin{aligned}
& \text { I } 4 \text { =ft. Rods weigh about } 23 \text { ozs. Price } \mathbb{E} 15 \mathrm{~s} \text {. } \\
& \text { I } 5 \text { =ft. Rods weigh about } 26 \text { ozs. Price } \& 35 s \text {. }
\end{aligned}
$$

The Reel recommended for the $\mathrm{I}_{4}$-ft. Rod, size $3^{\frac{3}{4}}$ inches,' weighs IO $\frac{1}{2}$ ozs. Price $\boldsymbol{E}_{3}$.

For the I 5 -ft. Rod, size 4 inches, weighs I2 ozs. Price $\boldsymbol{t}_{3} \mathbf{5 s}$.

These Reels are made of Alloyed Aluminium, and can be regulated to any stiffness at will.

\section{SILK LINES (Suitable):}

40 yds. Double Taper, specially soft dressed, $20 /=$, and 60 yds. Hemp Back Line, Spliced to above, $5 /=$.

Books on Angling kept in stock.

Illustrated Price List Gratis and Post Free.

\section{FARLOW \& Co., Ltd.,}

10, CHARLES STREET, ST. JAMES'S SQUARE, LONDON, And 191, STRAND, LONDON.

Telegrams : "Greenheart," London.

Charles St. Telephone No. : 2380 Gerrard. Strand

," 2620 


\section{ROWLAND WARD, LTD.,}

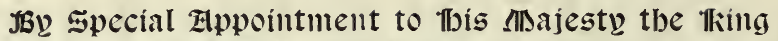
allo $\mathbb{W}$. $\mathbb{R} . \mathbb{W}$. the $\mathbb{P}$ rince of vales.

Practical Naturalists and Artistic Taxidermists, Designers of Trophies of Natural History, Preservers and Adapters of all Specimens of Animal Life. Natural Features of Animals adapted in Original Designs for Decorative Purposes and every-day uses. Furriers and Plumassiers and Collectors in Natural History.

\section{HEAD TROPHIES \& HORNS} FOR DECORATION.

The preservation and careful artistic treatment of Head Trophies are among the most noted achievements in the Jungle studios.

\section{Bird Stuffing \& the Stuffing of Small Animals}

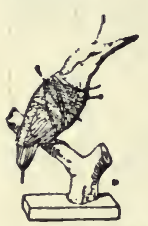

In the simplest and most inexpensive way are undertaken by ROWLAND WARD, LTD., with the same rigid attention to the best artistic result as they bestow on the most elaborate and costly designs and combinations of rare specimens.

FISH MOUNTING A SPECIALITY, by New and Artistic Methods.

\section{HOOFS of ANIMALS MOUNTED IN NEW}

"Observations on the Preservation of Hoofs and the Designing of Hoof Trophies," by

ROWLAND WARD, F.Z.S. Post Free, 2d.

\section{CABINETS \& APPARATUS fOr ENTOMOLOGISTS.}

\section{ILLUSTRATED CATALOGUE POST FREE.}

ESTIMATES for the desired preparation or setting up of specimens

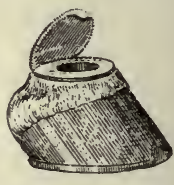
can be presented, when it will appear that the prices charged, even when compared with those quoted by ill-instructed and unprofessional practitioners for common shop sale, are in reality not incommensurate with the highest-class workmanship and art quality.

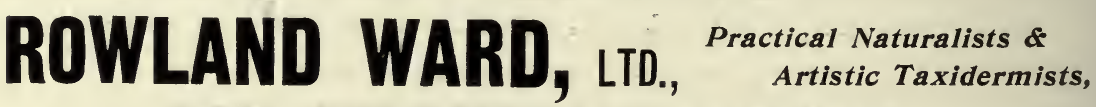 167, PICCADILLY, LONDON.




\section{JAMES OGDEN,}

\section{CHELTENHAM,}
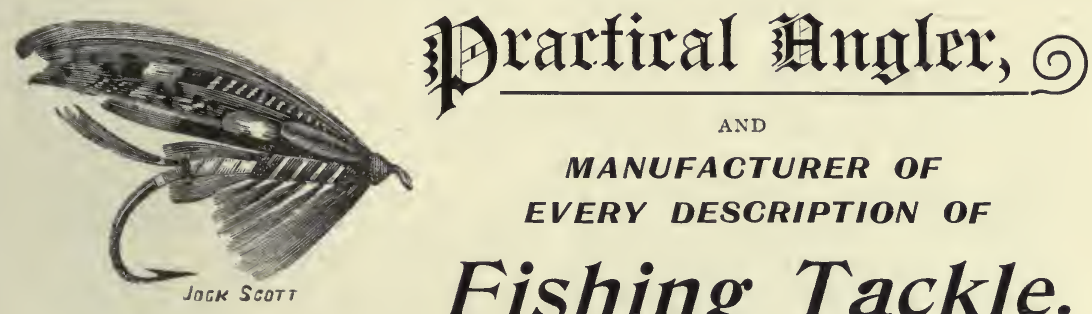

\section{MANUFACTURER OF EVERY DESCRIPTION OF Fishing Tackle.}

MAKER OF HICH-CLASS SALMON, GRILSE, AND TROUT RODS.

बरू०

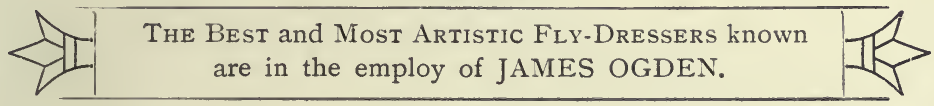

वरros

\section{JAMES OGDEN'S}

\section{"Multum in Parvo" Fly Rod, 21s.}

A better Fly Rod is beyond the art of Rod-Making.

Sent on approval for inspection.

IMPORTANT CAUTION.-The only man by the name of Ogden engaged in the Fishing Tackle Business in Cheltenham. 


\section{LLANGAMMARCH WELLS, BRECON.}

\section{LAKE HOTEL.}

Surrounded by splendid scenery, with lake and river fishing, two miles flowing through the Hotel grounds.

\section{TROUT FISHING, FEBRUARY TO OCTOBER.}

GOLFING, LAWN TENNIS, ROUGH SHOOTING over about 1000 acres, FISHING, BOATING, LOVELY WALKS, BILLIARDS, BOWL s.

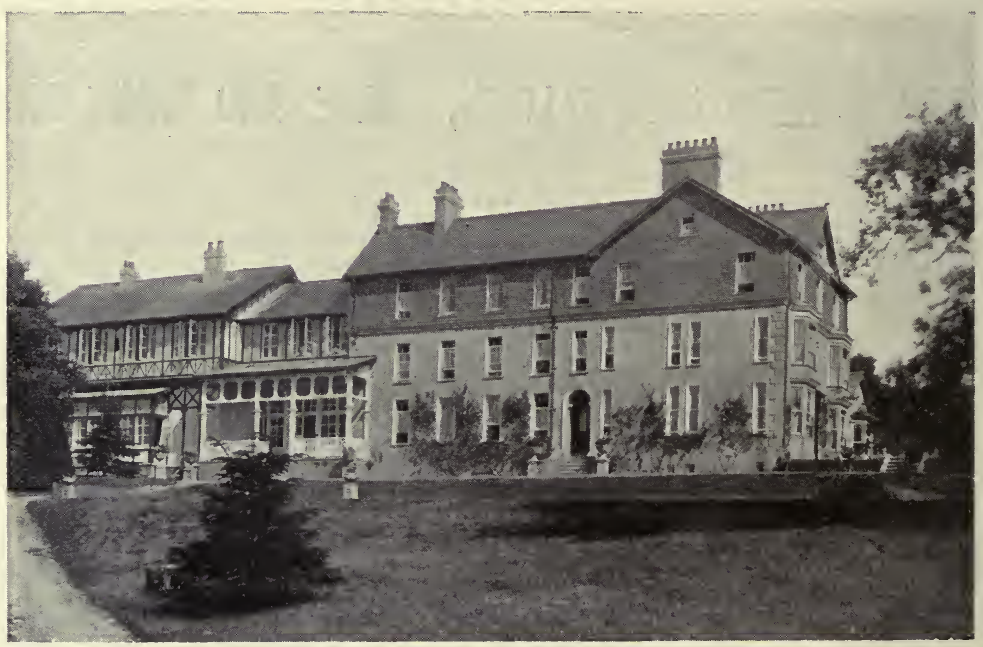

This first-class Hotel, standing about 800 feet above sea-level in its own ornamental grounds, is situated on the slope of the Eppynt Hills, and looks down one of the most beautiful valleys of Wales.

The grounds have been planted with some hundreds of fine Rhododendrons and Rose-trees.

ADJOINING THE HOTEL GROUNDS ARE THE

\section{GOLF LINKS OF THE LLANGAMMARCH CLUB.}

A Professional is in attendance, and visitors are welcomed by the club and are permitted to play at a shilling a day or five shillings a week. 


\section{LLANGAMMARCH WELLS, BRECON.}

\section{LAKE HOTEL.}

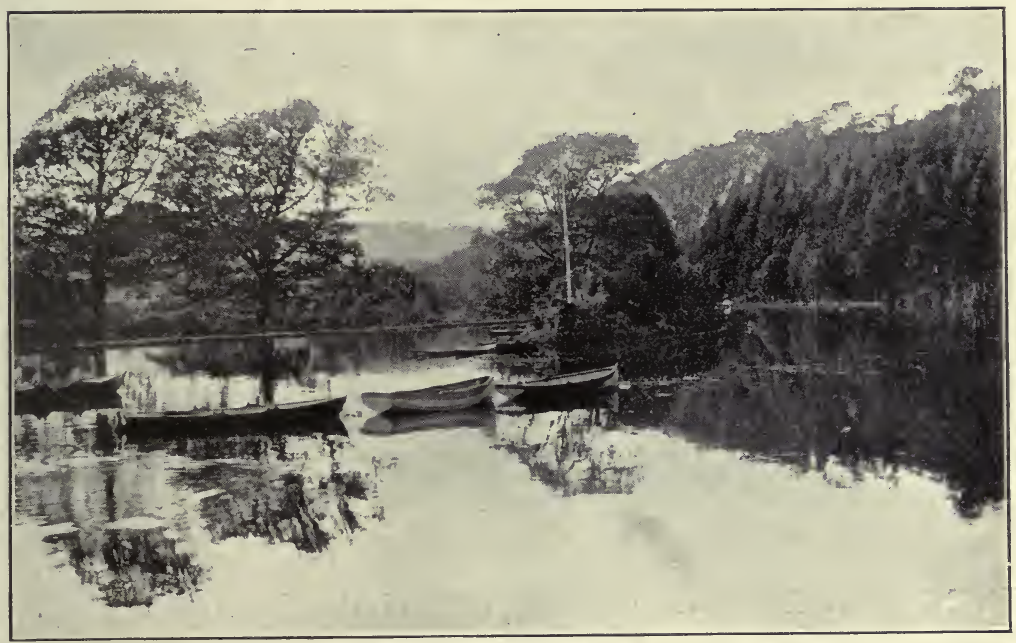

The Proprietors of the Llangammarch Wells have secured the attendance of a Physician at the Pump Room and Bath House, which are within the Hotel grounds. The well-known methods employed so successfully by Dr. Schott at Nauheim (Exercises and Baths) for the relief of Gout, Rheumatism and Chronic Heart Affections are available to patients.

The Bathing House has been fitted with porcelain reclining baths, douche, shower, wave and needle baths, and is supplied with hot and cold Barium Water. Dressing and resting rooms are available with each bath-room.

The sanitary drainage and water-supply, both of the Hotel, Pump House, and Bath House, have been carried out on modern principles, and the Hotel furnished throughout with every regard to comfort.

For the convenience of Visitors bringing their own horses, carriages, and motors, Stabling, Loose-boxes, Coach-houses and Garage have been erected.

The Hotel is conveniently situated, being ten minutes' walk from the Llangammarch Wells station on the L. and N. W. Railway, and can be reached from Shrewsbury and Swansea in two hours, Liverpool and Manchester in four and half hours, Birmingham and Potteries five hours, and London in five and half hours. Carriage meets all trains by arrangement. 


\section{Corporation of fimmingham.}

\section{WELSH RESERVOIRS, RHAYADER, Radnorshire.}

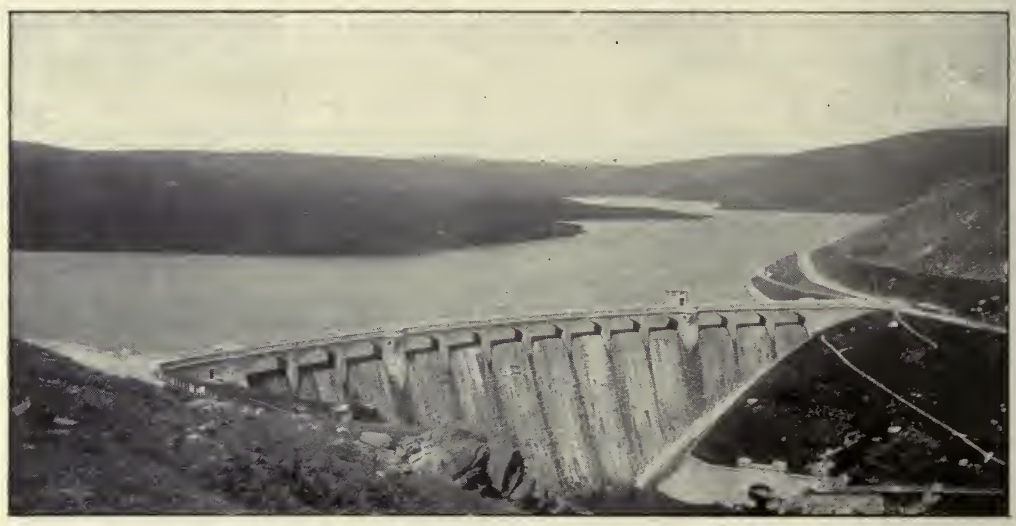

UNEQUALLED by any other Trout Fishing in the Kingdom.

These waters consist of a series of four reservoirs, with an area of about 864 acres, several natural lakes with an area of about I 34 acres, and upwards of 30 miles of rivers and streams, all of which are teeming with brown trout.

Season opens I $_{5}$ th February and ends Ist October.

Good and ample hotel and private accommodation may be had at Rhayader (Cambrian Railways).

Eight hours' journey from Euston, via Shrewsbury, Welshpool and Moat Lane.

Four hours' journey from Birmingham.

(Special travelling facilities during the summer months.)

Copies of Rules and Regulations, including a printed summary of last year's returns, may be had on application to Mr. John Jones, Estate Agent, Rhayader (who will also supply local information), or to

E. A. LEES, 


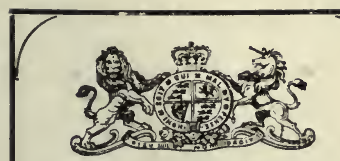

Gun Makers

By Appointment to H.M. the King.

SEND FOR List.

Fishing Gazette...." A most attractive illustrated Catalogue. The best photographs of rods I have ever seen. The most interesting part of the Catalogue is that entitled,

"Notes on Gut."

Blackburn GazeTte. - "A work of art. There is evidence that brains have been used."

County Gentleman. -"Seemis to us to merit special description."

Siorting Goods Review."An interesting and wellcompiled Catalogue. A very excellent production.

Canadian Military Gazette. - "Can get real pleasure as well as profitable amusement by a perusal of the Cata. logue.

Darwen's County Gazet7e. - "A credit both to compiler and printer. Mr. W. Baden. Powell's curve system is fully explained."

INDIAN FIEI.D. - "We must confess that for general attractiveness, style, and contents we have never seen anything to approach ' Rods and Tackle.'

AMERICAN Field. - " Any angler would enjoy and derive information from a perusal of 'Rods and Tackle.' The well-known character of Westley Richards \& Co. is a guarantee of quality."

" Westley Richards are scientific rod builders."

-The Asian.

The County Gentleman says of Westley Richards' Rods :

"In care of construction and finish down to the minutest details we have seen nothing to surpass them."

\section{WESTLEY

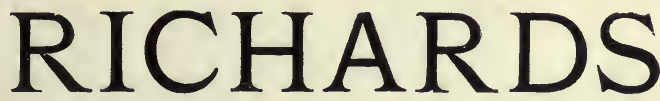

AND CO., LTD.,

\section{$\mathrm{B}^{\mathrm{EG}}$ to recommend-}

"The "Baden-Powell" II ft. 6 in. Dry Fly Rod, two joints, split cane, extra top, etc.

$£ 3$ I5s. od.

The "Gallichan," Io ft. Fly Rod, two pieces, in split cane or greenheart. $£ 2$ I5s. to $£ 5$.

As made by them for Walter M. Gallichan, Esq., Author of "Fishing in Derbyshire,"

"Fishing in Wales."

The "W. R." three-piece split cane Dry Fly Rod, with Agate butt and end rings.

$f_{4}$ I7s. 6d.

\section{2, Corporation Street, BIRMINGHAM.}

The Pioneer. - "A beautifully illustrated Catalogue. Shows rod building on scientific lines."

Shooting Times. - "Westley Richards do not go in for rule of thumb work, but carefully produce all their rods and accessories on scientific principles."
The Fifld, - " Handsomely got up and prìnted, and thoroughly well arranged. Contains one or two noticeable features, also some interesting notes on silk-worm gut."

The Sporting Goons Dealer. -- "An interesting feature of the list is an essay on gut, illustrated with micro-photographs." 


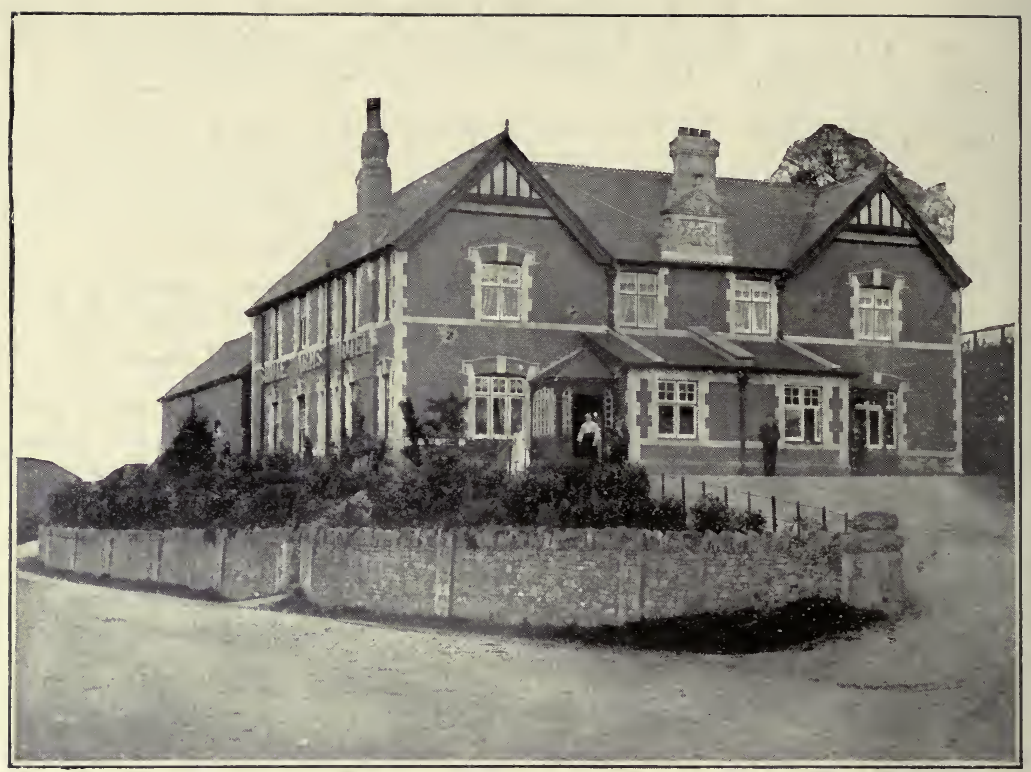

\section{SHUTE ARMS HOTEL,}

\section{SEATON JUNCTION, DEVON.}

SITUATED close to the rivers Axe, Coly, and Shute Streams, and within three miles (15 minutes rail) of Seaton, a favourite South Devon Watering-place.

Visitors to this delightful Fly Fishing Resort are granted a limited number of tickets for the river Axe.

Tariff on application. 


\section{THE ITCHEN RIVER TROUT BREEDING ESTABLISHMENT.}

River Stocking for Dry Fly Fishermen.

OVa, Fry, Yearling and Two-year-old Trout from that noted river the Iтchen can now be obtained from the

\section{ITCHEN RIVER TROUT BREEDING ESTABLISHMENT,}

where fish are reared in the river itself, and feed naturally on the surface, being to all intents and purposes wild fish, and therefore certain to thrive when turned into other waters.

Also Test Trout, Rainbows and Loch Levens, Fly Larve, Shrimps, and Fish Foods.

For full particulars apply to

The Manager, Lower Chilland, near Winchester. 


\section{Shaw's Fly Fisherman's}

\section{Fly=Catching Net \&" Priest."}

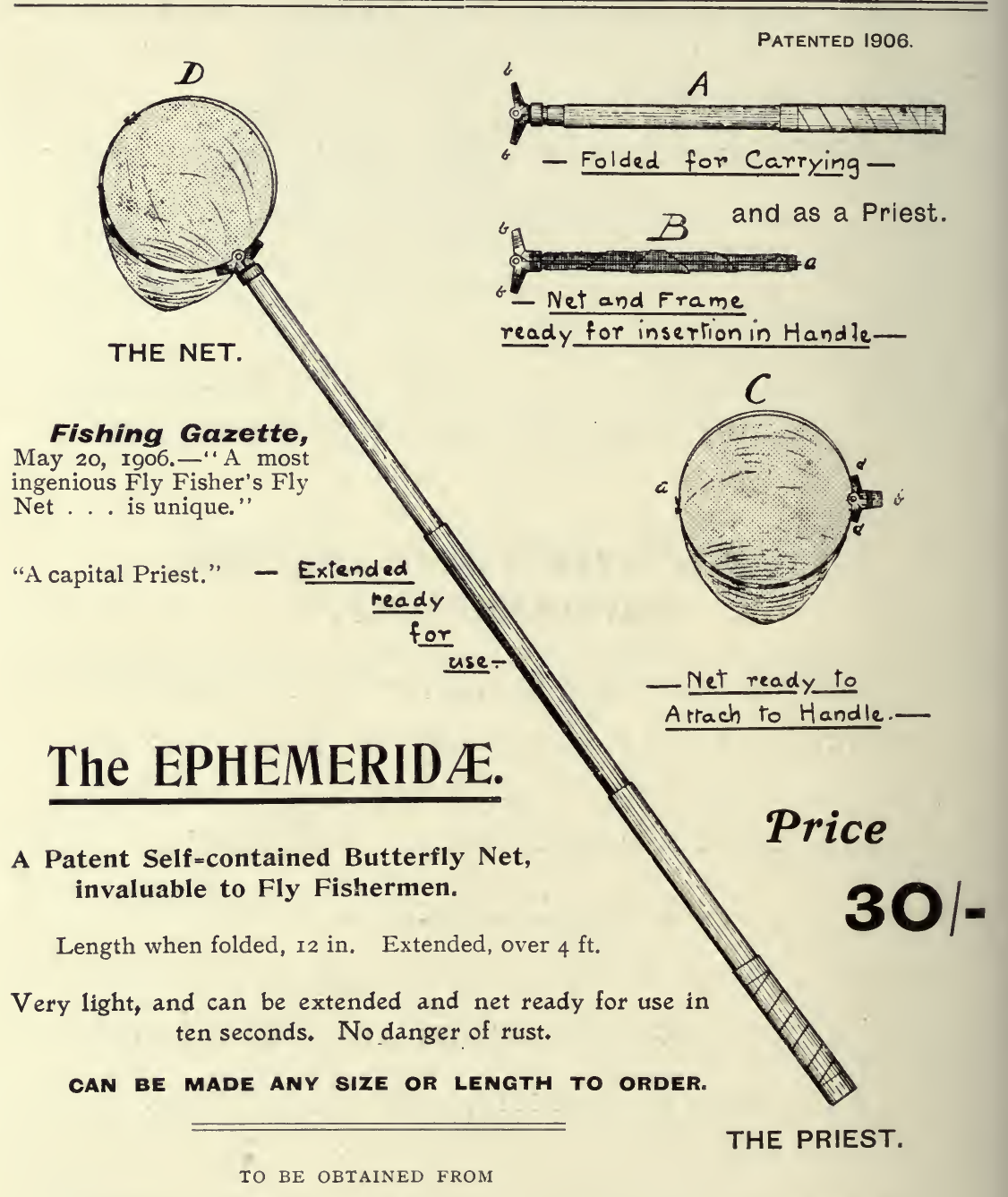

FRED. G. SHAW, II, Neville Court, Abbey Road, N.W., And from all Fishing Tackle Shops. 
THE

\section{NORTON \& RADWELL FISHERIES, \\ Near BaLdock, Herts.}

We can supply the VERY BEST

\section{BROWN TROUT and RAINBOW TROUT,}

as fry, yearlings, or two-year-olds, for stocking purposes, and cordially invite any intending purchasers to pay the Fisheries a visit, which is within easy reach of King's Cross.

As well as supplying Trout for sporting purposes, we take a limited number of Rods on our well-stocked stretch of river and lake, and consider our water second to none as regards the stock of fish and the sport obtained.

We charge 35 Guineas per Rod for the season, which commences on April $15^{\text {th }}$ and closes on October ist for Brown Trout, and on the 31 st for Rainbows.

OUR PRICE LIST WILL BE SENT ON APPLICATION

TO THOSE INTERESTED IN IMPROVING THEIR WATERS, AND ADVICE GIVEN ON ALL

FISHING MATTERS.

Apply to Secretary. xvii 


\section{A Burberry Suit}

The only possible answer to the Angler's question, "What can I wear that is healthful and absolutely weatherproof, in place of airtight mackintosh or hampering oilskins ?"

\section{Wear BURBERRY and discard other Proofs for ever.}

A "BURBERRY" is ideal for fishing because it keeps the Angler comfortable, be the weather fine and warm, or cold and wet. Light in weight, perfect freedom for limb movements, a model of convenience in pocket accommodation, with nicely adjusted balance. Rain cannot permeate, wind cannot penetrate, yet air-freedom remains perfect.

A “BURBERRY” OF AIRYLIGHT GABARDINE, lighter than summer suiting, cooler than flannels, warmer than winter cloth in cold winds, and proof against thorns, while fish-hooks cannot penetrate beyond the barb.

Full particulars of complete Angler's Kit in "BURBERRY-PROOF KIT," 17th Edition, 240 pages, over 100 Illustrations of Garments for Sport, together with Patterns and Measure Forms, free on application.

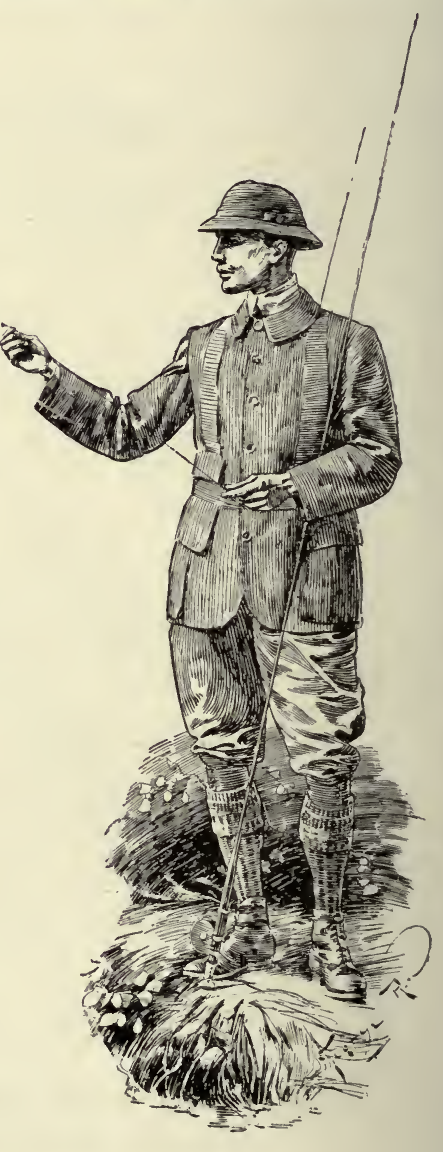

\section{BURBERRYS,}

Haymarket, LONDON, and BASINGSTOKE. 


\section{Burberry Slip-Ons}

Leave Nothing to Chance.

I. Ventilate the same as unproofed coats : (a) The best top-coats for fine days.

2. Turn more rain than mackintosh : (b) The best weatherproofs for wet weather.

3. Do not soak in wet: $(c)$ Never become sodden; $(d)$ always remain light; $(e)$ dry in remarkably short time.

4. Proofed with an imperishable proofing: $(f)$ May be dried close to a fire; $(g)$ maintain proofness for years.

5. Gabardine, from which they are made, is so finely and densely woven that it is impenetrable: $(h)$ Thorns cannot tear; ( $i$ ) fish-hooks never catch or hang up in them.

6. Exceedingly light weight. This, combined with dense texture and faultless air freedom, overcomes the seeming paradox: $(j)$ Cool in warm weather; $(k)$ warm in cold winds; ( $l$ ) never tiring.

7. Colours tone exactly with rural scenery: $(m)$ Invisible to the quarry.

8. Loose-flowing, easy-fitting : $(n)$ Perfect freedom for every movement.

9. EVERYTHING TO COMMEND THEM TO SPORTSMEN.

The WADING SLIP=ON is shortskirted, and protects the body without hampering the angler's movements. Far more protective than a cape, and more comfortable, allowing full play to arms and shoulders.

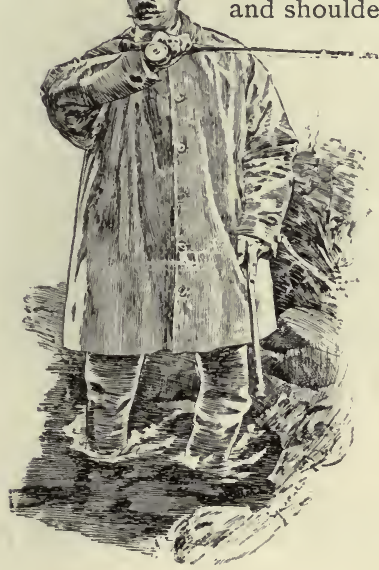

"Rain runs off it like dew from a leaf."

-The Lancet.

"As a medical man I frequently orcier your garments for rheumatic patients, and those with chest or kidney troubles. . . I have almost forgotten what rheumatic pains are like since... wearing Bur berry."

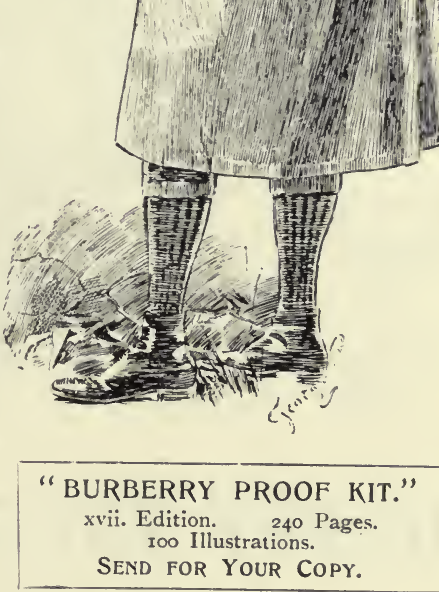

\section{BURBERRYS, HaYMARkEt, LONDON. AND BASINGSTOKE.}




\section{MANUFACTURERS \\ $-\mathrm{BY}-$ \\ Royal Appointment.}

\section{SPECIALISTS IN} DRY FLY RODS, REELS, LINES, FLIES, LANDING NETS, \&C.

CANE BUILT (Steel Centre), CANE BUILT and GREENHEART RODS for all Parts of the World.

More Awards and Championships have been won by Hardy

Rods than with any others.

\section{CATALOCUE FREE.} CONTAINS

\section{I3 ILLUSTRATIONS}

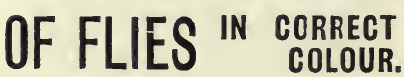

TROUT FLIES (Wet), TROUT FLIES (Dry),

MR. HALFORD'S NEW SERIES MAYFLIES,

LOCH \& SEA TROUT FLIES. SALMON FLIES.

Send your Address and we will send a Copy Free.

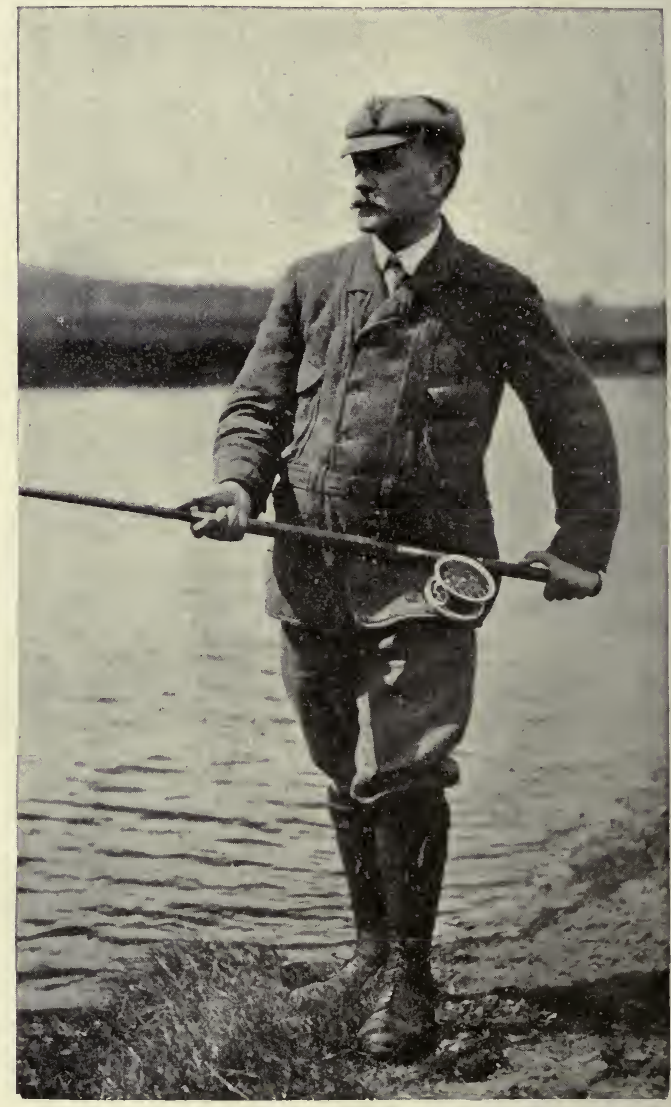

\section{HARDY BROS., LTD., ALNWICK.}

Retail Branches $\left\{\begin{array}{l}\text { LONDON : 61, Pall Mall, S.W. } \\ \text { EDINBURGH : } 5 \text { South St. David Street. } \\ \text { MANCHESTER: } 12 \text { \& 14, Moult Street. }\end{array}\right.$ 


\section{THE "SHAW" DRY FLY ROD. \&5 10s. $6 d$.}
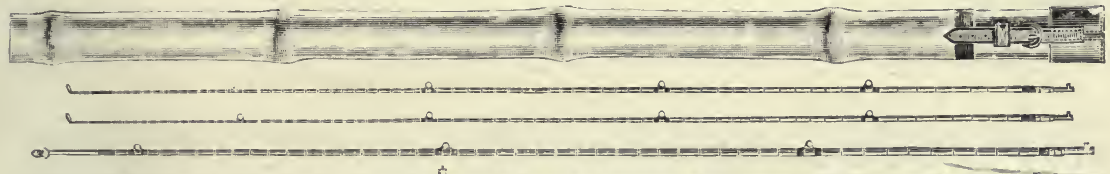

c.

11, NEVILLE COURT,

ABBEY ROAD, N.W.

Dear Sirs,

I am delighted with the trout rod you made to my specification this summer. Its action is pleasant, and its lightness is an excellent feature. You have my permission to call it the "Shaw" Rod.

Yours truly, FRED. G. SHAW.

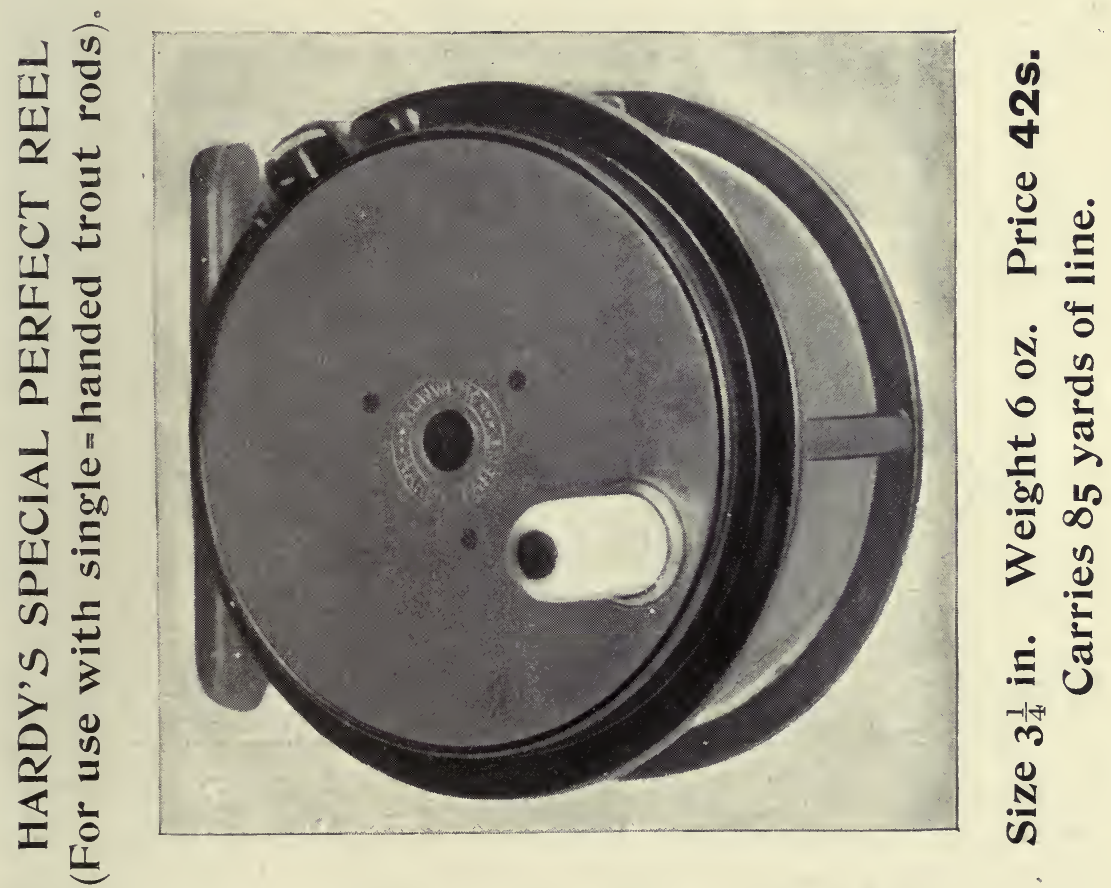

HARDY BROS., LTD., ALNWICK.

Retail Branches $\left\{\begin{array}{l}\text { LONDON : 61, Pall Mall, S.W. } \\ \text { EDINBURGH : } 5 \text { South St. David street. } \\ \text { MANCHESTER: } 12 \text { \& 14, Moult street. }\end{array}\right.$ 


\section{KENNET VALLEY FISHERIES,}

I $\frac{1}{2}$ hours from Paddington, G.W.R.

HUNGERFORD, BERKS.

\section{Trout-Breeding Establishment on the River Dun.}

$1 \frac{1}{2}$ miles from Hungerford Station.

Most satisfactory results have been achieved by stocking with Brown, Rainbow, and Loch Leven Trout from these Fisheries.

Expert advice and supervision given in connexion with the improvement and development of streams, rivers, and lakes, prior to stocking.

Water Plants and Fish Food (natural and artificial) supplied.

The Proprietors control many miles of Fishing on the Kennet and Tributaries. Application for rods should be made early in the season, as vacancies are speedily filled.

Apply: MANAGER, FISHERIES OFFICE,

\section{SUTHERLANDSHIRE.}

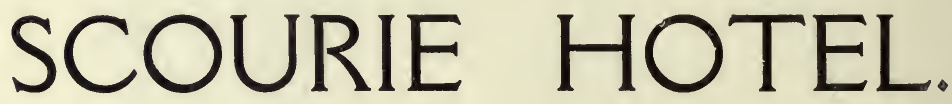

(A)

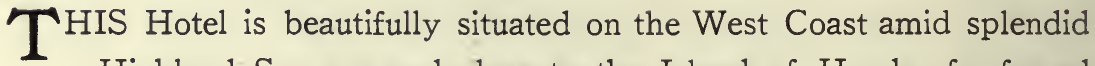
Highland Scenery and close to the Island of Handa, far-famed for its myriads of Sea Fowl and magnificent Cliff Scenery. There is superior and extensive Brown Trout, Sea Trout, and Sea Fishing, for which 16 Boats are kept. There is a resident Doctor, and Postal and Telegraph communication, also Hiring and Sea Bathing and Boating. Route: Rail to Lairg, thence per Daily Motor, Mail Coach, or Hire, or per Macbrayne's Weekly Steamers, Glasgow to Badcall, 3 miles distant.

\section{E. ROSS, Proprietor.} xxii 


\section{HOLBROW \& CO.}

40, DUKE STREET, ST. JAMES'S.

Manufacturers of FIRST $=$ CLASS

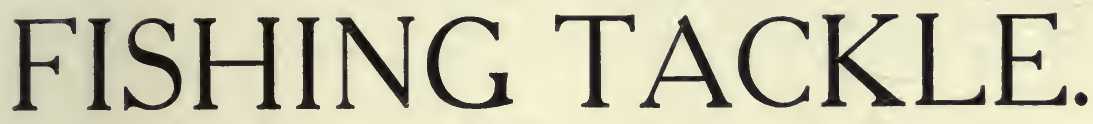

Lessons in

SALMON AND TROUT

FLY-TYING.

Terms on application.
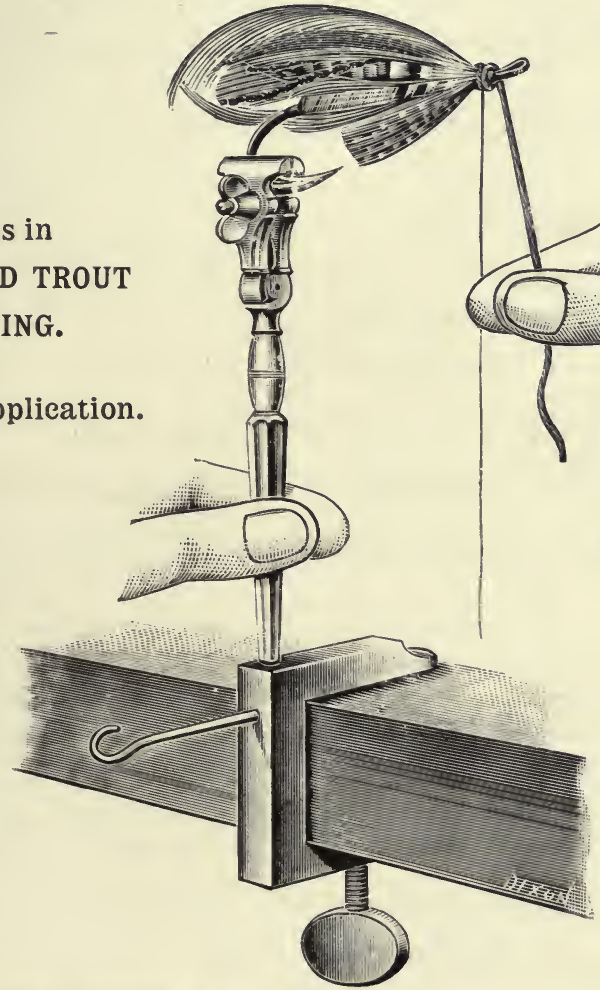

Every description of

TYING MATERIALS kept in stock.

6

Rods built to

pattern.

Can be tried in

the rough.

Sole Manufacturers of

\section{THE "WYLYE" ROD,}

MADE IN SPLIT=CANE, WHOLE=CANE, and Price, from $\mathcal{L I}_{\mathrm{I}} \mathrm{2S} .6 \mathrm{~d}$.
GREENHEART, in two and three pieces, = HOLBROW \& CO., 40, DUKE STREET, ST. JAMES'S, LONDON, S.W. 


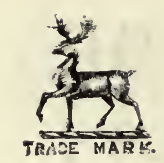

27 GOLD MEDALS AND

HIGHEST AWARDS.

“ GRAND PRIX,"

PARIS, 1900.
“DOUBLE GRAND PRIX,"

LIÉGE, 1905.

"GRAND PRIX,"

MILAN, 1906.

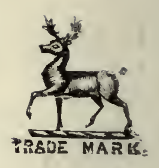

WHOLESALE ONLY.

\section{S. ALLCOCK \& CO., LTD., REDDITCH.}

\section{THE “HERCULES” GUT CASTS.}

We claim that by steeping the Gut in a special preparation the pliability and softness are so greatly increased that the subsequent process of knotting it into Casts does not injure the Gut in the least.

It not only gives to the Gut flexibility and greater strength, but also durability, as the preparation protects the Gut from the action of air and light.

\section{EVERY CAST TESTED.}

\section{THE "HERCULES", CASTS ARE NUMBERED AS UNDER:-}

No. 3490. Refina, Fine, Medium, and Strong.

, 3491. Strong for Lake Fishing.

, 3492. Extra Fine, Ix, 2x, 3x.

, 3493. Extra Extra Fine 4x.

, 3494. Light Salmon.

, 3495. Strong Salmon.

" 3496. Extra Strong Salmon.

, 3497. Extra Extra Strong Salmon.
No. 3498. May Fly Casts, Specially Tapered. Pad. 2nd to Extra Fine Undrawn.

, 3499. Tapered Refina to 3x Undrawn Trout Casts.

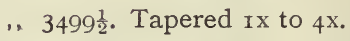

, 03499. Extra Long Undrawn Gut, Tapered Fina to Ix.

All the above are made from the very best selected Spanish Gut, and each Cast carefully tested.

Can be bad in 1,2 , or 3 Yards, except where Tapered.

THE STRONGEST. Each Cast is labelled "Hercules," with our Trade Mark on.

\section{THE “HERCULES" GUT CASTS.}

THE ABOVE CAN BE HAD FROM ANY GOOD TACKLE DEALER. 


\section{SHAW'S FISHERMAN'S LAMP.}

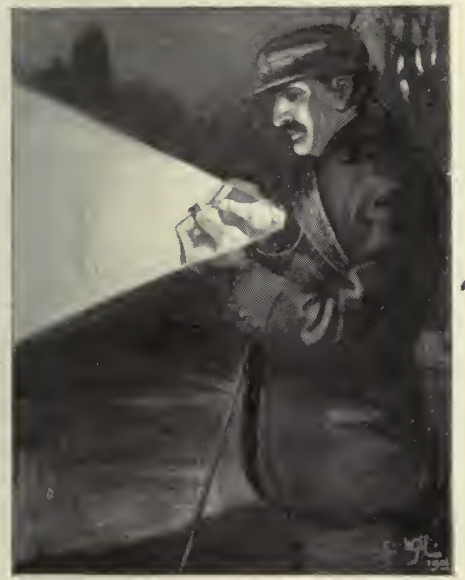

ATTACHING THE FLY

WHEN DARK.

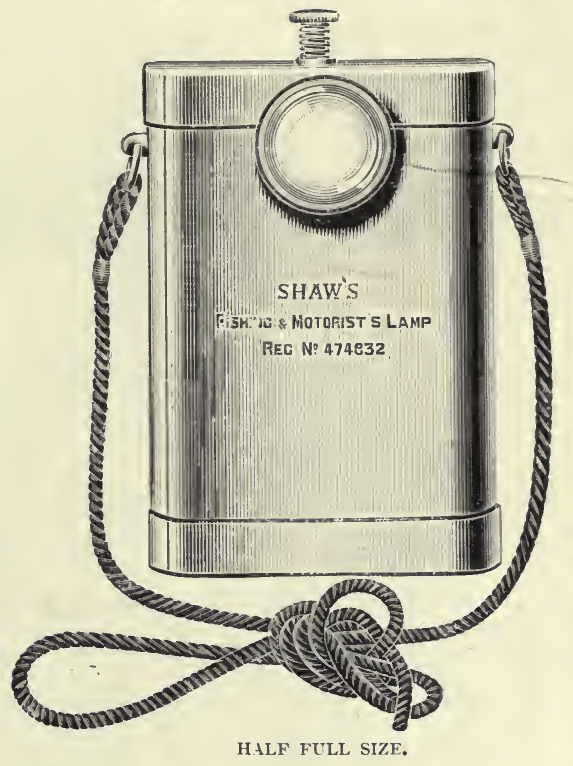

HALF FULL SIZE.

\section{Suitable for Fresh and Salt Water Fishermen,}

\section{Motorists, Travellers, and Theatre-goers.}

It is portable, steady, and self-contained.

No liquid to spill, and perfectly safe with petrol.

Easily and cheaply recharged.

Can be used as a Flashlight.

Beautifully finished throughout.

Price complete, with Neck Lanyard, 10s. ; Postage, 3d.

\section{FISHING GAZETTE, May zoth:}

Mr, Marston says : "Most useful for the angler, and also for the motorist."

To be obtained from the leading Fishing Tackle Shops, or from FRED G. SHAW, Neville Court, Abbey Road, N.W. 


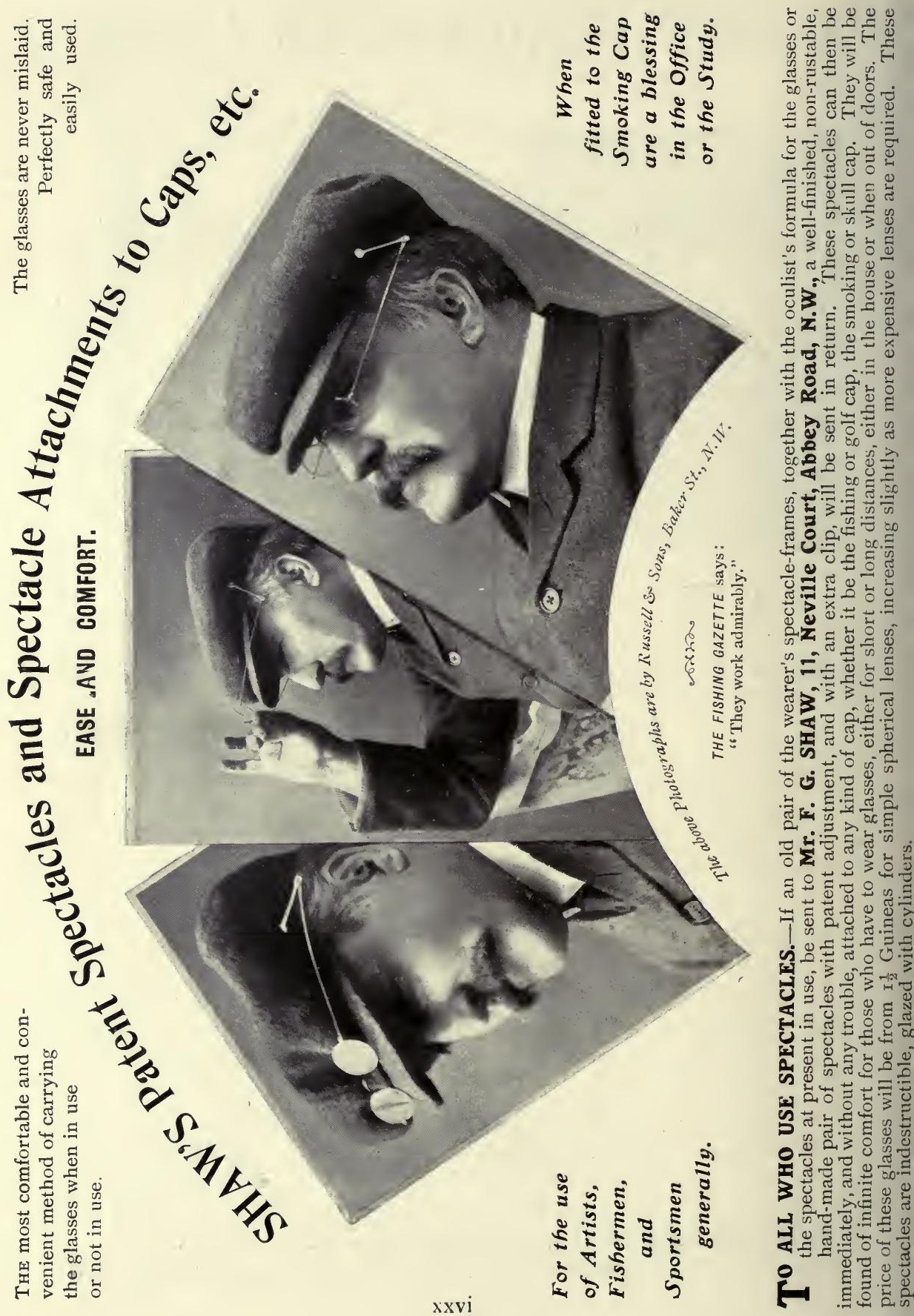


FISHING AND SHOOTING. By Sydney Buxton, M.P. With Illustrations by Archibald Thorburn. Third Edition. Demy 8vo. Ios. 6d. net.

"He writes in so lucid and charming a manner, that we have not often read a book on fishing with greater int erest, and have no doult that Mr. Buxton's readers will ke many."-Ficld.

PARTRIDGE=DRIVING. Some Practical Hints on Increasing and Preserving a Stock of Birds, and on Bringing them over the Guns, with a Description of the "Euston" System. By Charles E. A. Alington. With Diagrams. Crown 8vo. 5s. net.

"One of the most complete and convincing of treatises on the fascinating subject of partridge-driving that we have yet met with. Very few men, keen on providing and shooting a few head of partridges, can afford to miss Mr. Alington's clearly-written account of his own experiences."- County Gentleman.

HINTS ON HORSES. How to Judge Them, Buy Them, Ride Them, Drive Them, and Depict Them. By Capt. C. M. Gonne, R.A. With numerous Illustrations. Oblong 4 to. 5s. net.

"An excellent little book, abundantly clever, yet simple and unpretentious. No one who wishes to draw horses could fai! to profit by what Capt. Gonne has to show him."-Scotsman.

\section{THE WILD SPORTS AND NATURAL HISTORY OF THE HIGH=} LANDS. By Charles St. John. With Illustrations. Cheap Edition. 2s. 6d. net.

WILD LIFE AT THE LAND'S END. Records and Observations of the Habits and Haunts of the Fox, Badger, Otter, Seal, etc., and of their Pursuers in Cornwall. By J. C. Tregarthen. With Illustrations. Square demy 8vo. Ios. 6d. net.

"Mr. Tregarthen not only knows what he is writing about, but he knows how to write. The result is a singularly charming volume, which will be read with delight, not only by lovers of one of the most fascinating of English counties, but by all who follow the chase of the otter, the badger, and the fox."-County Gentieman.

\section{CREATURES OF THE NIGHT. A Book of Wild Life in Western} Britain. By A. W. Rees. With Illustrations. Large Crown 8vo. 6s. net.

"No one with a love of wild creatures can resist the charm of such a work, every page of which shows knowledge, insight, and sympathy. ... A fascinating work."-Daily Telegraph.

IANTO THE FISHERMAN. By A. W. ReEs. With Illustrations. Large crown 8 vo. Ios. $6 \mathrm{~d}$, net.

"The 'Old Fisherman' is an absolutely delightful character."--Standard.

"A very excellent and fascinating work, which no lover of nature should fail to read."-County Gentleman.

MAST AND SAIL IN EUROPE AND ASIA. By H. WARINGTON Sмyтн, Secretary, Mines Department, Transvaal; Author of "Five Years in Siam." With numerous Illustrations by the Author. Medium 8vo. 2IS, net.

"Mr. Smyth is one who loves the sea and ships. One sees in every sentence that a sail, a mast, a spar, are to him things of delight. He rejoices in the texture of ropes, in the smell of tar, and in the ring of deck planking under the foot; and it is just his love and understanding of these things that enables him to make close on 400 pages dealing with the different rigs and builds of boats of every kind, pages of real inierest to the most ignorant of land-lubbers. . . . Full of interest and charm-the charm of the sea."-County Gentleman.

SMALL BOAT SAILING; or, Practical Hints for Practical Yachtsmen. By E. F. KNight, Author of "Where Three Empires Meet," "The Cruise of the Falcon," etc. With numerous Diagrams. Large crown 8vo. 5s. net.

"A most valuable work for young yachtsmen who wish to become proficient in handling their boats."Yachtsman.

JOHN MURRAY, ALBEMARLE STREET, W. 


\title{
COMETS and their Tails,
}

AND

\section{THE GEGENSCHEIN LIGHT.}

\author{
By FREDERICK G. SHAW, F.G.S., \\ Assoc.M.Inst.C.E., etc., \\ AUTHOR OF "FISCAL FACTS AND FICTIONS."
}

\section{Opinions of the Press.}

London Quarterly Review.- "Mr. Shaw's ingenious theory cannot fail to interest anyone who has a taste for such subjects. The ronance of science is well represented in this acute and nost interesting little book."

Nature.- "The work as a whole is brief; its tone is very nodest."

Sheffield Telegraph._-"Mr. Shaw's theory is plausible, ingenious and interesting, evincing close reasoning on the part of its author."

Glasgow Herald.--"Accurate in its general facts, sound in its authorities, and cautious in its tone."

Morning Post.- "Mr. Shaw in this admirably printed little book propounds a theory which is certainly worth consideration. It is put forward in a very readable and even lively manner, and is forced by several carefully-prepared p'ates."

Dublin Irish Times. - "With full comnrand of the most advanced astrononical learning, Mr. Frederick G. Shaw, F.G.S., a traveller of wide experience and a deep scientific thinker, now advances a novel theory as to cometic tails, and as to that mysterious light commonly known as the Gegenscliein. Singularly interesting study ... it will, there can be no doubt, engage the earnest attention of all astronomers, and give rise to fruitful discussion."

Scotsman._- "Of unusual interest to readers who study astronomy. Simply enough and lucidly enoingl expounded in the book. Original, ingenions, and suggestive, the book deserves the attention of every one interested in its subject."

African Review.- "Revealing a fund of knowledge in astrononical and meteorological science."

LORD RAYLEIGH.- "With regard to your theory of the Gegenschein, I do not remember seeing the lens-like action of the earth's atnospliere noticed before."

Critic._"But, as I lave known Mr. Fred. G. Shaw for some years, and have recognized his ability as a writer and a scientist more than once in my columins, his late departure as an author of a new theory on the most abstruse astronomical problems merits some attention. His ingenious solution of the great geological puzzle of the Witwatersrand conglomerates is still fresh in the ninds of scientific men; and in turning to astral problems, as he has done in his work 'Comets and their 'Tails, etc.,' he exhibits the san1e logical deductive thouglit shown in his pseudo-norphic theory as to the formation, etc., of the said conglomerates. It is certain that he has scored a success in his solution of the Gegenschein light. I heartily commend this book to my readers."

Price 2s. 6d. net.

To be obtained from the Author, 11, Neville Court, Abbey Road, N.W. xxviii 


\title{
FISCAL FACTS AND FICTIONS.
}

\author{
FREDERICK G. SHAW, F.G.S., Assoc.M.Inst.C.E., etc.
}

\section{The following extracts are taken from a few of the first three weeks' reviews of the above work.}

The Morning Post.- "An able and concise book. . . . There is not a single point in the controversy on which $\mathrm{Mr}$. Shaw does not touch concisely. . . The book is admirably arranger, and so simple that even a Free Trader can understand it, and vivaciously written."

THE IRISH TIMES.- "Precise and elaborate . . full of authenticated statistics, and is a very valuable addition. . . . He is a writer of old standing and of acknowledged ability, and his range is exceptionally wide. . . ' Comets and their Tails' has been recognised as a most ingenious theoretical speculation in celestial science. . . But this work, in a sober, serious style, gives the reformer's view of the position with admirable lucidity, and pleads their case with extreme cleverness and strength."

The Southampton Observer. - "An admirable text-book. . . . This book should have the widest possible circulation amongst the English-speaking race.'

The Sheffield Telegraph.- "T There is force and originality about it. He takes up, one by one, the arguments of Free Traders, and shatters them. Lord Rosebery comes out very badly damaged, and there is little left of men like Mr. Asquith, Sir Henry Campbell-Bannerman, Mr. Morley, and Lord Goschen. . . . This book will prove invaluable. . . . Sir Alfred Bateman's estimates, from which the Free 'Traders get most of their inspiration, are subjected to a critical analysis, and shown to be unsound. . . I I here is much more in this valuable volume."

The Nottingham Daily Guardian._-"An able and trenchant writer; . . . in short and clearly-cut sentences; . . . and the facts and figures upon which his arguments and criticisms are ... striking to the eye, helpful to the memory, and very convenient for reference. . . . He also submits recent speeches of leading opponents of fiscal reform to severe and scathing criticism, exposing the weaknesses of their position, and showing in many instances the misleading nature of their mode of handling the statistical materials with which they are dealing. . . . ' These arguments are supported at every step by figures that cannot be impugned.'

The Derby Mercury.- "Mr. Frederick G. Shaw is an enthusiastic Tariff Reformer, whose words, written and spoken, have exercised a wide influence, and whose habit it is to call a spade a spade, and who tackles the arguments of the principal exponents of the Cobdenite case with a freedom and energy which is refreshing in these days of kid-glove controversy."

The Newcastle Daily Journal. - "As a student of political economy, and, moreover, a man with a wide knowledge of commerce . . . Mr. Shaw's style is fresh and vigorous, so that he is enabled to invest his ' facts and figures' with an interest and attractiveness too rarely found in works in any way concerned, ... its presentation of vital information being effective to a degree."

THE AFRICAN REviEw.- " The style is eminently plain and colloquial, easy and conventional, pithy and forcible, and without ambiguity.",

The BRitish Canadian Review.- "We have come across no book on the fiscal question in which the necessary statistics and other usually dry data are presented in so interesting a form. ... If the majority can assimilate the facts collected in this instructive work, this country will then achieve a position of industrial prosperity and national wealth far in excess of any records in the past. IVe would warmly recommend a careful study of this book by all open to honest argument."

JACKSON's OXFORD JouRNAL. - "He shows the advantages . . . and the advisability and feasibility of subsidising home-grown wheat. . . The work contains much that is original, and should prove helpful in the present controversy."

THE LowestofT STANDARD._-“'Fiscal Facts and Fictions' . . . is likely to become a recognised text-book for fiscal students. . . This work is characterised by remarkable force and originality.",

'THE FARM AND HOME.- "The question of the day is not often presented in a livelier or more telling manner than it is in this the latest book on the fiscal question.",

The Huddersfield Daily Chronicle.- "But few have succeeded in throwing such a fierce light on the absurdity of England continuing to be a Free Trade country than does the volume before us. . . Is an exceedingly well-got-up volume of some 250 pages, every one of which, it is not too much to say, contains some startling truth, some convincing argument. . . . Mr. Shaw has accomplished his self-imposed task of setting up new and substantial facts and demolishing ancient and absurd fictions in a very able and lucid manner. . . . An admirable work."

To be obtained from the Author, II, Neville Court, Abbey Road, N.W. Price 5s. net. 


\section{EVERY STYLE OF SALMON \& TROUT FLY GASTING}

Taught by the Author of this Book, Mr. FRED G. SHAW, The present holder of the Amateur Championship of the World in Trout Fly Casting (International Tournament, 1904).

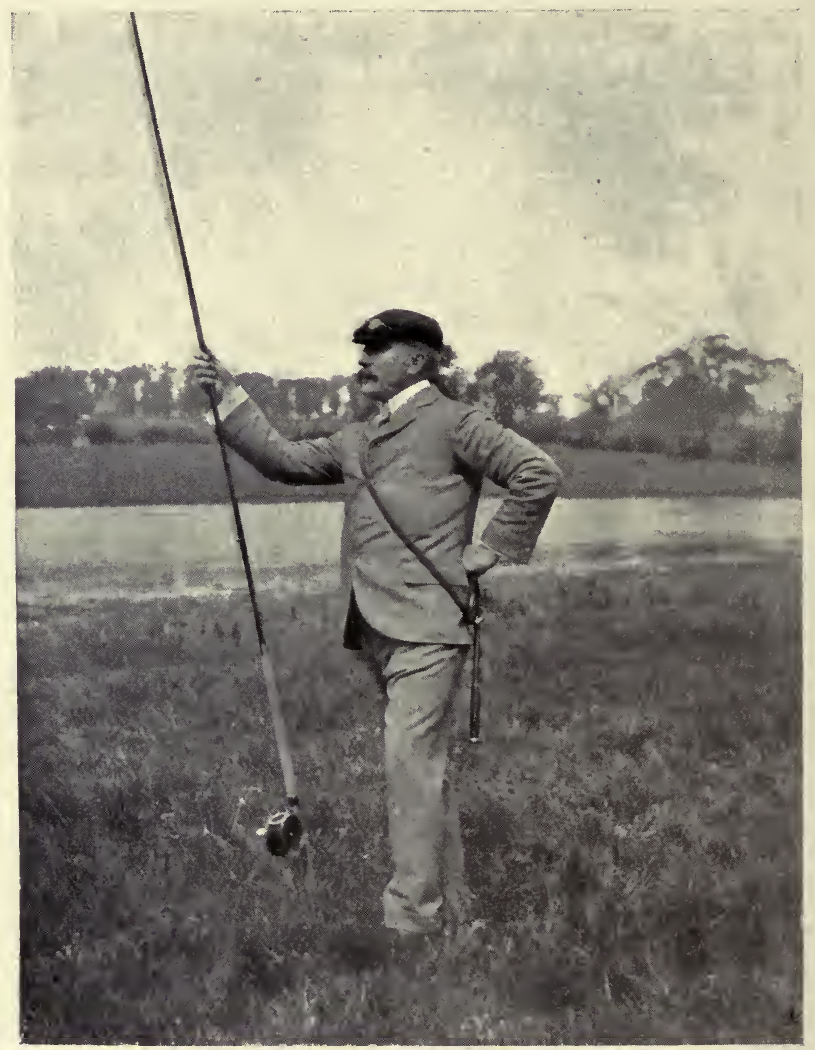

Mr. Shaw's coaching ground is situated within a few minutes of Marlborough Road (Met.) Station, N.W. ; and within five minutes of Lord's Cricket Ground

Mr. Shaw has available an excellent trout stream near London, on which a day's practical tuition can be given in Fly Fishing for Trout, \&c.

Mr. FRED G. SHAW, F.G.S., Assoc.M.Inst.C.E., etc., can be consulted on all matters velating to TROUT BREEDING PONDS, DAMS, ETC., or with reference to the districts in which to obtain good Trout, Salmon, or Sea Trout Fishing. 


\title{
DRY FLY FISHING. WET FLY FISHING, \\ BOTH UP STREAM AND DOWN STREAM.
}

\section{THROWING AGAINST THE WIND. AVOIDING THE "DRAG."}

\author{
Also the following Salmon and Trout Casts: The Overhead, The Side, The Loop, \\ The Wye, The Spey, The Galway, The Wind, and
}

PROFICIENCY IN ANY STYLE OF CASTING GUARANTEED IN 3 HALF-DAY LESSONS.

CLIENTS CAN, IF THEY SO DESIRE, BE COACHED ON THEIR OWN WATERS.

The Nature and Art of Dry and Wet Fly Fishing thoroughly explained, accuracy and delicacy in casting, striking from the reel, shooting the line, distance casting both with Salmon and Trout rod, and How to avoid the Drag, being thoroughly taught.

THE FOLLOWING TWO LETTERS ARE TAKEN FROM MANY SIMILAR ONES.

TROUT FLY CASTING.

Dear Mr. Shaw,

Windham Club, Fuly 29 th, 1906.

I have had two days' fishing since I saw you, and there is no doubt you have given me very great help, and I found I could get my fly to places and under difficulties which would have been impossible for me before you took me in hand. Neither is casting such a trouble and anxiety as previously, so that I am certain I shall get on much better when there is a head wind than I ever could have hoped for previously. Your instructions were so clear, and explained so admirably, that I should have been a duffer indeed had I not vastly improved.

Thanking you for the trouble and patience you bestowed on me during my two lessons. Yours very truly,

\section{SALMON FLY CASTING.}

Invercauld Arms, Ballater, N.B. April sth, 1906.

Dear Mr. Shaw,

Thanks entirely to the trouble you took over my few lessons, I have been acquitting myself very well. The head gillie and my friend, although they knew I had had lessons, were more than astonished, and both have assured me over and over again that I fish as well or better than men who have been up here for ten or twelve years. I have not been in difficulties yet, although it has been very windy, and only damaged two flies. I was quite at home with my rod the first day I went out. I quite recognize that the credit of my success is due to you, and think it only right to let you know.

Yours sincerely,

For TERMS, for a Single, or for a course of Lessons, apply to Mr. Shaw, Neville Court, Abbey Road, London, N.W. 


\section{SHAW'S FLY FISHING KNIFE.}

Contains the $\mathbf{8}$ Necessary Tools of the Fly Fisherman.

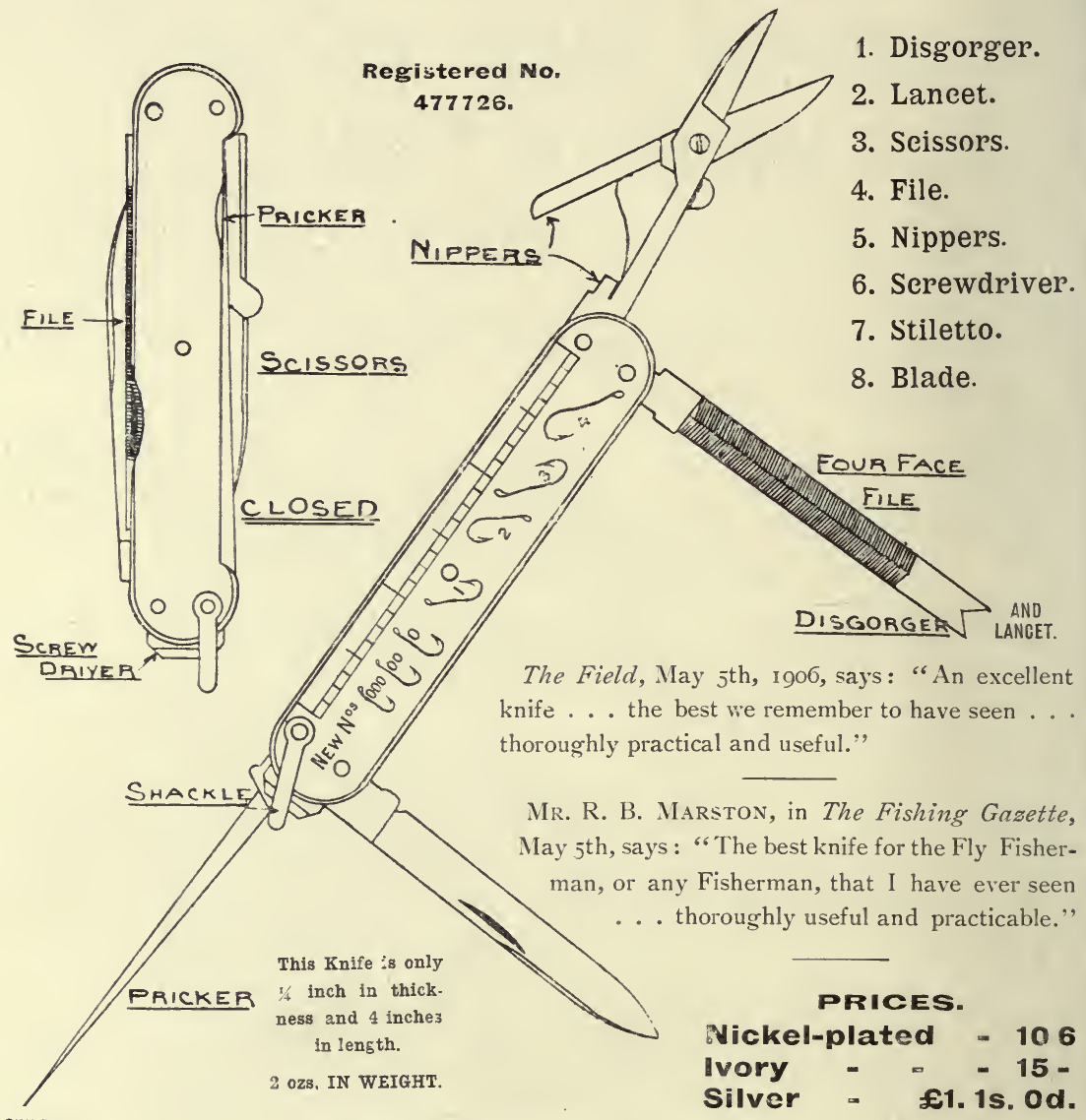

MARVELLOUS ATTRACTION

Each part of this knife is of the best Sheffield steel, and is a magnet; and, whichever tool is being used, it will at once serve to pick out any required fly from among its fellows in the fly-box.

THE FILE, LANCET, AND DISGORGER MAKES ONE OF THE BEST MANICURE INSTRUMENTS EVER INVENTED.

To be obtained from

Mr. SHAW, Neville Court, Abbey Road, N.W.;

Or from the Army and Navy Stores, Farlows \& Co., Bernard \& Sons, Eaton \& Dillar, Ogden Smith, Hardy Bros., A. Barrett \& Sons, 63, Piccadilly, W., John Weiss \& Sons, 289, Oxford Street, W., and from any well-established Firm. 


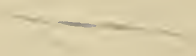




$$
\frac{\text { ald }}{x_{x}}
$$



